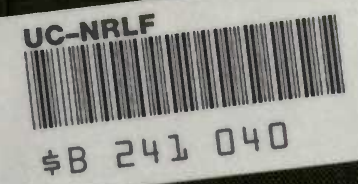



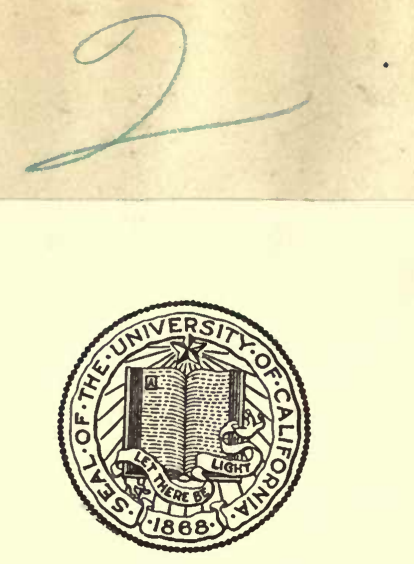

\section{THE LIBRARY} OF

\section{THE UNIVERSITY OF CALIFORNIA}

PRESENTED BY

PROF. CHARLES A. KOFOID AND MRS. PRUDENCE W. KOFOID 





\section{ATLAS AND PRINGIPLES,}

\section{BACTERIOLOGY \\ AND TEXT-BOOK OF}

\section{SPECIAL BACTERIOLOGIC DIAGNOSIS}

BY

PROF. DR. K. B. LEHMANN

Director of the Hygienic Institute in Würzburg

AND

R. O. NEUMANN, DR. PHIL. and MED.

Assistant in the Hygienic Institute in Würżburg

AUTHORIZED TRANSLATION FROM THE SECOND ENLARGED AND REVISED GERMAN EDITION

EDITED BY

GEORGE H. WEAVER, M.D.

Assistant Professor of Pathology, Rush Medical College, Chicago

\section{PART I-ATLAS}

With 632 Figures on 69 Lithographic Plates

PHILADELPHIA AND LONDON

W. B. SAUNDERS \& COMPANY 


\section{Withdrawn \\ INDEX OF PLATES.

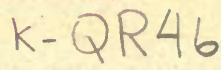 \\ 452

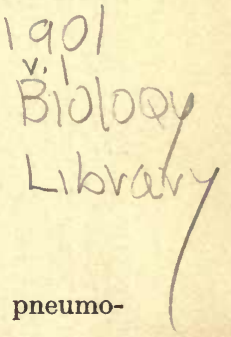

PLATE.

1. Streptococcus pyogenes. Rosenbach.

2. Streptococcus lanceolatus. Gamaleia. (Diplococcus pneumoniæ. A. Fränkel.)

3. Sarcina flava. De Bary, emended by Lehm. and Stubenrath.

4. Sarcina aurantiaca. Flügge.

5. Sarcina cervina. Stubenrath.

Sarcina pulmonum. Virchow.

Sarcina erythromyxa. Král.

Sarcina lutea. Flügge.

Sarcina aurantiaca. Flügge.

Sarcina rosea. Schröter, emended by Zimmermann.

Micrococcus badius. Lehm. and Neum.

Sarcina canescens. Stubenrath.

6. Micrococcus luteus. Cohn, emended by Lehm. and Neum.

Sarcina pulmonum. Virchow, Hauser.

7. Micrococcus tetragenus. Koch, Gaffky.

8. Micrococcus pyogenes a aureus. (Ros.) Lehm. and Neum. (Staphylococcus pyogenes aureus. Rosenbach.)

9. Micrococcus pyogenes $\gamma$ albus. (Ros.) L. and N. (Staphylococcus pyogenes albus. Rosenbach).

Micrococcus pyogenes $\beta$ citreus. (Ros.) (Staphylococcus pyogenes citreus. Rosenbach.)

Micrococcus candicans. Flügge.

10. Micrococcus gonorrhœe. Neisser, Bumm.

11. Micrococcus roseus. (Bumm.) Lehm. and Neum.

12. Bacterium septicæmiæ hæmorrhagicæ. Hüppe. (Chicken cholera, rabbit septicemia.)

13. Bacterium pestis. Lehm. and Neum.

14. Bacterium acidi lactici. Hïppe. (Lactic acid bacillus.)

15. Bacterium pneumoniæ. Friedländer.

16. Bacterium typhi. Eberth, Gaffky. (Typhoid bacillus.)

17. Bacterium typhi. Eberth, Gaffky.

18. Bacterium coli. (Escherich.) Lehm. and Neum.

19. Bacterium coli. (Escherich.) Lehm. and Neum.

20. Bacterium latericium. Adametz.

Bacterium hæmorrhagicum. (Kolb.) Lehm. and Neum. (Morb. Werlhofii.)

21. Bacterium prodigiosum (Ehrenberg) Lehm, and Neum. 
PLATE.

22. Bacterium kiliense. (Breunig and Fischer.) Lehm. and Neum.

23. Bacterium violaceum. (J. Schröter.) Lehm. and Neum.

24. Bacterium pyocyaneum. (Flügge.) Lehm. and Neum. (Green pus.)

25. Bacterium fluorescens. (Flügge.) Lehm. and Neum. (Bacillus fluorescens liquefaciens, Flügge.)

26. Bacterium putidum. (Flügge.) Lehm. and Neum.

27. Bacterium syncyaneum. (Ehrenberg.) Lehm. and Neum. (Bacillus cyanogenes Flügge. Blue milk.)

28. Bacterium syncyaneum. (Ehrenberg.) Lehm. and Neum.

29. Bacterium Zopfii. Kurth.

30. Bacterium Zopfii. Kurth.

31. Bacterium vulgare. (Hauser.) Lehm. and Neum. (Proteus vulgaris Hauser.)

32. Bacterium vulgare $\beta$ mirabilis. (Hauser.) Lehm. and Neum.

33. Bacterium erysipelatos suum. (Löffler.) Migula. (Hog erysipelas.)

Bacterium murisepticum. (Flügge.) Migula. (Mouse septicemia.)

34. Bacillus anthracis. F. Cohn and R. Koch. (Splenic fever.)

35. Bacillus anthracis. F. Cohn and R. Koch. (Splenic fever.)

36. Bacillus anthracis. F. Cohn and R. Koch. (Splenic fever.)

37. Bacillus mycoides. Flügge. (Root-bacillus.)

38. Bacillus mycoides. Flügge.

Bacillus butyricus. Hüppe. (Butyric acid bacillus.)

Bacillus vulgatus. (Flügge.) Migula.

39. Bacillus subtilis. F. Cohn. (Hay-bacillus.)

40. Bacillus subtilis. F. Cohn.

41. Bacillus megatherium. De Bary.

42. Bacillus vulgatus. (Flügge.) Migula. (B. mesentericus vulgatus Flügge.) Potato bacillus.

43. Bacillus mesentericus. (Flügge.) Lehm. and Neum. (B. mesentericus fuscus Flügge.)

44. Bacillus tetani. Nicolaier. (Tetanus bacillus, lock-jaw.)

45. Bacillus Chauroei. Macè. (Symptomatic anthrax, black-leg.)

46. Bacillus œedematis maligni. Koch.

47. Vibrio choleræ. (Koch.) Buchner. (Comma bacillus.)

48. Vibrio choleræ. (Koch.) Buchner.

49. Vibrio choleræ. (Koch.) Buchner.

50. Vibrio choleræ. (Koch.) Buchner.

51. Vibrio choleræ. (Koch.) Buchner.

Vibrio Metschnikovii. Gamaleia.

52. Vibrio Proteus. Buchner. (Vibrio Finkler.)

53. Vibrio danubicus. Heider.

Vibrio berolinensis. Rubner.

Vibrio aquatilis. Günther.

54. Vibrio albensis. Lehm. and Neum. (Phosphorescent Elbe Vibrio.)

55. Spirillum rubrum. v. Esmarch. 
PLATE.

Spirillum concentricum. Kitasato.

56. Spirillum serpens. (E. O. Müller.) Zettnow.

Spirilla from nasal mucus.

Spirillum undula. Ehrenberg.

Spirillum spermatozoides. Löffler.

Spirochæte of oral mucus.

Spirillum Obermeieri. F. Cohn. (Spirilla of recurrent fever.)

57. Corynebacterium malleï. (Löffler.) Lehm. and Neum. (Glanders bacillus.)

58. Corynebacterium diphtheriæ. (Löffler.) Lehm. and Neum. (Diphtheria bacillus.)

Corynebacterium pseudodiphtheriticum. (Hoffmann-Wellenhof.) Lehm. and Neum. (Pseudodiphtheria bacillus.)

Corynebacterium xerosis. (Kuschbert, Neisser.) Lehm. and Neum. (Xerosis bacillus.)

59. Corynebacterium diphtheriæ. L. and N.

Corynebacterium pseudodiphtheriticum. L. and N.

Corynebacterium xerosis. L. and N.

60. Corynebacterium diphtheriæ. L. and N.

Corynebacterium pseudodiphtheriticum.

Corynebacterium xerosis. L. and N.

61. Mycobacterium tuberculosis. (Koch.) L. and N. (Tubercle bacillus.)

62. Mycobacterium lepræ. (Arm. Hansen.) L. and N. (Lepra bacillus.)

Mycobacterium tuberculosis $\gamma$ piscicola. L. and N.

63. Mycobacterium lacticola $\beta$ perrugosum. L. and N.

Mycobacterium phleï. Lehm. and Neum.

64. Mycobacterium lacticola $a$ planum. L. and N.

65. Actinomyces bovis. Harz. (Actinomycosis.)

66. Actinomyces farcinicus. (Nocard.) Gasperini. (Fracin du bœuf.)

67. Actinomyces chromogenes. Gasperini. (Cladothrix dichotoma Autorum non Cohn.)

68. Bacterium tussis convulsivæ. (Czaplewski and Hensel.) (Whooping-cough.)

Bacterium ulceris cancrosi. (Ducrey, Kruse.) L. and N. (Ulcus molle.)

Streptococcus meningitidis cerebrospinalis (Weichselbaum). Lehm. and Neum.

Bacterium influenzæ. (R. Pfeiffer.) L. and N. (Influenza bacillus.)

Bacillus gangrænæ pulpæ. Arkövy.

69. Leptothrix epidermidis. Biz. 


Tab. 1.
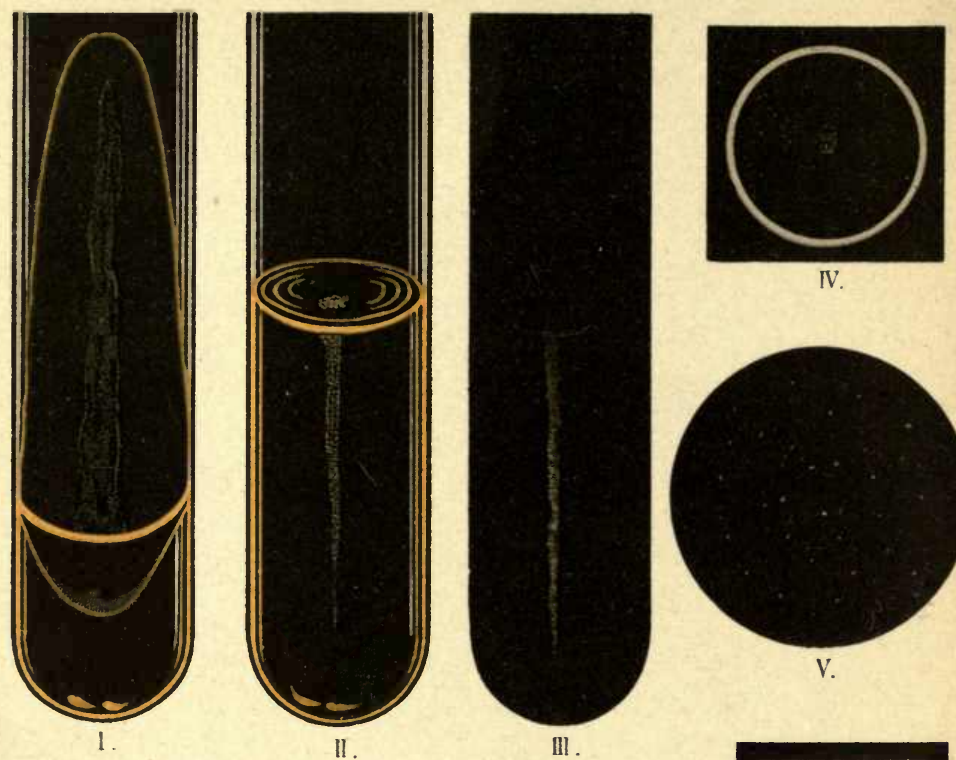

IV.

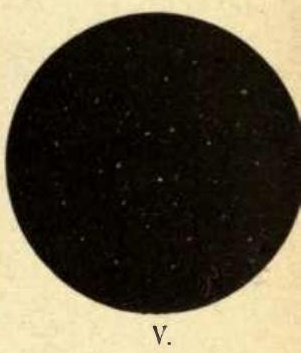

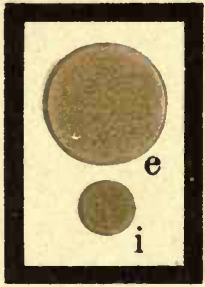

VII.

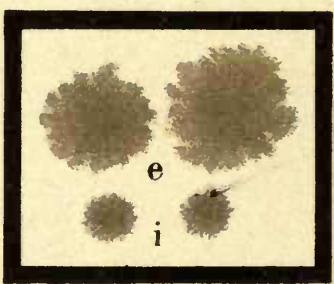

VI.

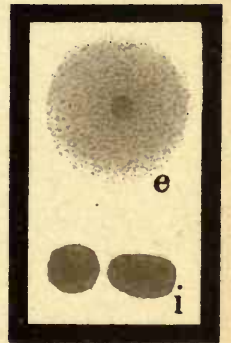

ITI!

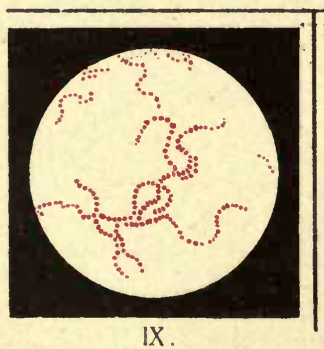

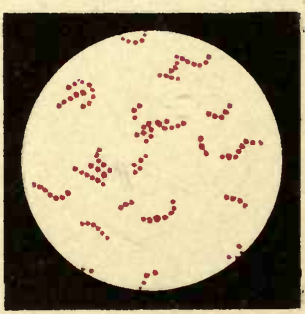

i

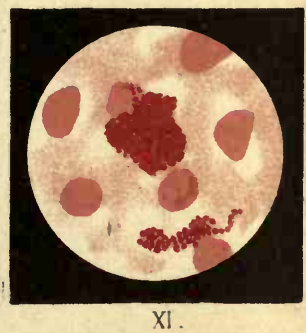




\section{PLATE I.}

Streptococcus pyogenes. Rosenbach.

I. Agar streak culture, ten days at $37^{\circ}$.

II. Gelatin stab culture, six days at $22^{\circ}$. So vigorous a growth does not often occur.

III. Agar stab culture, six days at $37^{\circ}$. Stab canal.

IV. Agar stab culture, six days at $37^{\circ}$. Surface growth.

V. Gelatin plate, six days at $22^{\circ}$.

VI. Gelatin plate, six days at $22^{\circ} . \times 70$. Somewhat abnormal form with irregular borders. The larger colonies are superficial; the smaller, deep.

VII. Gelatin plate, six days at $22^{\circ} . \quad \times 70$. Common form. The upper, superficial; the lower, deep.

VIII. Agar plate, eight days at $37^{\circ} . \times 50$. Larger colony superficial; smaller colonies, deep.

IX. Microscopic preparation from a two days' bouillon culture at $37^{\circ} . \times 700$. The individual cocci are usually more regularly round.

X. Microscopnc preparation from a two days' agar culture. Shorter chains. $\times 1000$.

XI. Microscopic preparation, designated Streptococcus conglomeratus. Smear preparation from the blood of the spleen from a case of scarlatina. Copied from Kurth (Kaiserl. Gesundheitsamt., Bd. vir, cfr. xv, 6 and 8).

XII. Chains of streptococci, before and during division. Highly magnified.

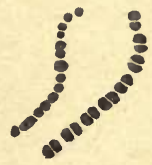

XII. 


\section{PLATE 2.}

Streptococcus lanceolatus. Gamaleia. (Diplococcus pneumoniæ A. Fränkel.) (Pneumococcus.)

I. Gelatin stab culture, ten days at $22^{\circ}$.

II. Agar streak culture, four days at $37^{\circ}$.

III. Agar stab culture, four days at $37^{\circ}$. Stab canal.

IV. Agar stab culture, four days at $37^{\circ}$. Surface growth.

V. Agar plate, three days at $37^{\circ}$. Natural size.

VI. Agar plate, three days at $37^{\circ} . \times 50$. Superficial colony. The darker colony lies near the surface.

VII. Agar plate, three days at $37^{\circ} . \times 50$. Deep colonies.

VIII. Gelatin plate, eight days at $22^{\circ}$. The upper colony is superficial; the lower ones, deep.

IX. Smear preparation from pneumonic sputum. $\times 1000$.

X. Pure culture from a three days' old agar plate. $\times 1000$.

XI. Microscopic preparations: (a) Diplococci as single pairs and in chains. Highly magnified. (b) Diplococci surrounded by gelatinous capsules.

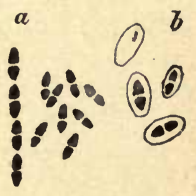

XI. 
Tab. 2.
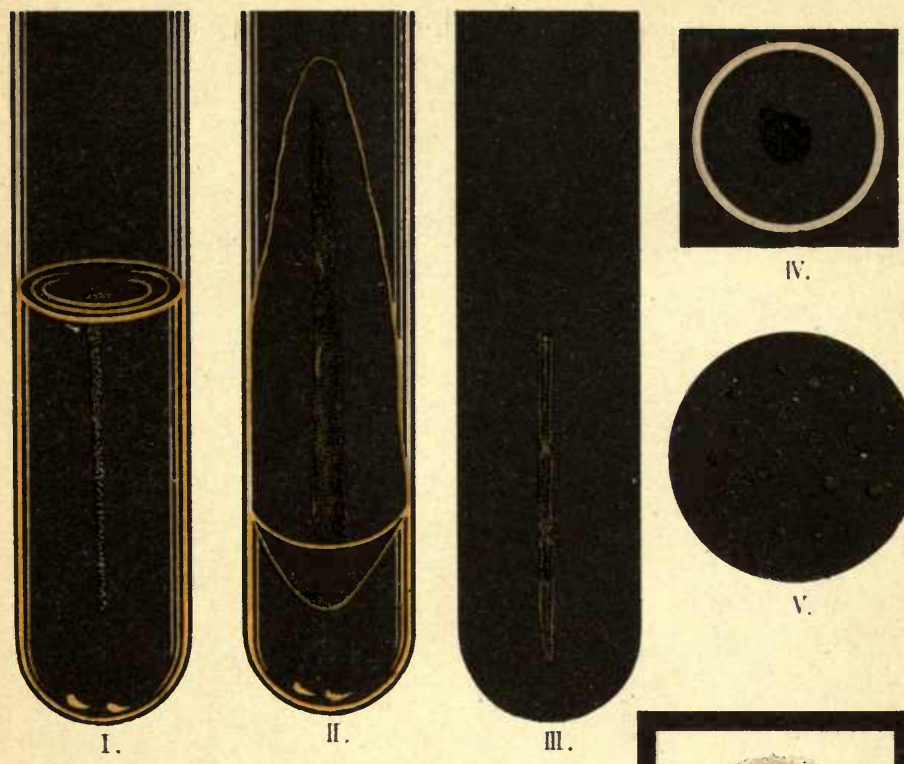

IV.

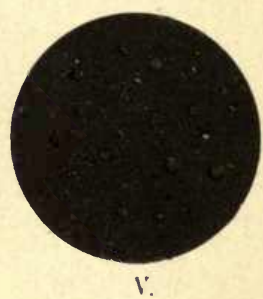

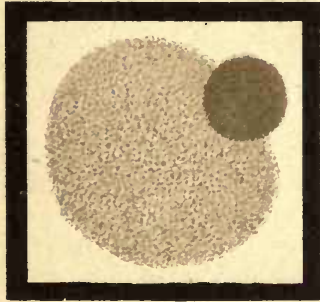

VI.

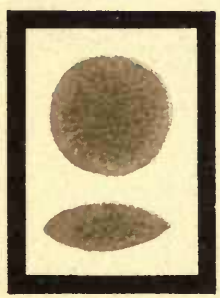

VII.

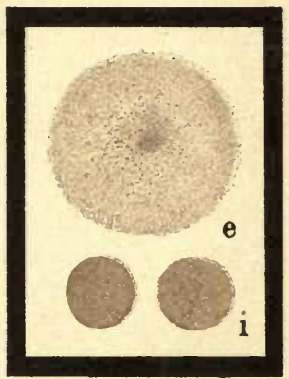

VIII

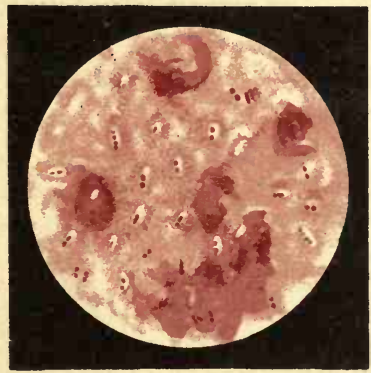

IX.

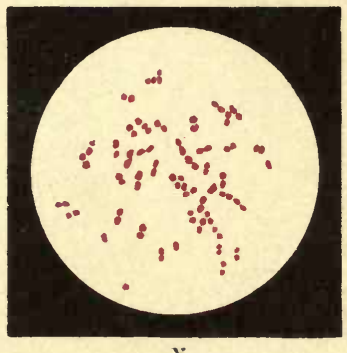

X. 




\section{PLATE 3.}

Sarcina flava. De Bary, emended by Lehm. and Stubenrath.

I. Gelatin stab culture, ten days at $22^{\circ}$.

II. Agar streak culture, six days at $22^{\circ}$.

III. Agar stab culture, six days at $22^{\circ}$; stab canal.

IV. Agar stab culture, six days at $22^{\circ}$; surface growth.

V. Gelatin plate, five days at $22^{\circ}$. Natural size.

VI. Gelatin plate, five days at $22^{\circ} \cdot \times 60$. Superficial colony.

VII. Agar plate, six days at $22^{\circ}$. Natural size.

VIII. Agar plate, six days at $22^{\circ} . \times 60$. Upper colony is superficial, lower ones are deep.

IX. Potato culture, ten days at $22^{\circ}$.

X. Microscopic preparation. Pure culture from an agar plate. $\times 1000$. Stained with fuchsin and differentiated with acetic acid.

XI. Microscopic preparation. Pure culture in bouillon; unstained. $\times 1000$.

XII. Sarcince forming bales of packets. (Single packets regularly grouped together.)

XIII. Sarcince in bunches of packets. (Single or irregular packets, grouped together irregularly.)

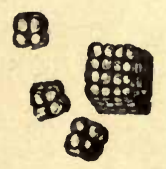

XII.

XIII. 


\section{PLATE 4.}

Sarcina aurantiaca. Flügge.

I. Gelatin stab culture, six days at $22^{\circ}$.

II. Agar streak culture, five days at $22^{\circ}$. The color is not so red in all cases; usually light orange. This is also true of the agar stab and potato cultures.

III. Agar stab culture, six days at $22^{\circ}$. Stab canal.

IV. Agar stab culture, six days at $22^{\circ}$. Surface growth.

V. Gelatin plate, five days at $22^{\circ}$. Natural size. The gray zone about the colonies indicates a depression.

VI. Gelatin plate, five days at $22^{\circ} . \quad \times 60$. A colony in the early stage. The gray ring represents a zone where it is sinking in.

VII. Agar plate, five days at $22^{\circ}$. Natural size.

VIII. Agar plate, five days at $22^{\circ} . \times 60$. Upper colony, superficial; lower colonies, deep. The superficial colonies usually become opaque toward the center.

IX. Potato culture, eight days old.

X. Microscopic preparation. Pure culture from agar. $\times 1000$. Stained with fuchsin, differentiated with acetic acid.

XI. Microscopic preparation. Pure culture in bouillon. $\times 1000$. Unstained, partly schematic. 
Tab. 4.
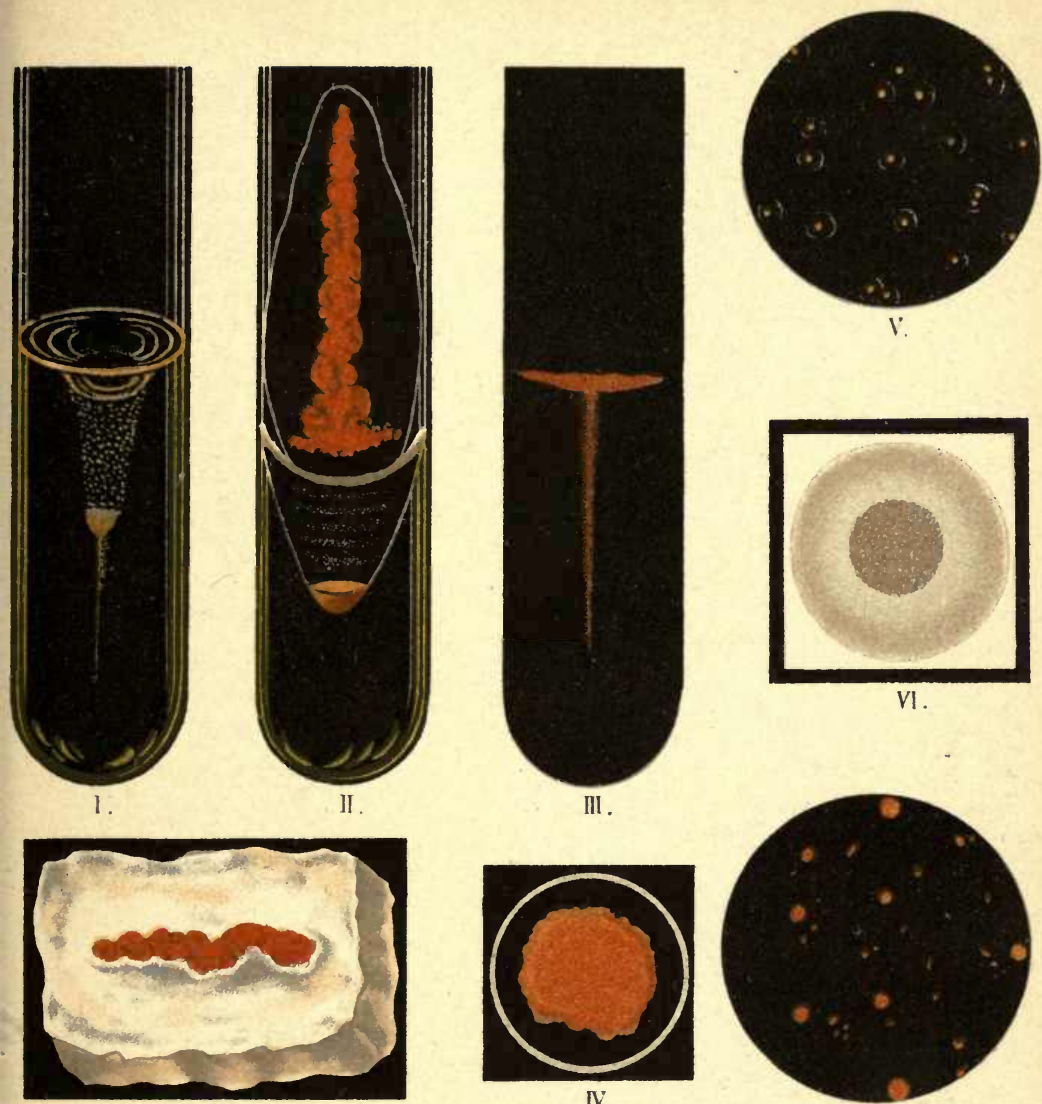

IX.

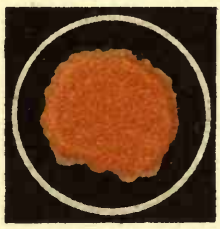

IV

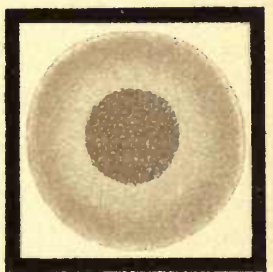

VI.
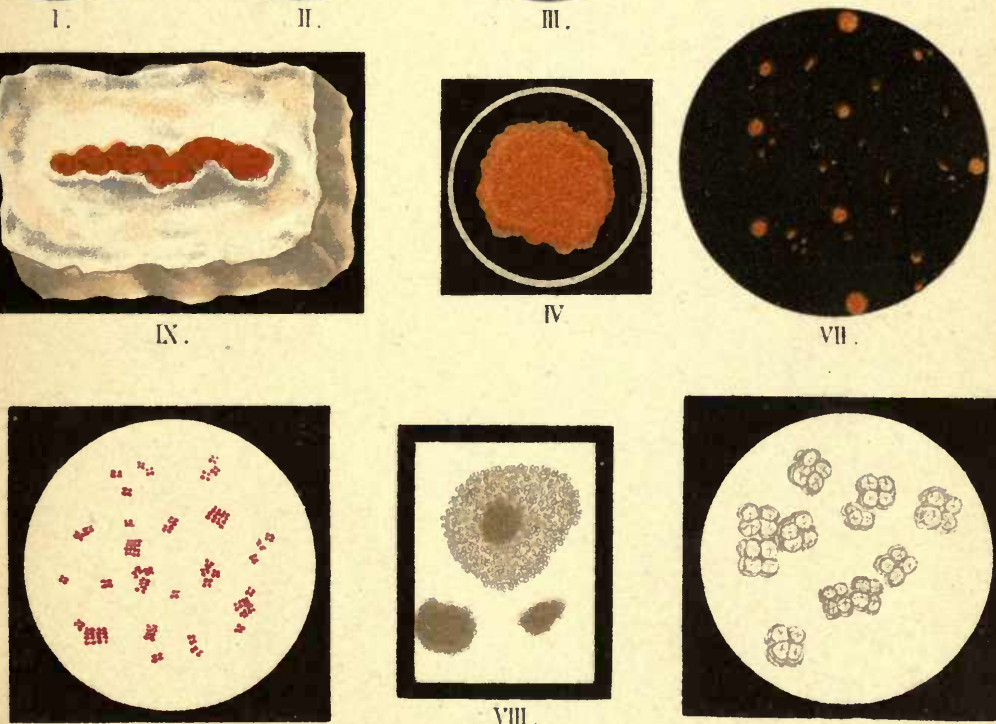

X

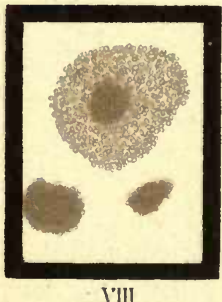

I'III.

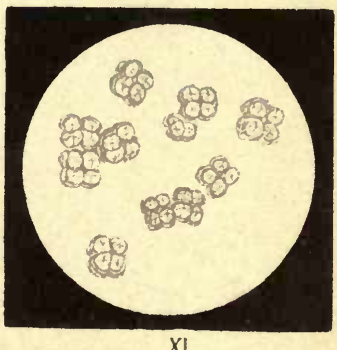

XI. 


Tab. 5.
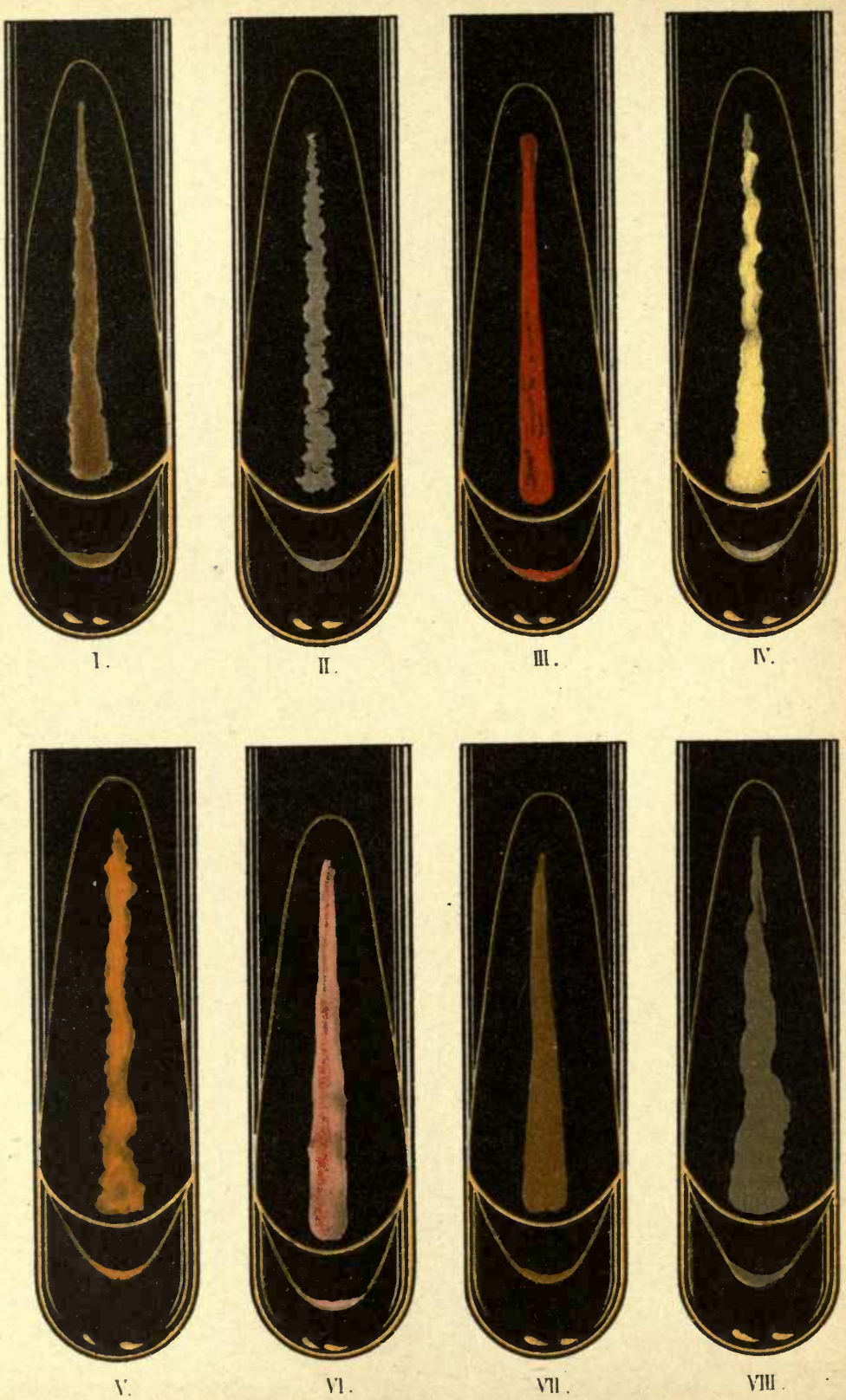

Lith. Anst F: Reichhold, München 


\section{PLATE 5. \\ Various Sarcinæ.}

I. Sarcina cervina Stubenrath. Agar streak culture, fifteen days at $22^{\circ}$, isolated from gastric contents.

II. Sarcina pulmonum Virchow. Agar streak culture, fifteen days at $37^{\circ}$.

III. Sarcina erythromyxa Král. Agar streak culture, thirty days at $22^{\circ}$, isolated from beer.

IV. Sarcina lutea Flügge. Agar streak culture, ten days at $22^{\circ}$, isolated from stomach.

V. Sarcina aurantiaca Flügge. Agar streak culture, ten days at $22^{\circ}$, isolated from yeast.

VI. Sarcina rosea Schröter, emended by Zimmermann. Agar streak culture, twenty-five days at $22^{\circ}$, isolated from light beer.

VII. Micrococcus radius Lehm. and Neum. Agar streak culture, fifteen days at $22^{\circ}$, isolated from air.

VIII. Sarcina canescens Stubenrath. Agar streak culture, twenty days at $22^{\circ}$, isolated from the stomach. 


\section{PLATE 6.}

Micrococcus luteus. Ferd. Cohn, emended by Lehm. and Neum.

I. Gelatin stab, six days at $22^{\circ}$.

II. Gelatin plate, three days at $22^{\circ} . \times 50$. To the left, superficial; to the right, a deep colony.

III. Microscopic preparation. $\times 1000$. From a twodays'-old agar plate. Often the micrococci are grouped in tetrads.

IV. Agar plate, five days at $22^{\circ}$. Natural size. The colonies are sometimes more yellow.

V. Potato culture, six days at $22^{\circ}$. Sometimes it has a dull luster.

Sarcina pulmonum. Virchow. Hauser.

\section{(Pulmonary Sarcina.)}

VI. Gelatin stab, twenty days at $22^{\circ}$. The stab is in reality more gray.

VII. Agar streak, twenty days at $22^{\circ}$.

VIII. Gelatin plate, twenty days at $22^{\circ}$. To the left, a superficial; to the right, a deep colony.

IX. Potato culture, twenty days at $22^{\circ}$.

X. Stained flagella. Highly magnified.

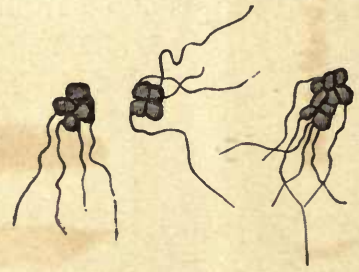

$\mathrm{X}$. 
Tab. 6.
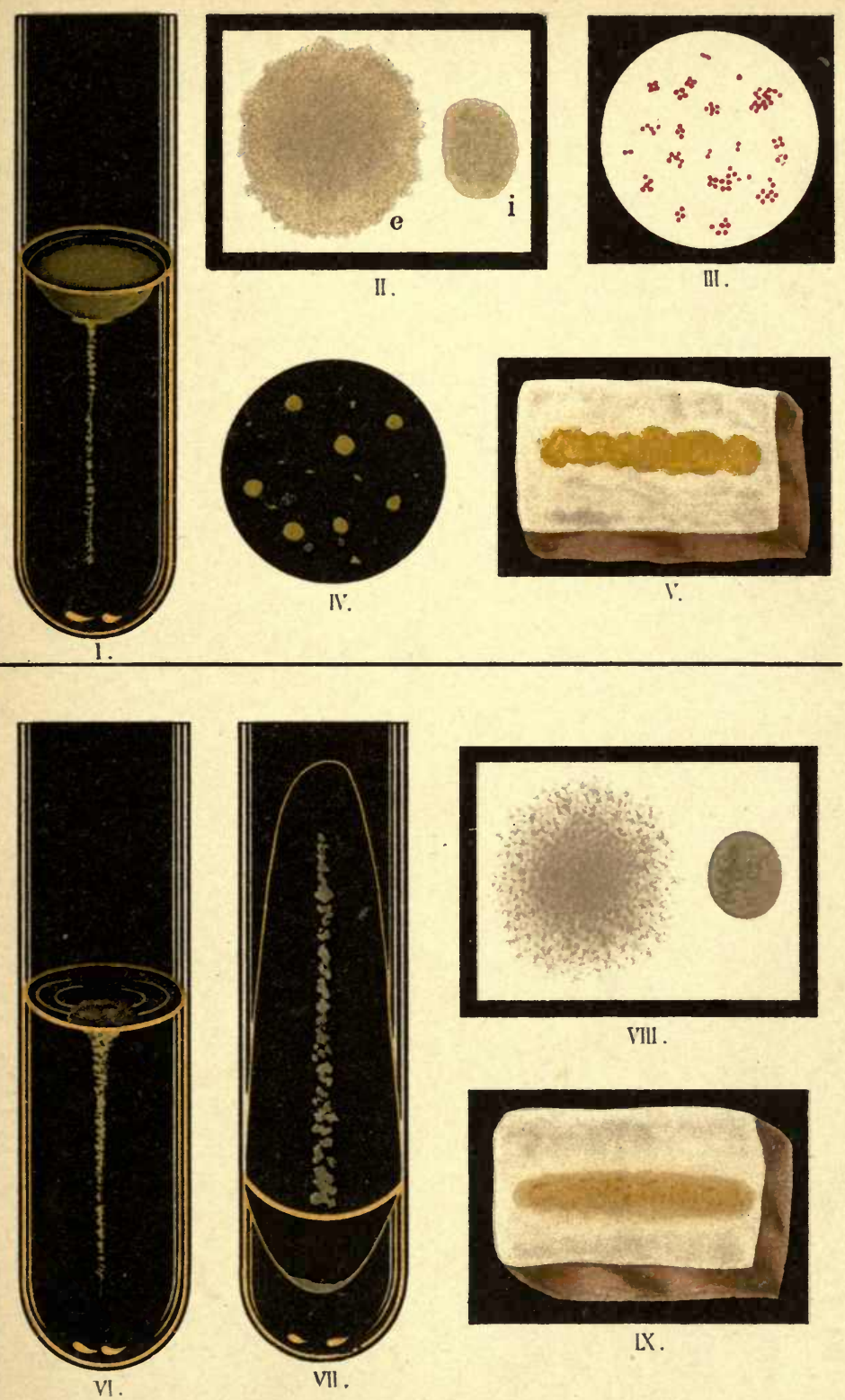

I'III.

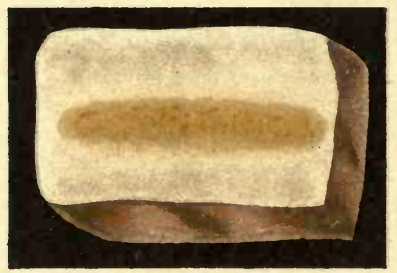

IX. 


Tab. 7.
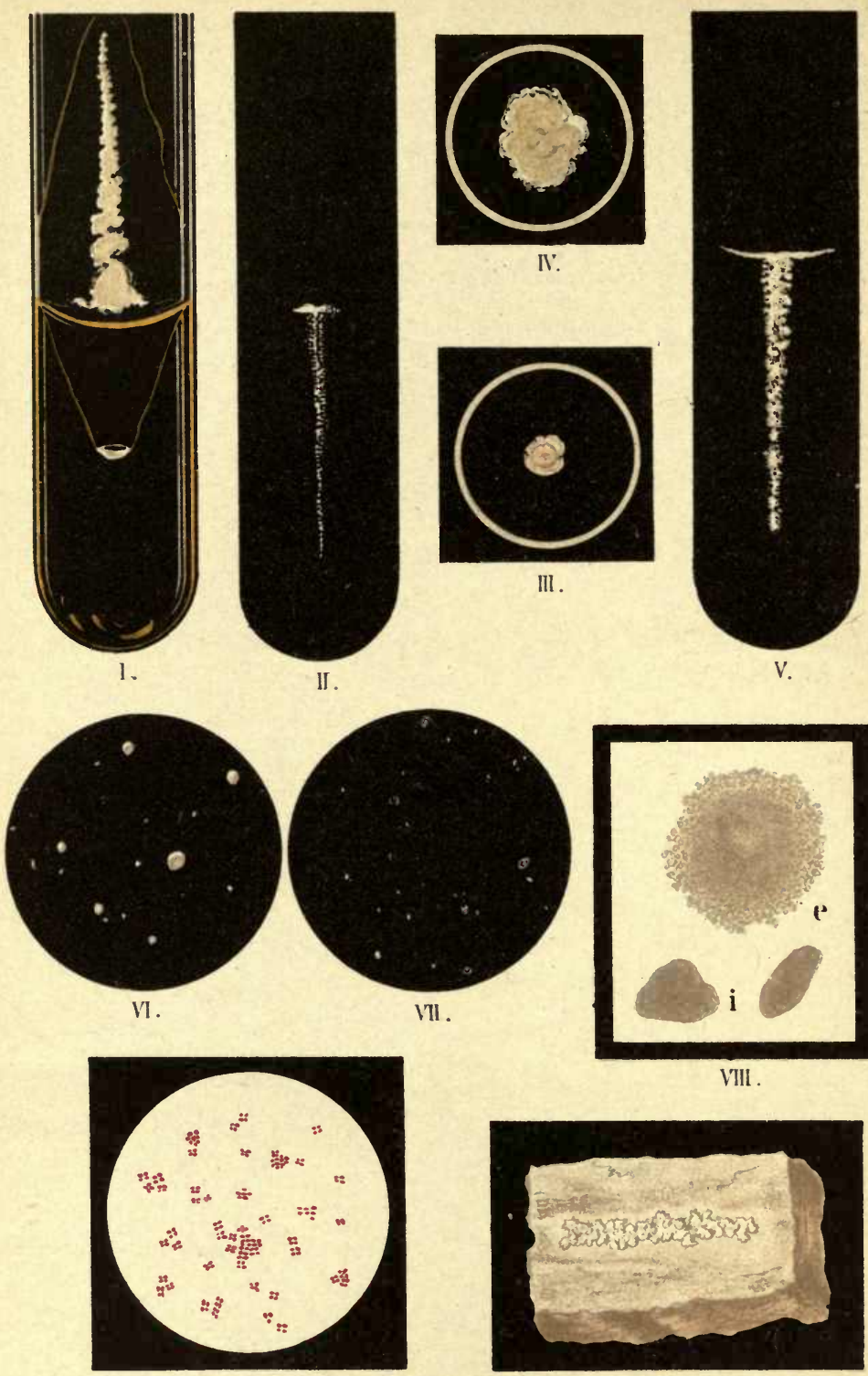

IN.

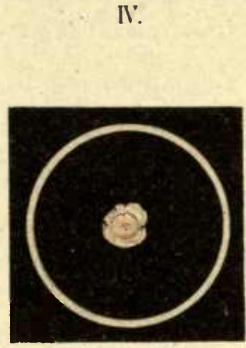

III.

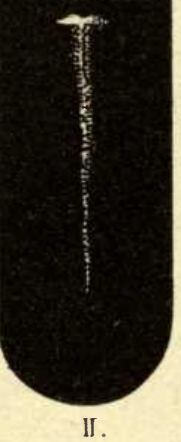

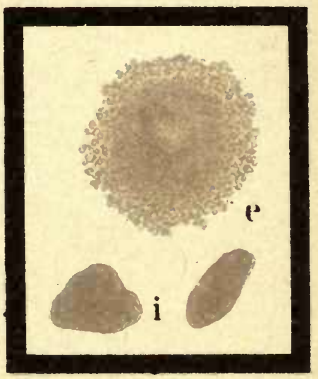

VIII.

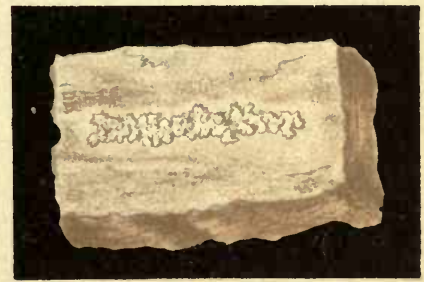

X. 


\section{PLATE 7.}

Micrococcus tetragenus. Koch. Gaffky.

I. Agar streak culture, five days at $37^{\circ}$.

II. Gelatin stab culture, ten days at $22^{\circ}$. Stab canal. Characteristic nail-head form.

III. Gelatin stab culture, ten days at $22^{\circ}$; surface growth. In the reproduction the color has turned out brown, but should be white.

IV. Agar stab culture, six days at $37^{\circ}$. Surface growth.

V. Agar stab culture, six days at $37^{\circ}$. The growth along the stab is not always so luxuriant.

VI. Agar plate, five days at $37^{\circ}$. Natural size.

VII. Gelatin plate, eight days at $22^{\circ}$. The colonies are naturally pure white. Natural size.

VIII. Gelatin plate, eight days at $22^{\circ} . \times 60$. The larger colony is superficial; the smaller, deep.

IX. Microscopic preparation. From a two-days'-old agar culture. $\times 800$. There are not always found tetrads alone, often also single cocci.

X. Potato culture, seven days at $37^{\circ}$.

XI. Microscopic picture. Tetrads before, during, and after division; highly magnified.
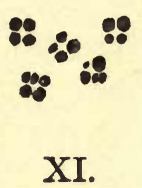


\section{PLATE 8.}

Micrococcus pyogenes $\alpha$ aureus. (Rosenbach.) Lehm. and Neum.

(Staphylococcus aureus Ros.)

I. Gelatin stab culture, six days at $22^{\circ}$.

II. Agar streak culture, five days at $22^{\circ}$.

III. Agar stab culture, five days at $22^{\circ}$. Stab canal.

IV. Agar stab culture, five days at $22^{\circ}$; surface growth.

V. Agar plate culture, six days at $22^{\circ}$, natural size. Superficial and deep colonies.

VI. Agar plate, six days at $22^{\circ} . \times 60$. Small superficial colony.

VII. Gelatin plate, four days at $22^{\circ}$, natural size. Superficial and deep colonies.

VIII. Gelatin plate, four days at $22^{\circ} . \times 60$. Superficial and deep colonies.

IX. Potato culture, six days at $22^{\circ}$.

X. Microscopic preparation. $\times 1000$. From an agar culture, two days old, at $22^{\circ}$.

XI. Microscopic preparation. Single cocci, before, during, and after division. $\times 1500$.

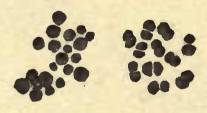

XI. 


Tab. 9 .
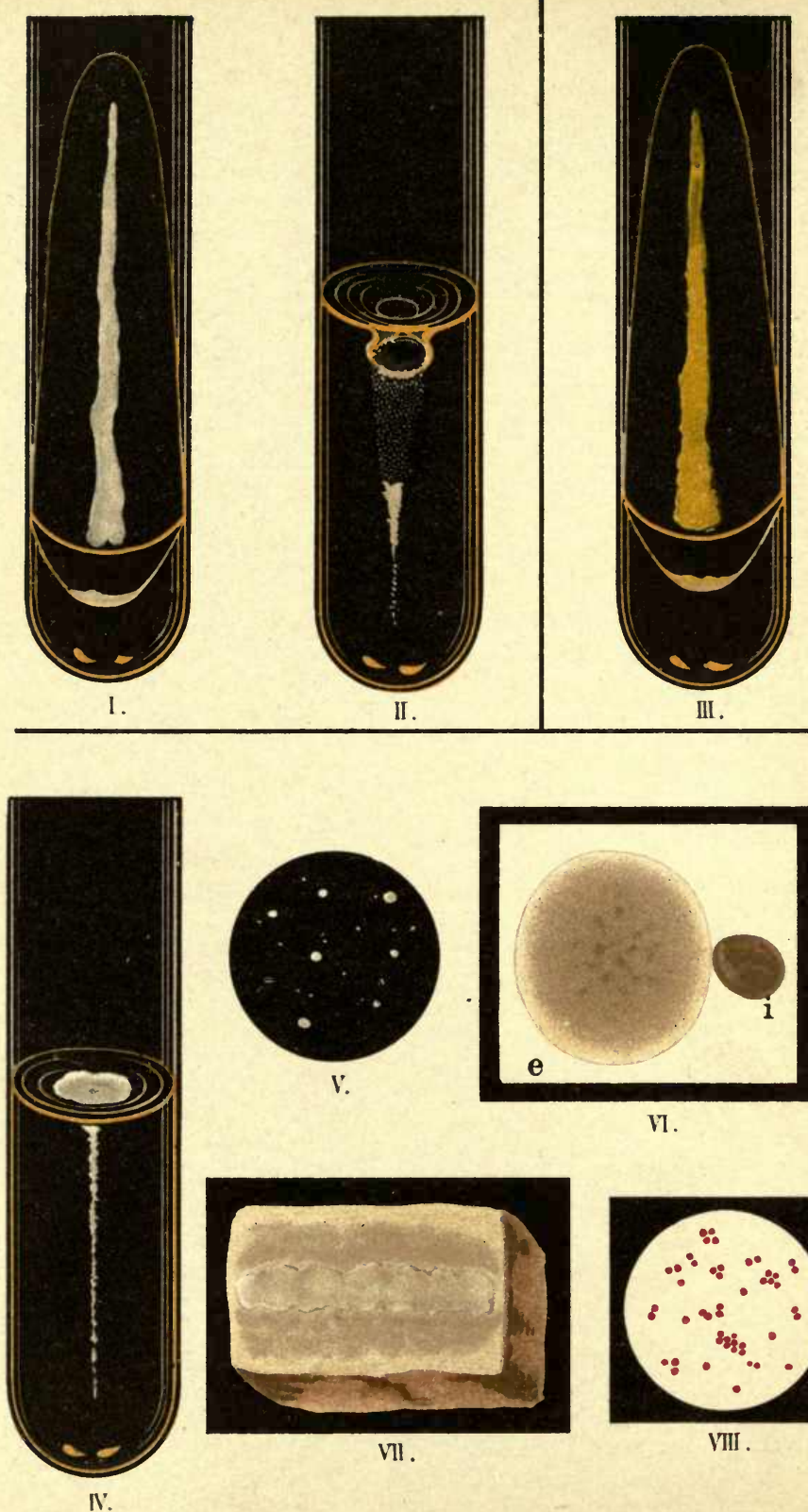

VI.

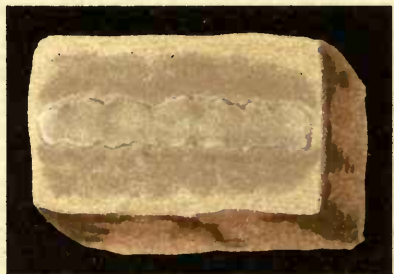

VII.

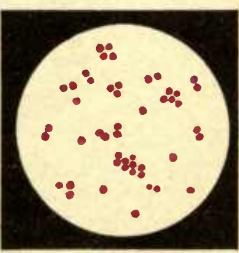

VIII. 


\section{PLATE 9.}

Micrococcus pyogenes $\gamma$ albus. (Rosenbach.) L. and N. (Staphylococcus albus Rosenbach.)
I. Agar streak culture, four days at $22^{\circ}$.
II. Gelatin stab culture, five days at $22^{\circ}$.

Micrococcus pyogenes $\beta$ citreus. (Rosenbach.) L. and N. (Staphylococcus citreus Rosenbach.)

III. Agar streak culture, six days at $22^{\circ}$.

Micrococcus candicans. Flügge.

IV. Gelatin stab culturé, six days at $22^{\circ}$.

V. Gelatin plate, eight days at $22^{\circ}$.

VI. Gelatin plate, six days at $22^{\circ} . \times 50$. To the left a superficial, to the right a deep colony.

VII. Potato culture, ten days at $22^{\circ}$.

VIII. Microscopic preparation from a two-days'-old culture on agar. $\times 700$. 


\section{PLATE Io.}

Micrococcus gonorrhœæ. Neisser. Bumm.

I. Agar streak culture, ascites-glycerin-agar, three days at $37^{\circ}$.

II. Agar plate, forty-eight hours at $37^{\circ} \times 60$. Superficial colonies. The agar was poured out, and blood from the finger-tip smeared upon it, and upon this was placed the gonorrheal pus. The reddish places are blood. The colonies of the gonococcus grow principally at the periphery of the blood smear.

III. Serum-agar plate. The upper colony three days, the lower twenty-four hours, at $37^{\circ} . \times 60$. Superficial colonies. One c.c. of human serum was added to the agar.

IV. Serum-agar plate. The same colonies after eight days.

V. Ascites-glycerin-agar plate, forty-eight hours at $37^{\circ}$. $\times 60$. Superficial colonies of a pure culture from blennorrheal pus. To 5 c.c. of a $2 \%$ agar, containing $5 \%$ of glycerin, 1.5 c.c. of human ascites-fluid were added.

VI. Ascites-glycerin-agar plate, forty-eight hours, at $37^{\circ}$. $\times 60$. Superficial colonies. After pouring out the agar, blennorrheal pus was smeared upon it. The darker septa are pus (pushed together by the growing colonies); also the material at the periphery of the colonies.

VII. Smear preparation from gonorrheal pus. $\times 1000$. Stained with methylene-blue.

VIII. Smear preparation from blennorrheal pus. $\times 1000$. Stained with methylene-blue. A pus cell in which lie the micrococci, almost always in fours in capsules. The preparation contains a great many micrococci thus situated.

IX. Smear preparation from blennorrheal pus. $\times 1000$. Stained with methylene-blue and eosin.

X. Micrococci, highly magnified, schematic.

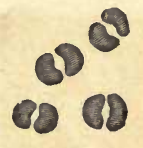


'Tab. 10.
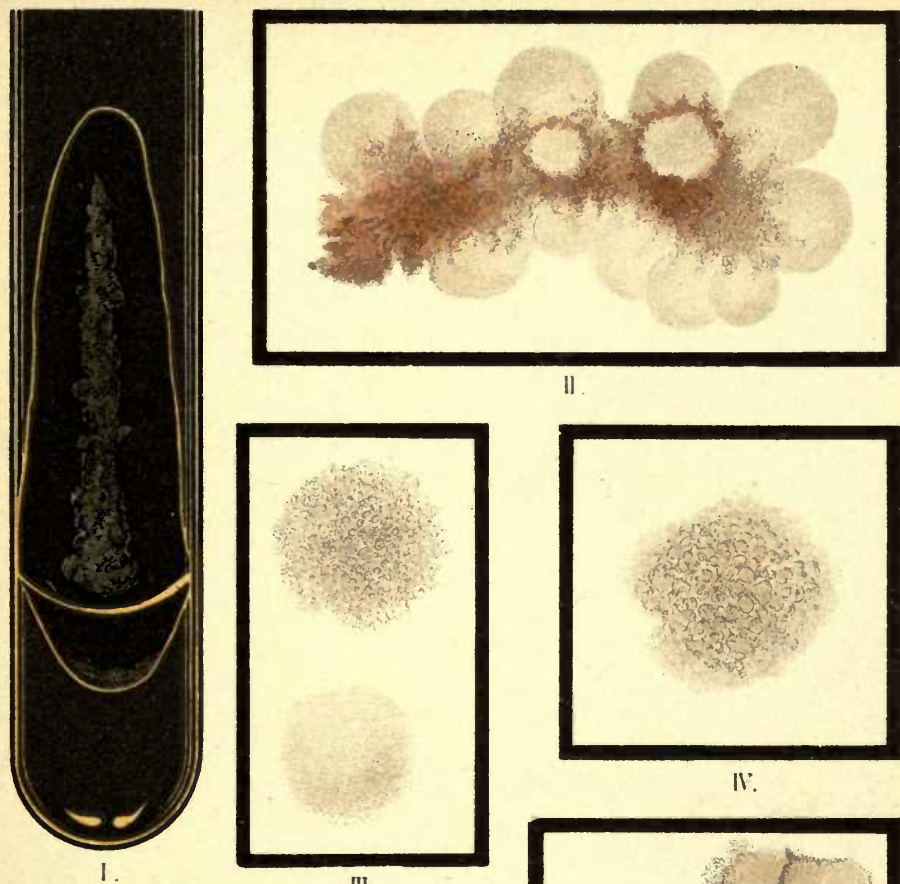

II.
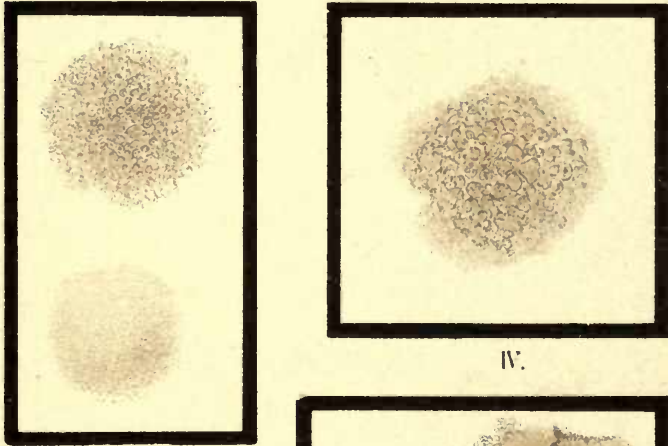

IV.
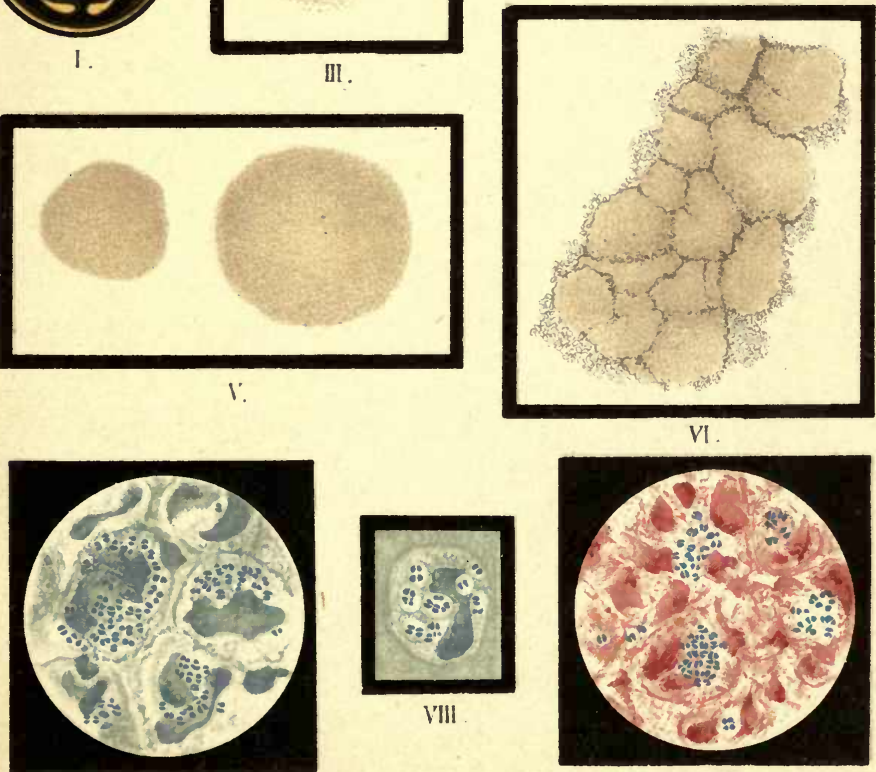

IX.

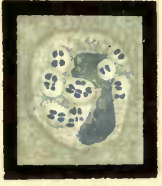

V'III 


Tab. 11.

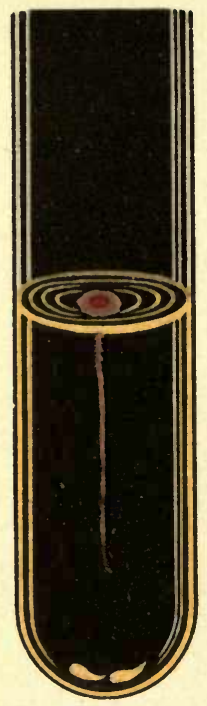

1.

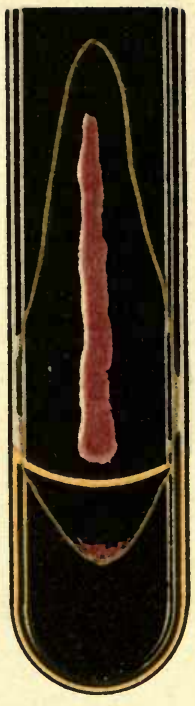

II.

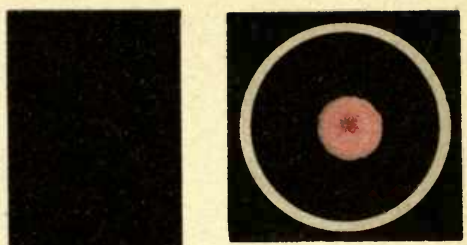

II.

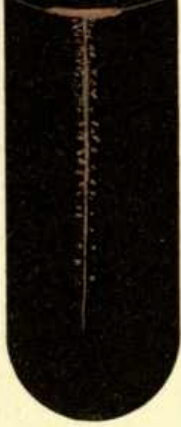

III .

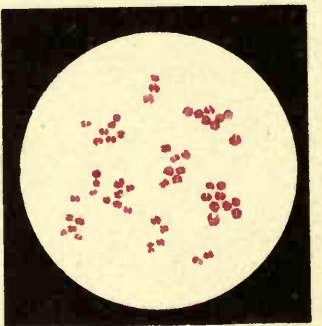

I'III.

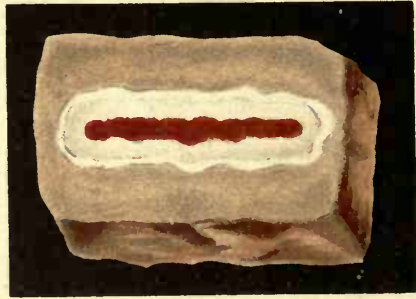

II.

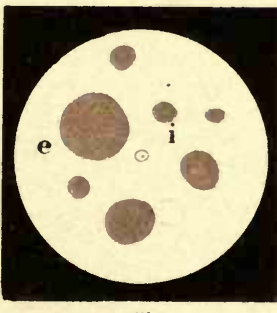

VII .

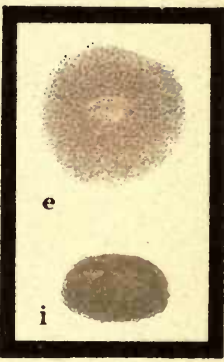

V.

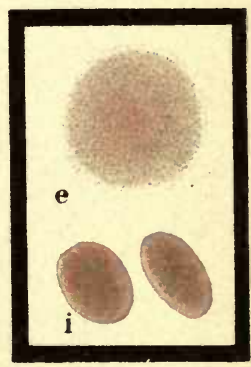

Vl 


\section{PLATE II.}

Micrococcus roseus. (Bumm.) Lehm. and Neum.

(Diplococeus roseus Bumm.)

I. Gelatin stab culture, twenty days at room temperature.

II. Agar streak culture, thirty days at room temperature. The white reflex on the right side is not always so marked.

III. Agar stab culture, ten days at $22^{\circ}$. Stab canal.

IV. Agar stab culture, ten days at $22^{\circ}$. Surface growth.

V. Agar plate, twelve days at $22^{\circ} . \times 50$. Above, a superficial; below, a deep colony.

VI. Agar plate, fourteen days at $22^{\circ} . \times 50$. More delicate structure. Above, a superficial; below, deep colonies.

VII. Gelatin plate, eight days at $22^{\circ} . \times 50$. Super. ficial and deep colonies.

IX. Potato culture. A culture of the Diploc. roseus, grown upon a culture of anthrax; ten days at room temperature.

X. Potato culture, twenty days at room temperature.

XIII. Microscopic preparation, from three-days'-old agar culture. $\times 1000$. The cocci are undergoing division. 


\section{PLATE 12.}

Bacterium septicæmiæ hæmorrhagicæ. Hüppe. (Chicken Cholera, Rabbit Septicemia, etc.)

I. Gelatin stab culture, seven days at $22^{\circ}$.

II. Agar streak culture, seven days at $22^{\circ}$.

III. Agar plate, five days at $22^{\circ}$. Natural size.

IV. Agar plate, five days at $22^{\circ} . \times 60$. Superficial colony. Compare also Plate 14, vi; Plate 17, vi; Plate 18, VII.

V. Agar plate, five days at $22^{\circ} . \times 60$. Deep colonies.

VI. Gelatin plate, five days at $22^{\circ}$. Natural size.

VII. Gelatin plate, five days at $22^{\circ} . \times 90$. Deep colonies.

VIII. Gelatin plate, five days at $22^{\circ} . \times 90$. Superficial colony. Compare also Plate 14, viII; Plate 17, I; Plate 16, viII; Plate 19, III, IV, vII.

IX. Microscopic preparation. $\times 1000$. Pure culture from agar plate.

X. Single bacteria. Highly magnified. Schematic.

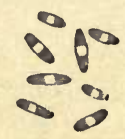

$\mathrm{X}$. 
Tab. 12.
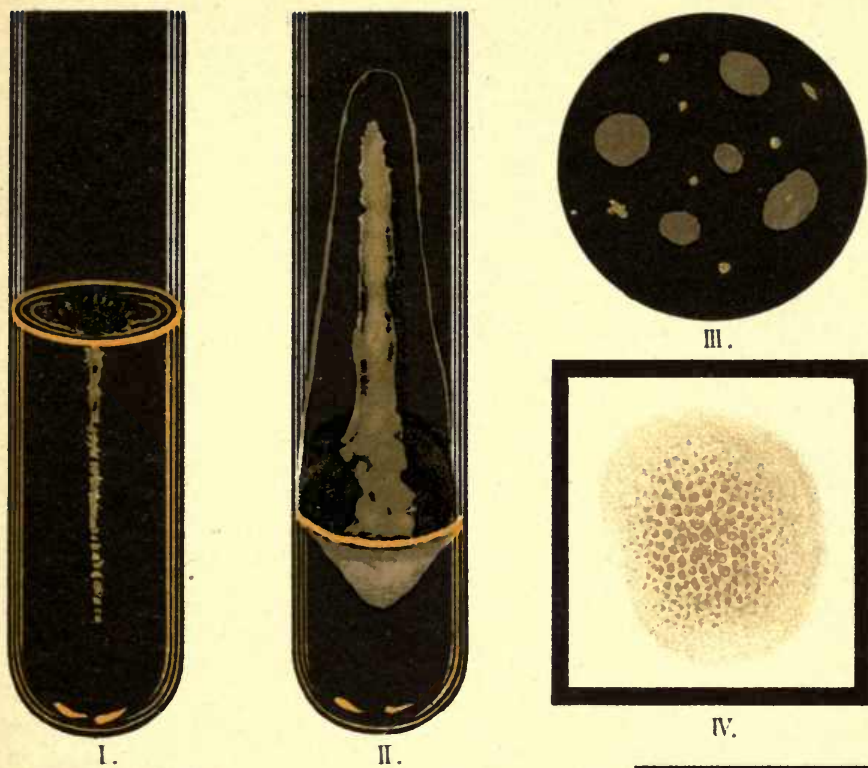

III.

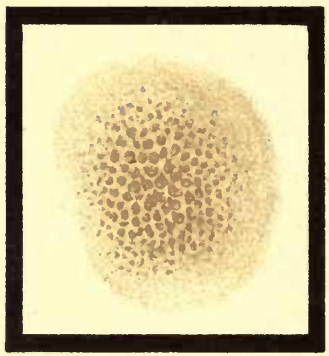

N.
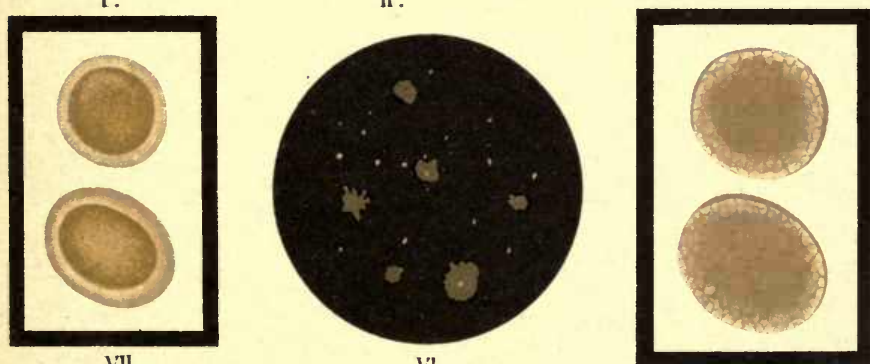

VII.

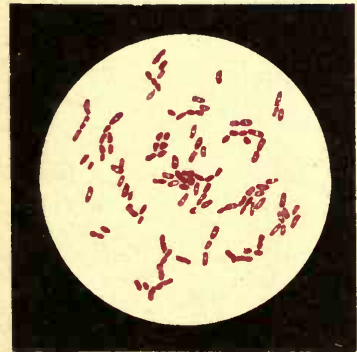

IX.

V.

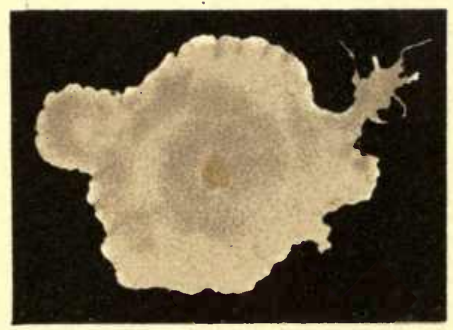

V'II . 

Tab. 13.
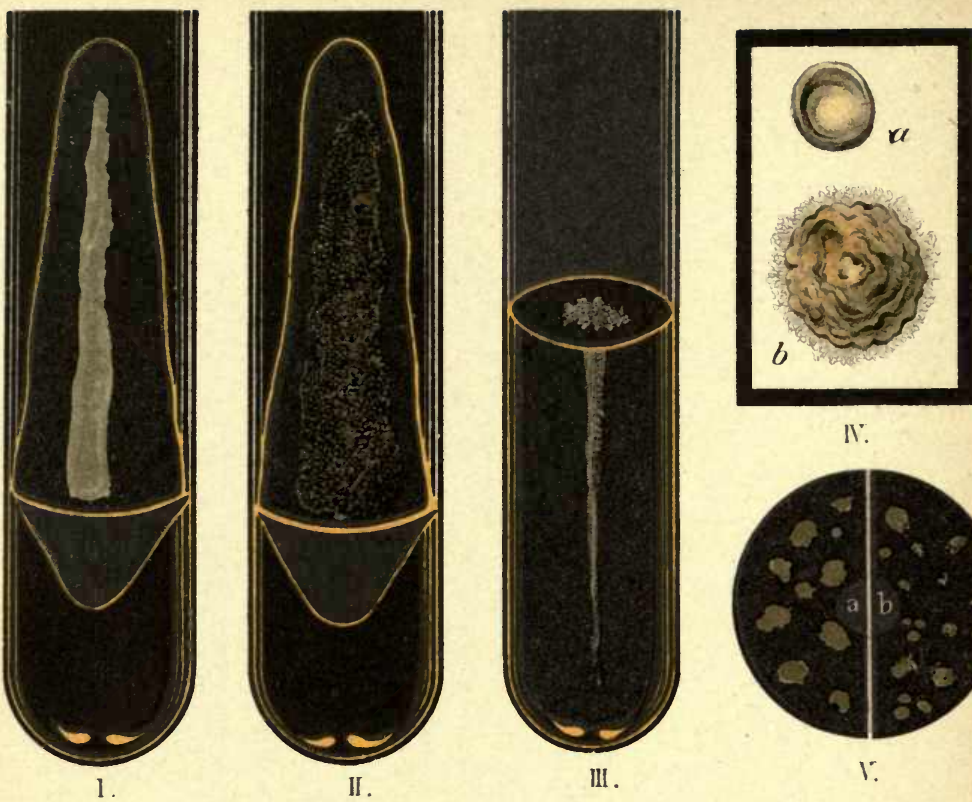

IV.
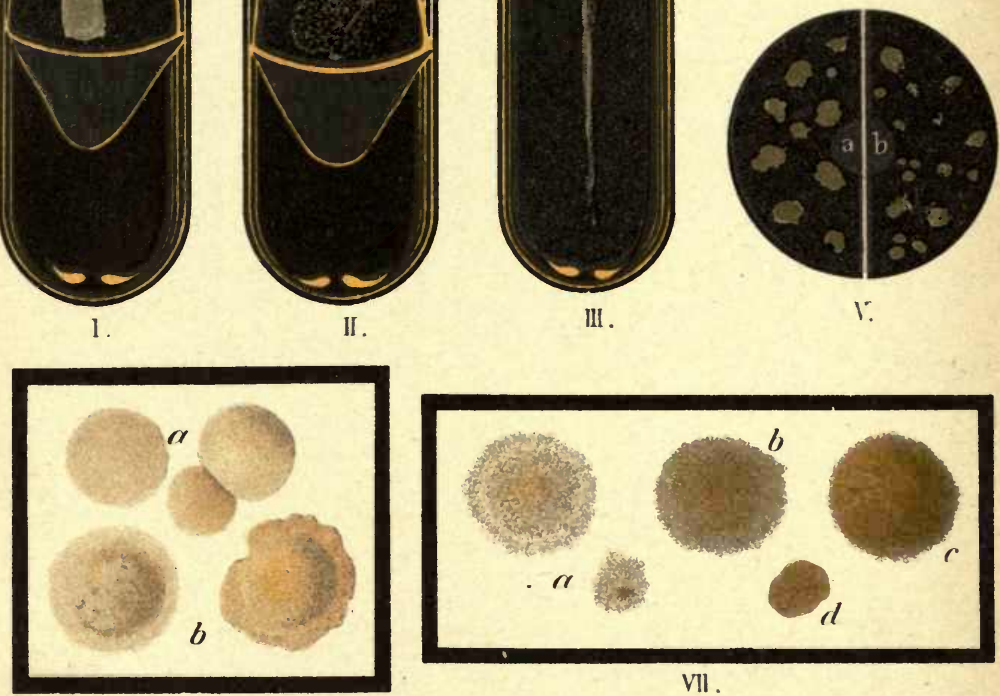

VI.

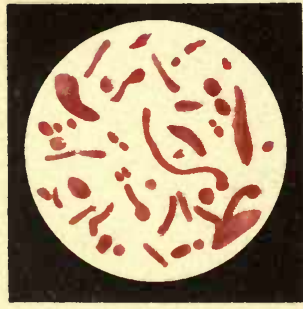

VIII

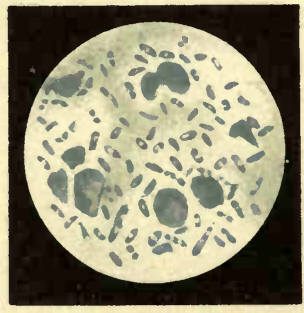

L.

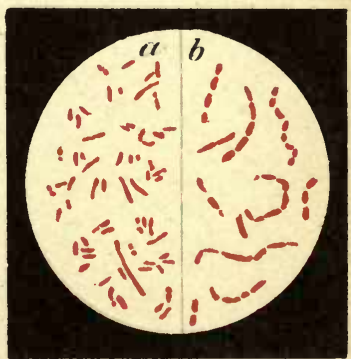

$X$ 


\section{PLATE 13.}

Bacterium pestis. Lehm. and Neum.

$37^{\circ}$.

I. Streak culture (ascites-glycerin-agar), three days at

II. Streak culture (agar), forty-eight hours at $37^{\circ}$. (After a culture of Dr. Dieudonnê, preserved with formalin.) The streak was made with the juice direct from a bubo. The transparent, dewdrop-like growth is characteristic.

III. Stab culture (gelatin), six days at $22^{\circ}$. The growth consists of minute, waxy, markedly elevated colonies, which become confluent; also the same upon the gelatin plate $(\mathrm{v}, b)$.

IV. Plate culture (gelatin), six days at $22^{\circ} . \times 60$. Deep colony ; $(b)$ superficial colony.

V. Plate culture: (a) Glycerin-agar, three days at $37^{\circ}$. Natural size. Superficial colonies. (b) Gelatin, six days at $22^{\circ}$. Natural size. Superficial colonies. Compare what is said under Fig. III.

VI. Plate culture (agar), forty-eight hours at $37^{\circ}$. $\times 60$. Superficial colonies. They correspond to the dewdrop-like colony in the agar streak culture (II). (a) Younger, (b) older colonies.

VII. Plate cultures, forty-eight hours at $37^{\circ} . \times 60$.
(a) Ordinary agar
(b) Glycerin-agar
(c) Ascites-glycerin-agar
Superficial colonies.
(d) Ascites-glycerin-agar, deep colony.

The crumbly character of cultures after being cultivated in contrast to very fresh cultures is to be noted (compare vI).

VIII. Microscopic preparation, three days at $37^{\circ}$ on glycerin-agar. $\times 1000$. Stained with fuchsin. Involution forms.

IX. Microscopic preparation: Smear from the juice of a bubo. $\times 1000$. Stained with methylene-blue. (From a preparation of Dr. Dieudonné.)

X. Microscopic preparation: (a) Ordinary agar, twenty-four hours at $37^{\circ} . \times 1000$. Stained with fuchsin. (b) Ordinary bouillon, twenty-four hours at $37^{\circ} . \times 1000$. Stained with fuchsin. 


\section{PLATE 14.}

Bacterium acidi lactici. Hüppe. (Lactic Acid Bacillus.)

I. Gelatin stab culture, five days at $22^{\circ}$. The stab canal in nature is somewhat whiter.

II. Agar streak culture, five days at $22^{\circ}$.

III. Agar stab culture, three days at $22^{\circ}$. Stab canal.

IV. Agar stab culture, three days at $22^{\circ}$. Surface growth.

V. Agar plate, three days at $22^{\circ}$. Natural size.

VI. Agar plate, three days at $22^{\circ} . \times 50$. Upper colony superficial, lower colonies deep. Compare also Plate 18, viI.

VII. Gelatin plate, two days at $22^{\circ}$. Natural size.

VIII. Gelatin plate, two days at $22^{\circ} . \times 50$. Upper colony superficial, lower colonies deep. The superficial colonies may vary very much. Compare also Plate 16 , vIII, Ix; Plate 17, I, II ; Plate 19, IV, vII.

IX. Microscopic preparation. Pure culture from an agar colony. $\times 800$.

X. Potato culture, six days at $22^{\circ}$. The air-bubbles on the surface often cover it completely. 
Tab. 14.
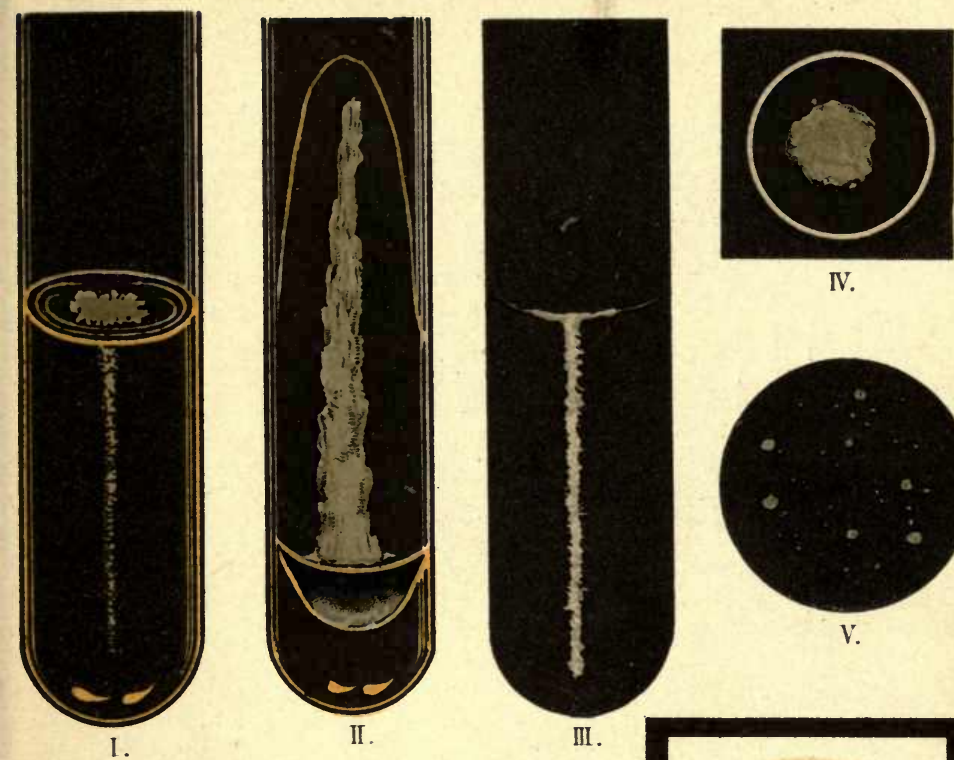

IV.

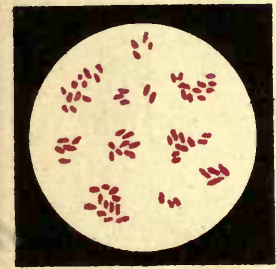

IX.

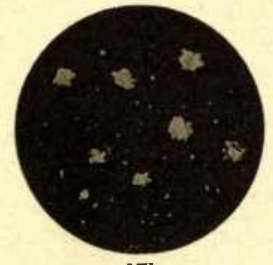

ITI.

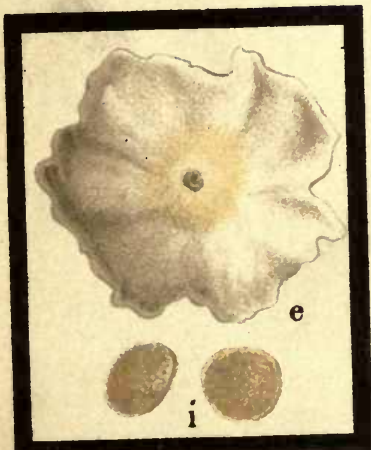

VIII.

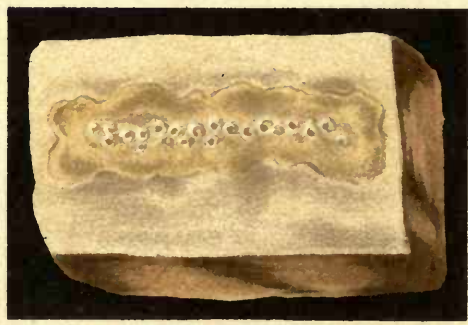

I.

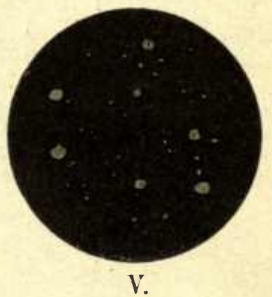

8

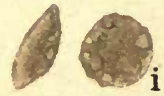

VI.

Lith. Anst E. Reichhold, München 

Tab. 15.
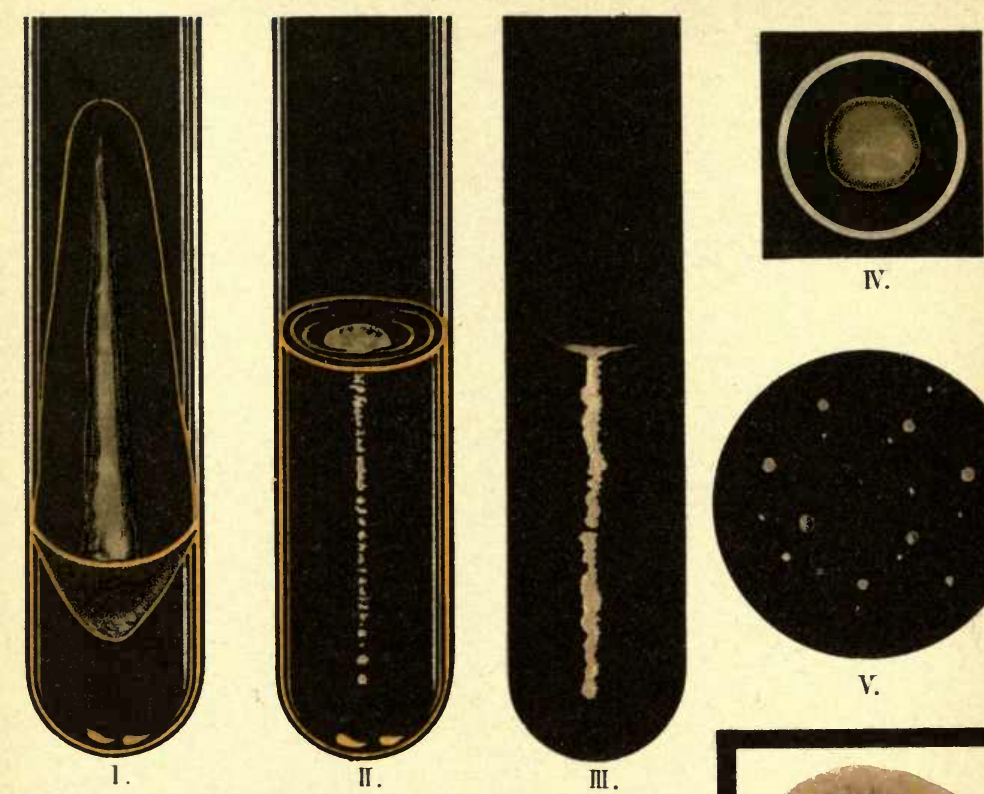

IV.
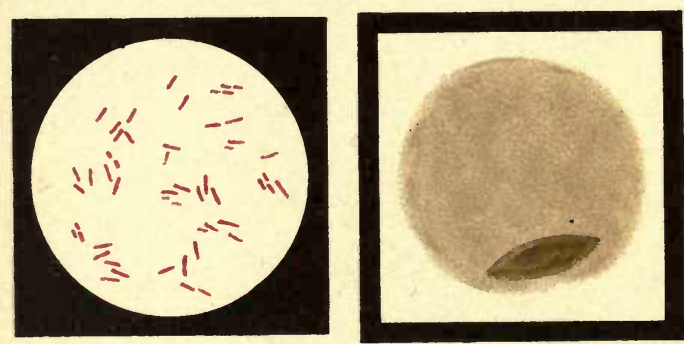

IX.

VI.
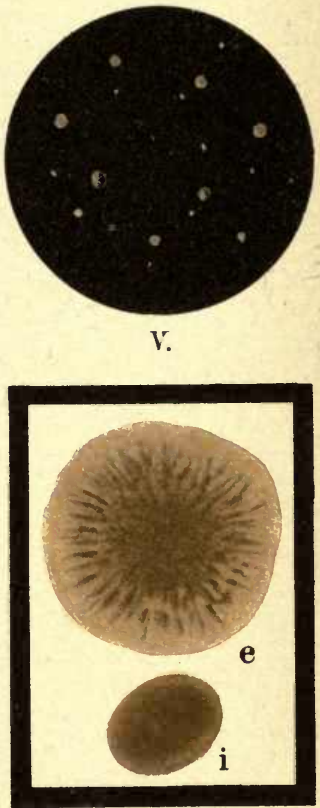

VII.

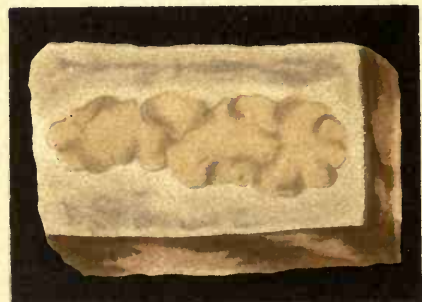

XI.
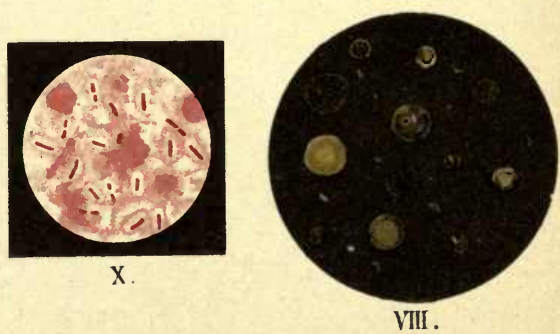

Lith Anst E Reichhold München. 


\section{PLATE 15.}

Bacterium pneumoniæ. Friedländer. (Friedländer's Pneumonia Bacillus.)

I. Agar streak culture, four days at $22^{\circ}$.

II. Gelatin stab culture, ten days at $22^{\circ}$.

III. Agar stab culture, four days at $22^{\circ}$. Stab canal.

IV. Agar stab culture, four days at $22^{\circ}$. Surface growth.

V. Gelatin plate, three days at $22^{\circ}$. Natural size.

VI. Agar plate, two days at $22^{\circ} . \quad \times 60$. The brown whetstone-shaped colony is deep.

VII. Gelatin plate, three days at $22^{\circ} . \times 50$. Upper, superficial; lower, deep colony.

VIII. Agar plate, four days at $22^{\circ}$. Natural size. The delicate gray colonies are deep; also the smallest colonies. One colony in the reproduction has turned out yellowish.

IX. Microscopic preparation. Pure culture from an agar plate. $\times 800$. Stained with fuchsin.

X. Microscopic preparation. Smear preparation from sputum. $\times 800$. Stained with fuchsin.

XI. Potato culture, six days. 
PLATE 16.

Bacterium typhi. Eberth. Gaffky. (Typhoid Bacillus.)

I. Agar stab culture, three days at $22^{\circ}$. Stab canal.

II. Agar stab culture, three days at $22^{\circ}$. Surface growth.

III. Gelatin stab culture, eight days at $22^{\circ}$. Stab canal.

IV. Gelatin stab culture, eight days at $22^{\circ}$. Surface growth.

V. Agar streak culture, four days at $22^{\circ}$. Compare also Plate 18, III.

VI. Gelatin streak culture, three days at $22^{\circ}$. Compare also Plate 18, II.

VII. Gelatin plate, thirty-six hours at $22^{\circ}$. Deep colony. Compare also Plate 14, vIIr; Plate 19, v.

VIII. Gelatin plate, thirty-six hours at $22^{\circ}$. Superficial colony. Compare also Plate 14, vIII; Plate 19, III.

IX. Gelatin plate, four days at $22^{\circ}$. Superficial colony. Compare also Plate 19, Iv, vir. 
Tab. 16.

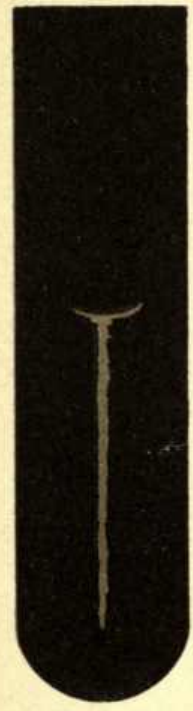

I.

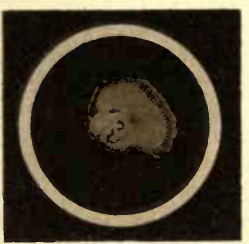

II.
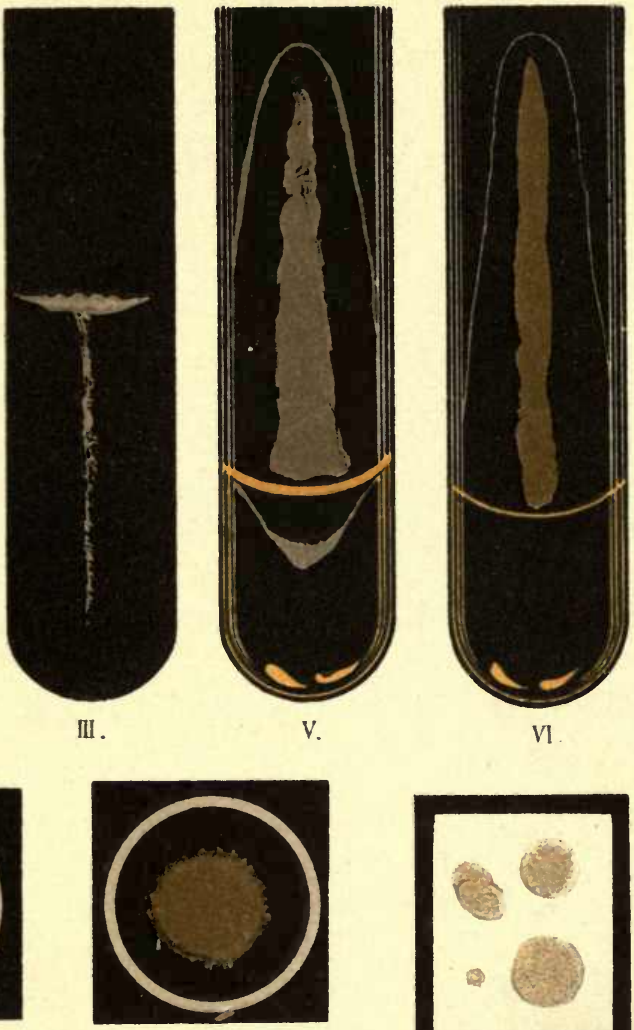

IV.

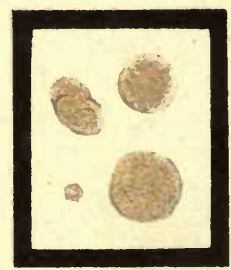

III.

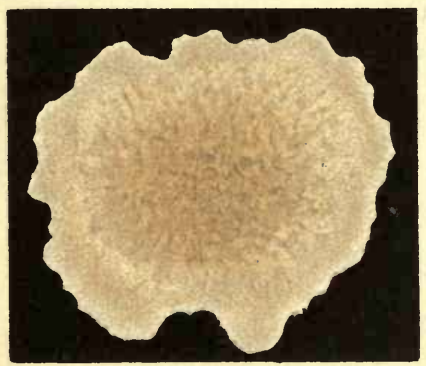

IX.

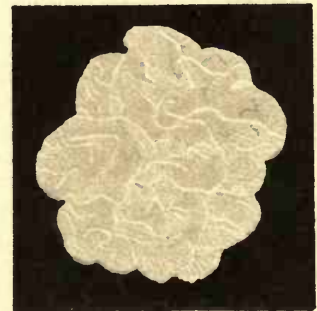

VIII.

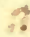



Tab. 17.

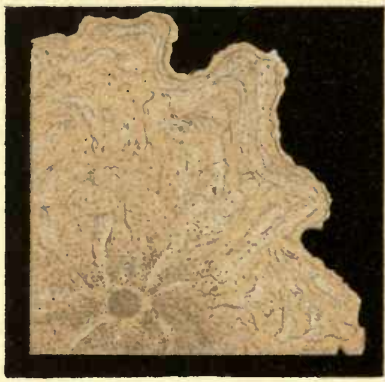

1.

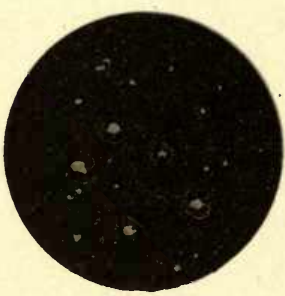

III.

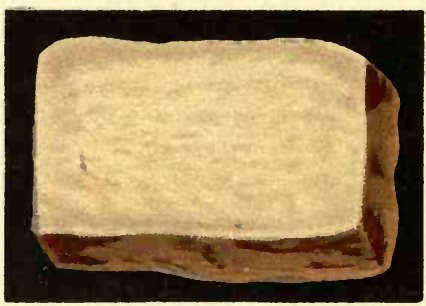

VII .

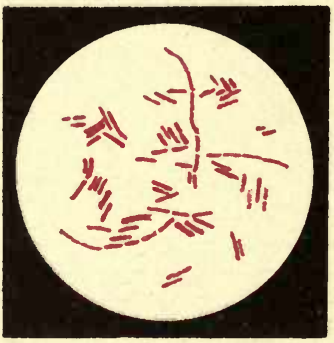

I'III

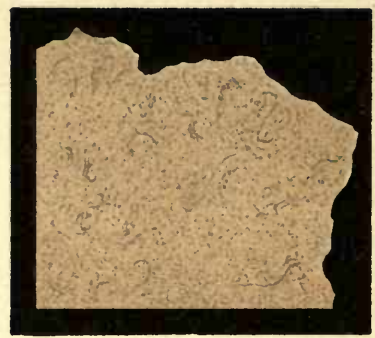

II.

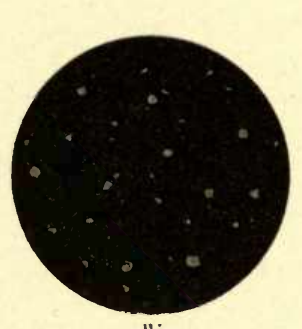

IV.

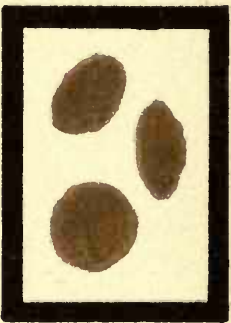

I:

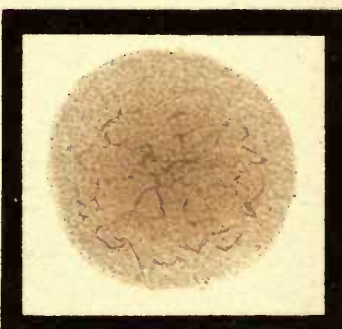

VI

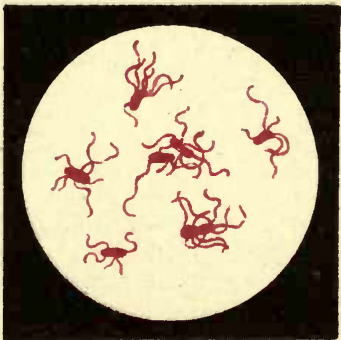

IX. 


\section{PLATE 17.}

Bacterium typhi. Eberth. Gaffky. (Typhoid Bacillus.)

I. Gelatin plate, eight days at $22^{\circ} . \times 90$. Superficial colony. Compare also Plate 19, vi, vir.

II. Gelatin plate, eight days at $22^{\circ} . \times 150$. Superficial colony.

III. Gelatin plate, four days at $22^{\circ}$. Natural size.

IV. Agar plate, four days at $22^{\circ}$. Natural size.

V. Agar plate, four days at $22^{\circ} . \times 60$. Deep colonies.

VI. Agar plate, four days at $20^{\circ} . \times 60$. Superficial colony.

VII. Potato culture, five days at $22^{\circ}$.

VIII. Microscopic preparation. Pure culture from agar plate. $\times 1000$.

IX. Microscopic preparation. Bacilli with flagella. Copied after Fränkel and Pfeiffer. "Atlas der Bakterienkunde," Plate 54, III.

X. Microscopic preparation. Long threads thickly beset with flagella. $\times 1500$. Stained by Löffler's method.

XI. Microscopic preparation of Bacterium typhi murium Löffler, with flagella and capsule. $\times 1500$. Stained by Löffler's method.

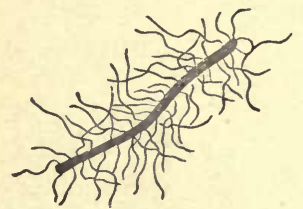

$\mathrm{X}$.

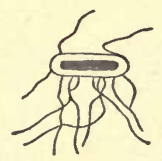

XI. 
Bacterium coli (Escherich). L. and N.

I. Gelatin stab culture, ten days at $22^{\circ}$.

II. Gelatin streak culture, four days at $22^{\circ}$. In nature is transparent, resembling mother-of-pearl in iridescence. Compare also Plate 16, vi.

III. Agar streak culture, four days at $22^{\circ}$. Compare also Plate 16 , v.

IV. Agar stab culture, two days at $22^{\circ}$. Stab canal.

V. Agar stab culture, two days at $22^{\circ}$. Surface growth.

VI. Agar plate, four days at $22^{\circ} . \times 60$. Deep colonies. Compare also Plate 14, vI.

VII. Agar plate, four days at $22^{\circ} . \times 60$. Part of a superficial colony. May also occasionally present forms like the bacillus acidi lactici. Compare Plate 12, Iv; Plate 14, vI; Plate 17, vI.

VIII. Agar plate, three days at $22^{\circ}$. Natural size.

IX. Potato culture, five days at $22^{\circ}$. May also be paler or more deeply colored.

$\mathrm{X}$. Bacteria with long flagella of Bacterium brassica acidoe. $\times 1000$. Stained according to Löffler.

XI. Bacterium of pigeon diphtheria surrounded by flagella. $\times 1000$. Stained according to Löffler.

XII. Bacteria with one flagellum, rarely two flagella, of Bact. coli $\beta$ unipolaris. $\times 1000$. Stained according to Löffler.

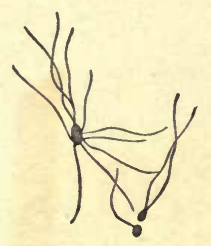

$\mathrm{X}$.

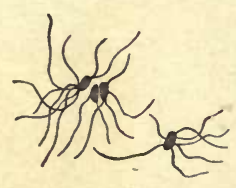

XI.

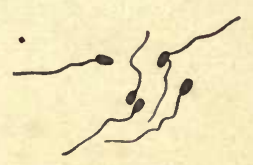

XII. 
Tab. 18.
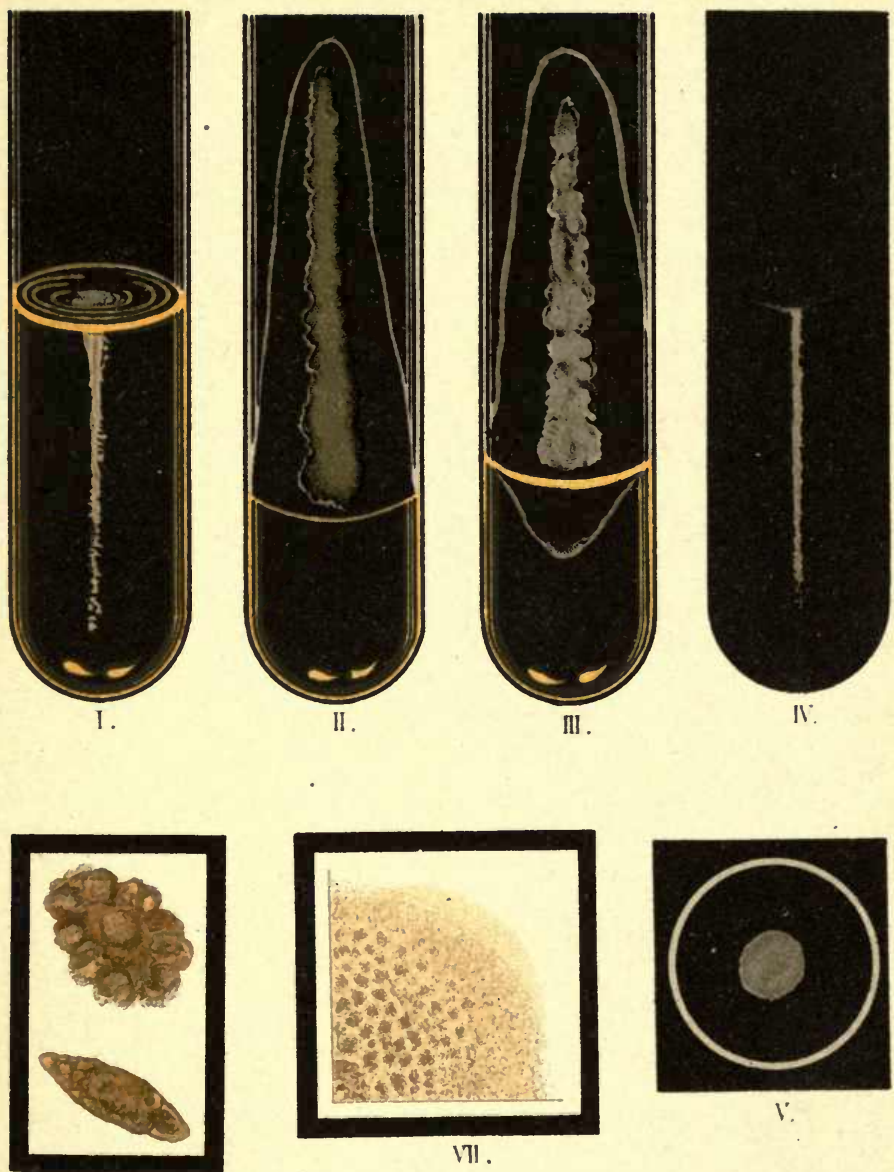

I.

171.
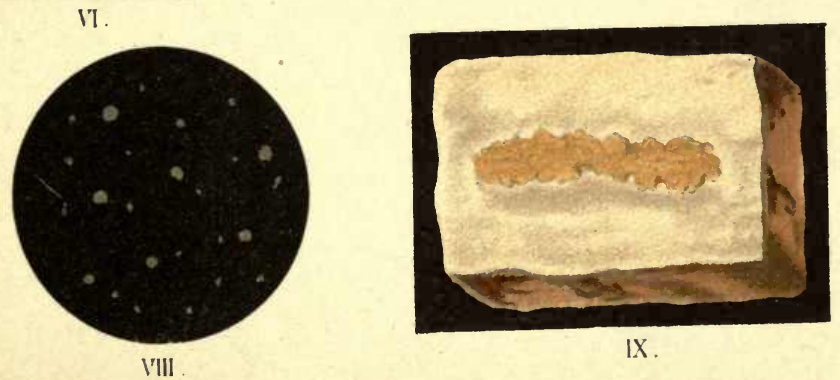

IX . 

Tab. 19 .
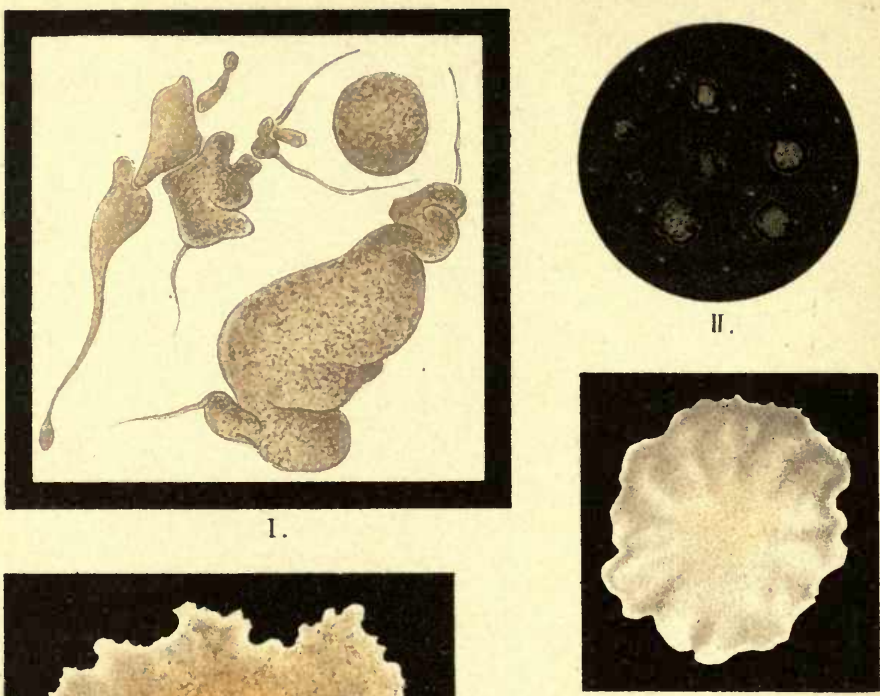

III.

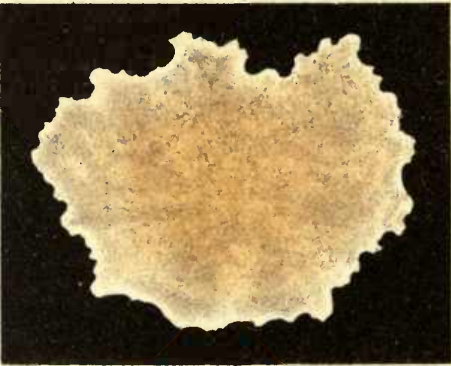

IV.
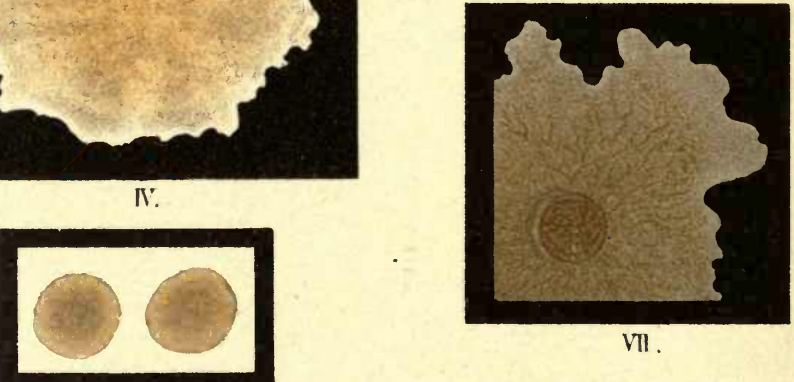

VII.

V.

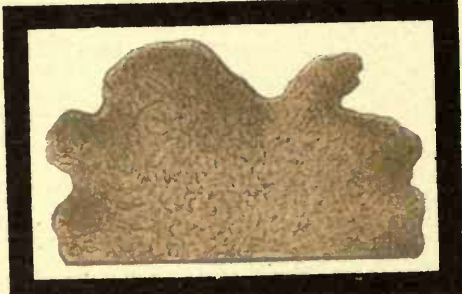

11.

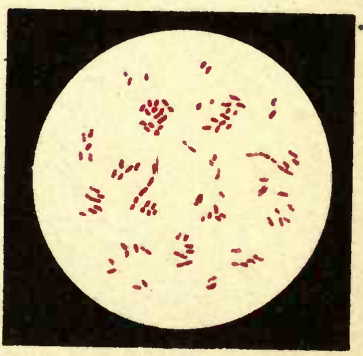

VIII 


\section{PLATE 19.}

\section{Bacterium coli (Escherich). L. and N.}

I. Gelatin plate, eight days at $22^{\circ} . \times 60$. Cultivated from pus. Deep colonies of abnormal form.

II. Gelatin plate, four days at $22^{\circ}$. Natural size.

III. Gelatin plate, one day at $22^{\circ} . \times 90$. Superficial colony. Compare also Plate 14, viIr ; Plate 16, vir..

IV. Gelatin plate, four days at $22^{\circ} . \quad \times 60$. Superficial colony. Compare also Plate 16, Ix; Plate 17, I, Ir.

V. Gelatin plate, four days at $22^{\circ} . \quad \times 60 . \quad$ Deep colonies.

VI. Gelatin plate, ten days at $22^{\circ} . \times 90$. Superficial colony.

VII. Gelatin plate, ten days at $22^{\circ} . \quad \times 90$. Superficial colony.

VIII. Microscopic preparation. Pure culture from agar plate. $\times 500$.

IX. Different varieties of coli bacteria.$\times 1000$. Variable sizes.

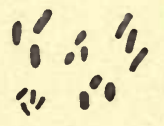

IX. 


\section{PLATE 20.}

\section{Bacterium latericium. Adametz.}

I. Agar streak culture, seven days at $22^{\circ}$.

II. Gelatin stab culture, fourteen days at $22^{\circ}$.

III. Gelatin plate, seven days at $22^{\circ} . \times 60$. To the right deep, to the left superficial colonies.

IV. Potato culture, thirty days at $22^{\circ}$. Natural size.

V. Agar plate, seven days at $22^{\circ} . \times 60$. To the right a superficial, to the left a deep colony.

VI. Microscopic preparation. Pure culture on agar, twenty-four hours old. $\quad \times$ about 800 .

Bacterium hæmorrhagicum (Kolb). L. and N.

\section{(Morbus Werlhofii.)}

VII. Microscopic preparation. Pure culture from bouillon, three days old. (Copied after Kolb, A. G., Bd. vir, Plate II, Figs. 1 and 2.)

VIII. Smear preparation from the liver of a dog. (Copied after Kolb, l.c., Bd. viI, Plate III, Fig. 8.) 
Tab. 20.
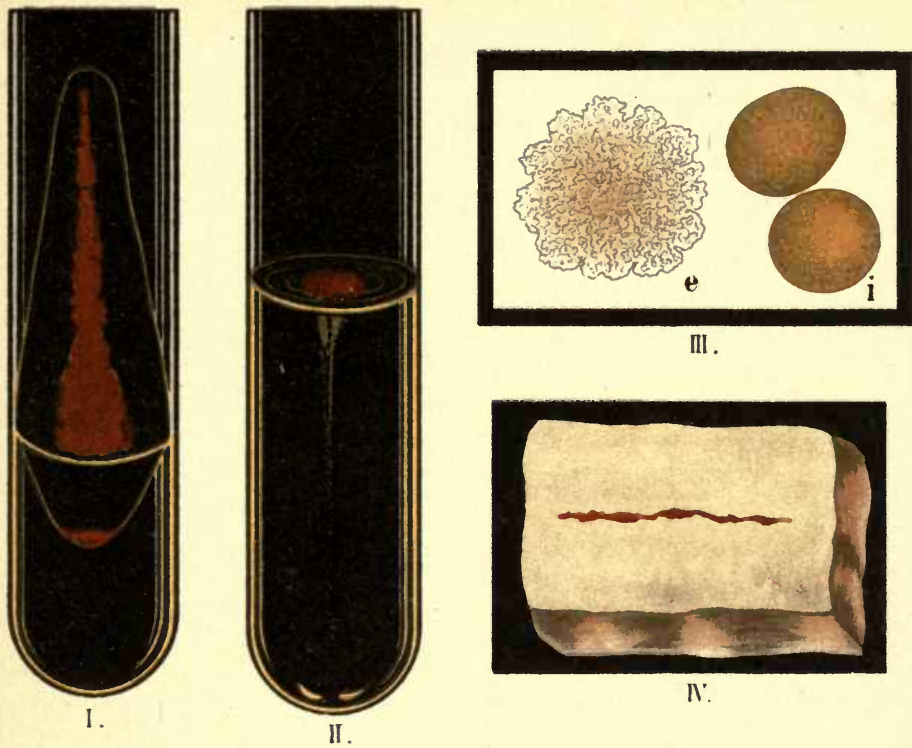

III.

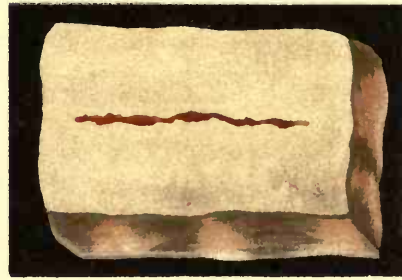

II.
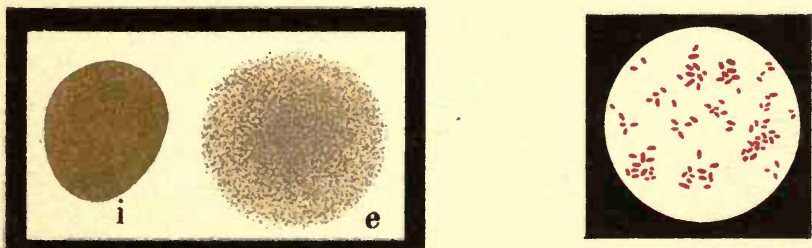

17.

l:

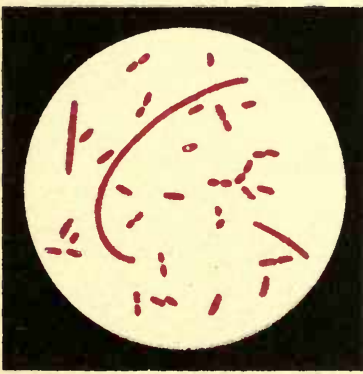

$|7|$.

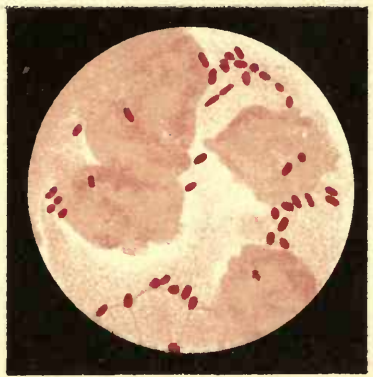

I'III 

Tab. 21.
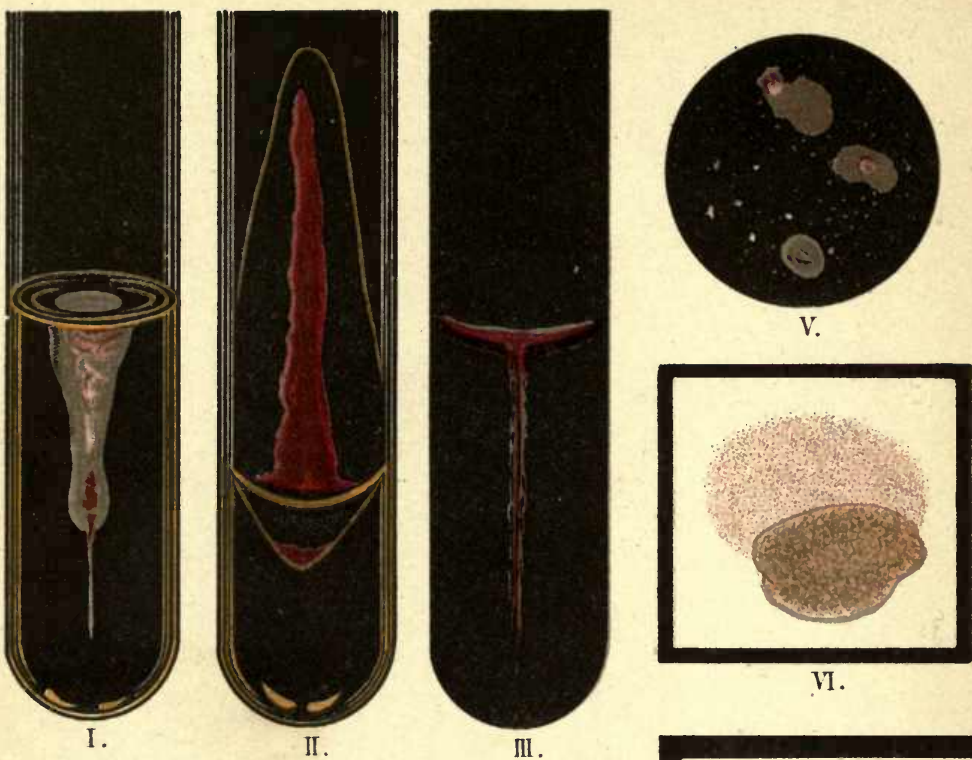

VI.
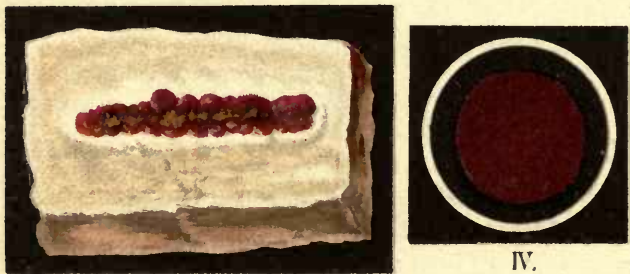

IX.
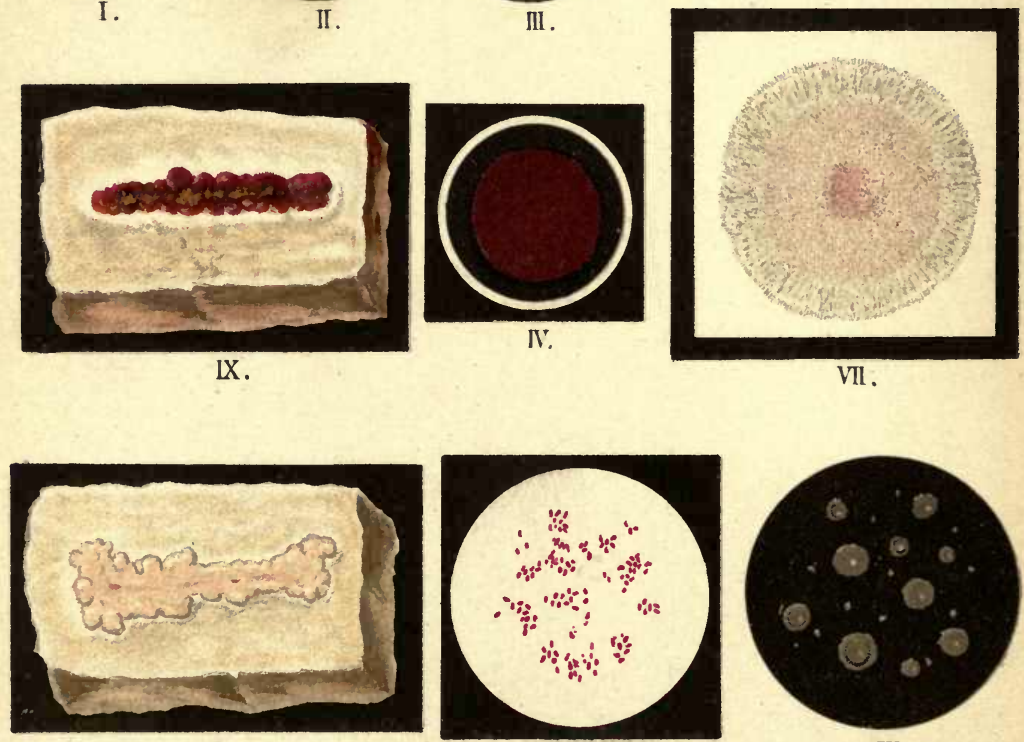

X.

XI.

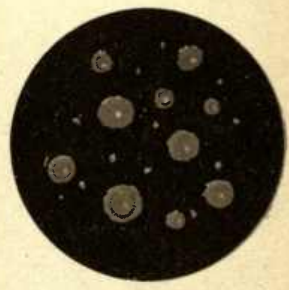

VIII. 


\section{PLATE 21.}

Bacterium prodigiosum (Ehrenb.). Lehm. and Neum.

I. Gelatin stab culture, one day at $22^{\circ}$.

II. Agar streak culture, four days at $22^{\circ}$.

III. Agar stab culture, four days at $22^{\circ}$. Stab canal.

IV. Agar stab culture, four days at $22^{\circ}$. Surface growth.

V. Agar plate, from two to four days at $22^{\circ}$. Natural size. Colonies with and without color.

VI. Agar plate, eight days at $22^{\circ} . \times 60$. Superficial colony reddish, deep one yellowish.

VII. Gelatin plate, two days at $22^{\circ} . \quad \times 60$. Superficial colony just beginning to sink in.

VIII. Gelatin plate, two days at $22^{\circ}$. Natural size.

IX. Potato culture, eight days at $22^{\circ}$. Typical with metallic luster on the surface.

X. Potato culture, eight days at $22^{\circ}$. Atypical white growth.

XI: Microscopic preparation. Pure culture from agar. $\times 800$. Stained with fuchsin.

XII. Bacteria with several flagella. $\times 1000$. Stained according to Löffler.

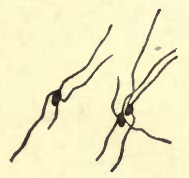

XII. 
PLATE 22.

Bacterium kiliense (Breunig and Fischer). L. and N. (Kiel Water Bacillus.)

I. Agar streak culture, four days at $22^{\circ}$.

II. Gelatin stab culture, four days at $22^{\circ}$. No formation of pigment.

III. Gelatin plate, five days at $22^{\circ}$. Natural size. Colonies with and without production of pigment.

IV. Gelatin plate, five days at $22^{\circ} . \quad \times 60$. Superficial colony.

V. Gelatin plate, five days at $22^{\circ} . \times 60$. Deep colony.

VI. Agar plate, five days at $22^{\circ}$. Natural size. Colored and uncolored, superficial and deep colonies.

VII. Agar plate, five days at $22^{\circ} . \times 60$. Colorless colonies. To the right, superficial; to the left, deep.

VIII. Agar plate, five days at $22^{\circ} . \times 60$. Colored colonies. To the right, superficial; to the left, deep.

IX. Microscopic preparation. Pure culture from agar plate. $\times 1000$. Stained with fuchsin.

X. Potato culture, five days at $22^{\circ}$.

XI. Bacteria with several flagella. $\times 1000$. Stained according to Löffler.

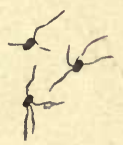

XI. 
Tab. 22.
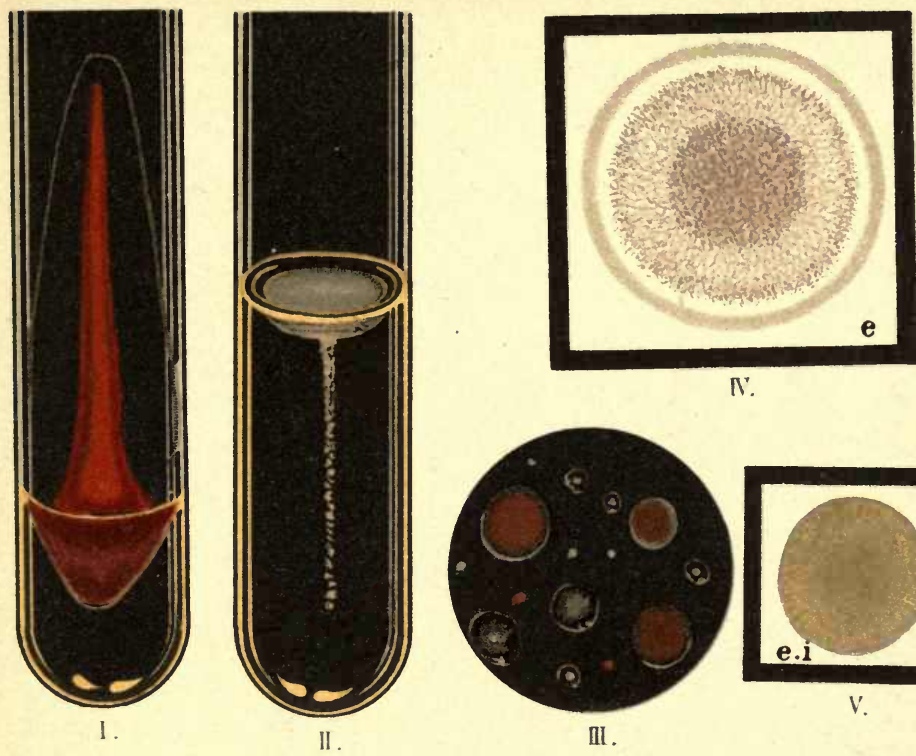

N
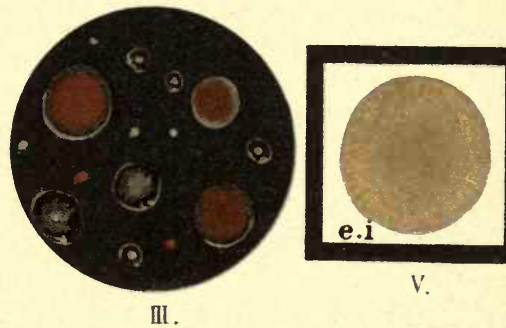

V.
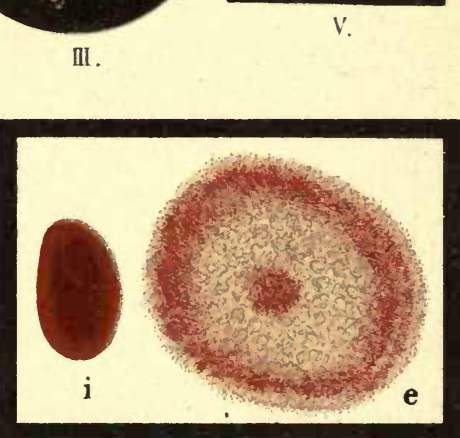

171.

VIII .
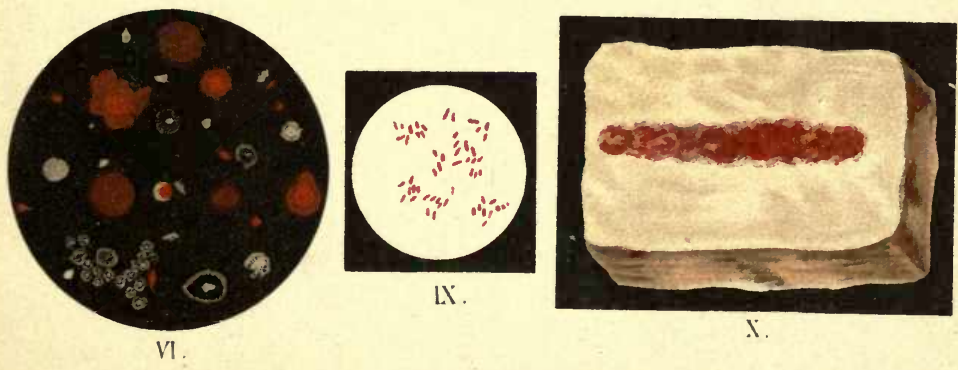

Tab. 23.
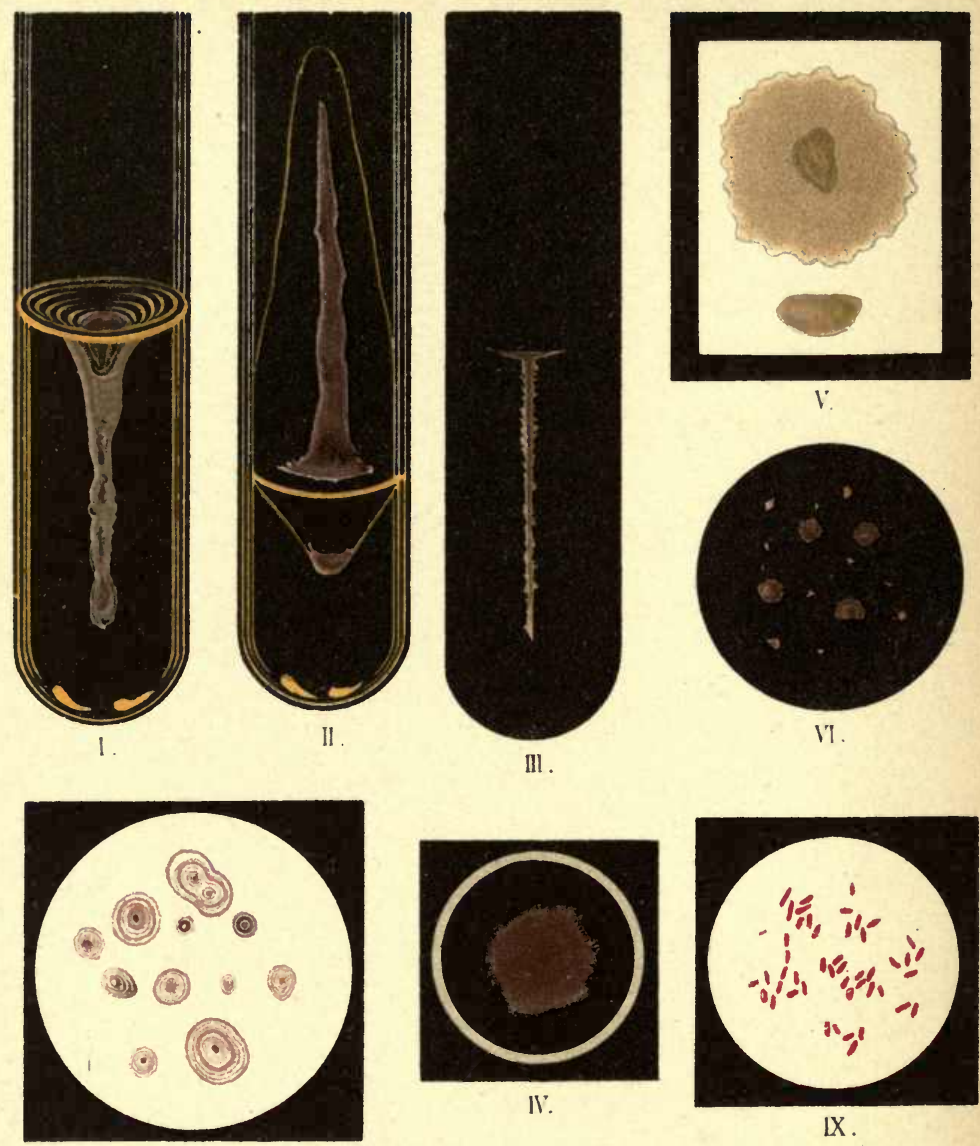

IV.

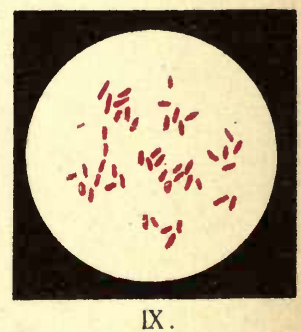

I'I .

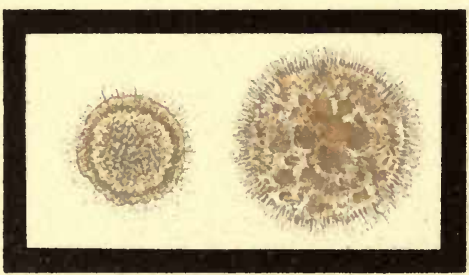

I'III.

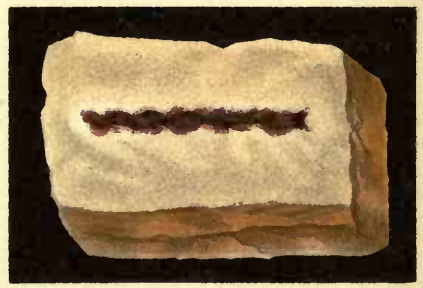

X 


\section{PLATE 23.}

Bacterium violaceum (J. Schröter). Lehm. and Neum. ature.

I. Gelatin stab culture, ten days at ordinary temper-

II. Agar streak culture, six days at ordinary temperature. The white borders after a longer time become likewise violet.

III. Agar stab culture, seven days at ordinary temperature. Stab canal.

IV. Agar stab culture, seven days at ordinary temperature. Surface growth.

V. Agar plate culture, four days at ordinary temperature. $\times 60$. Superficial and deep colonies. Within the former is to be seen the original deeply located colony.

VI. Agar plate culture, eight days at ordinary temperature. Natural size. The colonies often also become dark violet.

VII. Gelatin plate culture. Natural size. Six days at ordinary temperature. The blue zones are not always so intensely colored.

VIII. Gelatin plate culture, six days at ordinary temperature. $\times 60$. The smaller colony lies near the surface, the larger is on the surface.

IX. Microscopic preparation. $\times 700$. From a fivedays'-old agar culture.

X. Potato culture, six days at ordinary temperature.

XI. Bacteria with flagella. $\times 1000$. Stained according to Löffler.

XII. Bacteria with flagella. $\times 1000$. From a culture from Sweden.

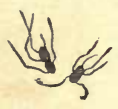

XI.

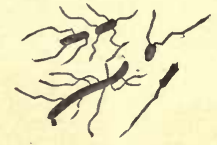

XII. 
PLATE 24.

Bacterium pyocyaneum (Flügge). Lehm. and Neum. (Green Pus.)

I. Gelatin stab culture, three days at $22^{\circ}$.

II. Agar streak culture, two days at $37^{\circ}$.

III. Gelatin plate, two days at $22^{\circ} . \times 60$. Colonies located deeply and just below the surface, in young and older stages.

IV. Gelatin plate, five days at $22^{\circ} . \times 60$. Part of a superficial colony.

V. Gelatin plate, two days at $22^{\circ}$. Natural size.

VI. Agar plate, two days at $37^{\circ}$. Natural size.

VII. Agar plate, two days at $37^{\circ} . \times 60$. Above, superficial; below, deep colonies.

VIII. Potato culture, three days at $37^{\circ}$. Natural size.

IX. Microscopic preparation. Pure culture from agar plate. $\times 800$.

X. Bacteria with one, more rarely two polar flagella. $\times 1000$. Stained according to Löffler.

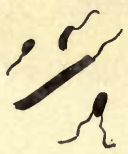

$\mathrm{X}$. 
Tab. 24.
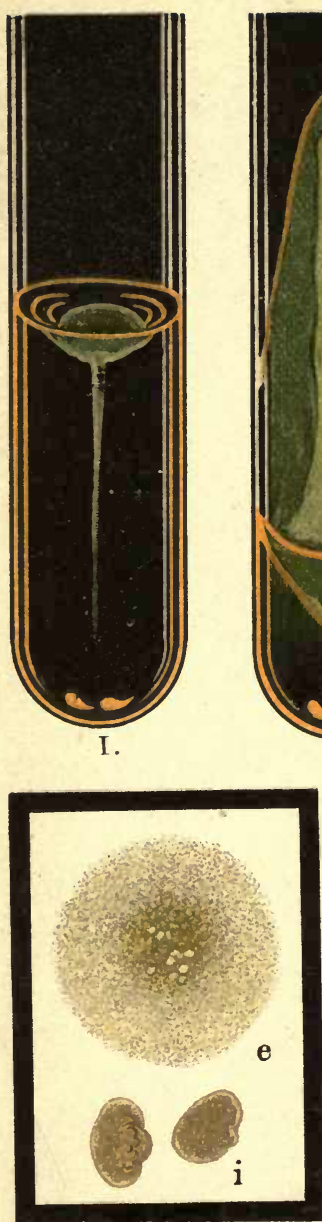

VII.

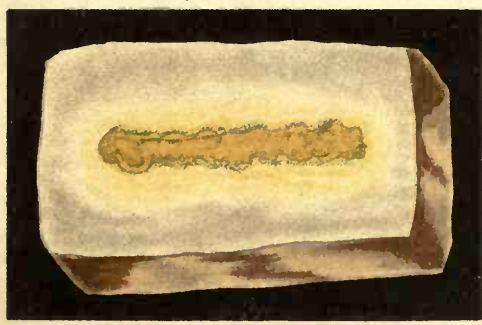

VIII.

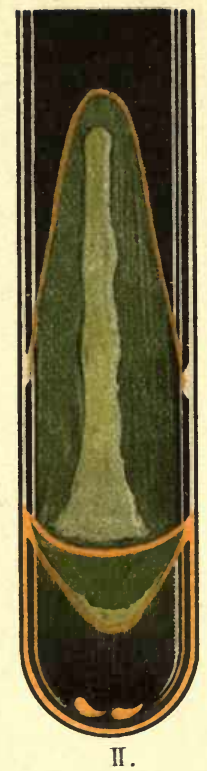

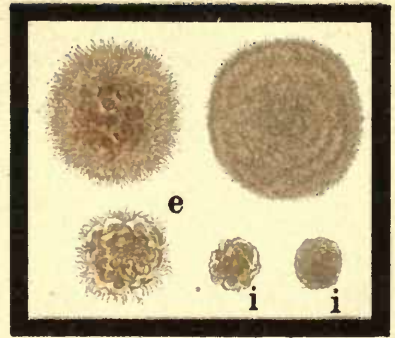

III.

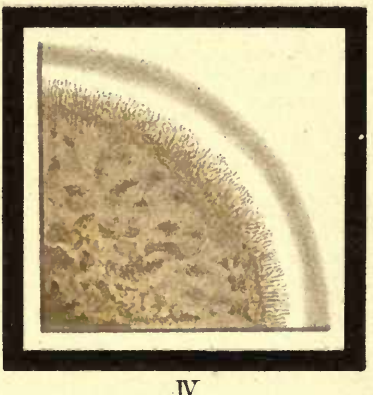

IV.
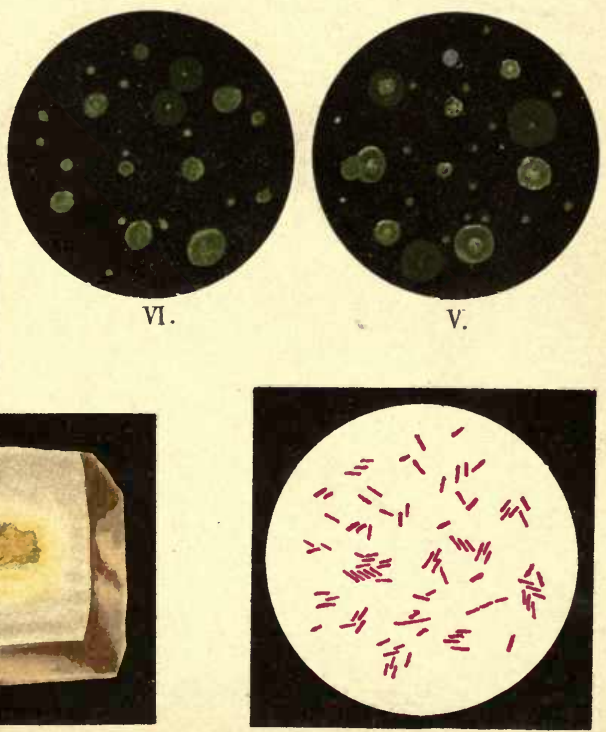

IX.

Lith. Anst. F Reichhold, München. 


Tab. 25.
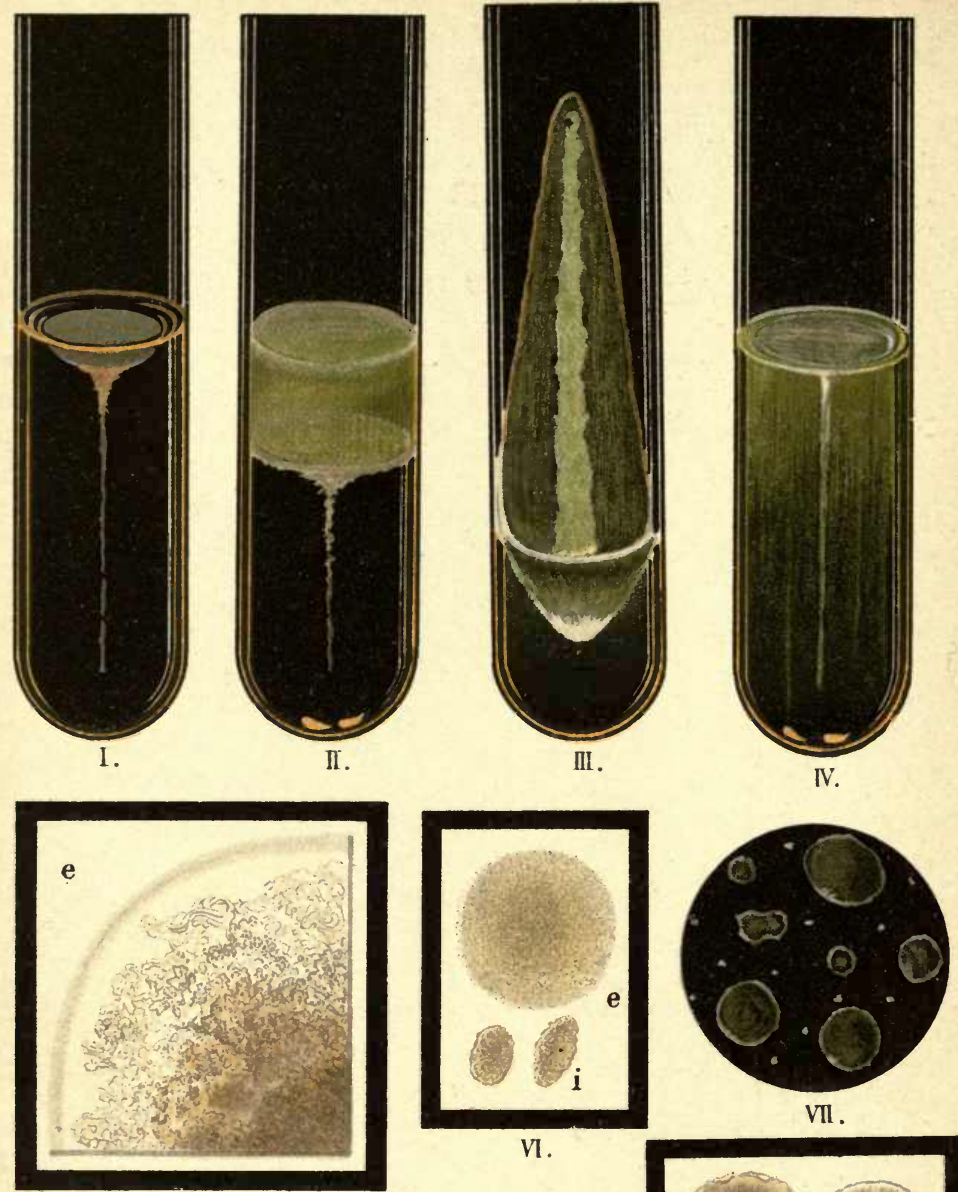

V.

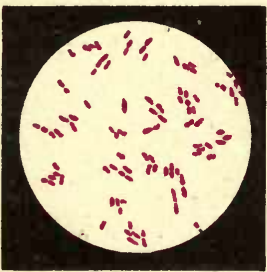

VIII.

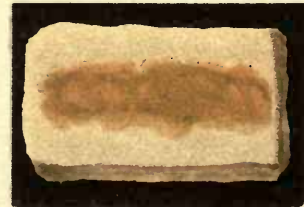

L. 


\section{PLATE 25.}

Bacterium fluorescens. Lehm. and Neum.' (Bacillus fluorescens liquefaciens. Flügge.)

I. Gelatin stab culture, two days at $22^{\circ}$.

II. Gelatin stab culture, eight days at $22^{\circ}$.

III. Agar streak culture, three days at $22^{\circ}$.

IV. Agar stab culture, four days at $22^{\circ}$.

V. Gelatin plate, two days at $22^{\circ} . \times 90$. Part of a superficial colony.

VI. Agar plate, twenty-four hours at $22^{\circ} . \times 60$. Superficial, (i) deep colonies.

VII. Gelatin plate, three days at $22^{\circ}$. Natural size.

VIII. Microscopic preparation. Pure culture from agar plate. $\times 800$.

IX. Potato culture, four days at $22^{\circ}$. Natural size. Compare also Plate 18, Ix; Plate 26, v.

$\mathrm{X}$. Bacteria with flagella, usually one, more rarely two or more. $\times 1000$. Stained according to Löffler.

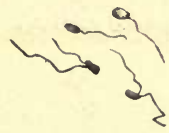

$\mathrm{X}$. 
PLATE 26.

Bacterium putidum (Flügge). Lehm. and Neum. Bacterium fluorescens putidum Flügge. (Bacterium

fluorescens non-liquefaciens Autor.)

I. Gelatin stab culture, three days at $22^{\circ}$.

II. Gelatin plate, twenty-four hours at $22^{\circ} . \times 90$. Superficial colony. Compare Plate 14, viII; Plate 19, III.

III. Gelatin plate, twenty-four hours at $22^{\circ} . \quad \times 90$. Deep colony.

IV. Gelatin plate, four days at $22^{\circ}$. Natural size. Appearance of colonies upon a dark background.

V. Potato culture, four days at $22^{\circ}$. Natural size. Compare also Plate 18, IX.

VI. Microscopic preparation. Pure culture from gelatin plate. $\times 800$. Upon agar, threads are usually produced.

VII. Agar plate, eight days at $22^{\circ}$. Natural size. Appearance of the colonies upon a white background.

VIII. Agar plate, three days at $22^{\circ} . \times 60$. (e) Superficial, (i) deep colonies.

IX. Bacteria with one, more rarely two flagella. $\times$ 1000. Stained according to Löffler.

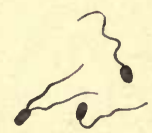

IX. 
Tab. 26.
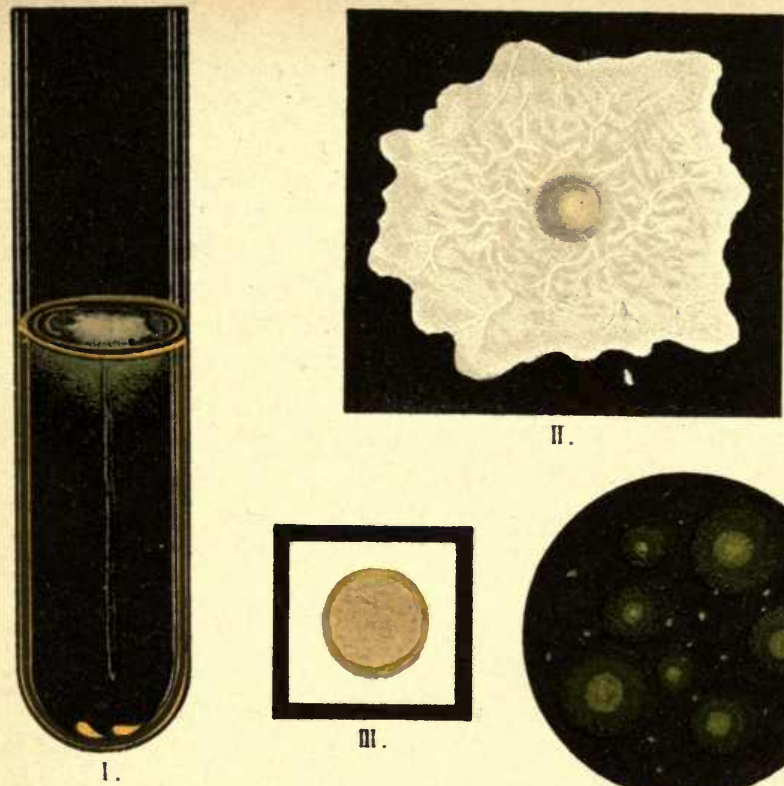

II.

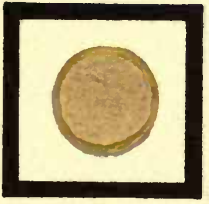

III.

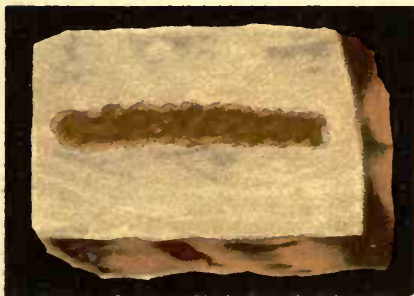

I.

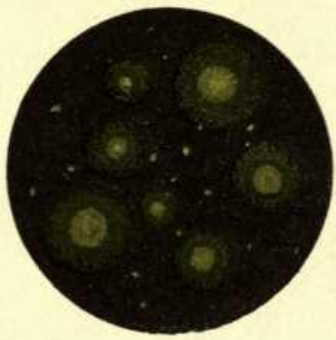

IV.
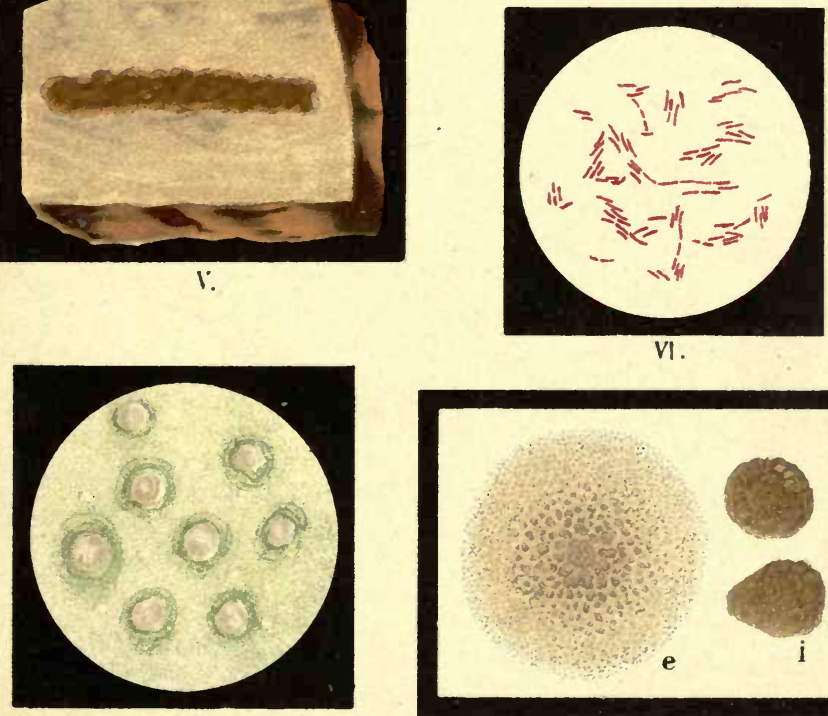

VI! .

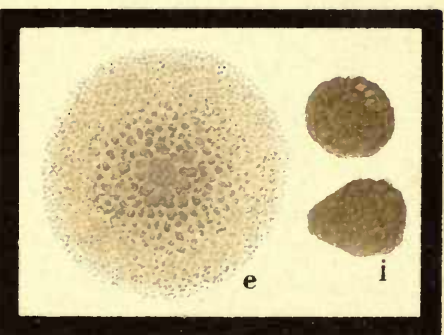





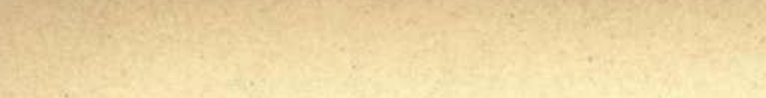


Tab. 27.

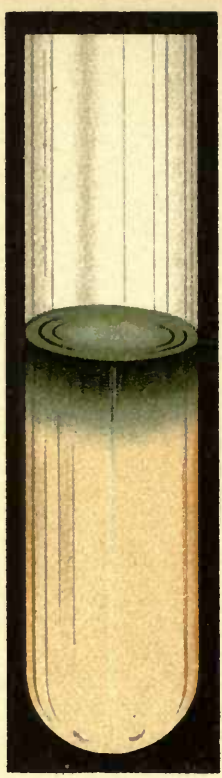

I.

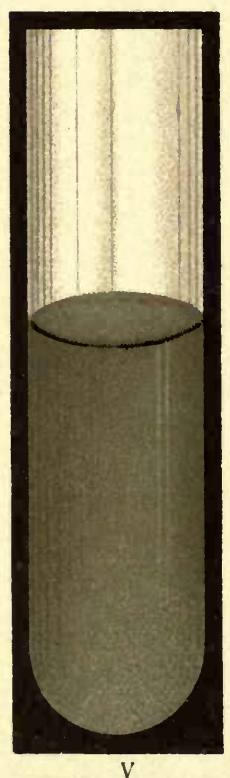

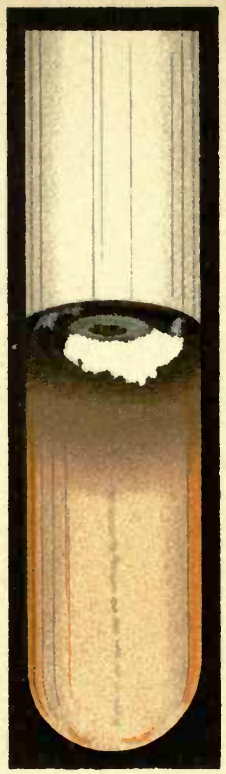

II.

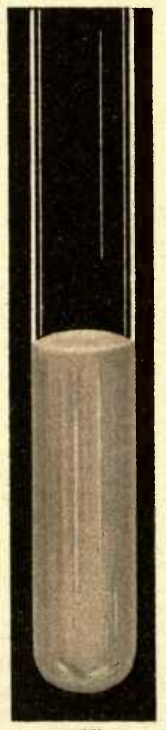

VI.

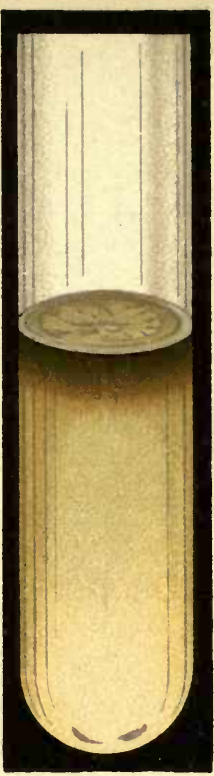

III.

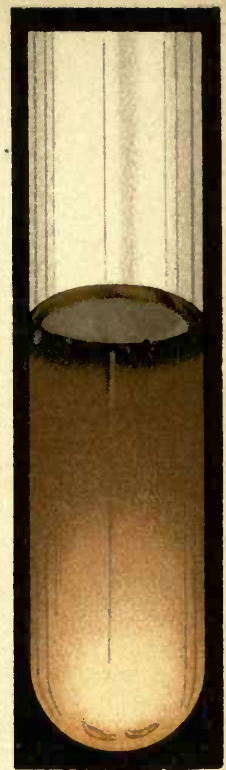

IV.
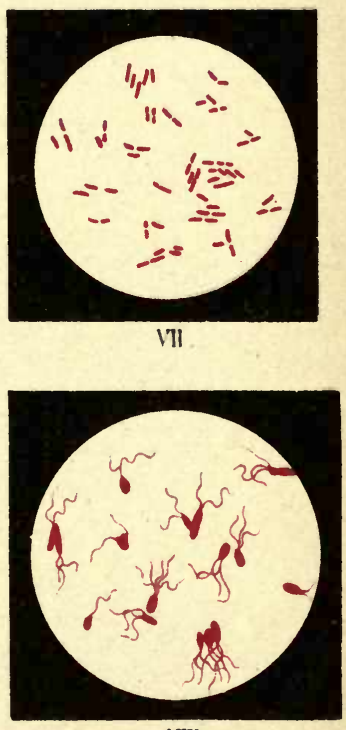

VIII . 


\section{PLATE 27.}

Bacterium syncyaneum (Ehrenb.). Lehm. and Neum. (Bac. cyanogenes Flügge; Blue Milk.)

I-III. Gelatin stab cultures, from six to ten days at $22^{\circ}$. There occur still other shades of color.

IV. Agar stab culture, ten days at $37^{\circ}$.

V. Bouillon culture, four days at $37^{\circ}$.

VI. Milk culture, three days at $37^{\circ}$. Inoculated upon unsterilized milk.

VII. Microscopic preparation. Pure culture from agar plate. $\times 800$.

VIII. Microscopic preparation. Pure culture. Flagella staining with Löffler's mordant. $\times 800$.

IX. Bacteria with flagella, one or more at one pole. $\times 1000$. Stained according to Löffler.

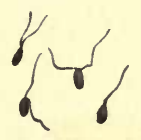

IX. 


\section{PLATE 28.}

Bacterium syncyaneum (Ehrenb.). Lehm. and Neum. (Bac. cyanogenes Flügge; Blue Milk.)

I-III. Potato cultures, from three to ten days at $22^{\circ}$. Many varieties of potato inoculated with the same culture. The differences in colors may be still more numerous.

IV. Agar plate, three days at $22^{\circ}$. Natural size.

V. Agar plate, three days at $22^{\circ} . \times 60$. To the right, deep; to the left, superficial colonies.

VI. Gelatin plate, three days at $22^{\circ}$. Natural size.

VII. Gelatin plate, eight days at $22^{\circ}$. Natural size. Appearance of colonies upon a white background.

VIII. Gelatin plate, three days at $22^{\circ} . \times 60$. Above, superficial; below, deep colonies. 
Tab. 28.

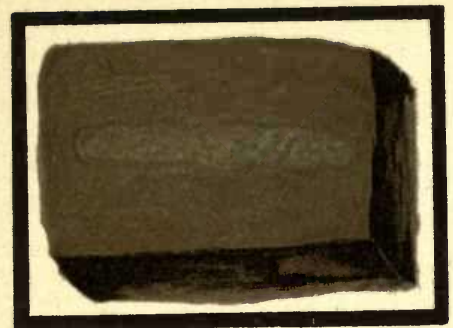

1.

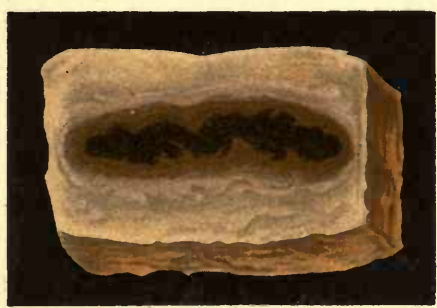

II.

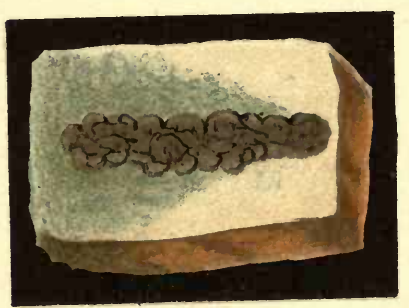

III.

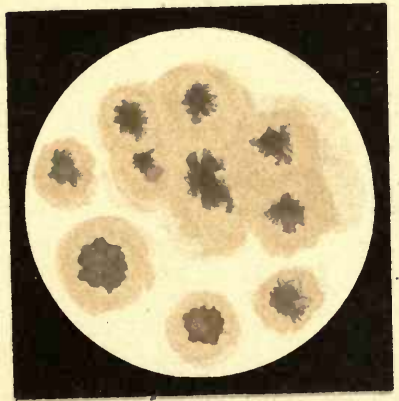

VII.

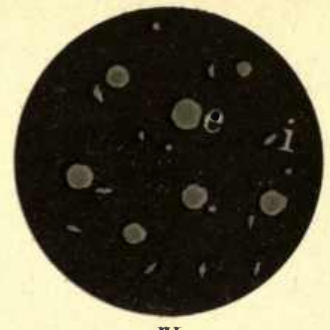

IV.
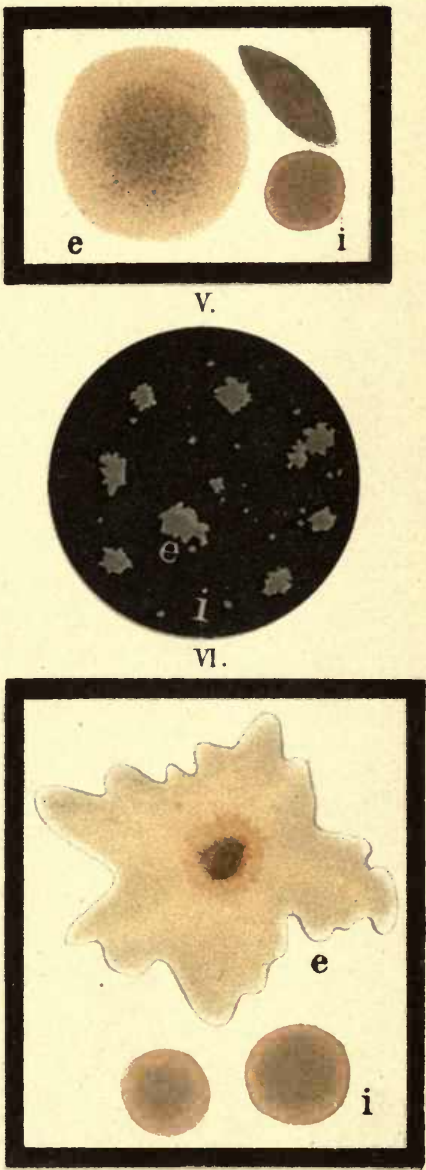

VIII. 
Tab. 29.
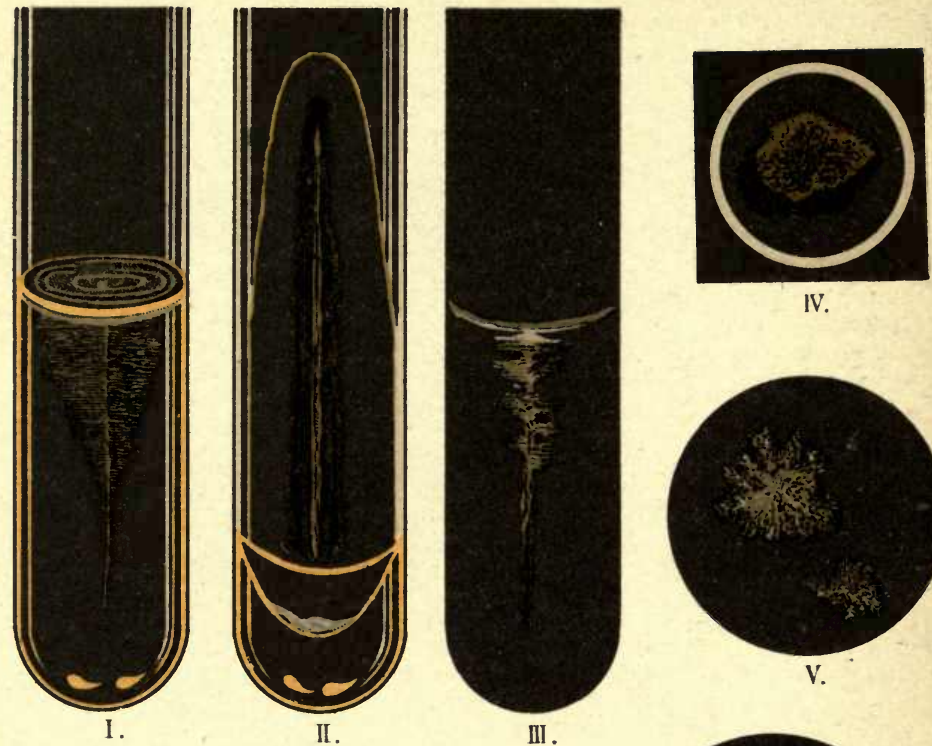

IV.
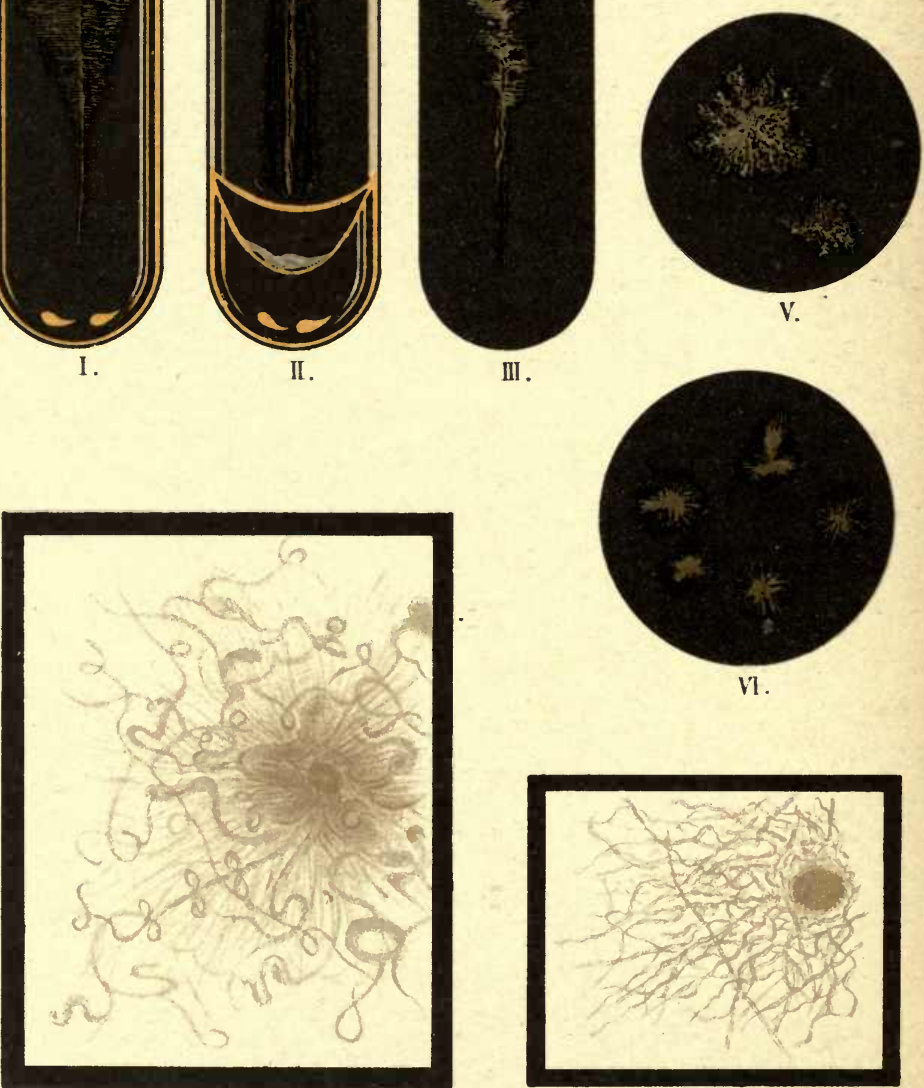

VIII.

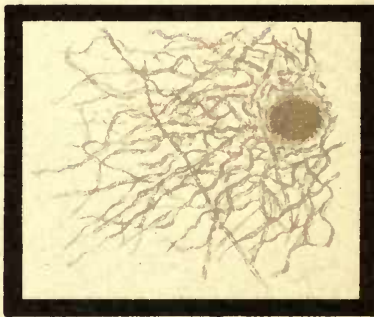

VII.

Lith Anst F' Reichnold. München. 


\section{PLATE 29. \\ Bacterium Zopfii. Kurth.}

I. Gelatin stab culture, six days at $22^{\circ}$.

II. Agar streak culture, thirty-six hours at $37^{\circ}$. It is actually a grayish color and transparent.

III. Agar stab culture, six days at $22^{\circ}$. Stab.

IV. Agar stab culture, six days at $22^{\circ}$. Surface growth.

V. Gelatin plate, seven days at $22^{\circ}$. Natural size.

VI. Gelatin plate, thirty-six hours at $22^{\circ}$. Natural size.

VII. Gelatin plate, twenty-four hours at $22^{\circ} . \times 90$. Thread-like portion of the deep colony.

VIII. Gelatin plate, twenty-four hours at $22^{\circ} . \times 60$. Superficial colony. Compare Plate 31, vir; Plate 32, virr. 


PLATE 30.

\section{Bacterium Zopfii. Kurth.}

I. Gelatin plate, eight days at $22^{\circ} . \times 90$. Peripheral portion of a colony.

II. Microscopic preparation. $\times 1000$. Pure culture, from agar plate, stained with fuchsin.

III. Agar plate, four days at $22^{\circ}$. Deep colony.

IV. Agar plate, twenty-four hours at $37^{\circ}$. Natural size.

V. Agar plate, twelve hours at $37^{\circ}$. Deep and superficial colony.

VI. Agar plate, twenty-four hours at $37^{\circ} . \times 60$. Superficial colony, surrounded by innumerable bacteria swarming outward.

VII. Gelatin plate, eight days at $22^{\circ}$. Sausage-shaped forms of the deep colony.

IX. Bacteria with numerous flagella. $\times 1000$. Stained according to Löffler.

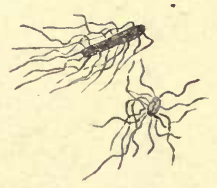

IX. 
Tab. 30.
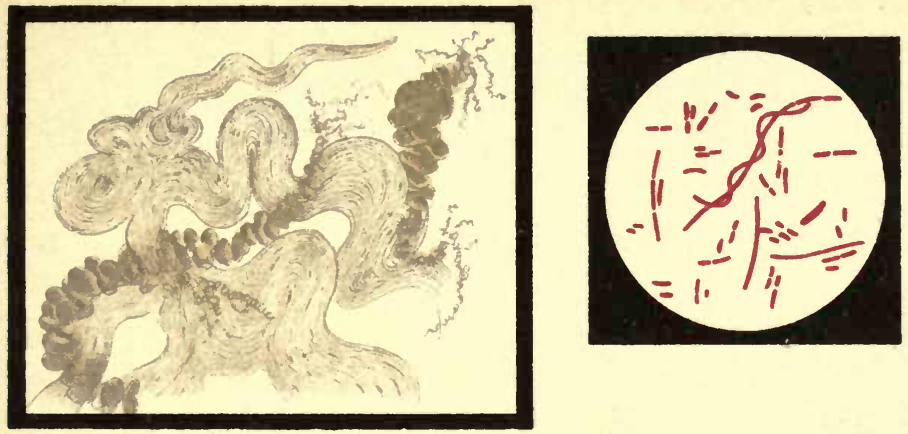

1 .

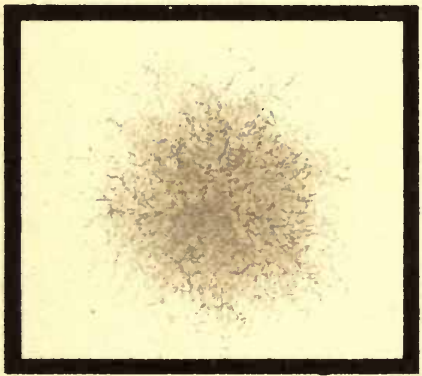

III.

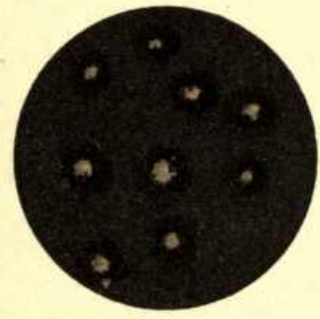

N1:

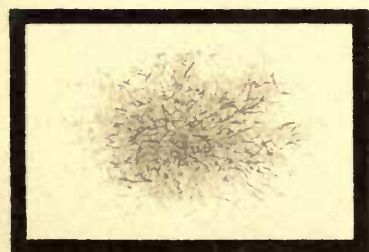

l:

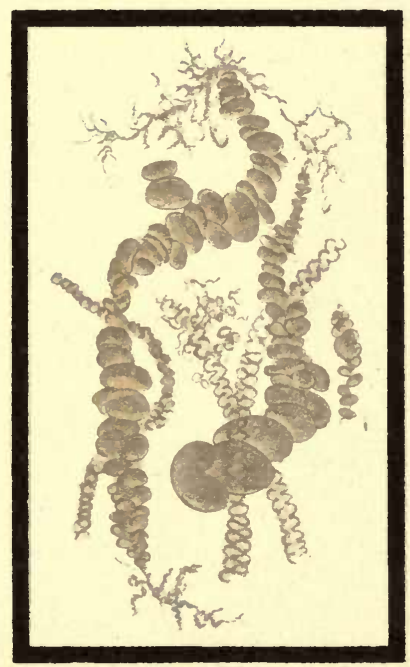

VII. 


'Tab. 31.
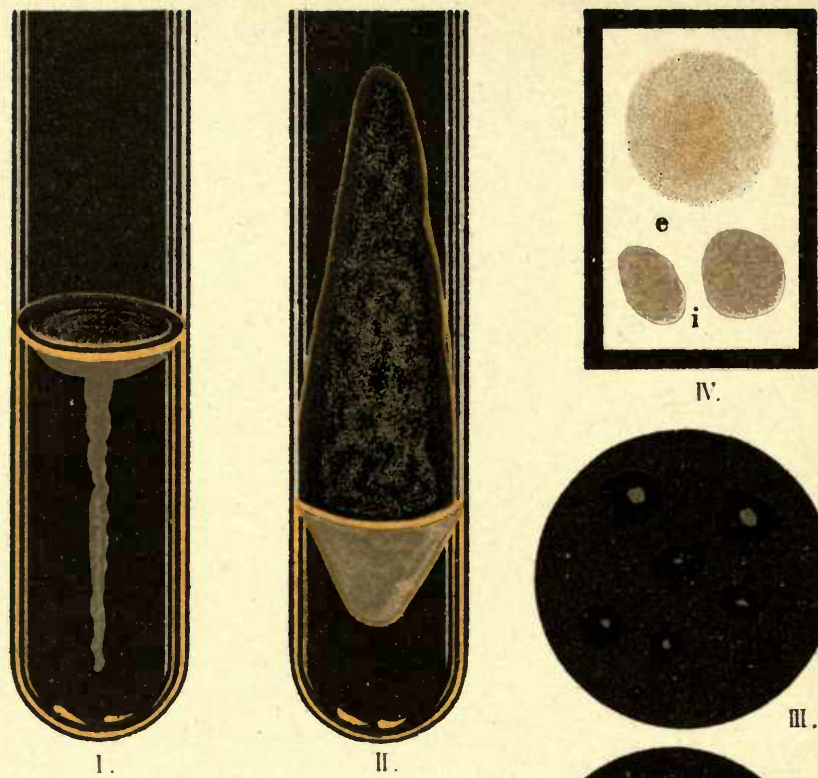

NV.
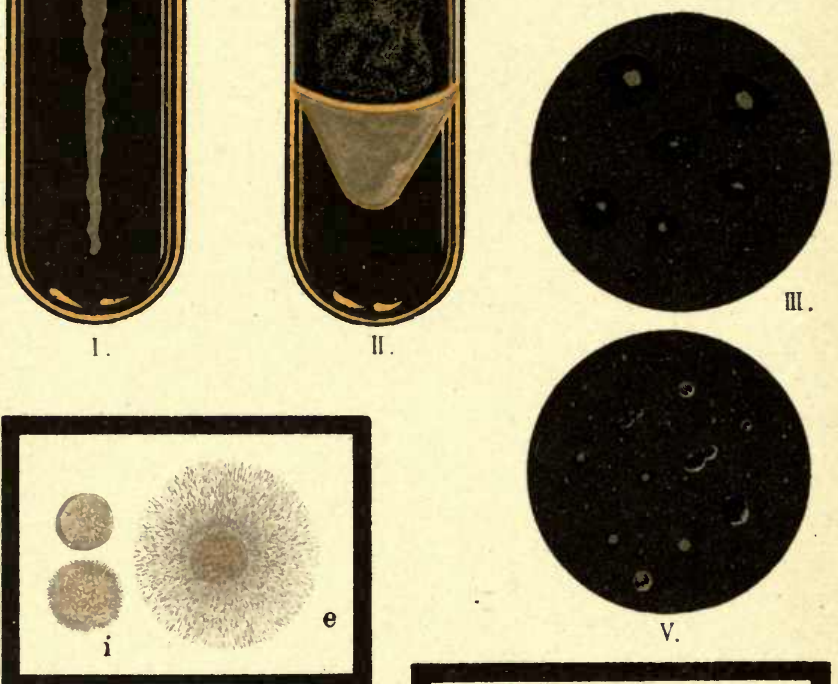

VI.
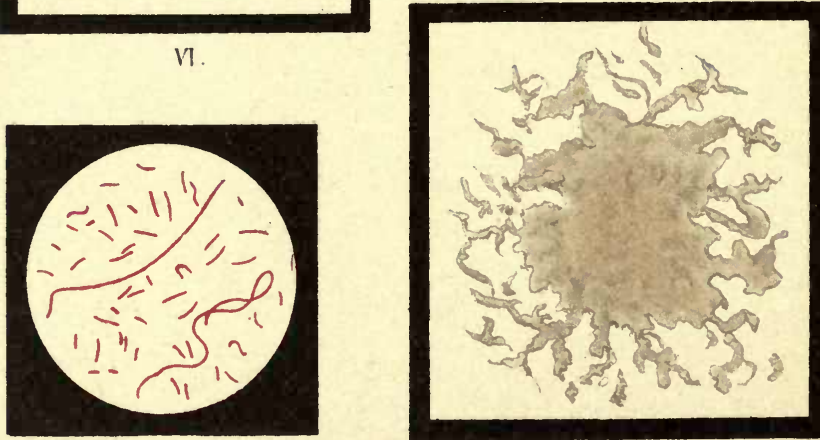

I'II. 
PLATE 3 r.

Bacterium vulgare (Hauser). Lehm. and Neum. (Proteus vulgaris Hauser.)

I. Gelatin stab culture, twenty-four hours at $22^{\circ}$.

II. Agar streak culture, thirty-six hours at $22^{\circ}$.

III. Agar plate, thirty-six hours at $22^{\circ}$. Natural size.

IV. Agar plate, four days at $22^{\circ} . \quad \times 60$. Above, superficial; below, deep colonies.

V. Gelatin plate, thirty-six hours at $22^{\circ}$. Natural size.

VI. Gelatin plate, thirty-six hours at $22^{\circ} . \times 60$. To the right, superficial; to the left, deep colonies. The lower, approaching the surface, begins to liquefy.

VII. Gelatin plate, three days at $22^{\circ} . \times 60$. Deep colony. Zooglea form, similar to the Bact. Zopfii.

VIII. Microscopic preparation. Pure culture upon agar. $\times 800$. Stained with fuchsin.

IX. Bacteria with very numerous flagella. $\times 1000$.

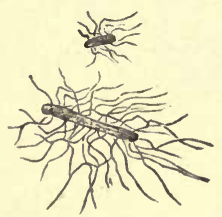

IX. 


\section{PLATE 32.}

Bacterium vulgare $\beta$ mirabilis (Hauser). L. and N. (Proteus mirabilis Hauser.)

I. Agar stab culture, two days at $22^{\circ}$. Stab canal.

II. Agar stab culture, two days at $22^{\circ}$. Surface growth.

III. Gelatin stab culture, six days at $22^{\circ}$.

IV. Agar streak culture, two days at $22^{\circ}$.

V. Agar plate, seven days at $22^{\circ}$. Natural size.

VI. Agar plate, seven days at $22^{\circ} . \quad \times 60$. Above, superficial; below, deep colony.

VII. Gelatin plate, two days at $22^{\circ} . \quad \times 60$. Deep colonies.

VIII. Gelatin plate, two days at $22^{\circ} . \times 60$. Superficial colony.

IX. Potato culture, eight days at $22^{\circ}$. Natural size.

X. Microscopic preparation. Pure culture on agar two days old. $\times 800$. 
Tab. 32.

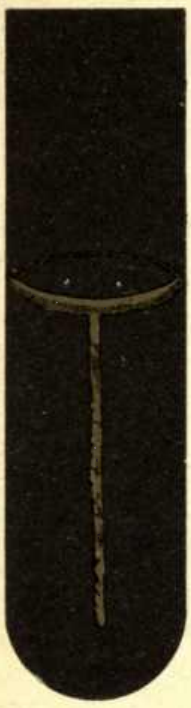

I.
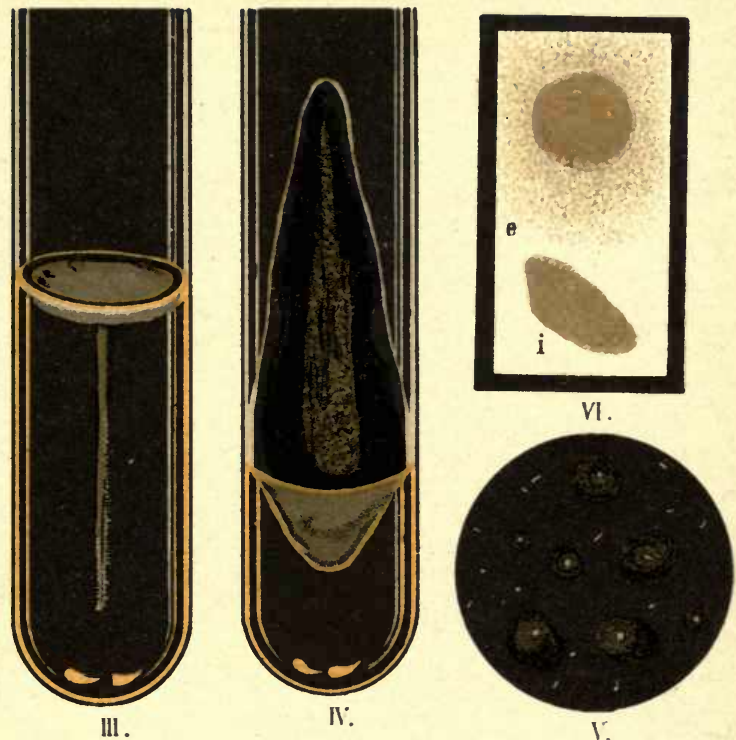

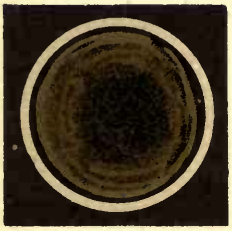

II.

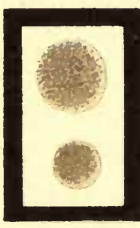

VII .

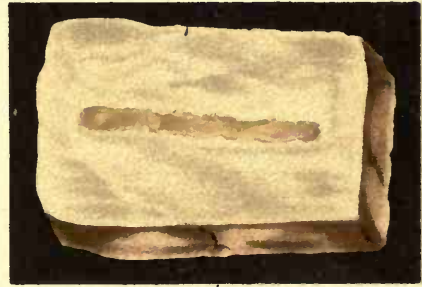

IX.

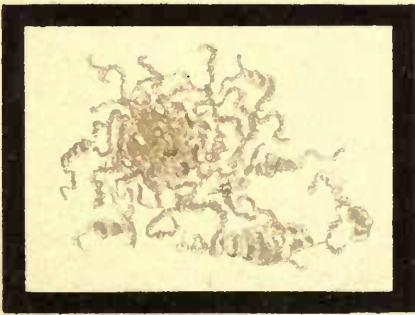

VIII.

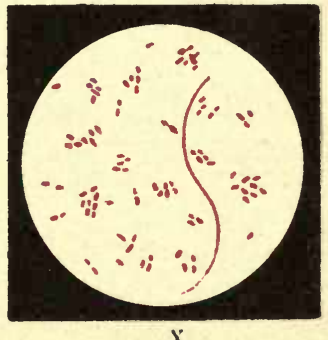

$x$. 

Tab. 33.
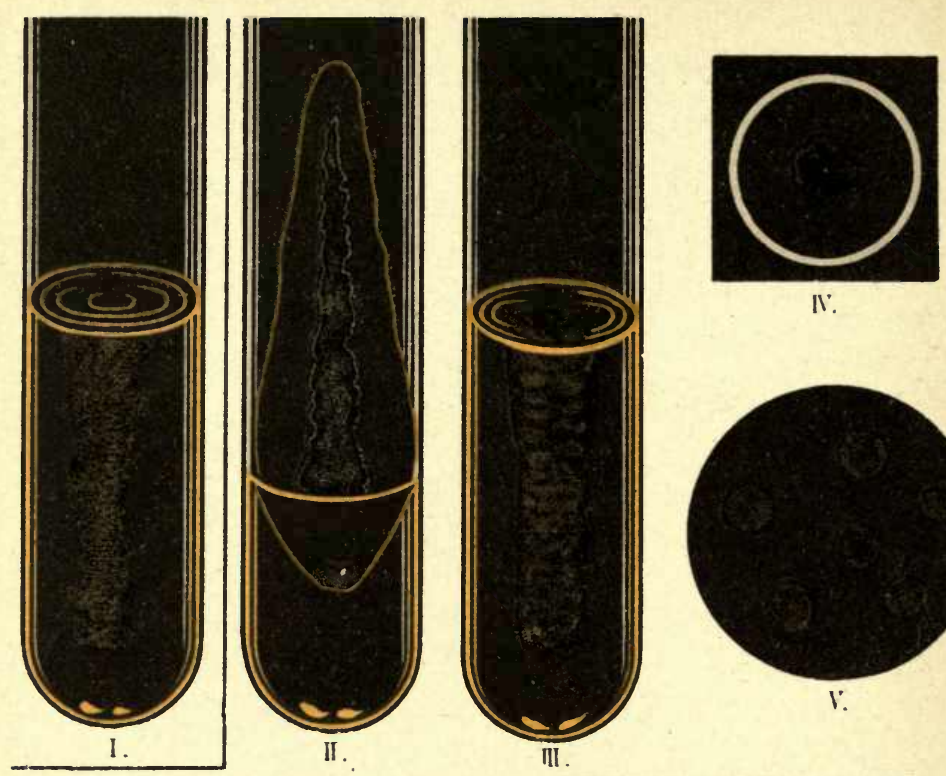

IV.
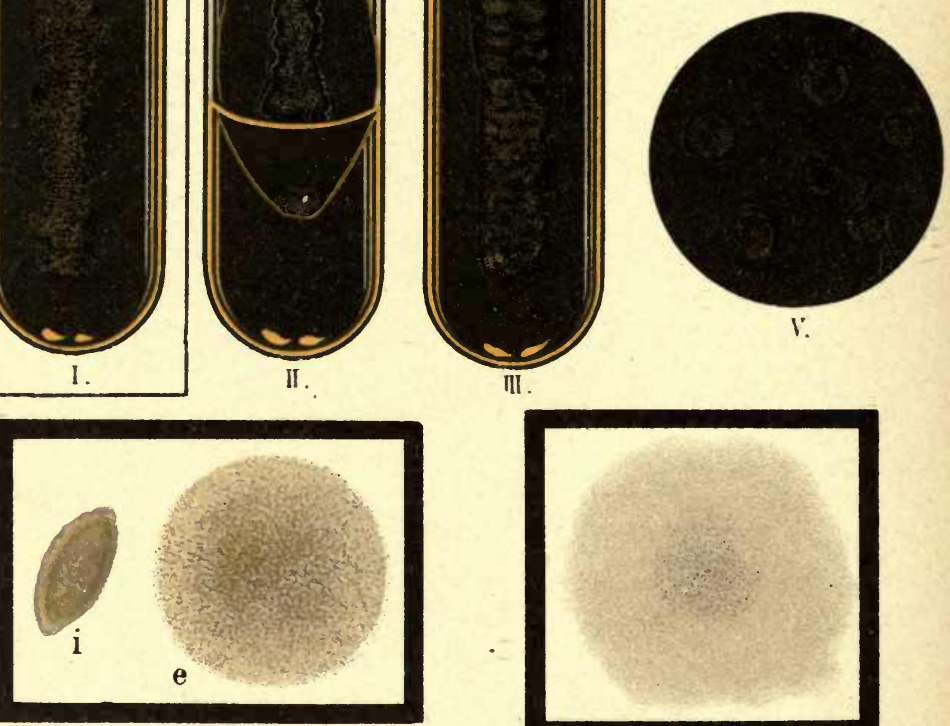

17! .

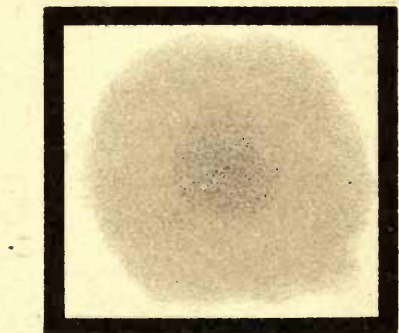

17.

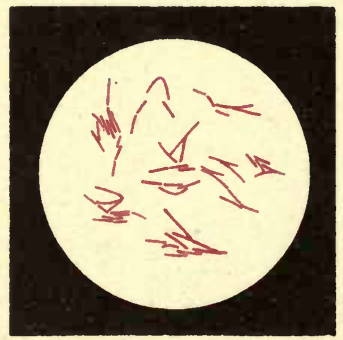

IIII.

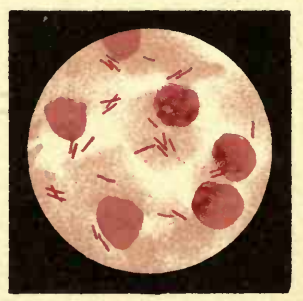

IX. 


\section{PLATE 33.}

Bacterium erysipelatos suum. Migula. (Swine Erysipelas.)

I. Gelatin stab culture, five days at $22^{\circ}$.

Bacterium murisepticum. Migula. (Mouse Septicemia.)

II. Agar streak culture, four days at $22^{\circ}$.

III. Gelatin stab culture, four days at $22^{\circ}$.

IV. Agar stab culture, four days at $22^{\circ}$. Surface growth.

V. Gelatin plate, four days at $22^{\circ}$. Natural size.

VI. Gelatin plate, four days at $22^{\circ} . \times 60$. Superficial colony.

VII. Agar plate, four days at $22^{\circ} . \times 60$. To the right, superficial; to the left, deep colony.

VIII. Microscopic preparation. Pure culture on agar two days old. $\times 800$.

IX. Microscopic preparation. Smear preparation from the blood of a mouse's spleen. $\times 800$. 
PLATE 34 .

Bacillus anthracis. F. Cohn and R. Koch. (Splenic Fever.)

I-V. Gelatin stab cultures, three days at $22^{\circ}$. Figures I and II are typical; the others, atypical.

VI. Agar streak culture, two days at $22^{\circ}$.

VII. Agar stab culture, five days at $22^{\circ}$. Stab canal.

VIII. Agar stab culture, five days at $22^{\circ}$. Surface growth, which is atypical.

IX. Agar stab culture, five days at $22^{\circ}$. Surface growth typical; often also is homogeneous whitish-gray. 
Tab. 34 .
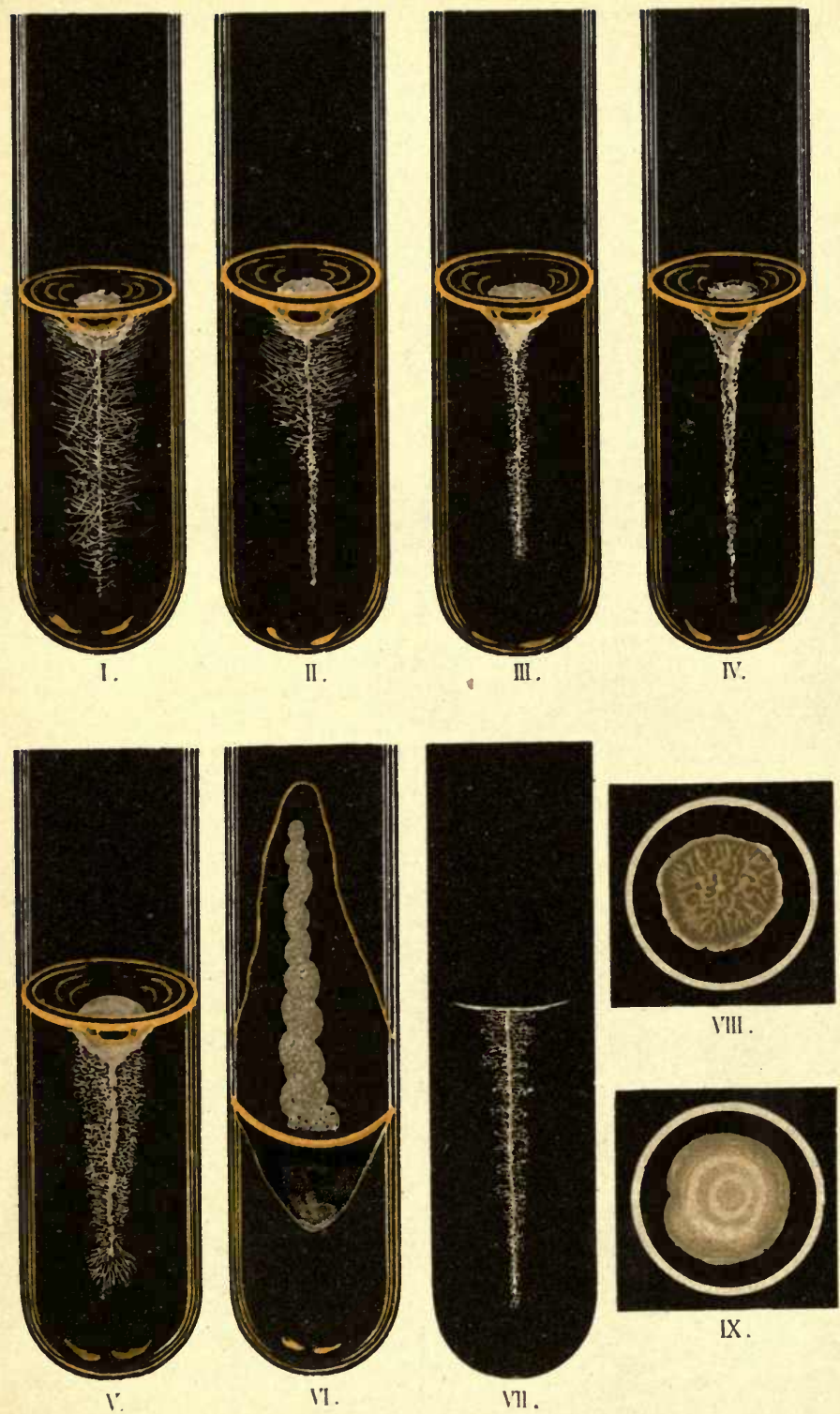


Tab. 35.
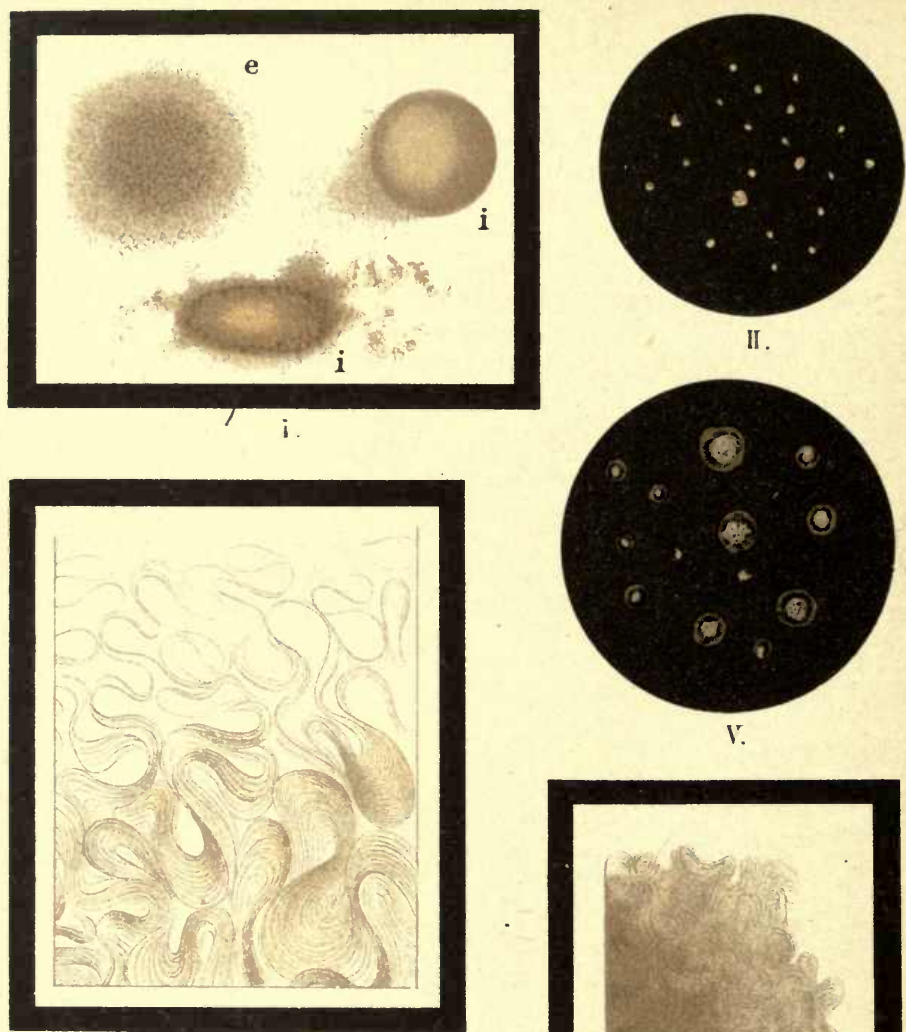

III.

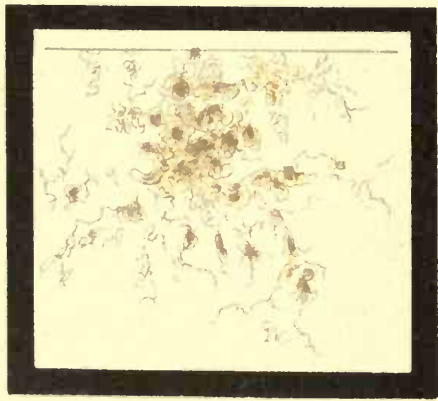

N".

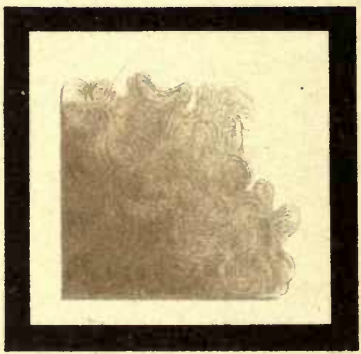

11.

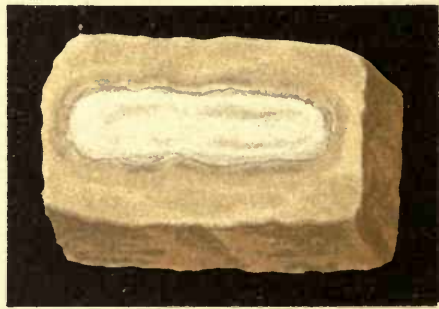

VII. 


\section{PLATE 35 .}

Bacillus anthracis. F. Cohn and R. Koch.

(Splenic Fever.)

I. Agar plate, four days at $22^{\circ} . \quad \times 60$. To the left, a superficial colony; to the right, a colony directly below the surface; below, a deep colony.

II. Agar plate, four days at $22^{\circ}$. Natural size.

III. Agar plate, thirty-six hours at $37^{\circ} . \times 150$. Surface growth. Peripheral part of a streak culture.

IV. Agar plate, thirty-six hours at $37^{\circ} . \times 150$. Deep colony.

V. Gelatin plate, three days at $22^{\circ}$. Natural size.

VI. Gelatin plate, three days at $22^{\circ} . \quad \times 60$. Superficial colony at the time of sinking in.

VII. Potato culture, six days at $22^{\circ}$. Natural size. 


\section{PLATE 36.}

Bacillus anthracis. F. Cohn and R. Koch. (Splenic Fever.)

I. Smear preparation from the blood of the spleen of a mouse. $\times 1000$.

II. Contact preparation of an agar plate culture, one day at $22^{\circ} . \quad \times 1000$.

III. Unstained preparation in hanging drop from a bouillon culture, thirty-six hours at $37^{\circ} . \times 1000$. Spores begin already to escape.

IV. Anthrax threads from agar, thirty-six hours at $37^{\circ}$. $\times 1000$. Stained with Ziehl's solution; spores red, bacilli blue.

V. Involution forms. Five-weeks'-old agar stab culture, stained with fuchsin. $\quad \times 1000$.

VI. Unstained preparation in hanging drop from a bouillon culture, eight hours at $37^{\circ} . \times 1000$. Beginning of spore-formation. 
Tab. 36.

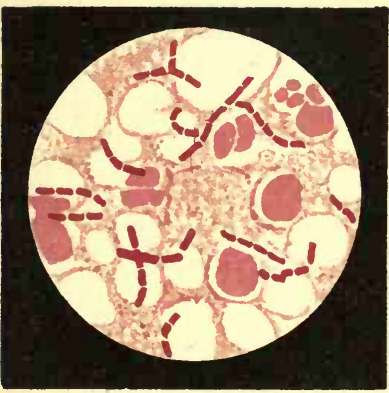

1.

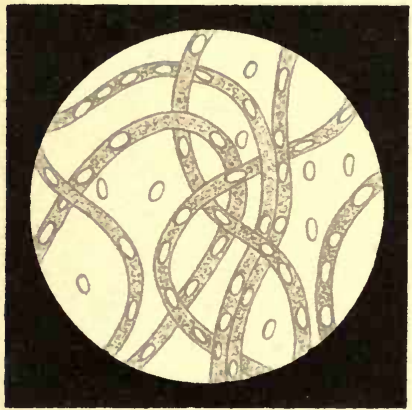

III.

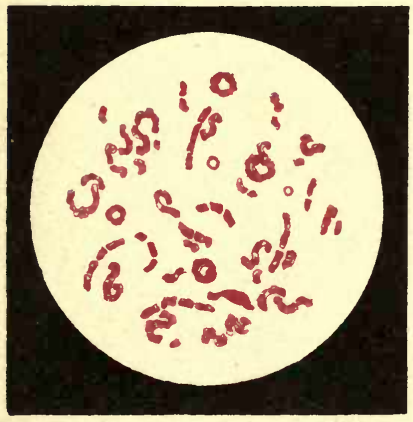

l:

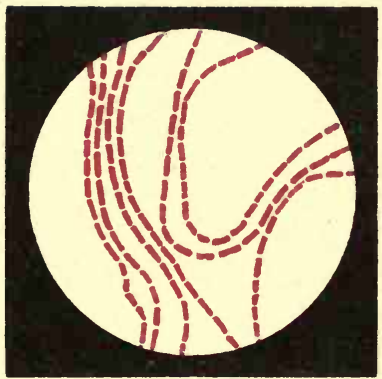

II.

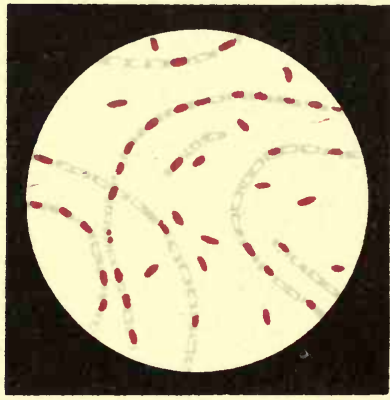

II.

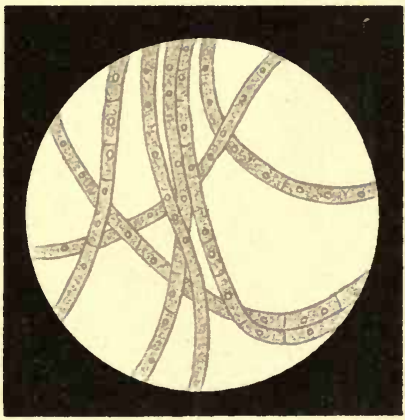

17. 

Tab. 37.
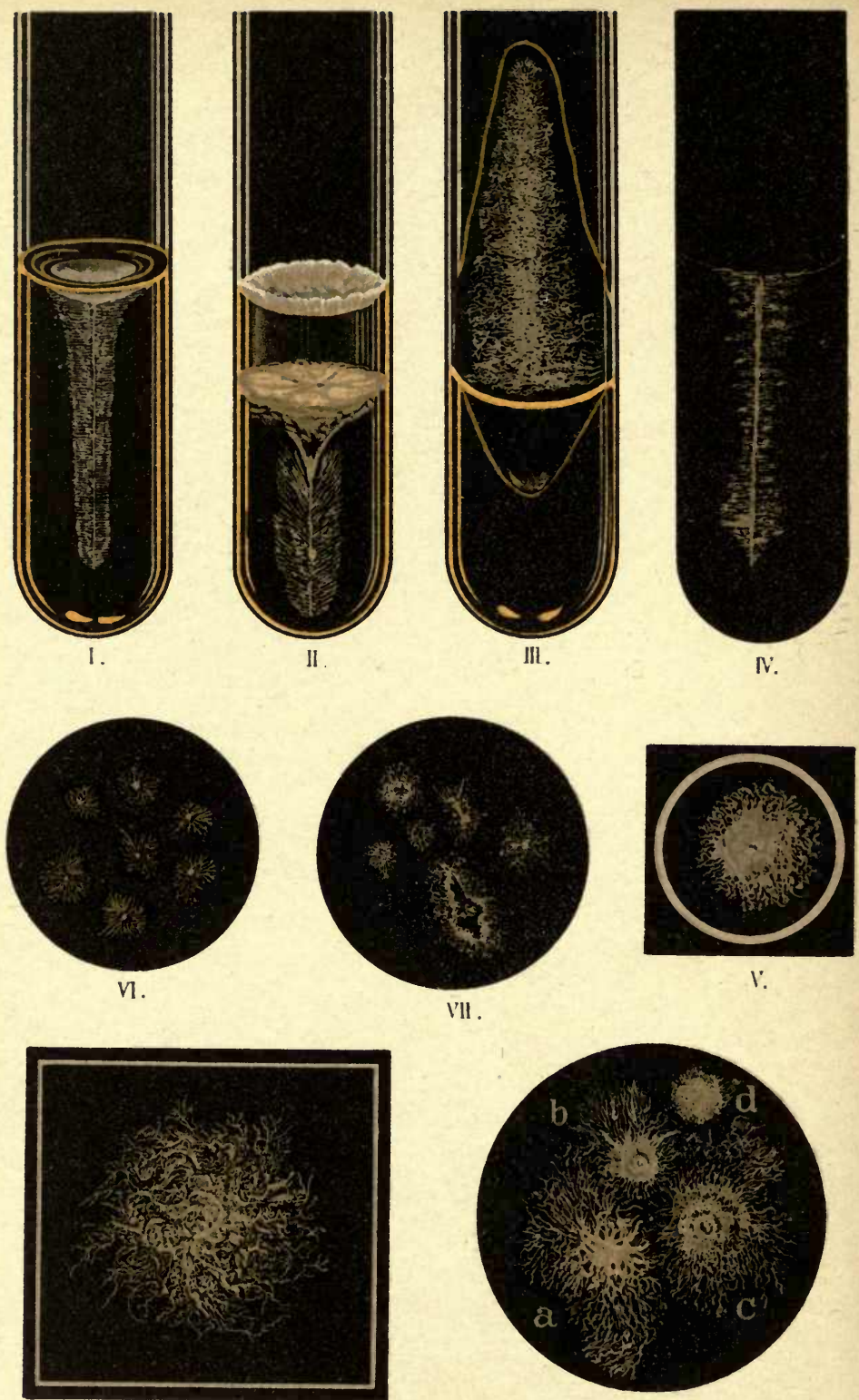

IX.

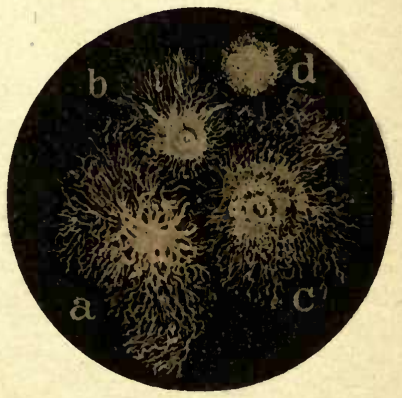

VIII. 
PLATE 37.

Bacillus mycoides. Flügge. (Root Bacillus.)

I. Gelatin stab culture, four days at $22^{\circ}$.

II. Gelatin stab culture, fourteen days at $22^{\circ}$.

III. Agar streak culture, two days at $22^{\circ}$.

IV. Agar stab culture, eight days at $22^{\circ}$. Stab canal.

V. Agar stab culture, eight days at $22^{\circ}$. Surface growth.

VI. Gelatin plate, one day at $22^{\circ}$. Natural size.

VII. Agar plate, one day at $22^{\circ}$. Natural size.

VIII. Agar plate, four days at $22^{\circ}$. Natural size.

IX. Gelatin plate, four days at $22^{\circ}$. Natural size. The colony is at the point of sinking in. 


\section{PLATE 38.}

\section{Bacillus mycoides. Flügge. (Root Bacillus.)}

I. Agar plate, one day at $22^{\circ} . \times 20$. Superficial and deep colony.

II. Potato culture, seven days at $22^{\circ}$. Natural size.

III. Microscopic preparation. Pure culture, twentyfour hours old, on agar. $\times 1000$. Stained with fuchsin. A few bacilli contain spores.

IV. Agar plate, one day at $22^{\circ} . \times 100$. Part of a superficial colony.

Bacillus butyricus. Hüppe. (Butyric Acid Bacillus.)

V. Potato culture, three days at $22^{\circ}$.

VI. Gelatin plate, one day at $22^{\circ} . \times 60$. Above, superficial; below, deep colonies.

VII. Gelatin plate, thirty-six hours at $22^{\circ} . \times 60$. Part of a superficial colony.

VII A. Flagella preparation. $\times 1000$. Stained according to Löffler.

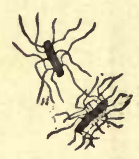

VII A.

Bacillus vulgatus. Migula. (B. mesentericus vulgatus Flügge. Potato Bacillus.)

VIII. Potato culture, five days at $22^{\circ}$.

IX. Potato culture, five days at $22^{\circ}$. Natural size. Both forms of growth occur. 
Tab. 38 .
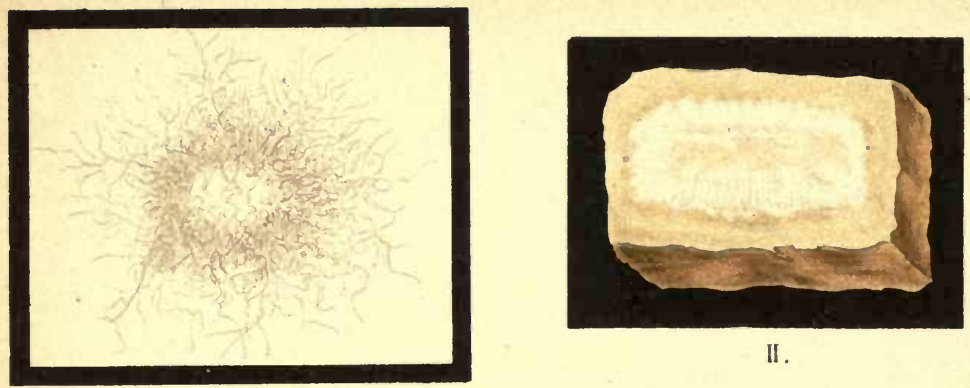

II.

1.

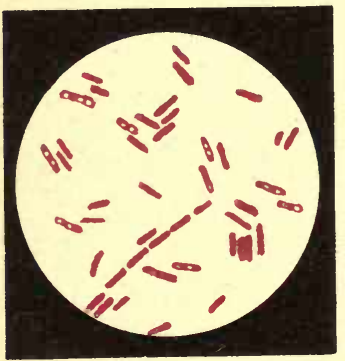

III.

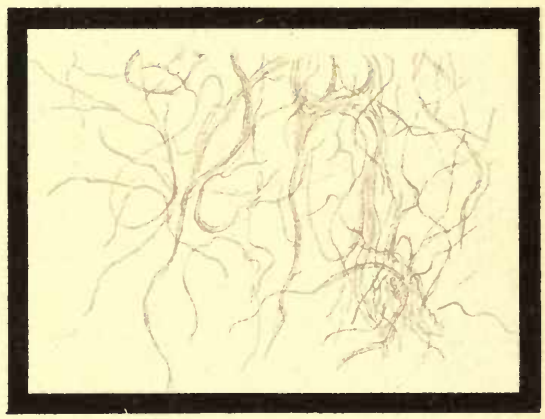

IV.

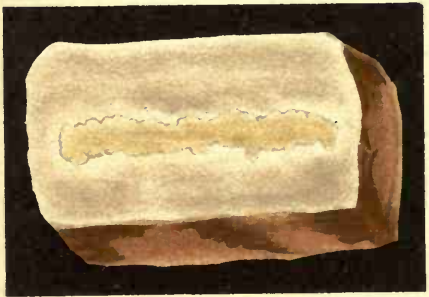

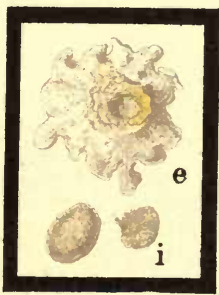

VI.

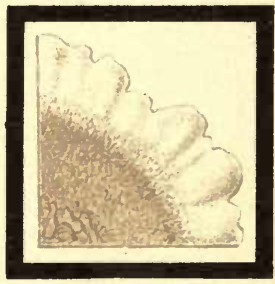

VII.

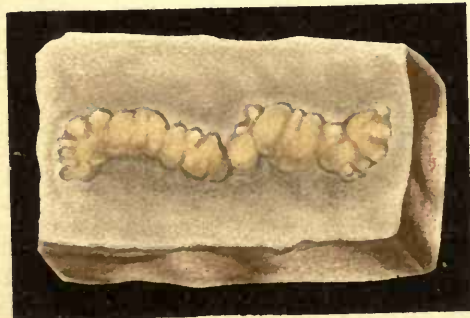

I'III.

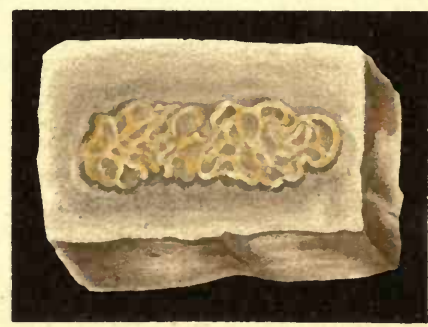

LX. 


Tab. 39.

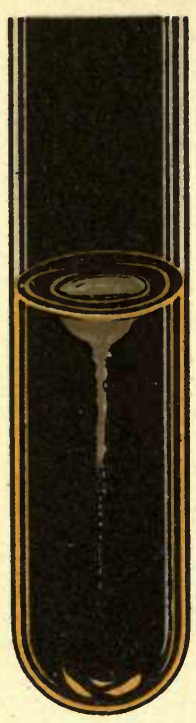

I.

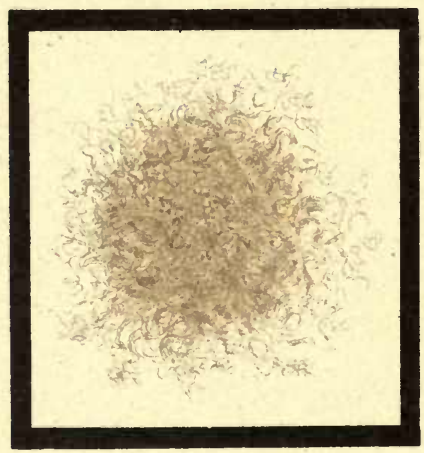

VI.

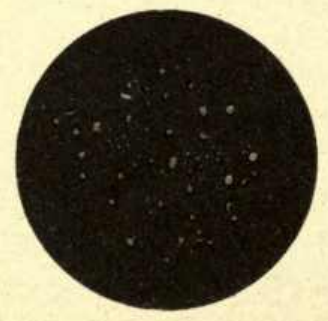

VIII.

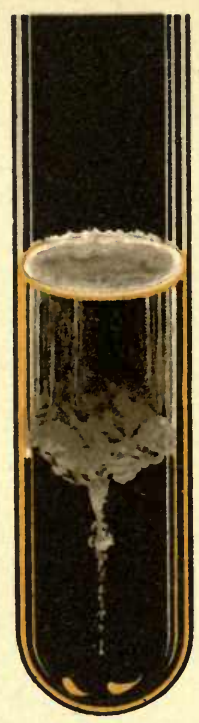

II.

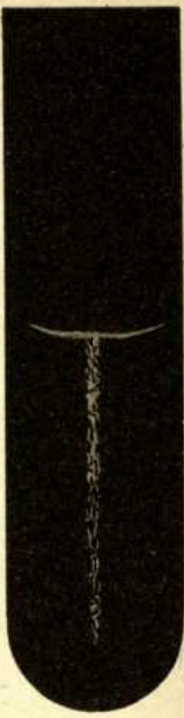

IV.

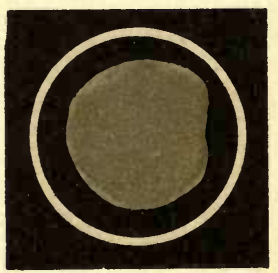

V.

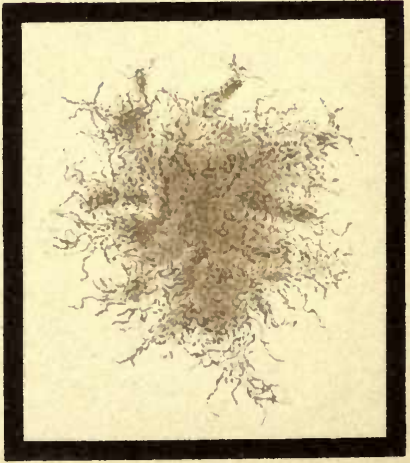

III. 


\section{PLATE 39. \\ Bacillus subtilis (Ehrenberg). F. Cohn. \\ (Hay Bacillus.)}

I. Gelatin stab culture, thirty-six hours at $22^{\circ}$.

II. Gelatin stab culture, eight days at $22^{\circ}$.

III. Agar streak culture, two days at $37^{\circ}$.

IV. Agar stab culture, two days at $37^{\circ}$. Stab canal.

V. Agar stab culture, two days at $37^{\circ}$. Surface growth.

VI. Agar plate, twelve hours at $37^{\circ} . \times 60$. Superficial colony.

VII. Agar plate, twelve hours at $37^{\circ} . \times 60$. Deep colony.

VIII. Agar plate, twelve hours at $37^{\circ}$. Natural size. 


\section{PLATE 40.}

\section{Bacillus subtilis (Ehrenberg). F. Cohn. (Hay Bacillus.)}

I. Potato culture, seven days at $22^{\circ}$.

II. Gelatin plate, two days at $22^{\circ} . \times 60$. Above and to the left, a deep colony; below this, one lying directly at the surface; to the right, a superficial colony.

III. Gelatin plate, two days at $22^{\circ}$. Natural size.

IV. Gelatin plate, two days at $22^{\circ} . \quad \times 10$.

V. Microscopic preparation. $\times 1000$. From an agar culture three hours old at $37^{\circ}$, stained with fuchsin.

VI. Microscopic preparation. Bacilli with flagella, after Fischer. Very highly magnified.

VII. Microscopic preparation. $\times 1000$. From an agar culture, ten days at $22^{\circ}$. Contains spores. Unstained.

VIII. Microscopic preparation. $\times 700$. From an agar culture, ten days at $22^{\circ}$. Double stain with carbol-fuchsin and methylene-blue.

IX. Bacilli with numerous flagella. $\times 1000$. Stained according to Löffler.

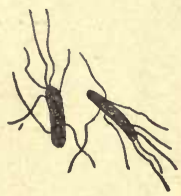

IX. 
Tab. 40 .
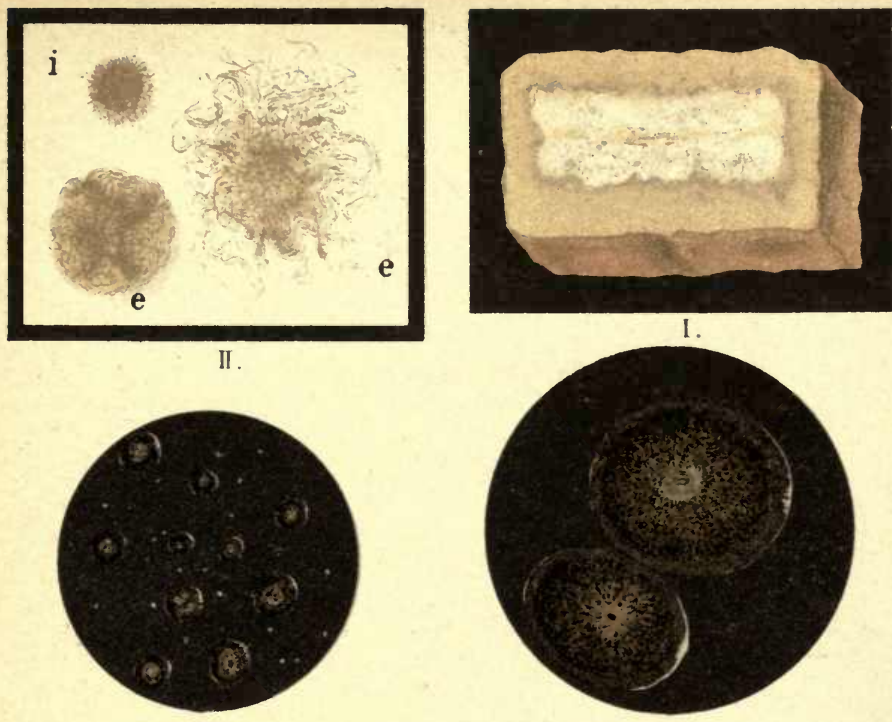

IIl.

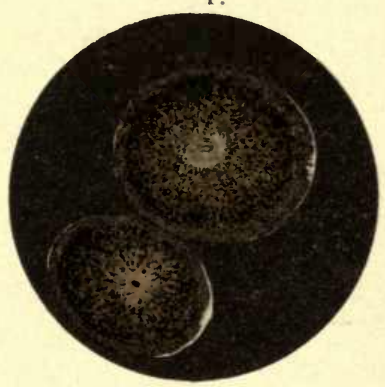

IV.

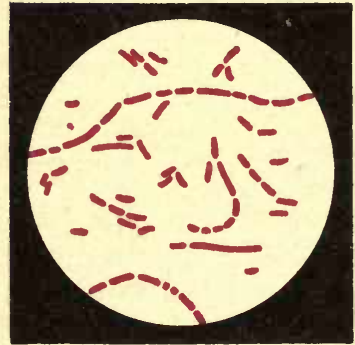

V.

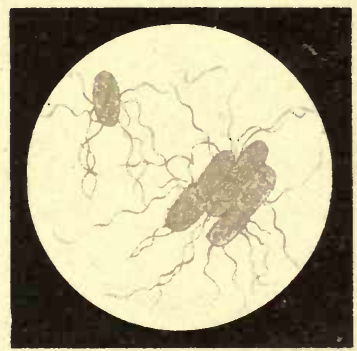

VI.

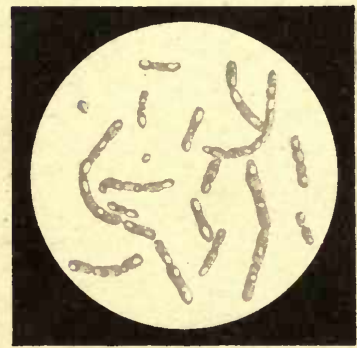

VII.

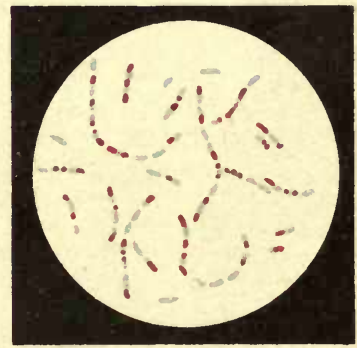

VIII.

Lith. Anst. F' Reichhold, Miunchen. 

Tab. 41.
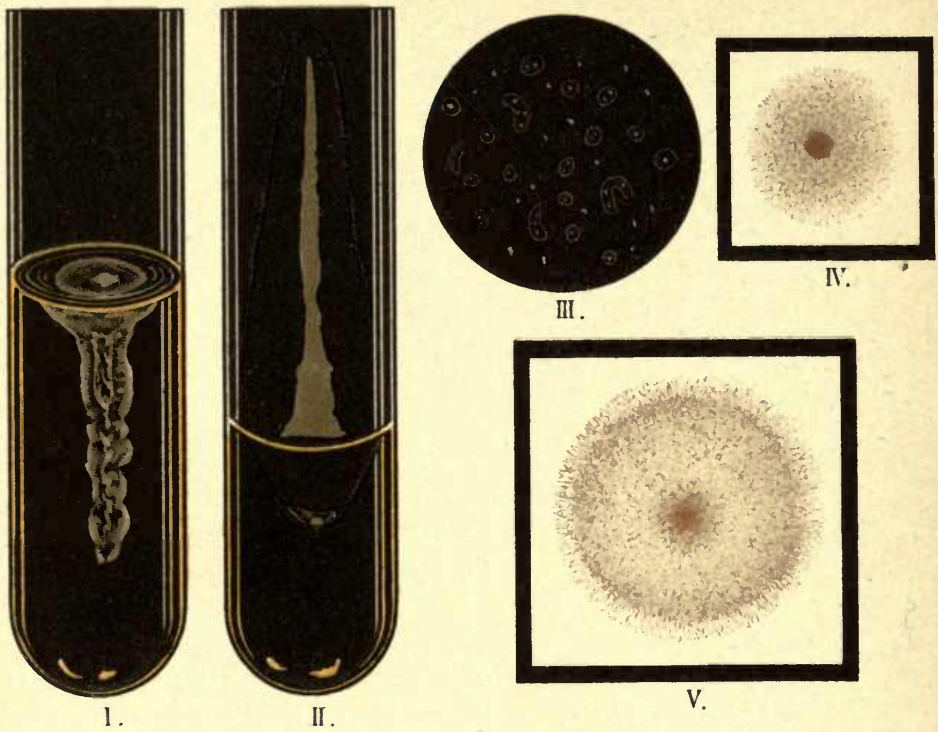

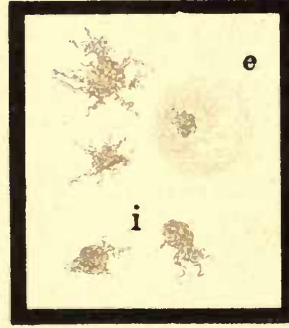

VII.

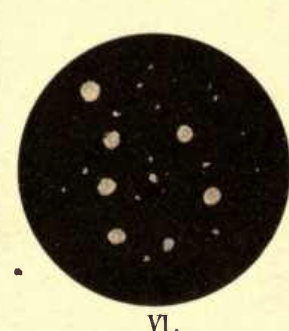

VI.

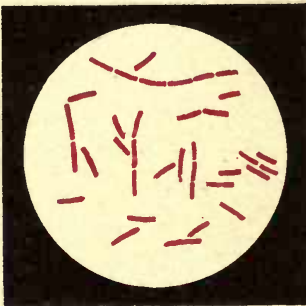

X.

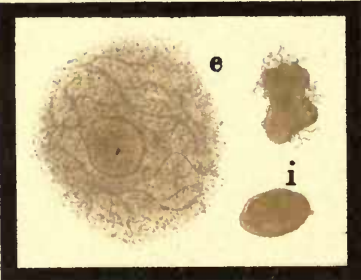

VIII .

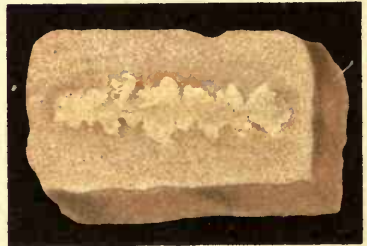

IX. 


\section{PLATE 4r. \\ Bacillus megatherium. De Bary.}

I. Gelatin stab culture, twenty-four hours at $22^{\circ}$.

II. Agar streak culture, three days at $22^{\circ}$.

III. Gelatin plate, thirty-six hours at $22^{\circ}$. Natural size.

IV. Gelatin plate, thirty-six hours at $22^{\circ} . \times 60$. Deep colony.

V. Gelatin plate, thirty-six hours at $22^{\circ} . \quad \times 60 . \quad$ Superficial colony.

VI. Agar plate, four days at $22^{\circ}$. Natural size.

VII. Agar plate, one day at $22^{\circ} . \times 60$. To the right, superficial; to the left, deep colonies.

VIII. Agar plate, four days at $22^{\circ} . \times 60$. To the right, deep; to the left, superficial colonies.

IX. Potato culture, five days at $22^{\circ}$. Natural size.

X. Microscopic preparation. Pure culture on agar. $\times 800$.

XI. Bacilli with numerous flagella. $\times 1000$. Stained according to Löffler.

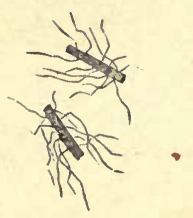

XI. 


\section{PLATE 42.}

Bacillus vulgatus. Migula. (B. mesentericus vulgatus Flügge. Potato Bacillus.)

I. Gelatin stab culture, ten days at $22^{\circ}$.

II. Agar streak culture, ten days at $22^{\circ}$.

III. Agar stab culture, six days at $22^{\circ}$. Surface growth.

IV. Agar plate, six days at $22^{\circ}$. Natural size.

V. Agar plate, six days at $22^{\circ} . \times 60$. Deep colonies.

VI. Agar plate, six days at $22^{\circ} . \times 60$. Superficial colony.

VII. Gelatin plate, eight days at $22^{\circ}$. Natural size.

VIII. Gelatin plate, eight days at $22^{\circ} . \times 60$. Part of a superficial colony.

IX. Gelatin plate, eight days at $22^{\circ} . \times 150 . \quad$ Part of a superficial colony.

X. Potato culture, five days at $22^{\circ}$. Natural size.

XI. Microscopic preparation. Pure culture from agar, one day old. $\times 800$. Stained with fuchsin.

XII. Bacilli with numerous flagella. $\times 1000$. Stained according to Löffler.

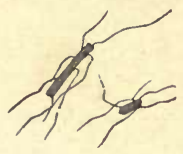

XII. 
Tab. 42.
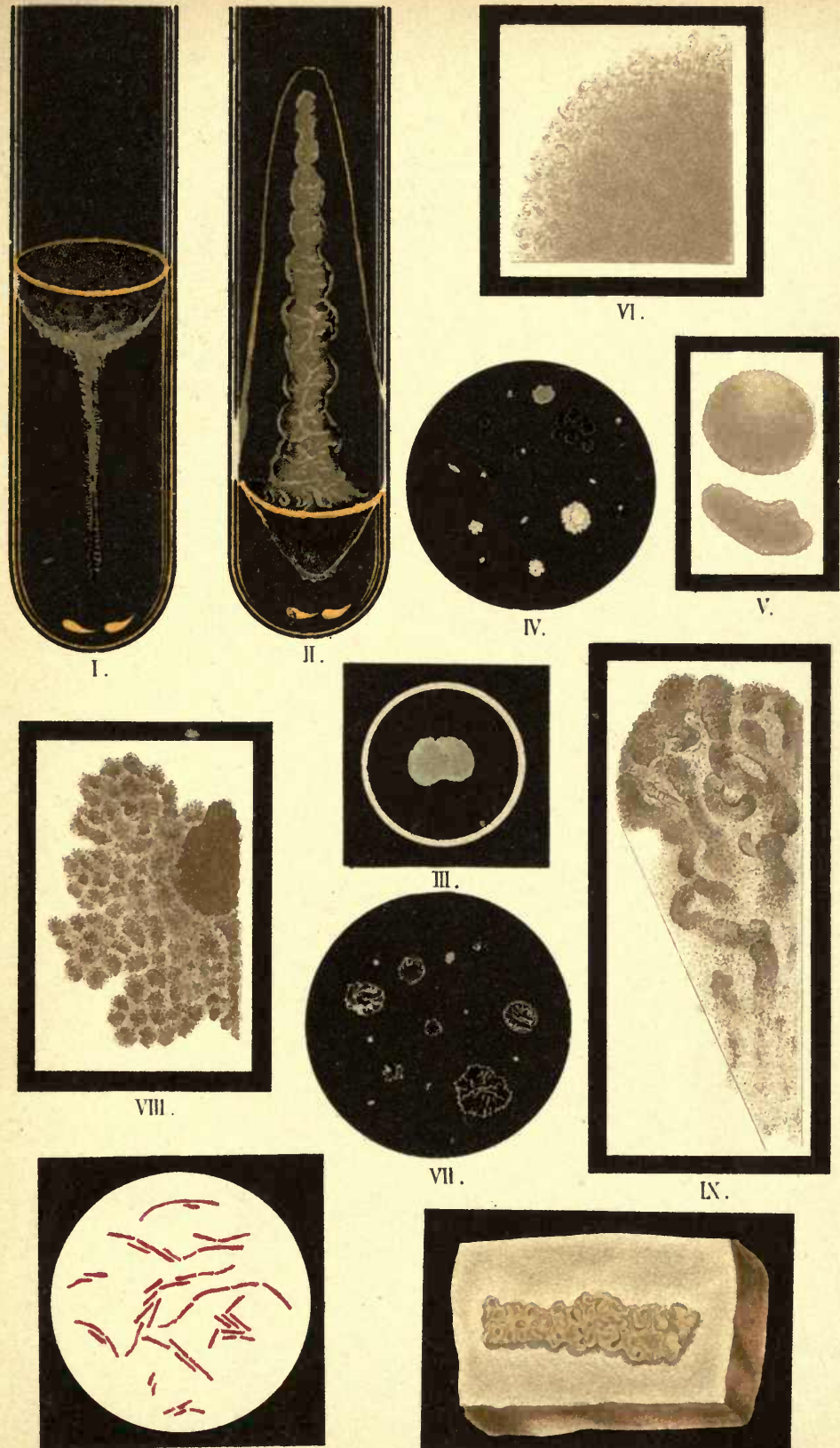

VII

IX.

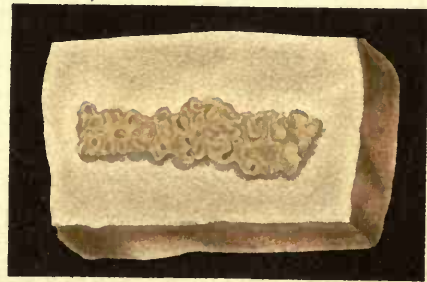




Tab. 43.
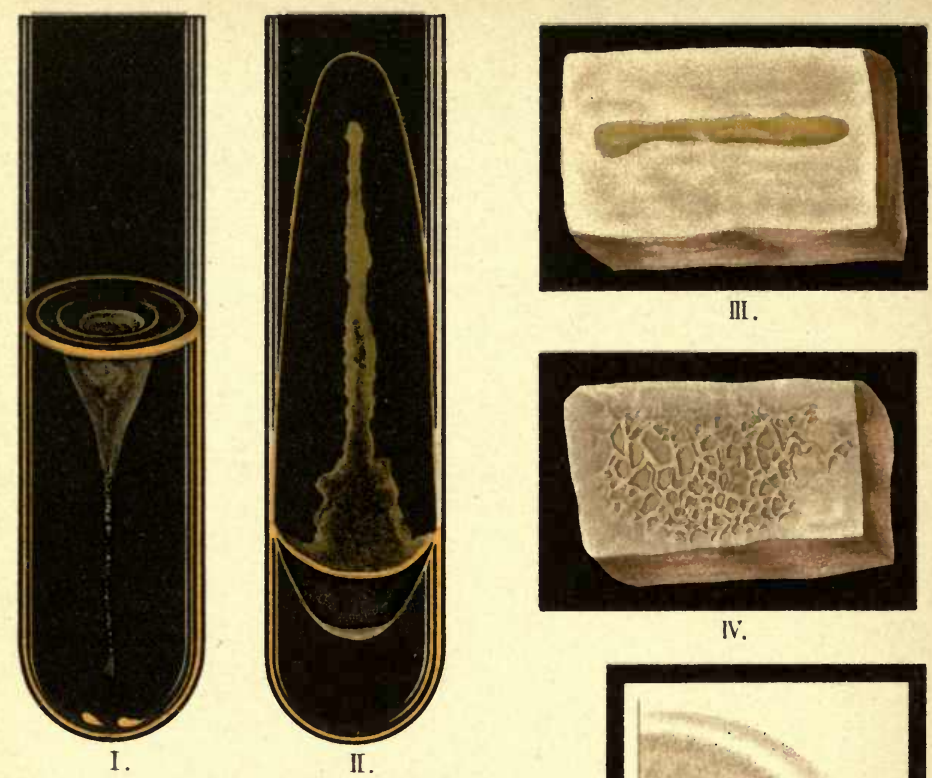

III.

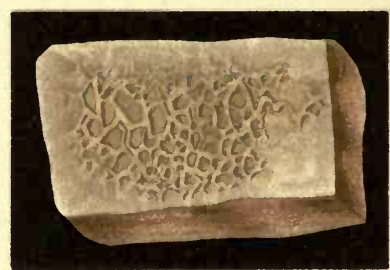

IV.

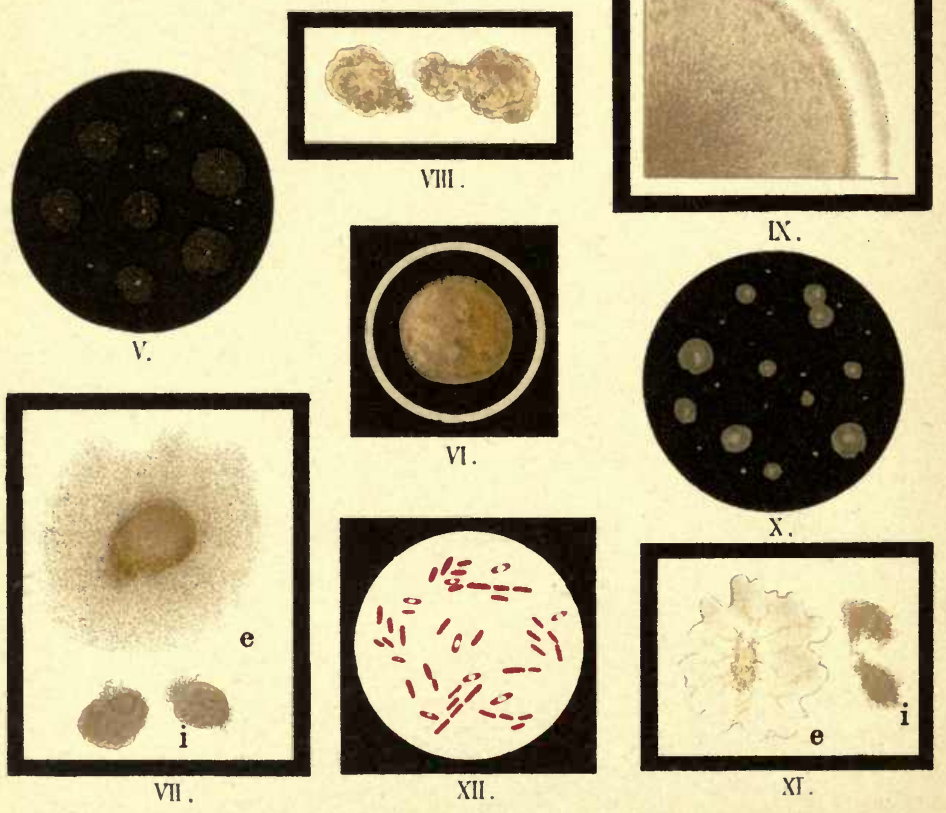




\section{PLATE 43.}

Bacillus mesentericus. Lehm, and Neum. (B. mesentericus fuscus Flügge.)

I. Gelatin stab culture, two days at $22^{\circ}$.

II. Agar streak culture, three days at $22^{\circ}$.

III. Potato culture, one day at $22^{\circ}$. Natural size.

IV. Potato culture, five days at $22^{\circ}$. Natural size.

V. Agar plate, two days at $22^{\circ}$. Natural size.

VI. Agar stab culture, four days at $22^{\circ}$. Surface growth.

VII. Agar plate, two days at $22^{\circ}$. $\times 60$. Above, superficial; below, deep colonies.

VIII. Gelatin plate, thirty-six hours at $22^{\circ} . \times 60$. Deep colonies.

IX. Gelatin plate, thirty-six hours at $22^{\circ} . \quad \times 60$. Superficial colony.

X. Gelatin plate, two days at $22^{\circ}$. Natural size.

XI. Gelatin plate, one day at $22^{\circ} . \times 60$. To the right, deep; to the left, superficial colonies.

XII. Microscopic preparation. $\times 800$. From a pure culture on agar two days old. Stained with fuchsin. Some bacilli contain spores.

XIII. Bacilli with numerous flagella. $\times 1000$. Stained by Löffler's method.

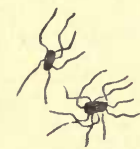

XIII. 
PLATE 44.

\section{Bacillus tetani. Nicolaier. (Tetanus Bacillus.)}

I. Sugar-agar stab culture, three days at $37^{\circ}$.

II. Sugar-gelatin stab culture, six days at $22^{\circ}$.

III. Sugar-gelatin plate, four days at $22^{\circ}$. Grown without air.

IV. Sugar-gelatin plate, four days at $22^{\circ} . \times 60$. Natural size. Superficial and deep colonies. Grown without air.

V. Sugar-agar plate, four days at $37^{\circ}$. Natural size. Grown without air.

VI. Sugar-agar plate, four days at $37^{\circ} . \times 60$. Superficial and deep colonies. Grown without air.

VII. Microscopic preparation. Pure culture on sugaragar, three days at $37^{\circ} . \times 1000$. Bacilli with spores. Double staining according to Ziehl.

VIII. Microscopic preparation. Pure culture on sugaragar, two days at $37^{\circ} . \times 1000$. Some bacilli contain spores. Stained with fuchsin.

IX. Microscopic preparation. Pure culture on sugaragar, twenty-four hours at $37^{\circ} . \times 1000$. Extremely long threads with faintly stained intervals.

X. Microscopic preparation. Pure culture on sugaragar, six days at $37^{\circ} . \times 1000$. Stained with fuchsin. Long threads and chains of spores with faintly stained intervals.

XI. Microscopic preparation. Flagella staining. Highly magnified.

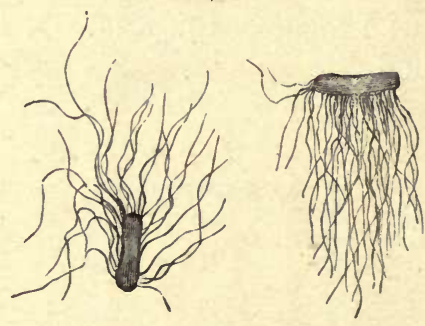

$\mathrm{XI}$. 
Tab. 44.
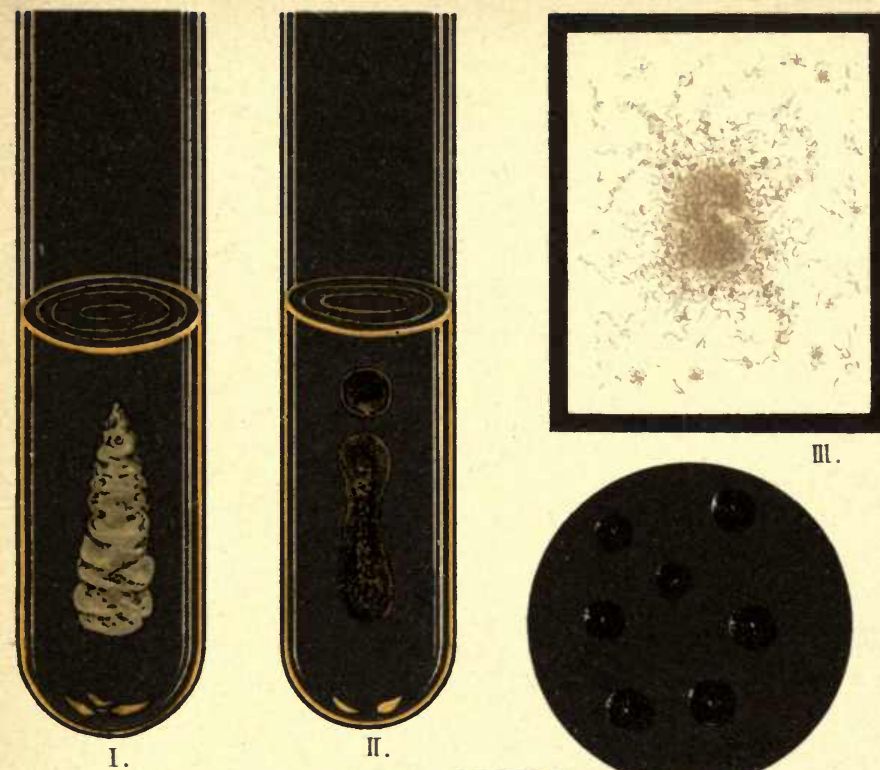

III.

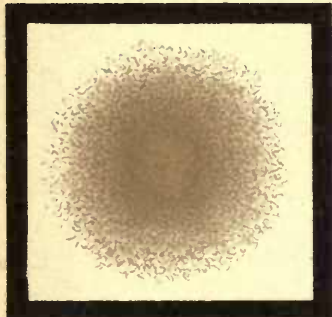

VI.

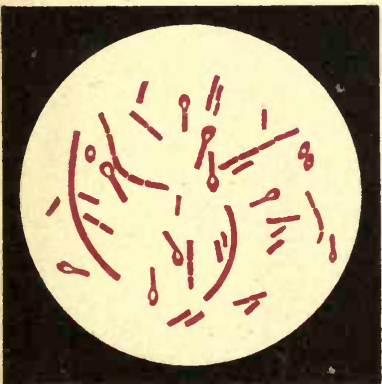

VIII.

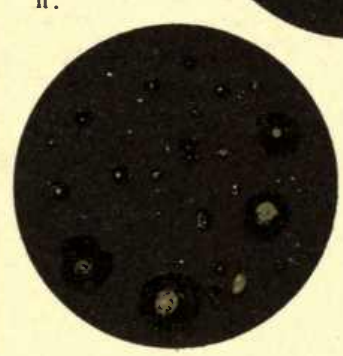

l.

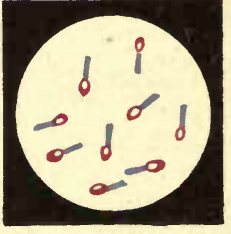

VII.

IV.

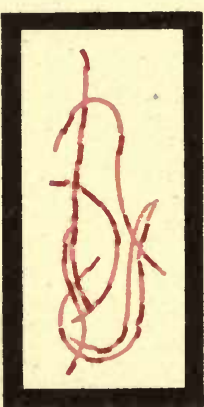

LX.

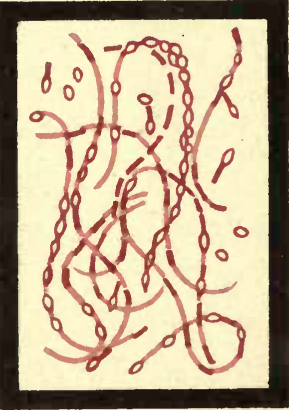

X. 


Tab. 45 .
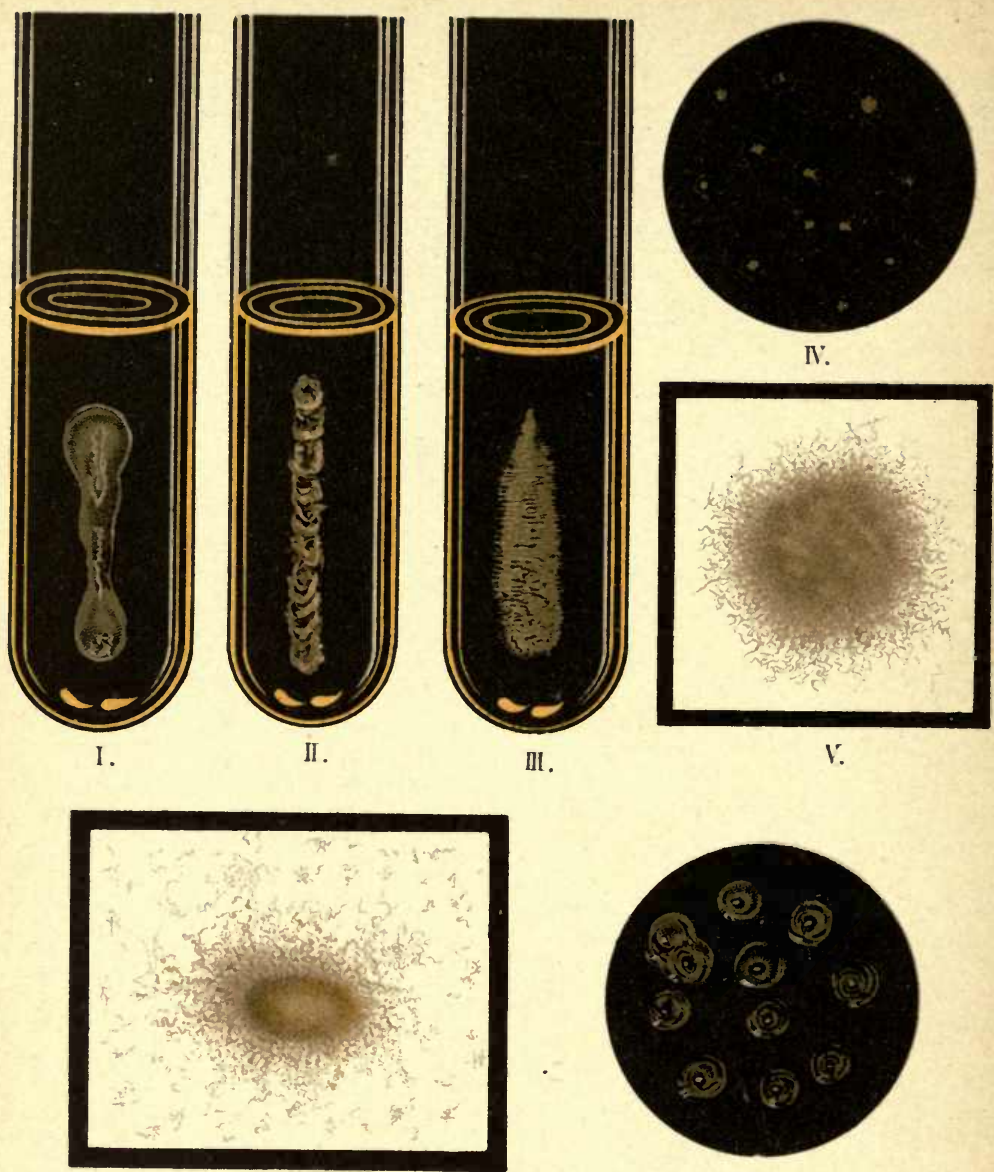

VII .
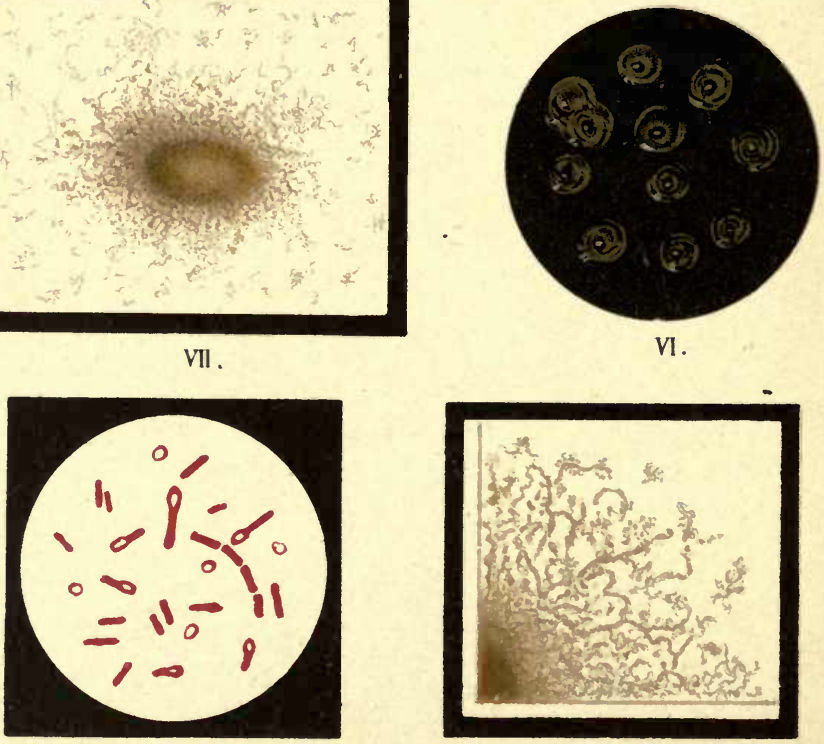

IX.

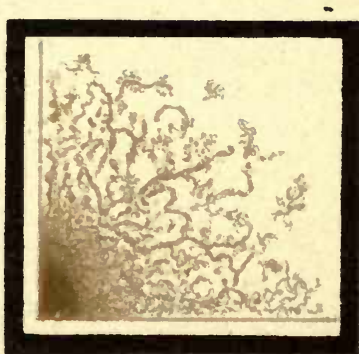

VIII. 


\section{PLATE 45.}

\section{Bacillus Chauvœi. Macé. (Symptomatic Anthrax.)}

I. Sugar-gelatin stab culture, six days at $22^{\circ}$.

II. Sugar-agar stab culture, three days at $37^{\circ}$.

III. Sugar-agar stab culture, three weeks at $37^{\circ}$.

IV. Sugar-agar plate, four days at $37^{\circ}$. Natural size. Grown as anaerobe.

V. Sugar-agar plate, four days at $37^{\circ} . \times 60$. Superficial and deep colony. Grown as anaerobe.

VI. Sugar-gelatin plate, four days at $22^{\circ}$. Natural size. Grown as anaerobe.

VII. Sugar-gelatin plate, four days at $22^{\circ} . \times 60$. Deep colony, grown as anaerobe.

VIII. Sugar-gelatin plate, two days at $22^{\circ} . \times 150$. Part of a superficial colony. Grown as anaerobe.

IX. Microscopic preparation. Pure culture on sugaragar, three days at $37^{\circ} . \times 1000$. Bacilli with spores and free spores. Stained with fuchsin. 
PLATE 46.

Bacillus œdematis maligni. Koch. (Malignant Edema.)

I. Sugar-agar stab culture, eight days at $37^{\circ}$.

II. Microscopic preparation. Tuft of flagella. $\times$ about 1500. Copied from G. Novy ("Zeitschrift f. Hygiene," Bd. xvir, Taf. 1, 2).

III. Microscopic preparation. Bacilli with flagella. Pure culture on agar, twenty-four hours old. $\times 1000$. Stained according to Löffler.

IV. Sugar-agar plate, four days at $22^{\circ} . \quad \times 60$. Part of a superficial colony.

V. Sugar agar plate, six days at $22^{\circ}$. Natural size.

VI. Microscopic preparation. Pure culture on agar, two days old at $37^{\circ}$. Bacilli with spores. $\times 1000$. Stained with fuchsin.

VII. Microscopic preparation. Tissue-juice from guinea-pig. Smear preparation. Copied after Fränkel and Pfeiffer (Mikrophotogr. Atlas, Taf. xxiII, 46). 
Tab. 46.
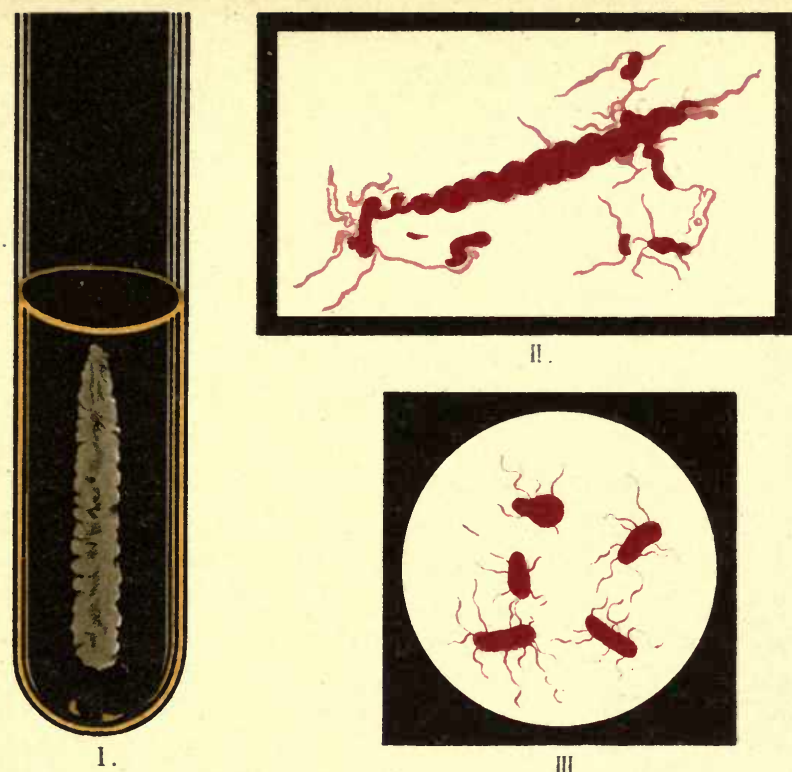

I! .

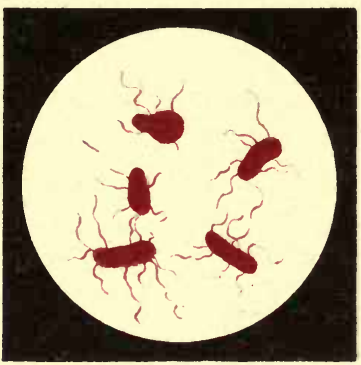

III.

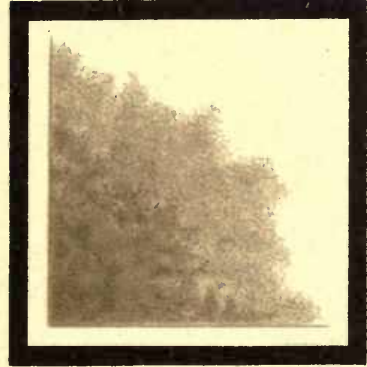

IV.

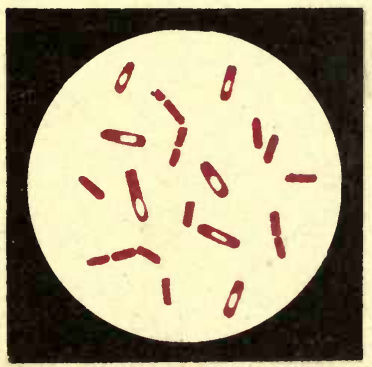

VI.
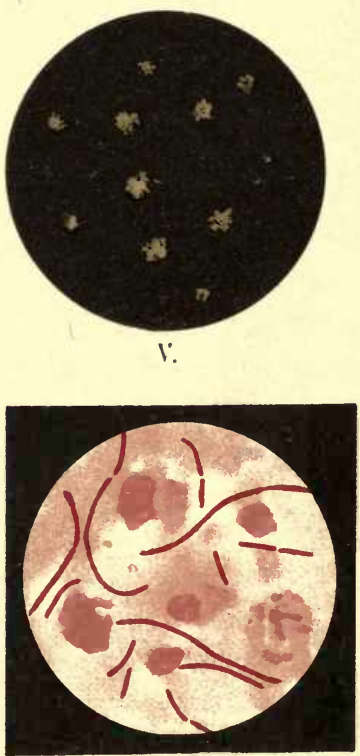

VII . 

Tab. 47.
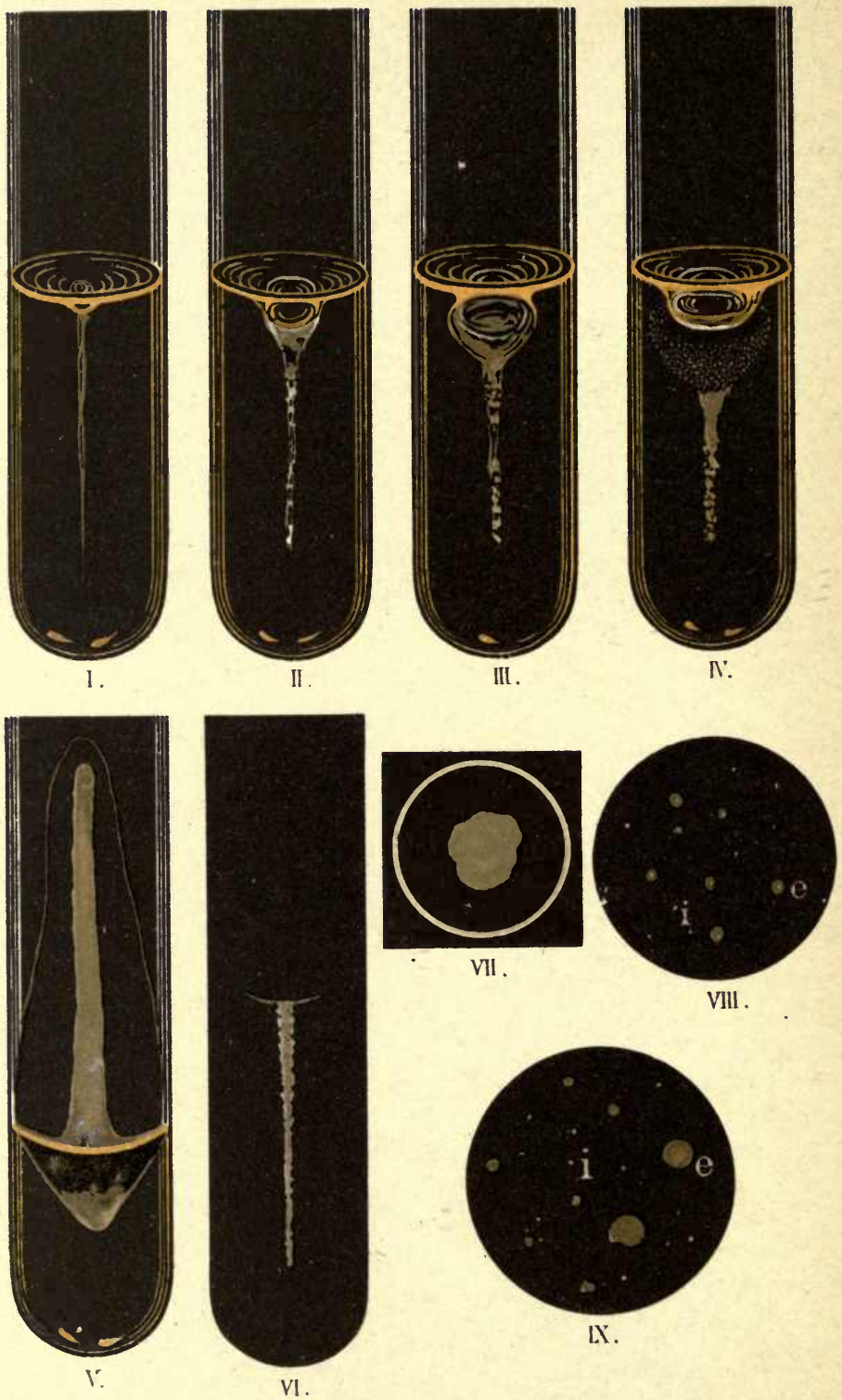
PLATE 47.

Vibrio choleræ. (Koch.) Buchner. (Comma Bacillus.)

I. Gelatin stab culture, two days at $22^{\circ}$.

II. Gelatin stab culture, seven days at $22^{\circ}$.

III. Gelatin stab culture, eight days at $22^{\circ}$. Culture from a case of cholera asiatica in Hanover.

IV. Gelatin stab culture, eight days at $22^{\circ}$.

V. Agar streak culture, eleven days at $22^{\circ}$.

VI. Agar stab culture, eight days at $22^{\circ}$. Stab canal.

VII. Agar stab culture, eight days at $22^{\circ}$. Surface growth.

VIII. Agar plate, six days at $22^{\circ}$. Natural size.

IX. Agar plate, six days at $22^{\circ}$. Culture from a case of cholera asiatica in Hanover. 
PLATE 48.

Vibrio choleræ. (Koch.) Buchner. (Comma Bacillus.)

I. Agar plate, thirty-six hours at $22^{\circ} . \times 60$. To the left superficial, to the right deep colonies.

II. Agar plate, two days at $22^{\circ} . \times 60$. To the left superficial, to the right deep colonies.

III. Agar plate, three days at $22^{\circ} . \times 60$. To the left superficial, to the right deep colonies.

IV. Agar plate, three weeks at $22^{\circ} . \times 60$. To the left superficial, to the right deep colonies.

V. Agar plate, five days at $22^{\circ} . \times 60$. Colonies of a culture of cholera asiatica from Hanover. Superficial and deep colonies.

VI. Gelatin plate, four days at $22^{\circ}$. Natural size. Deeply sunken funnels of liquefaction.

VII. Gelatin plate, fourteen days at $22^{\circ}$. Natural size. Colony with a pronounced formation of zones.

VIII. Gelatin plate, four days at $22^{\circ}$. Shallow zones of liquefaction.

IX. Gelatin plate, six days at $22^{\circ}$. Superficial sinking in of colonies with concentric zones of liquefaction. 
Tab. 48 .

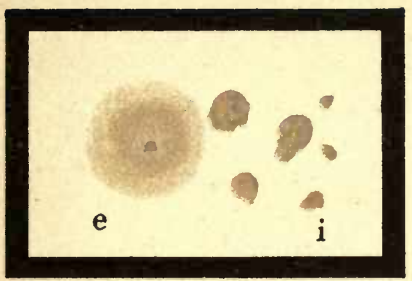

1.

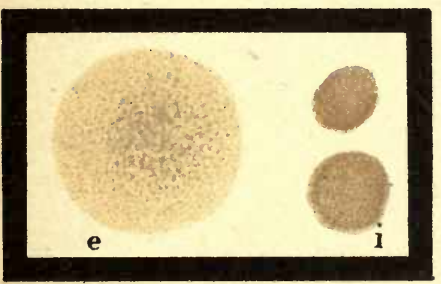

III.

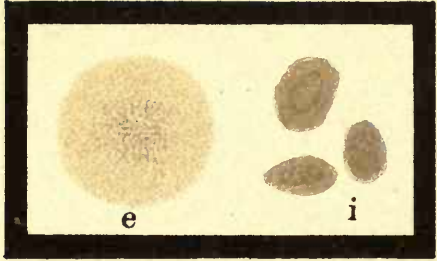

II.

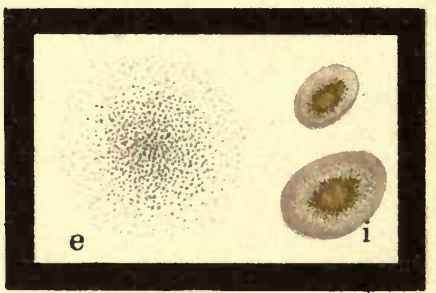

IV.

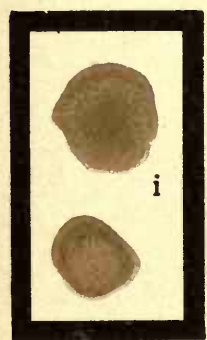

I.

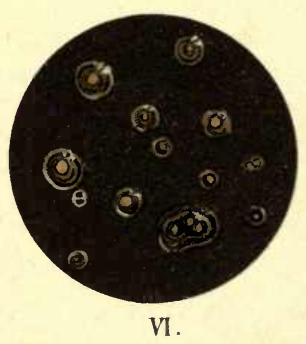

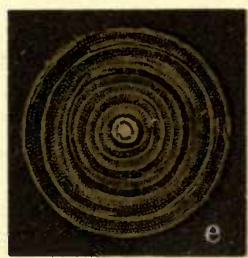

VII.

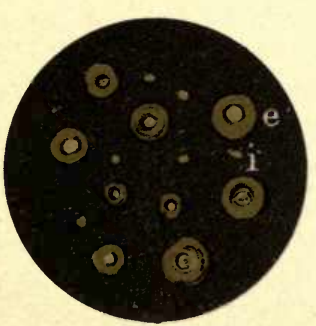

VIII.

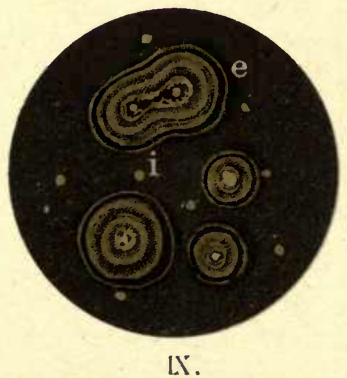




Tab. 49.

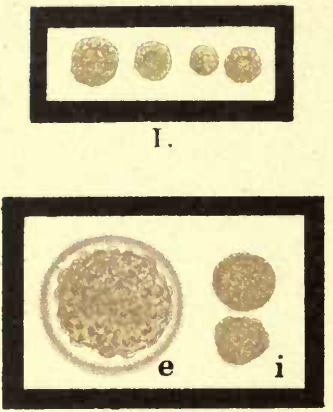

II.

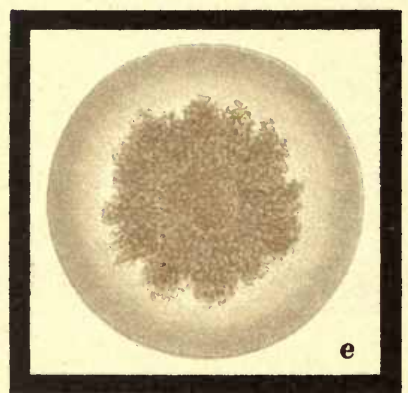

V.

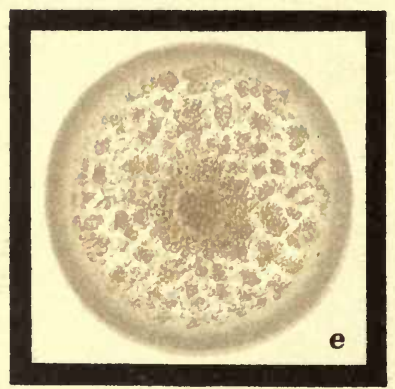

VIII.

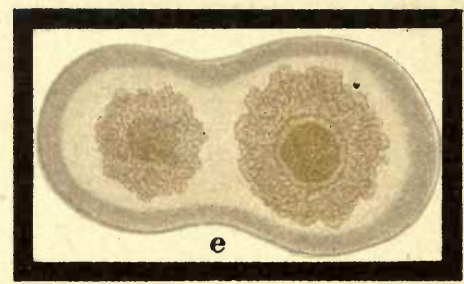

III.

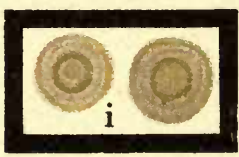

IV.
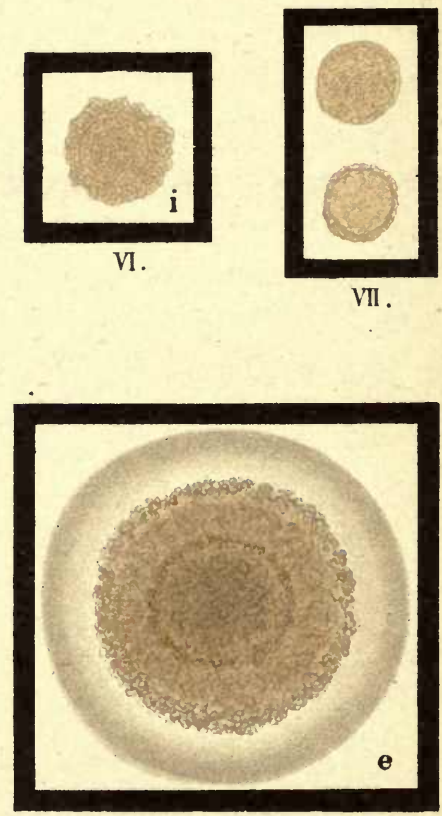

LX. 
PLATE 49.

Vibrio choleræ. (Koch.) Buchner. (Comma Bacillus.)

I. Gelatin plate, thirty-six hours at $22^{\circ} . \times 60$. Deep and superficial colonies.

II. Gelatin plate, forty-eight hours at $22^{\circ} . \times 60$. To the left superficial, to the right deep colonies.

III. Gelatin plate, three days at $22^{\circ} . \times 60$. Superficial colonies with zone of liquefaction.

IV. Gelatin plate, three days at $22^{\circ} . \times 60$. Deep colonies.

V. Gelatin plate, four days at $22^{\circ} . \times 60$. Superficial colony with zone of liquefaction.

VI. Gelatin plate, four days at $22^{\circ} . \times 60$. Deep colony.

VII. Gelatin plate, five days at $22^{\circ} . \times 60$. Deep colony from a culture of cholera from Hanover.

VIII. Gelatin plate, five days at $22^{\circ} . \times 60$. Superficial colony. Complete liquefaction has already taken place.

IX. Gelatin plate, eight days at $22^{\circ} . \quad \times 60$. Superficial colony with zone of liquefaction. 


\section{PLATE 50.}

Vibrio choleræ. (Koch.) Buchner. (Comma Bacillus.)

I. Gelatin plate, five days at $22^{\circ} . \times 60$. Abnormal form of superficial colony.

II. Gelatin plate, five days at $22^{\circ} . \times 90$. Abnormal form of superficial colony.

III. Gelatin plate, five days at $22^{\circ} . \times 60$. Deeply sunken superficial colony with a strongly reflecting zone of liquefaction.

IV. Gelatin plate, six days at $22^{\circ} . \times 60$. Abnormal superficial colony, with dense nucleus, evenly sunken in and with a zone of liquefaction.

V. Gelatin plate, six days at $22^{\circ} . \times 60$. Abnormal deep colony, without halo, dark, with radiating striations, from the same plate as IV.

VI. Potato culture, two days at $22^{\circ}$. Natural size. Soaked in soda solution before inoculation.

VII. Potato culture, five days at $22^{\circ}$. Inoculated upon ordinary potato. 
Tab. 50.

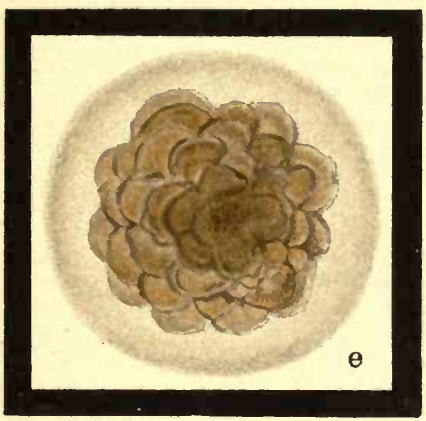

1.

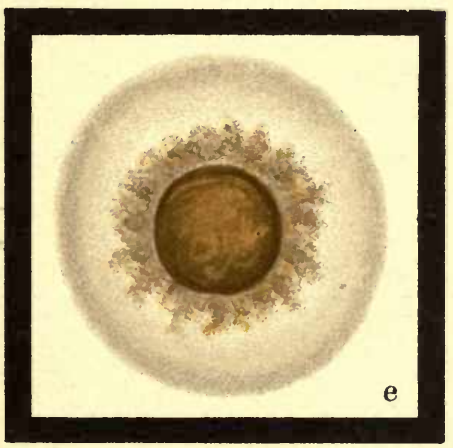

II.

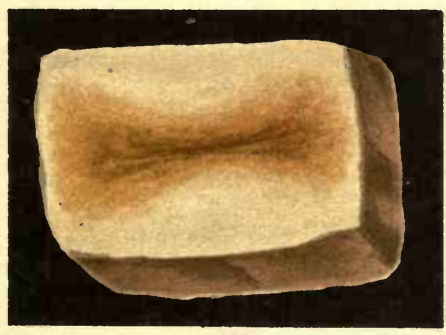

VII.

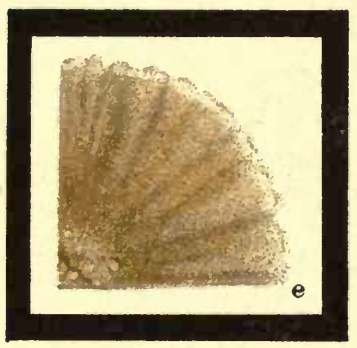

II.

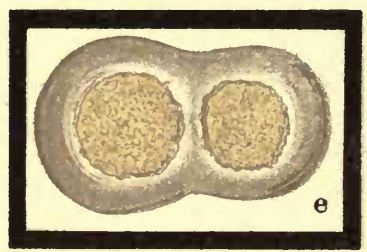

III .

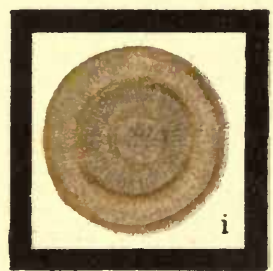

V.

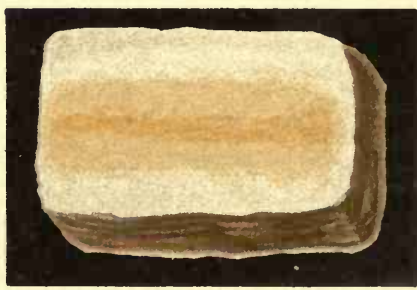

VI. 


Tab. 51.
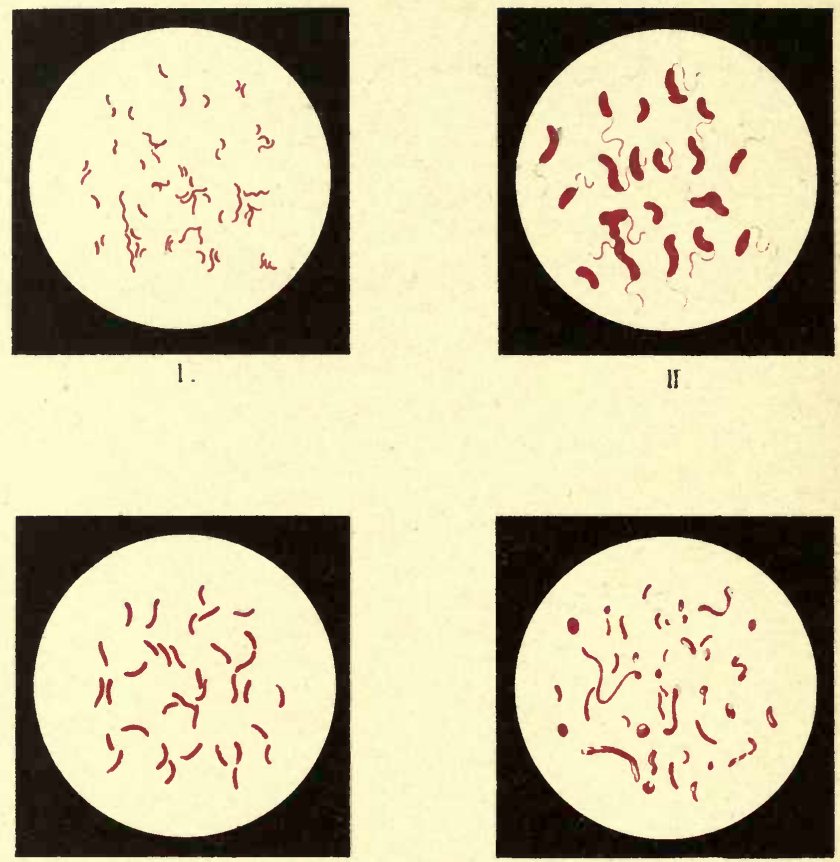

III.

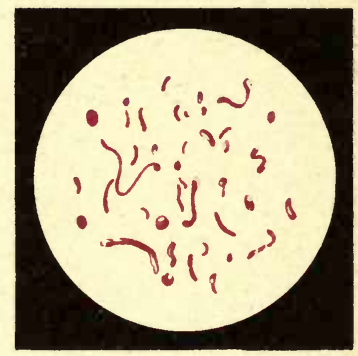

IV.

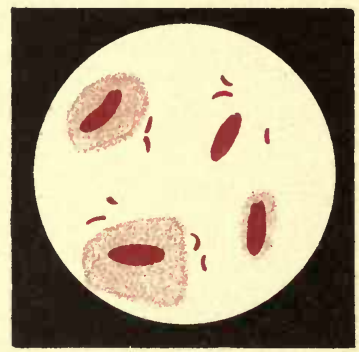

I.

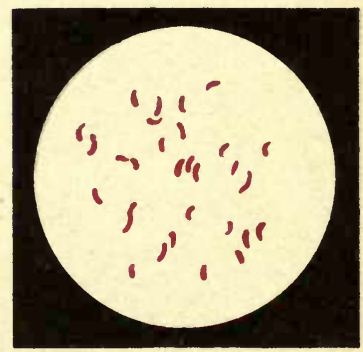

17. 


\section{PLATE 5I.}

Vibrio choleræ. (Koch.) Buchner. (Comma Bacillus.)

I. Pure culture in bouillon, twenty-four hours at $37^{\circ}$. Stained with fuchsin. $\times 1000$.

II. Pure culture on agar, twenty-four hours. $\times 1000$. Flagella staining according to Löffler.

III. Pure culture on gelatin, forty-eight hours. Very fresh from water. (Copied from Fränkel and Pfeiffer, Fig. 94.)

IV. Pure culture on agar, four weeks' old. Involution forms, stained with fuchsin.

V. Vibrio Metschnikovii Gamaleia. Smear preparation from pigeon's blood. (Copied after Fränkel and Pfeiffer, Fig. 102.)

VI. Vibrio Proteus Buchner. Pure culture in bouillon, twenty-four hours. Stained with fuchsin. 


\section{PLATE 52.}

Vibrio proteus. Buchner. (Vibrio Finkler.)

I. Gelatin stab culture, one day at $22^{\circ}$.

II. Gelatin stab culture, four days at $22^{\circ}$.

III. Gelatin plate, one day at $22^{\circ}$. Natural size.

IV. Gelatin plate, four days at $22^{\circ} . \quad \times 60$. Superficial colony.

V. Gelatin plate, four days at $22^{\circ} . \times 60$. Deep colony.

VI. Agar streak culture, six days at $22^{\circ}$.

VII. Agar plate, four days at $22^{\circ} . \times 60$. Superficial colony.

VIII. Agar plate, four days at $22^{\circ} . \quad \times 60$. Deep colony.

IX. Agar plate, four days at $22^{\circ}$. Natural size. 
Tab. 52.
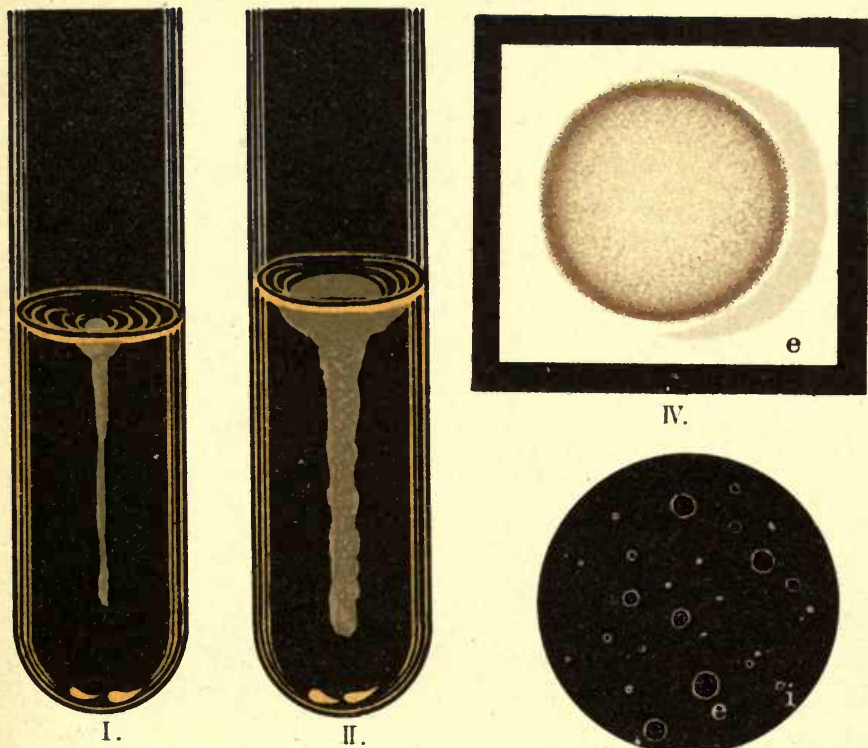

IV.
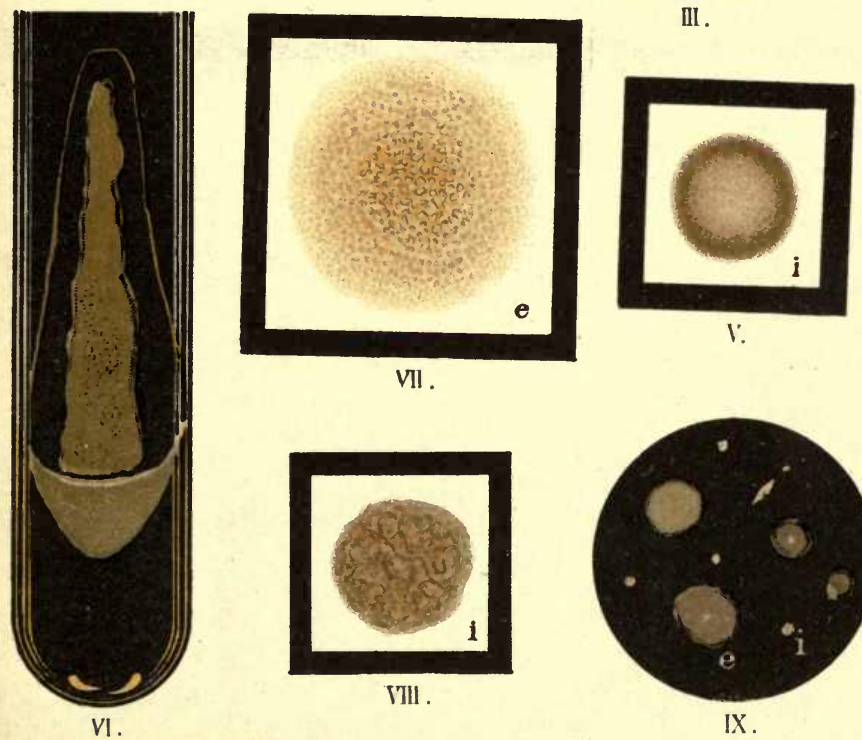

VII.

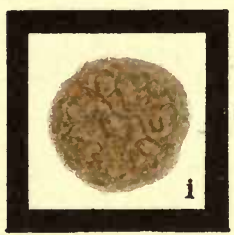

ITII.

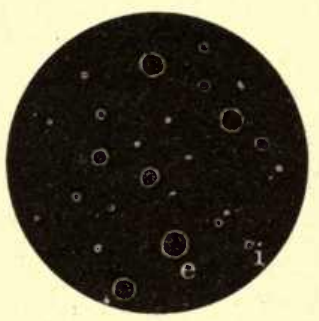

III.

I.

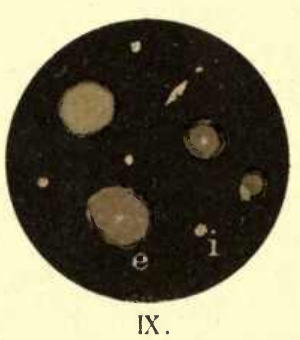




Tab. 53.
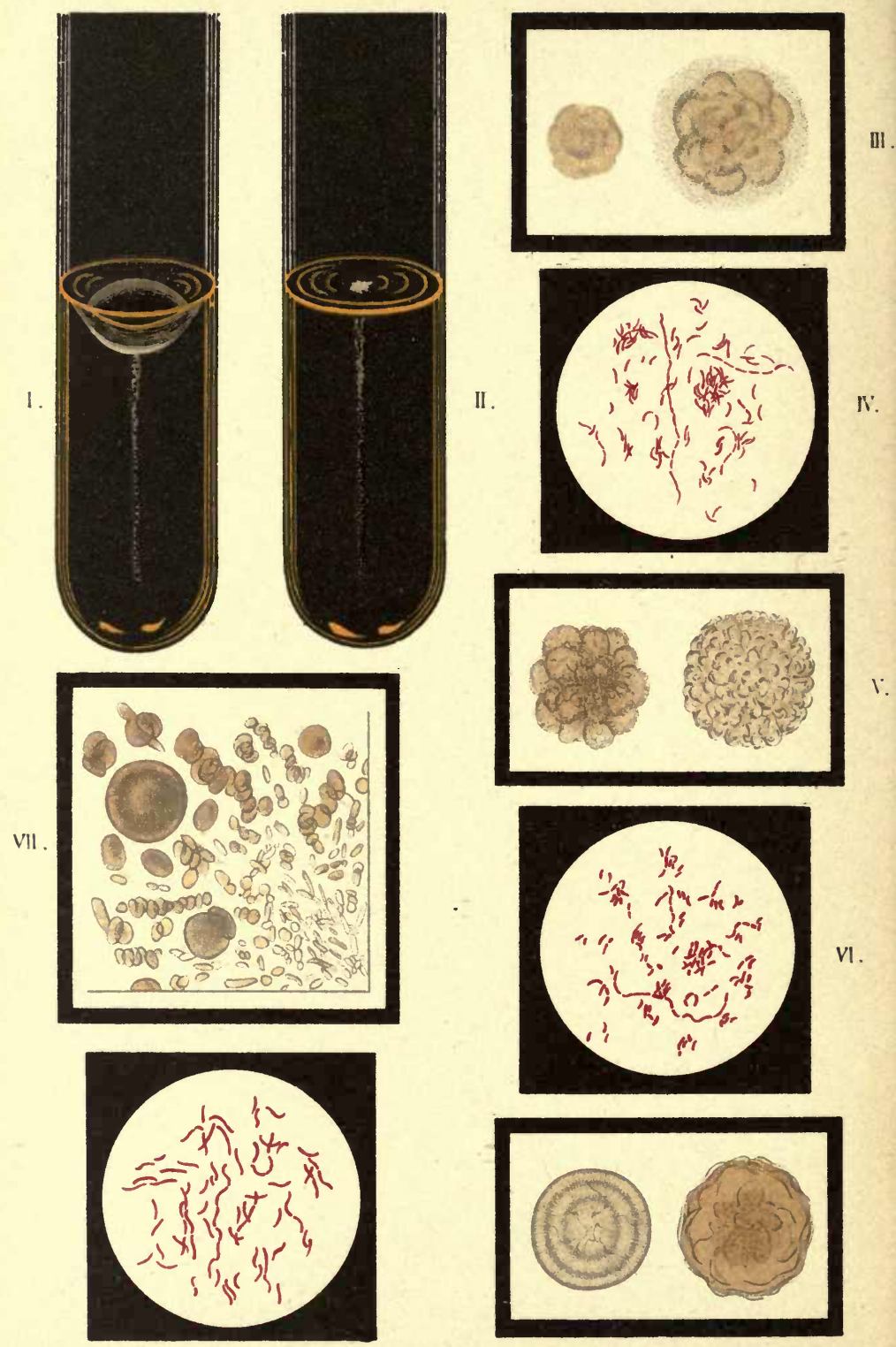

I'III
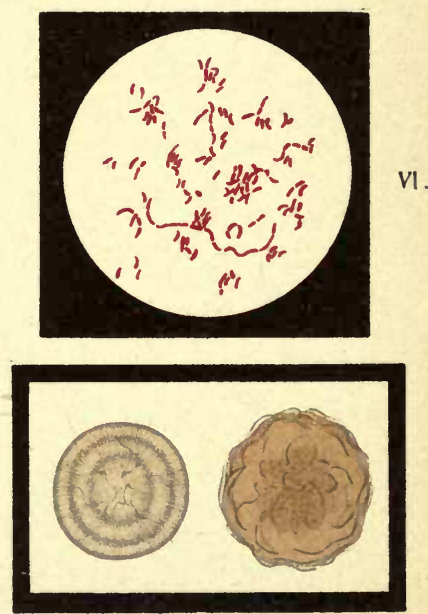

IX. 


\section{PLATE 53.}

Vibrio danubicus Heider, Vibrio berolinensis Rubner, Vibrio aquatilis Günther.

I. Vibrio danubicus: Gelatin stab culture, three days at $22^{\circ}$.

II. Vibrio aquatilis: Gelatin stab culture, three days at $22^{\circ}$.

III. Vibrio danubicus: Gelatin plate, three days at $22^{\circ}$. $\times 60$. To the right superficial, to the left deep colony.

IV. Vibrio danubicus: Microscopic preparation. Pure culture on agar, twenty-four hours. Stained with fuchsin. $\times 800$.

V. Vibrio berolinensis: Gelatin plate, three days at $22^{\circ}$. $\times 60$. To the right superficial, to the left deep colony. VI. Vibrio berolinensis: Microscopic preparation. Pure culture from agar, twenty-four hours. $\times 800$. Stained with fuchsin.

VII. Vibrio aquatilis: Gelatin plate, three days at $22^{\circ}$. $\times 60$. Deep colonies, swarming outward from one point forming secondary ones.

VIII. Vibrio aquatilis: Microscopic preparation. Pure culture on agar, twenty-four hours at $22^{\circ} . \quad \times 800$. Stained with fuchsin.

IX. Vibrio aquatilis: Gelatin plate, three days at $22^{\circ}$. $\times 60$. To the right superficial, to the left deep colony. 


\section{PLATE 54.}

Vibrio albensis. Lehm. and Neum. (Phosphorescent Elbe Vibrio.)

I. Gelatin stab culture, twenty-four hours at $22^{\circ}$.

II. Gelatin stab culture, four days at $22^{\circ}$.

III. Gelatin stab culture, ten days at $22^{\circ}$.

IV. Indol reaction after ten days. Bouillon culture with dilute sulphuric acid, warmed.

V. Gelatin plate, three days at $22^{\circ} . \times 60$. Superficial colony.

VI. Gelatin plate, three days at $22^{\circ} . \times 60$. Deep colonies.

VII. Gelatin plate, thirty-six hours at $22^{\circ}$. Natural size.

VIII. Microscopic preparation. Pure culture from agar, forty-eight hours. Stained with fuchsin. 
Tab. 54.
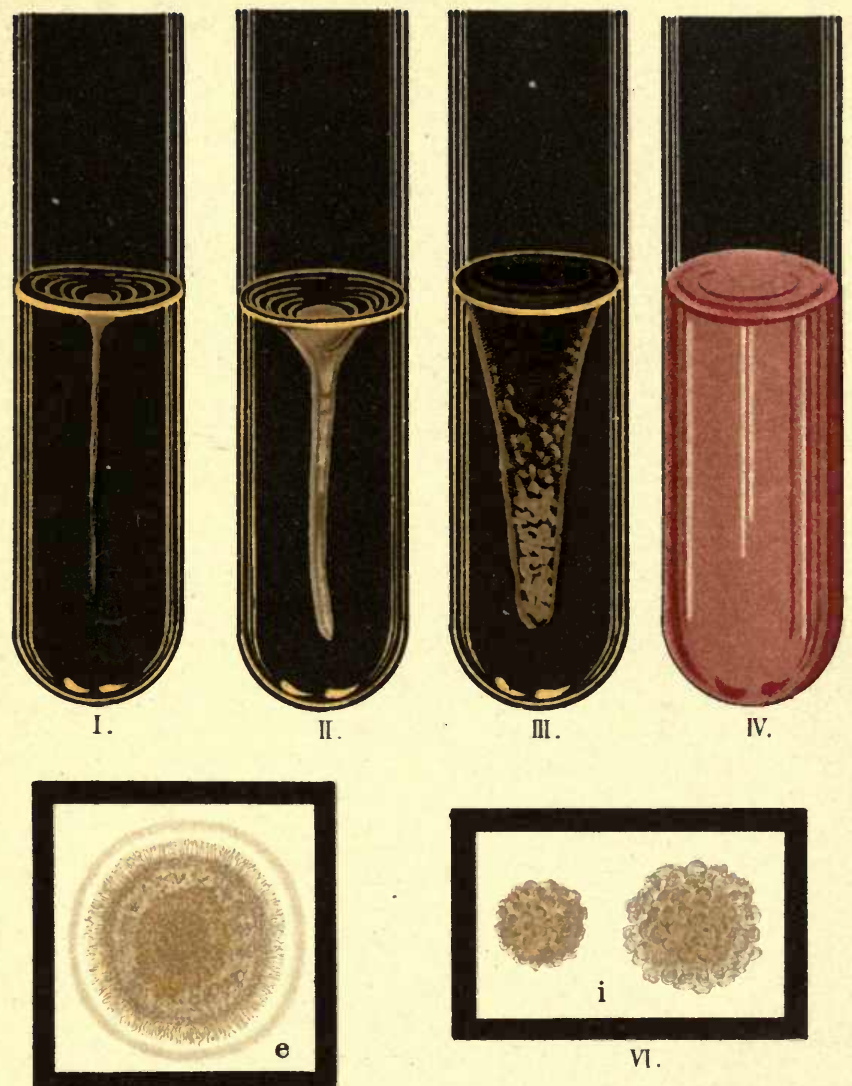

V.
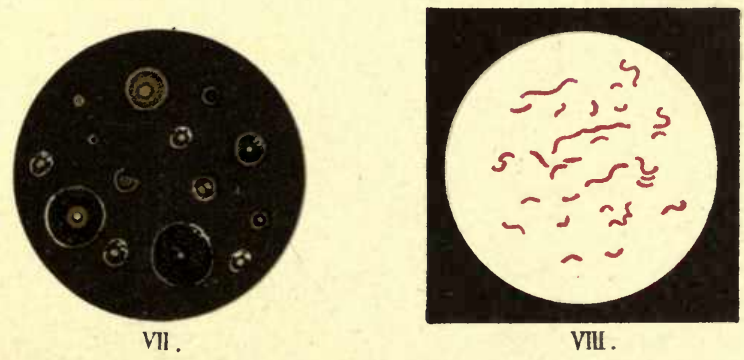

Lith. Anst E' Reichhold, München. 


Tab. 55 .
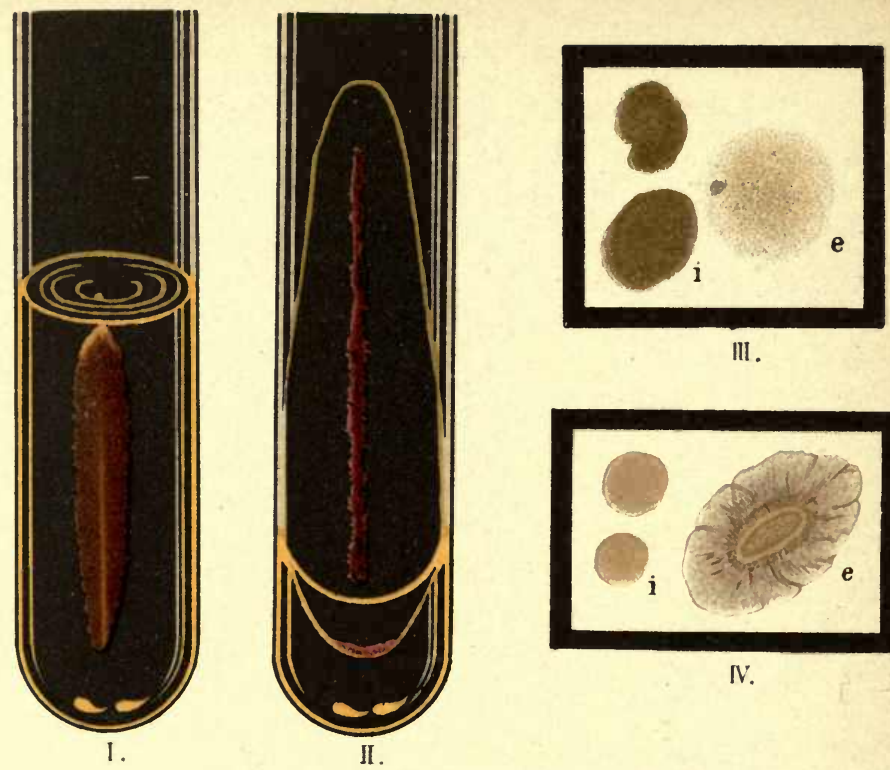

III.

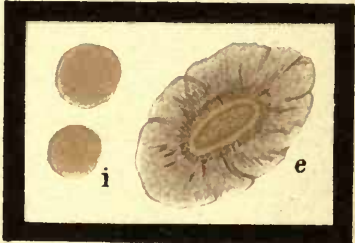

IV.
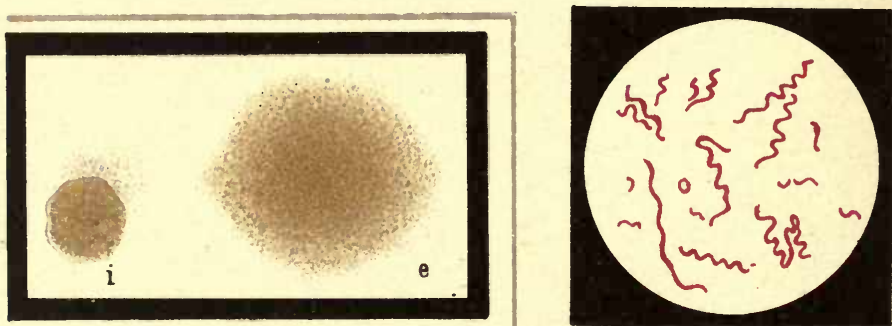

VI.

V.

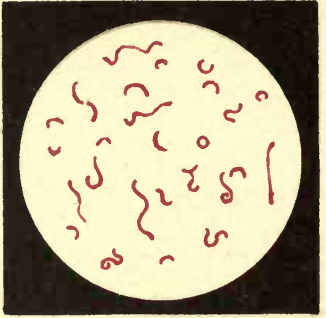

IX.

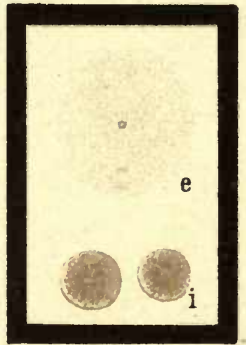

VII.

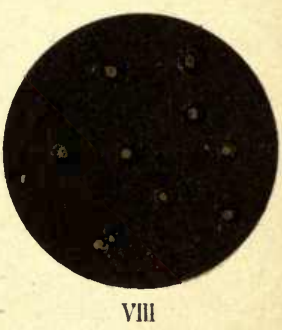




\section{PLATE 55.}

\section{Spirillum rubrum. Von Esmarch.}

I. Agar stab culture, ten days at $22^{\circ}$.

II. Agar streak culture, twenty datys at $22^{\circ}$.

III. Agar plate, five days at $22^{\circ}$. $\times 60$. (e) Superficial, (i) deep colonies.

IV. Gelatin plate, seven days at $22^{\circ} . \times 60$. (e) Superficial, (i) deep colonies.

V. Microscopic preparation. Pure culture from bouillon, diluted ten times; two days at $37^{\circ} . \times 1000$. Stained with fuchsin.

V A. Flagella preparation of spirillum rubrum. $\times 1000$. Stained according to Löffler.

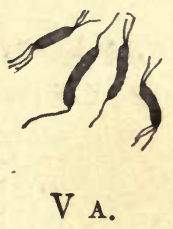

Spirillum concentricum. Kitasato.

VI. Agar plate, seven days at $22^{\circ} . \quad \times 60$. (e) Superficial, (i) deep colonies.

VII. Gelatin plate, three days at $22^{\circ} . \times 60$. (e) Superficial, (i) deep colonies.

VIII. Agar plate, seven days at $22^{\circ}$. Natural size.

IX. Microscopic preparation. Pure culture in bouillon, two days at $37^{\circ} . \quad \times 1000$. Stained with fuchsin. 


\section{PLATE 56. \\ Spirilla.}

I. Spirillum serpens Müller. With difficulty staining protoplasmic border. $\times$ about 1000 . Stained with fuchsin. Copied after Zettnow (C. B. x, Taf. 5).

II. Spirilla from Nasal Mucus. Smear preparation with two cells. $\times$ about 1000 . Copied after Weibel (C. B. II, p. 468, Fig. 1).

III. Spirilla from Nasal Mucus. Agar plate. Pure culture. $\times$ about 1000 . (Copied C. B. II, p. 468, Fig. 2.)

IV. Spirilla from Nasal Mucus. Gelatin plate. Pure culture. $\times$ about 1000. (Copied C. B. II, p. 468, Fig. 3.)

V. Spirillum undula Müller. With flagella. $\times$ about 800. Copied after Löffler (C. B. vi, Taf. I, Fig. 2).

VI. Vibrio spermatozoides Löffler. $\times$ about 1000. Copied after Löffler (C. B. viI, Taf. III, Fig. 7).

VII. Spirochæte from Mucus of the Mouth. (Copied after Löffler: Bakterien, Taf. I, Fig. 4.)

VIII. Spirochæte Obermeieri Cohn. Smear preparation from human blood. (Copied after Fränkel and Pfeiffer, Atlas, No. 134.)

IX. Spirilla of relapsing fever. Human blood. Spirilla grouped in the form of a star. (Copied after M. J. Soudakewitsch: Annales de l'instit. Pasteur, Bd. v, 1891, p. 514, plate 14, Fig. 1.) 
Tab. 56.

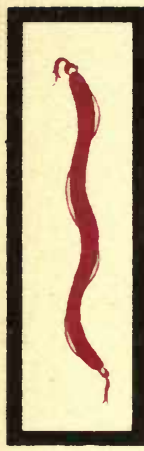

1.

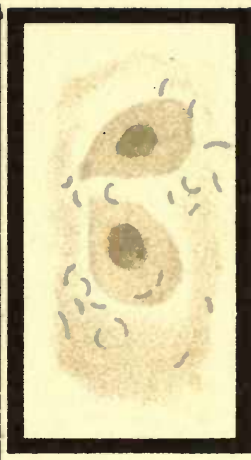

II.

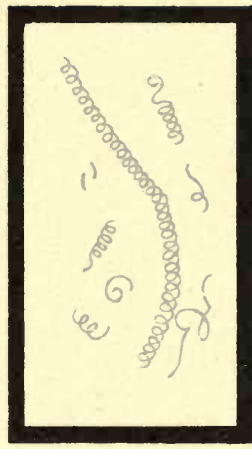

III.

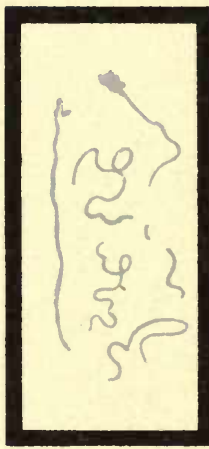

II.

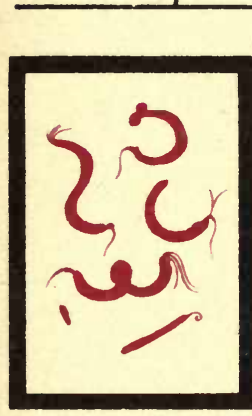

I.
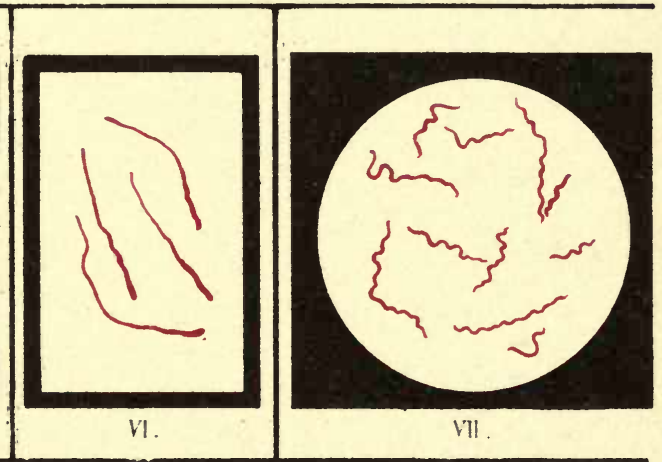

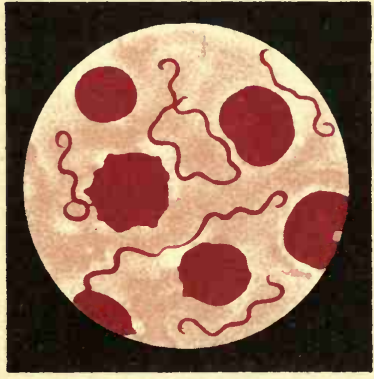

I'II

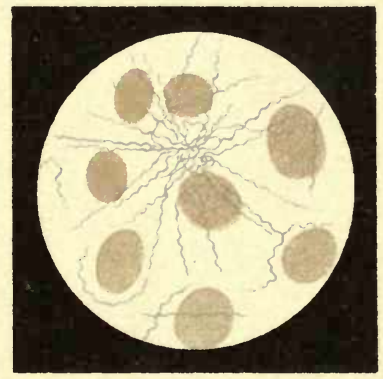

II. 


Tab. 57.
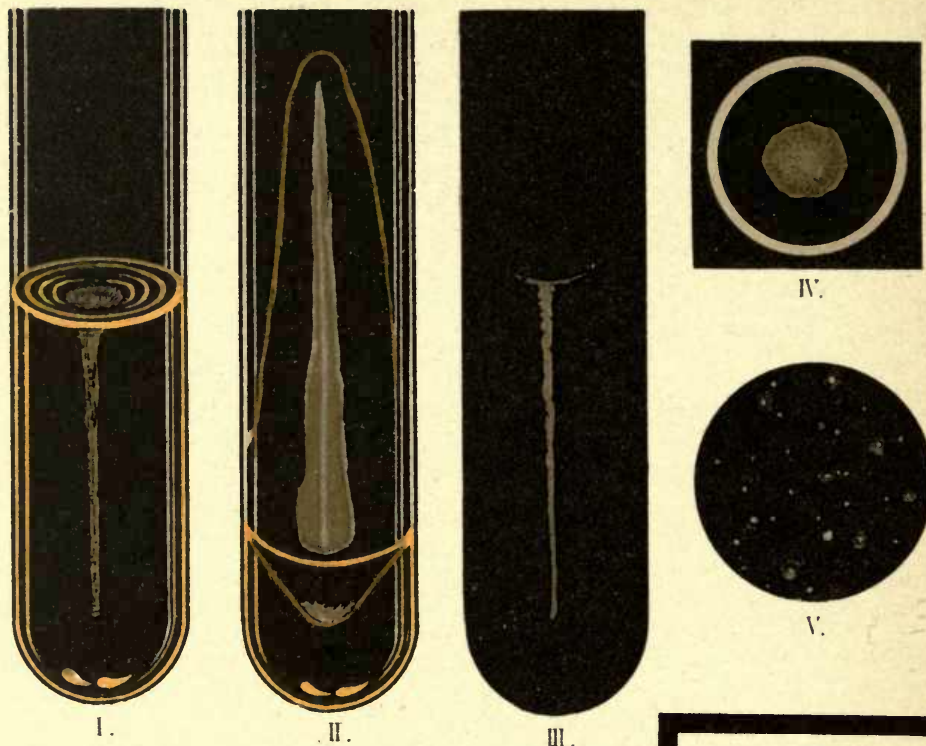

IV.

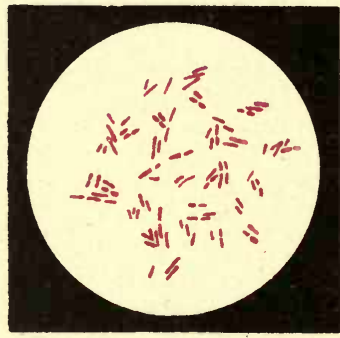

VI.

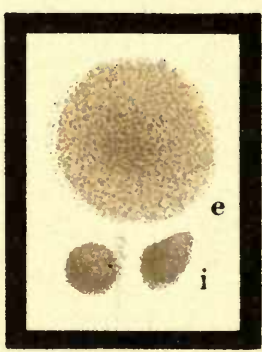

VII.
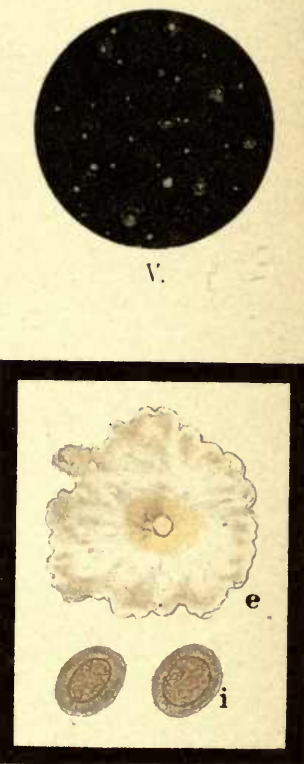

I'III.

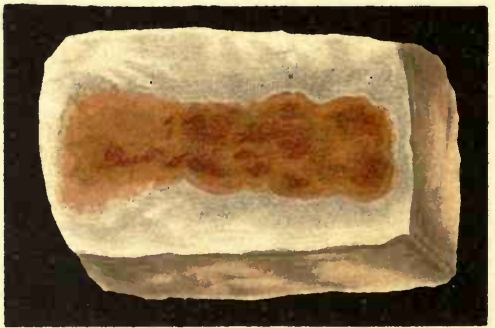

IX.

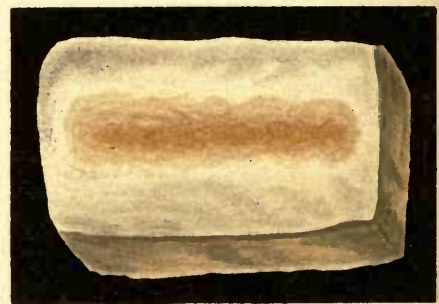


PLATE 57.

Corynebacterium mallei. (Löffler.) L. and N. (Glanders.)

I. Gelatin stab culture, six days at $22^{\circ}$.

II. Agar streak culture, six days at $37^{\circ}$. The central whitish streak is not always so pronounced.

III. Agar stab culture, three days at $37^{\circ}$. Stab canal.

IV. Agar stab culture, three days at $37^{\circ}$. Surface growth.

V. Gelatin plate, five days at $22^{\circ}$. Natural size.

VI. Microscopic preparation. Pure culture. $\times 800$. Stained with fuchsin.

VII. Agar plate, two days at $22^{\circ} . \quad \times 60$. Upper, superficial; lower, deep colonies.

VIII. Gelatin plate, four days at $22^{\circ} . \times 60$. Upper colony superficial, lower ones deep.

IX. Potato culture, two days at $37^{\circ}$.

X. Potato culture, twenty days at $37^{\circ}$.

XI. Single bacteria. Highly magnified. In many places the stain is taken poorly or not at all.

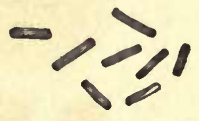

XI.

XII. Glycerin-agar plate. Microscopic preparation. $\times 1200$. Branching and formation of clubs.
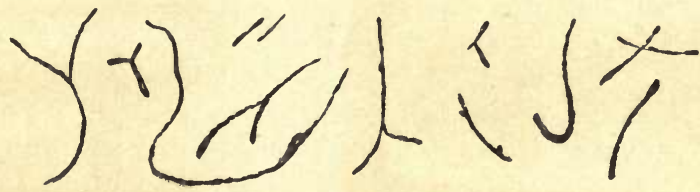

XII. 
PLATE 58.

Corynebacterium diphtheriæ. and $\mathrm{N}$.

(Klebs, Löffler.) L.

Corynebacterium pseudodiphtheriticum. (HofmannWellenhof.) Lehm. and Neum.

\section{Corynebacterium xerosis. \\ (Kuschbert, Neisser.)}

Lehm. and Neum.

I. Coryneb. diphtheriæ. Glycerin-agar streak culture, three days at $37^{\circ}$. Luxuriant growth; culture moist.

II. Coryneb. diphtheriæ. Glycerin-agar streak culture, three days at $37^{\circ}$. Delicate growth.

III. Coryneb. pseudodiphtherit. Glycerin-agar streak culture, three days at $37^{\circ}$. Luxuriant growth, culture moist.

IV. Coryneb. xerosis. Glycerin-agar streak culture, three days at $37^{\circ}$. Delicate growth; growth dry and dull.

V. Coryneb. pseudodiphtherit. Glycerin-agar stab culture. Surface growth, ten days at $37^{\circ}$. The culture is reproduced on account of its atypical brown color.

VI. Coryneb. diphtheriæ. Gelatin stab culture. Surface growth, ten days at $22^{\circ}$. The color fluctuates from white to dirty yellowish.

VII. Coryneb. diphtheriæ :

(a) Glycerin-agar plate. Colonies upon the surface, three

Natural days at $37^{\circ}$. Luxuriant growth. The same culture

size. as $\mathrm{I}$.

(b) Glycerin-agar plate. Colonies upon the surface, three days at $37^{\circ}$. Delicate growth. The same culture as II.

VIII a. Coryneb. pseudodiphtherit. Glycerin-agar plate, Colonies lying upon the surface, three days at $37^{\circ}$. Natural size. Luxuriant growth. Answers to culture III.

VIII b. Coryneb. xerosis. Glycerin-agar plate. Colonies lying upon the surface, three days at $37^{\circ}$. Natural size. Dry, dull growth. Answers to culture IV.

VIII c. Coryneb. xerosis. Glycerin-agar plate. Colonies lying upon the surface, three days at $37^{\circ}$. Natural size. Delicate growth. Sometimes it may be still more delicate.

IX. Coryneb. diphtheriæ. Potato culture, ten days at $22^{\circ}$. The growth is typical, like a delicate veil, which in many places leaves no trace on the potato.

X. Coryneb. pseudodiphtherit. Potato culture, ten days at $22^{\circ}$. The growth is sharply outlined, white to dirty yellowish. 
Tab. 58.
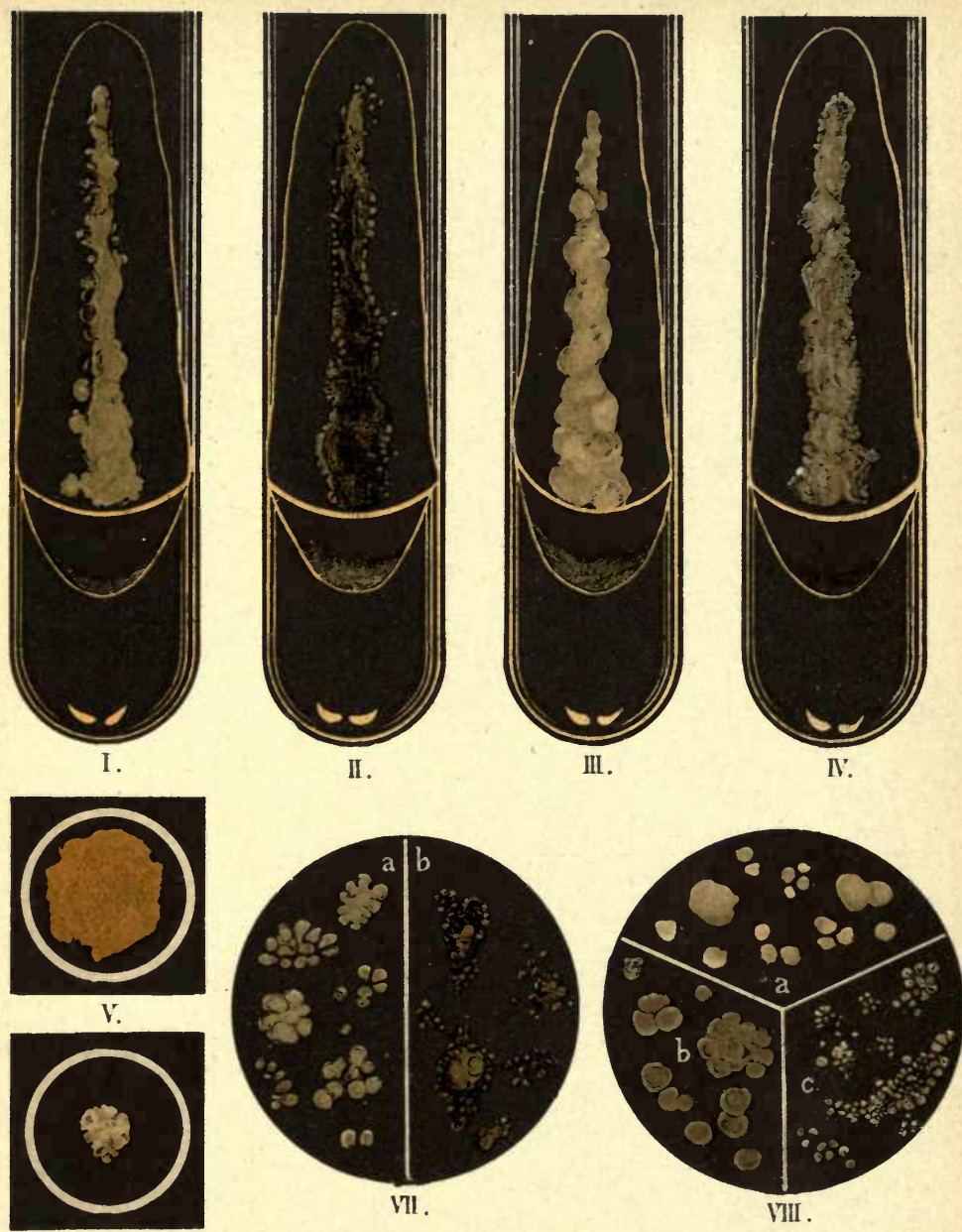

II.

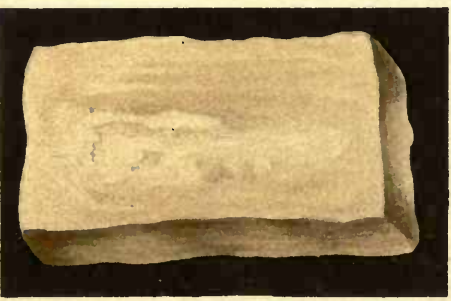

IX.

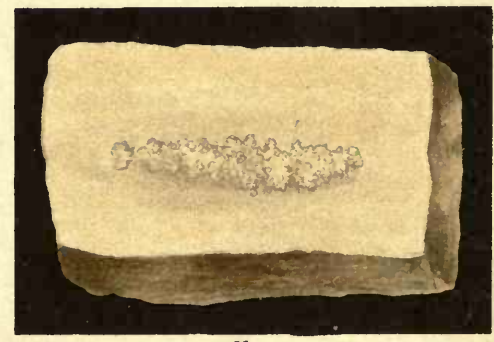




Tab. 59.

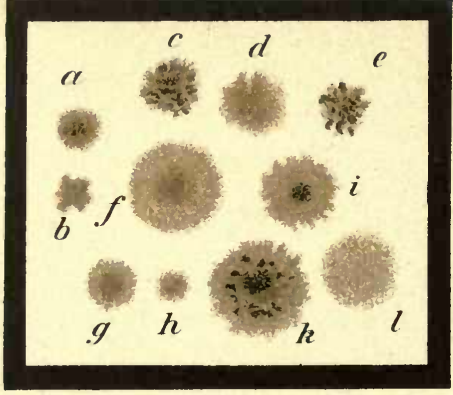

I.

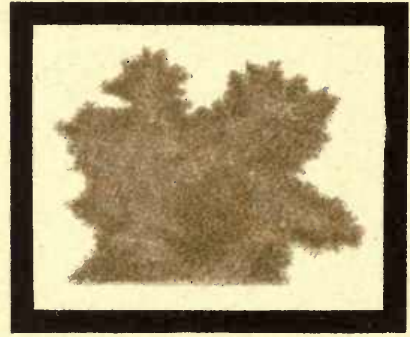

III.

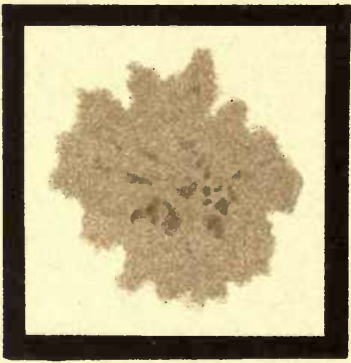

V.

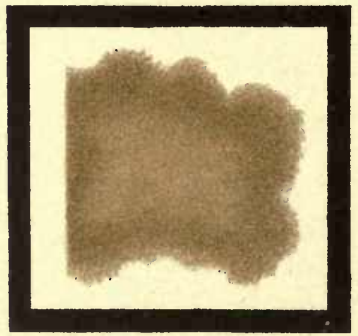

III.

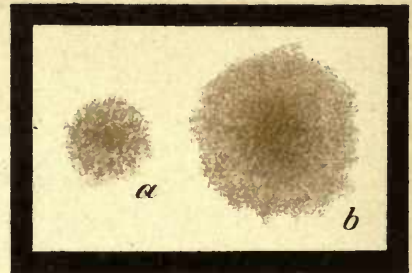

II.

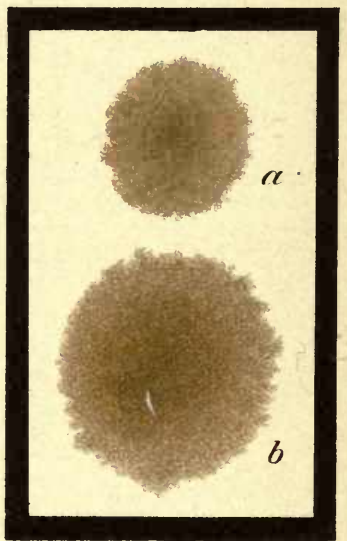

IV.

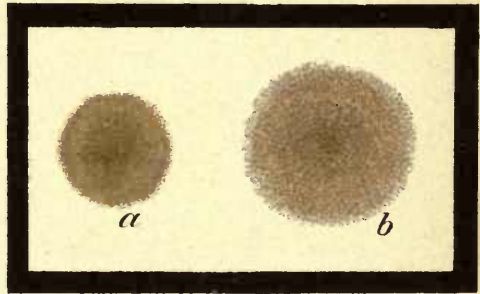

IT.

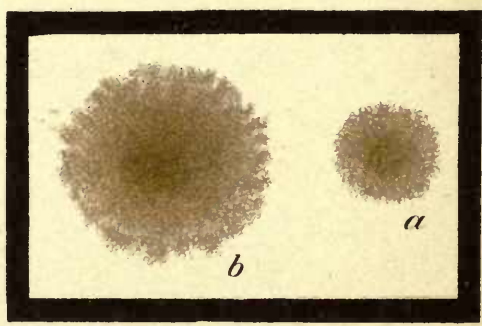

VIII . 


\section{PLATE 59.}

Corynebacterium diphtheriæ.

$$
\text { L. and } \mathrm{N} \text {. }
$$

(Klebs, Löffler.)

Corynebacterium pseudodiphtheriticum.

(HofmannWellenhof.) Lehm. and Neum.

Corynebacterium xerosis.

Lehm. and Neum.

I. Coryneb. diphtheriæ. Plate cultures (Ascitesfluid-agar and glycerin-agar). $\times 60$. Superficial colonies, twenty-four hours at $37^{\circ}$. Cultures of different origin.

II. Coryneb. diphtheriæ. Plate culture (glycerinagar). $\times 60$. Superficial colonies, forty-eight hours at $37^{\circ}$. The same culture as I, $g, h$.

III. Coryneb. diphtheriæ. Plate culture (ascitesfluid-agar). $\times 60$. Superficial colony, five days at $37^{\circ}$. The same culture as I, $c, e$, and Plate 58, II.

IV. Coryneb. Fseudodiphtherit. Plate culture (glycerin-agar). $\times 60$. Superficial colonies, forty-eight hours at $37^{\circ}$. The same culture as Plate 58, III.

V. Coryneb. xerosis. Plate culture (glycerin-agar). $\times 60$. Superficial colony, forty-eight hours, at $37^{\circ}$. Dry, dull, and very opaque. The same culture as Plate 58, Iv, VIII $b$.

VI. Coryneb. diphtheriæ. Plate culture (ascitesfluid-agar). $\times 60$. Superficial colonies, forty-eight hours at $37^{\circ}$. The same culture as I, $f, l$, and Plate 58, I, vir a.

VII. Coryneb. diphtheriæ. Plate culture. The same as VI, but ten days old.

VIII. Coryneb. xerosis. Plate culture (glycerin-agar). $\times 60$. Superficial colonies, forty-eight hours at $37^{\circ}$. The same culture as Plate 58, viII c. 
Corynebacterium diphtheriæ (Klebs, Löffler). L. and N. Corynebacterium pseudodiphtheriticum. Wellenhof.) Lehm. and Neum.

(HofmannCorynebacterium xerosis (Kuschbert, Neisser). Lehm. and Neum.

I. Coryneb. diphtheriæ. Glycerin-agar, forty-eight hours at $37^{\circ}$. $\times 1000$. Stained with fuchsin. Corresponds to Plate 58, II, vII $\mathrm{b}$; and Plate 59, II.

II. Coryneb. diphtheriæ. Glycerin-agar, forty-eight hours at $37^{\circ}$. $\times 1000$. Stained with fuchsin. Corresponds to Plate 58, I, viI a; and Plate 59, vi.

III. Coryneb. diphtheriæ. Glycerin-agar, forty-eight hours at $37^{\circ}$. $\times 1000$. Stained with fuchsin.

IV. Coryneb. diphtheriæ. Glycerin-agar, forty-eight hours at $37^{\circ} . \times 1000 . \quad$ Stained with fuchsin.

V. Coryneb. pseudodiphtherit. Glycerin-agar, forty-eight hours at $37^{\circ} . \times 1000$. Stained with fuchsin.

VI. Coryneb. pseudodiphtherit. Glycerin-agar, forty-eight hours at $37^{\circ} . \times 1000$. Stained with fuchsin. Corresponds to Plate 58, III, virI a; Plate 59, I, IV.

VII. Coryneb. xerosis. Glycerin-agar, forty-eight hours at $37^{\circ}$. $\times 1000$. Stained with fuchsin. Corresponds to Plate 58, Iv, viII b; and Plate 59, v.

VIII. Coryneb. xerosis. Glycerin-agar, forty-eight hours at $37^{\circ} . \times 1000$. Stained with fuchsin.

IX. Coryneb. xerosis. Glycerin-agar, forty-eight hours at $37^{\circ}$. $\times 1000$. Stained with fuchsin. Corresponds to Plate 58, virI c.

X. Coryneb. diphtheriæ. Bovine blood-serum, solidified at $100^{\circ}$, eighteen hours at $35^{\circ} . \times 1000$. Staining of Neisser's granules. The polar staining is characteristic. Corresponds to figure $\mathbf{I}$.

XI. Coryneb. pseudodiphtherit. Bovine blood-serum, solidified at $100^{\circ}$, eighteen hours at $35^{\circ} . \times 1000$. Staining of Neisser's granules. These occur also in many varieties of pseudodiphtheria, but not with such regularity at both poles.

XII. Coryneb. diphtheriæ. Glycerin-agar, four days at $37^{\circ}$. $\times 1000$. Stained with fuchsin. True branching.

XIII. Coryneb. diphtheriæ. Single organisms, highly magnified, schematic.

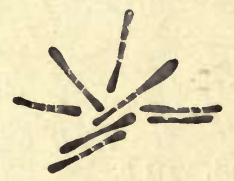

XIII. 

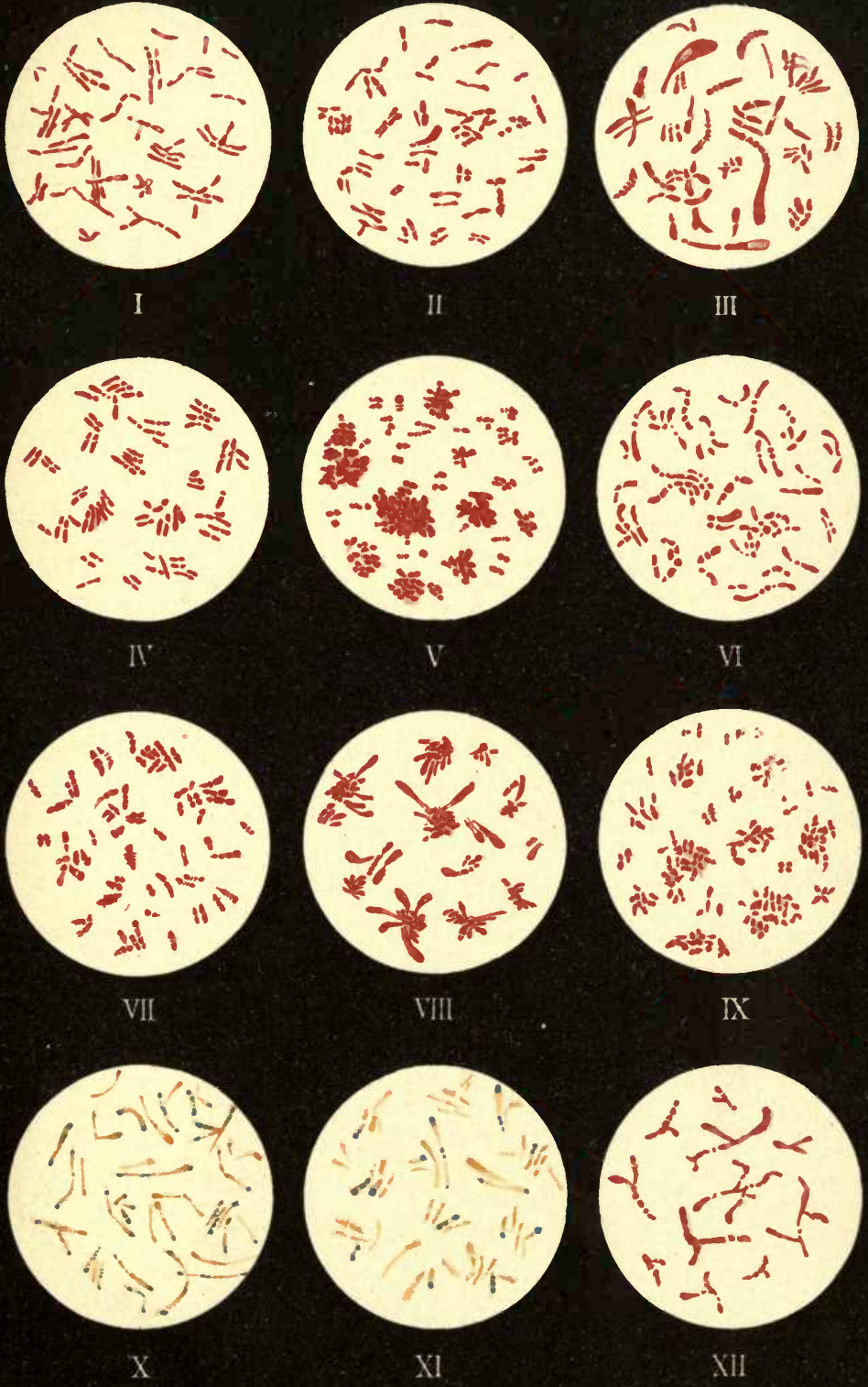


Tab. 61 .
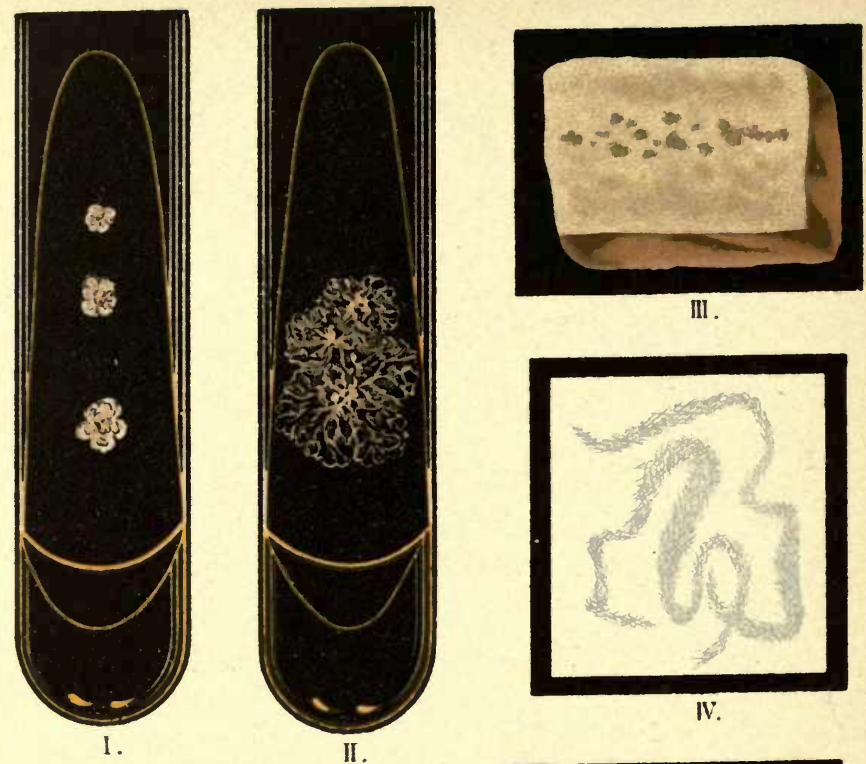

III.

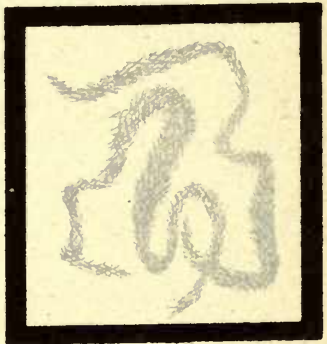

IV.

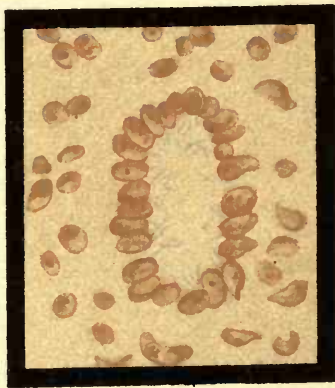

VI.

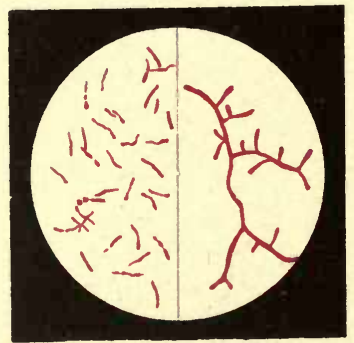

VII.

VIII.

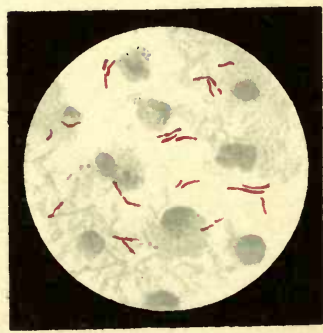

LX. 


\section{PLATE 6r.}

Mycobacterium tuberculosis (Koch). Lehm. and Neum. (Tubercle Bacillus.)

I. Glycerin-agar streak culture, fourteen days at $37^{\circ}$.

II. Glycerin-agar streak culture, forty days at $37^{\circ}$.

III. Potato culture, forty days at $37^{\circ}$.

IV. Colonies of tubercle bacilli from a blood-serum culture. $\times 700$. (Copied after R. Koch, Aetiologie der Tuberkulose. Mitteilungen des Kaiserl. Gesundheitsamt, Bd. 2, Taf. Ix, 44.)

V. Culture, upon blood-serum, from a piece of a freshly extirpated scrofulous gland. (Copied like the above, Bd. 2, Taf. Ix, 44.)

VI. Giant cell with radially arranged bacilli. From a caseous bronchial gland in a case of miliary tuberculosis. (Copied like above, Bd. 2, Taf. II, 9.)

VII. Microscopic preparation. Pure culture, stained according to Ziehl. $\times 1000$.

VIII. Branching of tubercle bacilli. (Copied after Hayo Bruns, C. B. XvII, No. 23.)

IX. Microscopic preparation. Sputum, stained according to Ziehl. $\times 1000$.

X. Single bacteria, highly magnified.

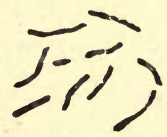

$\mathrm{X}$. 
PLATE 62.

Mycobacterium lepræ. (Arm. Hansen.) Lehm. and Neum.

I. Giant cell from a leprous ulcer of the epiglottis. $\times$ about 1000. Stained according to Rusell. (Copied from Seifert and Kahn, Atlas der Histopathologie der Nase, 1875, Taf. 38, Fig. 75 b.)

II. Transverse section of a blood-vessel in a leprous testicle. Bacilli in endothelium and in a white blood-corpuscle. Stained by Gram's method, Bismarck brown, eosin, oil of bergamot. $\quad \times$ about 1000. (Copied as No. III, fig. v.)

III. Ulnar nerve, longitudinal section, stained like above. (Copied from Lie, pathologische Anatomie der Lepra; Archiv für Dermatologie und Syphilis, Bd. xxıx, 1895, Taf. vI, Fig. viI.)

IV. Smear preparation from nasal mucus. Stained by method for tubercle bacillus. From a preparation of Dr. Dieudonné. $\times 1000$.

Mycobacterium tuberculosis $\gamma$ piscicola. L. and N.

V. Streak culture (glycerin-agar), one month old at $22^{\circ}$.

VI. Plate culture (glycerin-agar), ten days at $22^{\circ}$. Natural size. Superficial colonies.

VII. Plate culture (glycerin-agar), six days at $22^{\circ} . \quad \times$ 60. Superficial colony. The dark shadows and bright lights represent the strong reflection of the cartilaginous colony.

VIII. Potato culture, fourteen days at $22^{\circ}$. Sometimes also more homogeneous upon the surface.

IX. Microscopic preparation. Stained by the method for the tubercle bacillus. $\times 1000$. 
Táb. 62 .

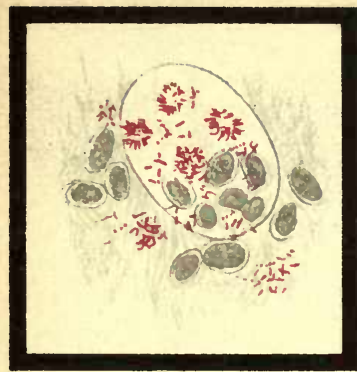

1.

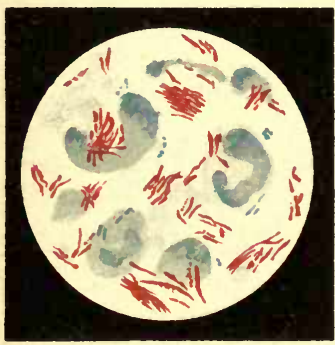

IV.

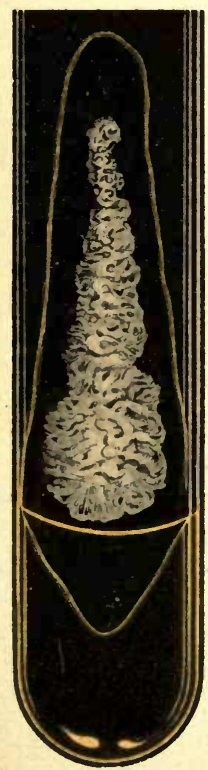

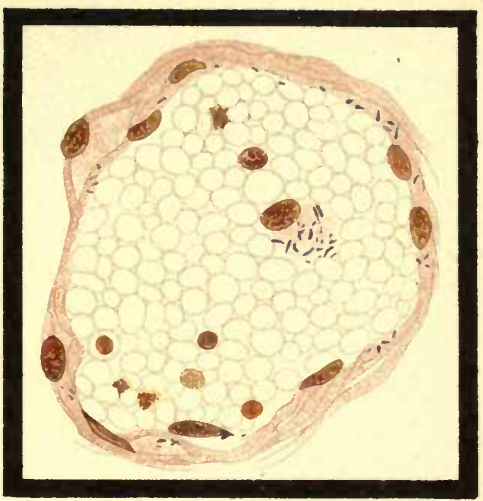

II

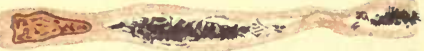

III

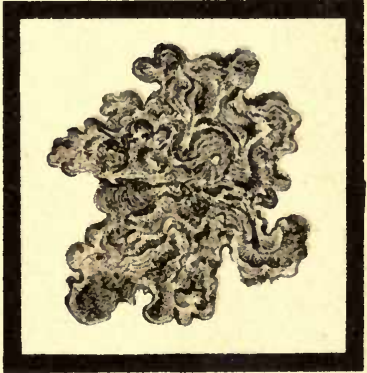

VII
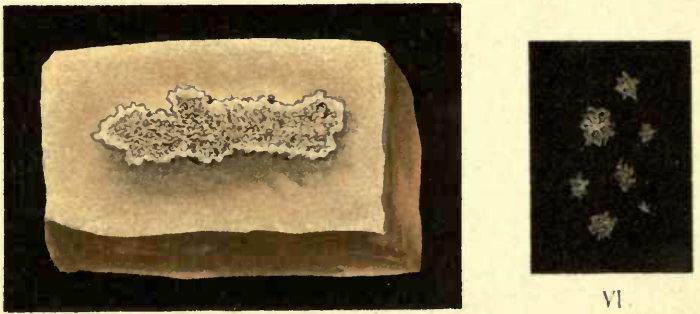

VI

\section{Iill}




Tab. 63.
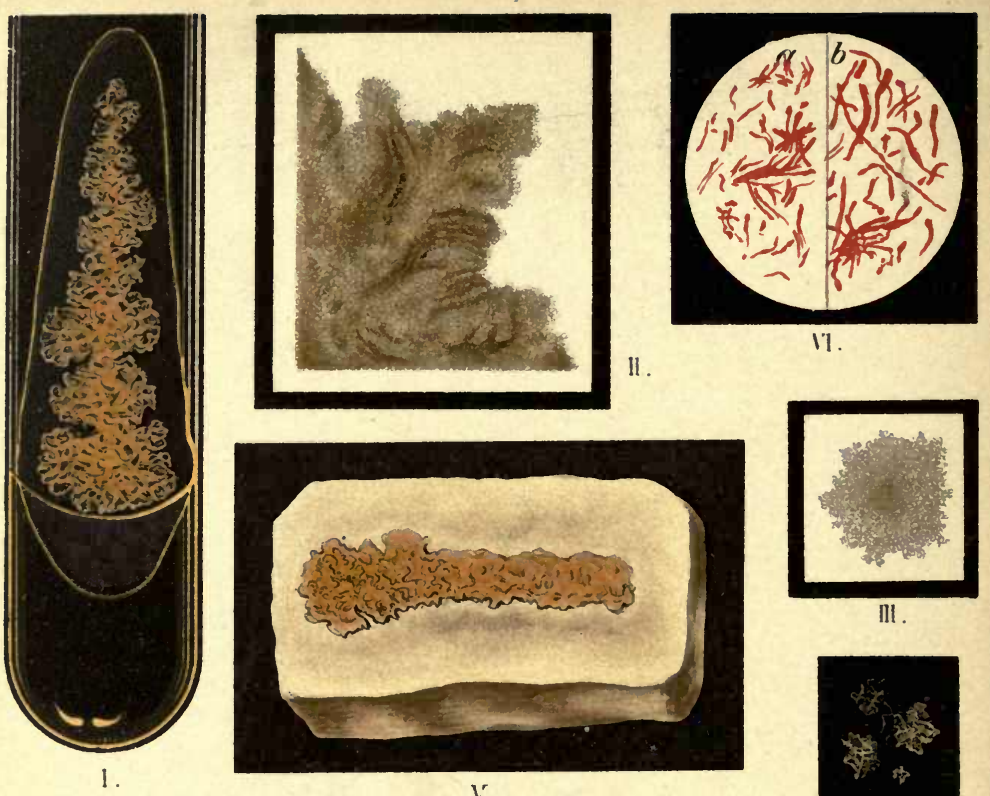

11.
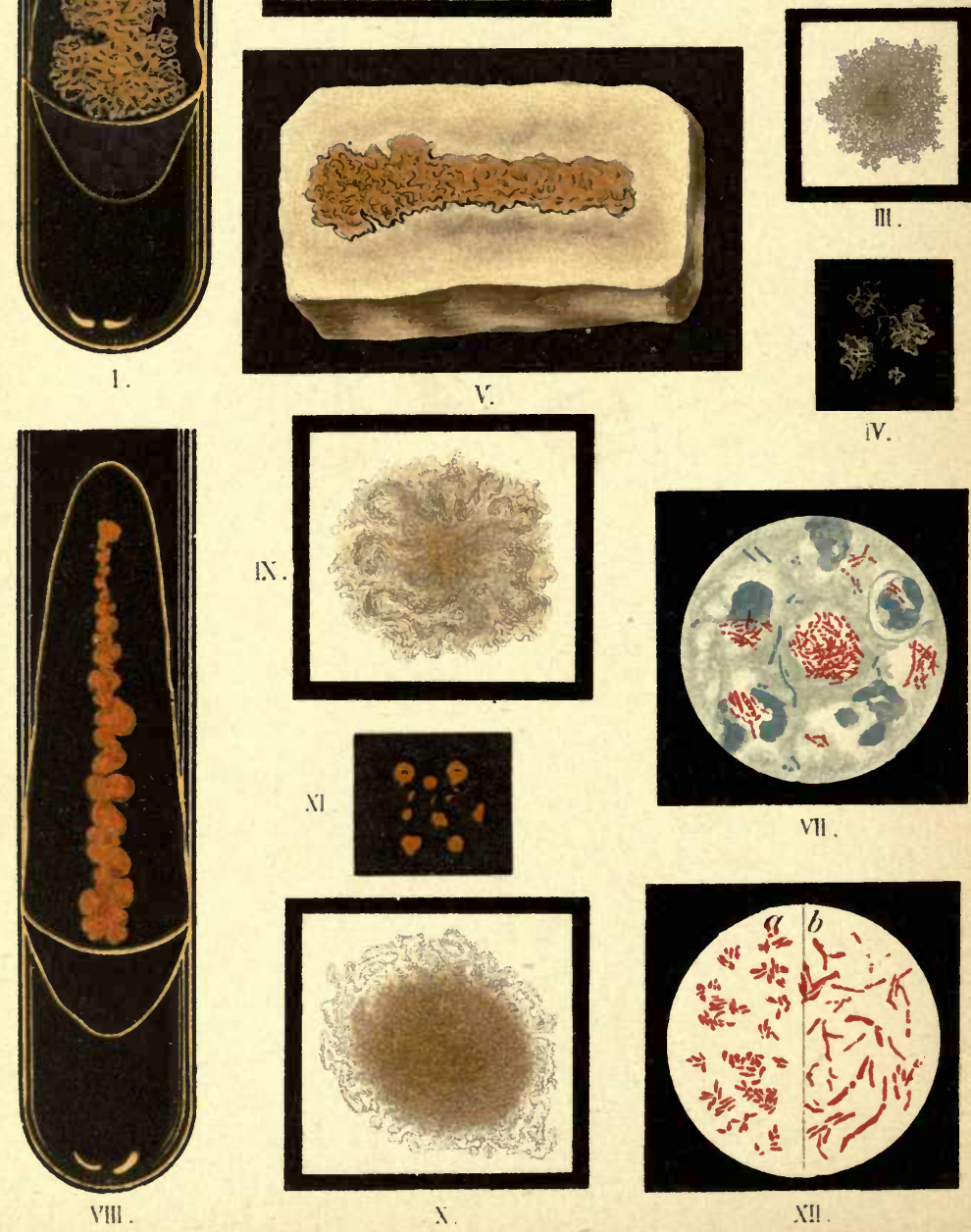

III.

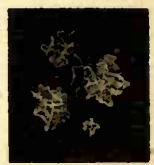

iv.

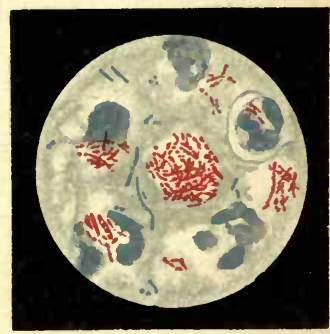

VII.

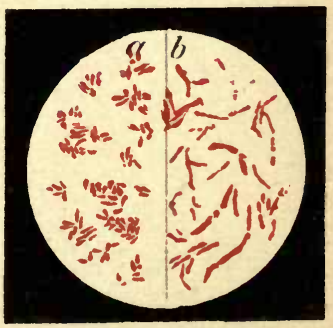




\section{PLATE 63.}

Mycobacterium lacticola $\beta$ perrugosum. L. and N.

I. Streak culture (glycerin-agar), two months old; three days at $37^{\circ}$, then at $22^{\circ}$. Much elevated and wrinkled.

II. Plate culture (glycerin-agar), six days at $37^{\circ}$. $\times$ 60. Superficial colony.

III. Plate culture (glycerin-agar), forty-eight hours at $37^{\circ} . \times 60$. Superficial colony.

IV. Plate culture (glycerin-agar), three days at $37^{\circ}$. Natural size. Superficial colonies. Later the same were larger, more wrinkled, and reddish.

V. Potato culture, six days at $22^{\circ}$. Later the same became still more wrinkled.

VI. Microscopic preparation. Glycerin-agar: (a) Three days at $37^{\circ} . \times 1000$. Stained with fuchsin. (b) Two months at $22^{\circ} . \quad \times 1000$. Stained with fuchsin.

VII. Microscopic preparation. Smear from the peritoneal fluid of a guinea-pig, inoculated with butter. $\times 1000$. Stained with tubercle bacillus stain. (From a preparation of Dr. Dieudonné.)

Mycobacterium phlei. Lehm. and Neum.

VIII. Streak culture (glycerin-agar), eight days at $22^{\circ}$. The culture at first is pale orange; later, it becomes darker and wrinkled.

IX. Plate culture (glycerin-agar), three days at $22^{\circ}$. $\times 60$. Superficial colony.

$\mathrm{X}$. Plate culture (glycerin-agar), eight days at $22^{\circ}$. $\times 60$. Superficial colony.

XI. Plate culture (glycerin-agar), eight days at $22^{\circ}$. Natural size. Superficial colonies.

XII. Microscopic preparation. Glycerin-agar: (a) Three days at $37^{\circ} . \times 1000$. Stained with fuchsin. (b) Two months at $22^{\circ} . \times 1000$. Stained with fuchsin. 


\section{PLATE 64.}

Mycobacterium lacticola $a$ planum. L. and N.

I. Streak culture (ordinary agar), two months at $22^{\circ}$.

II. Streak culture (glycerin-agar), six days at $37^{\circ}$.

III. Streak culture (glycerin-agar), three months at $22^{\circ}$. The culture at first is whitish; later, it becomes very intensely orange-red.

IV. Streak culture (gelatin), six days at $22^{\circ}$.

V. Potato culture, six days at $22^{\circ}$. Its appearance varies widely. Sometimes it is lighter, sometimes darker, sometimes moister, sometimes drier, sometimes smooth, sometimes wrinkled.

VI. Plate culture (gelatin), six days at $22^{\circ} . \times 60$. (a) Superficial colony, resembling the colon; $(b)$ deep colony.

VII. Plate culture (gelatin), six days at $22^{\circ}$. Natural size.

VIII. Plate culture (glycerin-agar), three days at $37^{\circ}$. $\times 60$. Superficial colony.

IX. Plate culture (glycerin-agar), three days at $37^{\circ}$. Natural size.

X. Microscopic preparation. Glycerin-agar, three days. $\times 1000$. Stained with fuchsin. The size of the rods scarcely varies in very old cultures. There as here are found small and large, slender and thick rods. 
Tab. 64 .
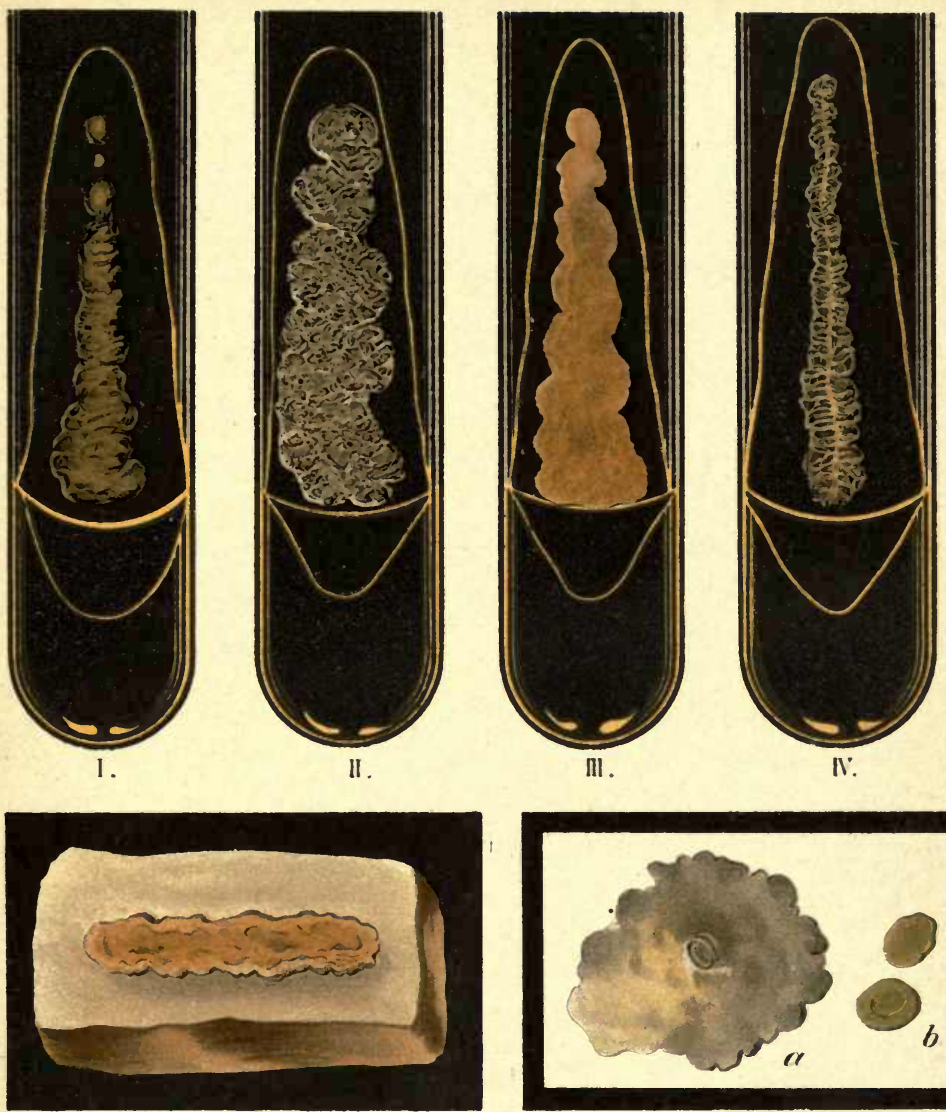

V.

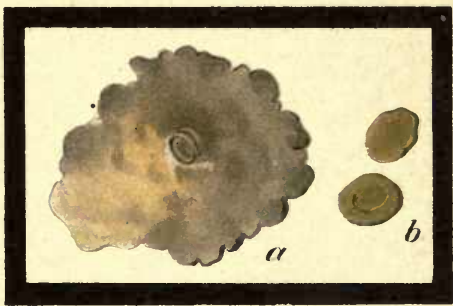

17.

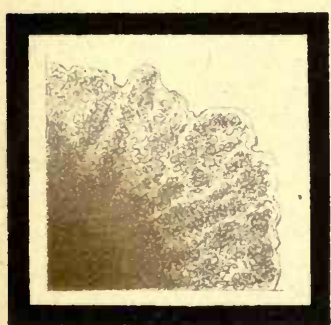

VIII.

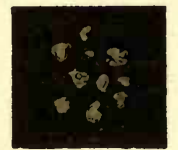

VII.

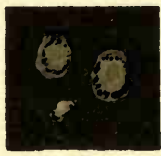

IX.

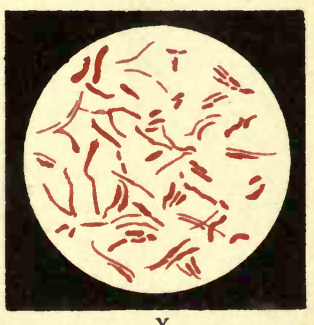

X 

Tab. 65.
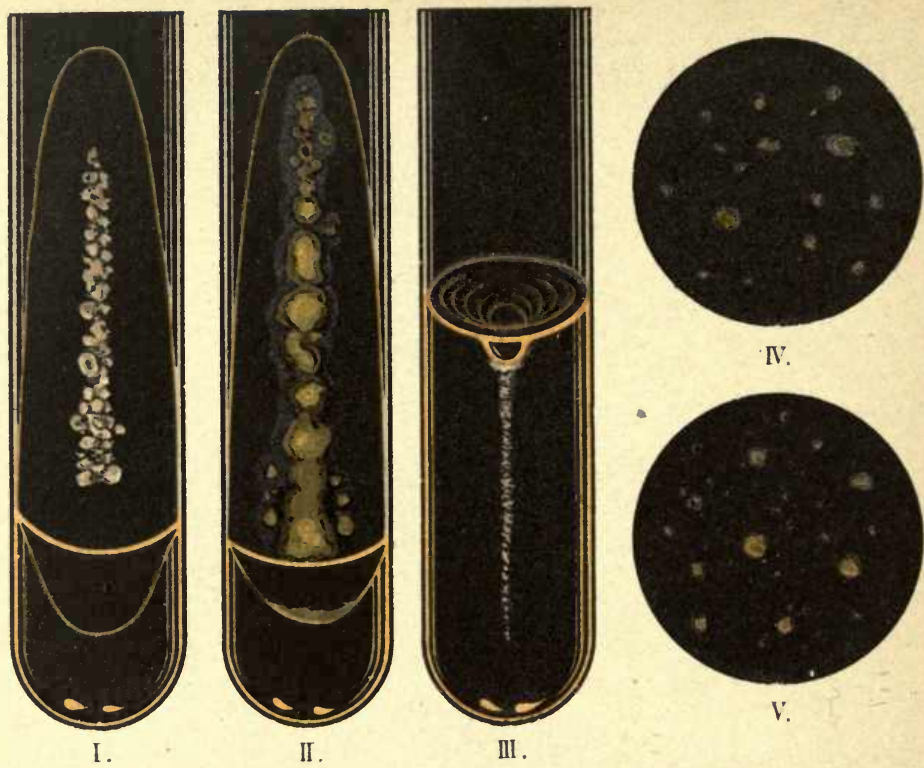

IV.
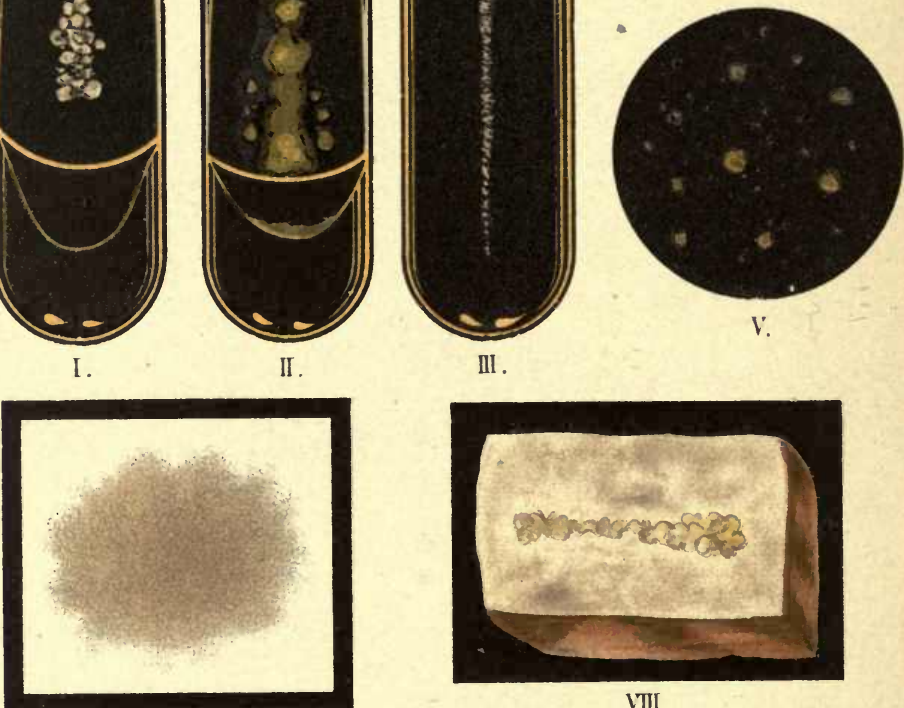

VI.

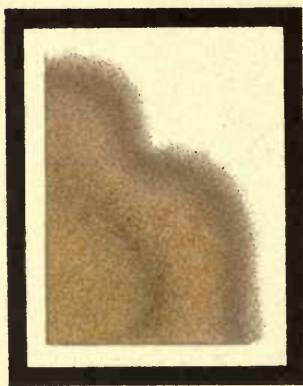

V71.

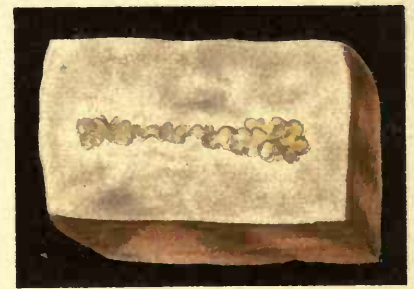

VIII .

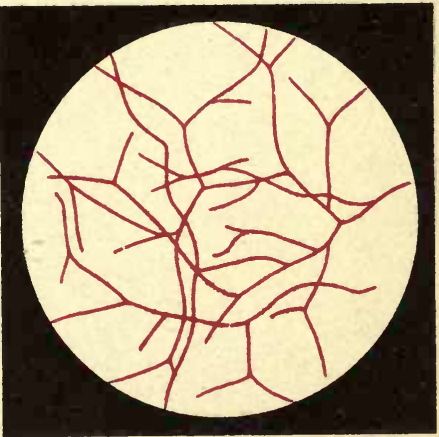

IX. 
PLATE 65.

\section{Actinomyces bovis. Harz.}

I. Agar streak culture, six days at $37^{\circ}$.

II. Agar streak culture, thirty days at $37^{\circ}$.

III. Gelatin stab culture, fourteen days at $22^{\circ}$.

IV. Gelatin plate, six days at $22^{\circ}$. Natural size.

V. Agar plate, six days at $37^{\circ}$. Natural size.

VI. Agar plate, six days at $37^{\circ} . \times 60$. Superficial and deep colony.

VII. Gelatin plate, six days at $22^{\circ} . \times 60$. Superficial and deep colony.

VIII. Potato culture, ten days at $37^{\circ}$. Natural size.

IX. Microscopic preparation. Pure culture in bouillon, three days at $37^{\circ} . \times 1000$. Stained with fuchsin. 
PLATE 66.

Actinomyces farcinicus. (Nocard.) Gasperini.

(Farcin du bœuf.)

I. Agar streak culture, eight days at $22^{\circ}$.

II. Gelatin stab culture, twelve days at $22^{\circ}$.

III. Agar stab culture, eight days at $22^{\circ}$. Stab canal.

IV. Agar stab culture, elght days at $22^{\circ}$. Surface growth.

V. Gelatin plate, ten days at $22^{\circ}$. Natural size.

VI. Gelatin plate, ten days at $22^{\circ} . \quad \times 60$. Superficial and deep colonies which are similar.

VII. Agar plate, six days at $22^{\circ}$. Natural size.

VIII. Agar plate, eight days at $22^{\circ}$. Upper colony superficial, lower ones deep.

IX. Potato culture, seven days at $22^{\circ}$. Natural size.

X. Microscopic preparation. Pure culture in bouillon, two days. $\times 800$. Stained with fuchsin. 
Tab. 66 .
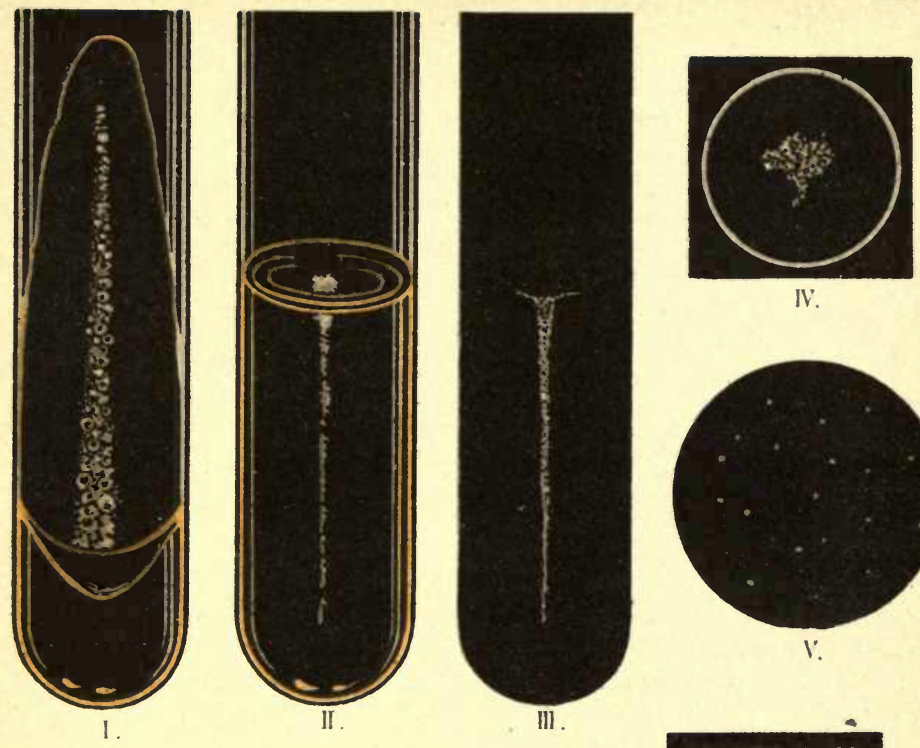

IV.
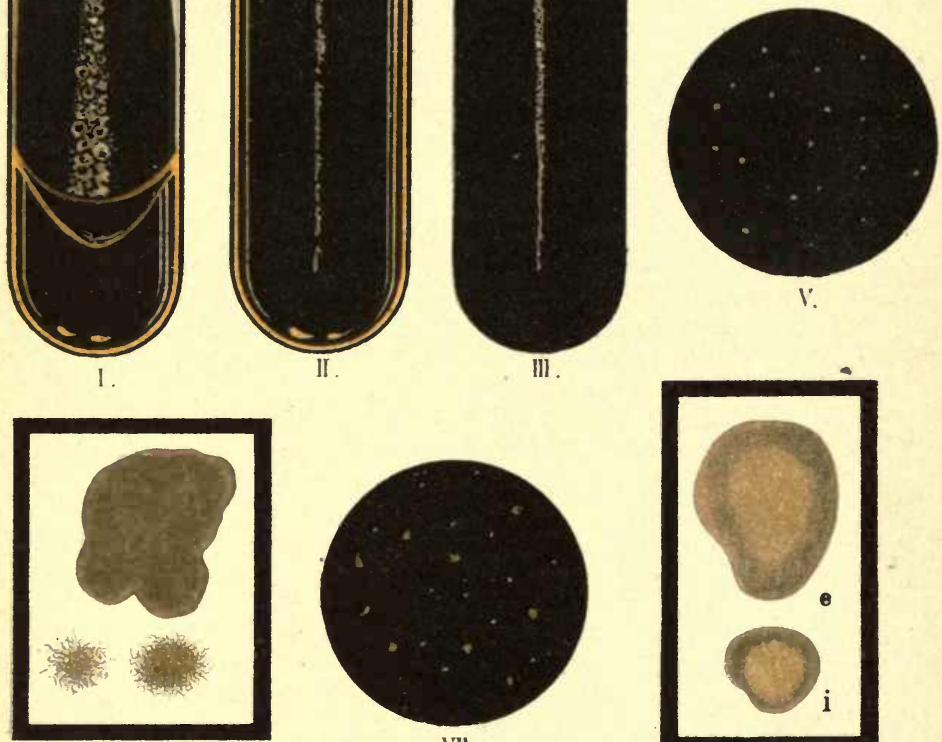

VIII
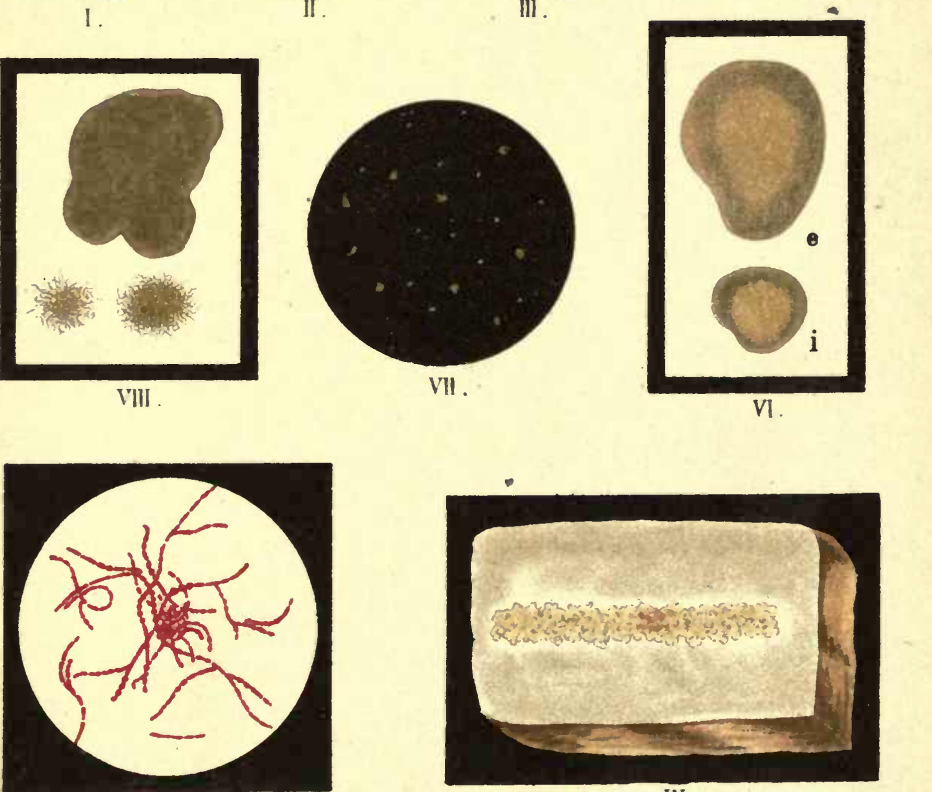

X.

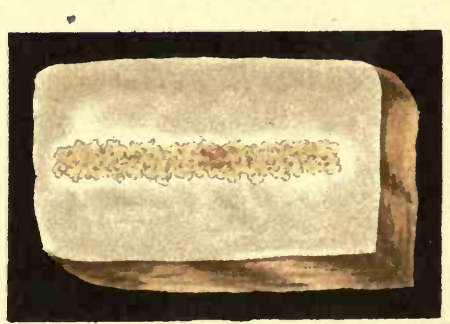

IX. 


Tab. 67.
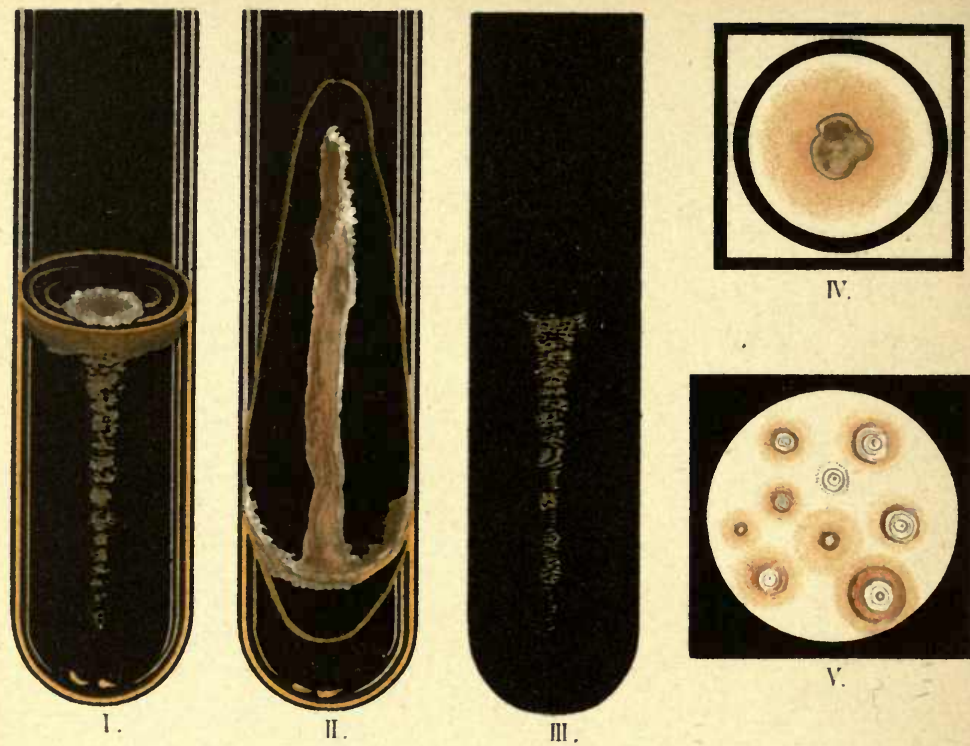

N.

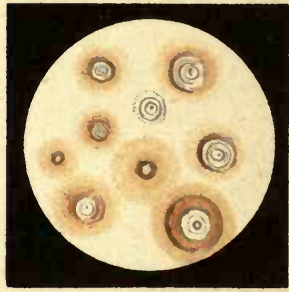

V.
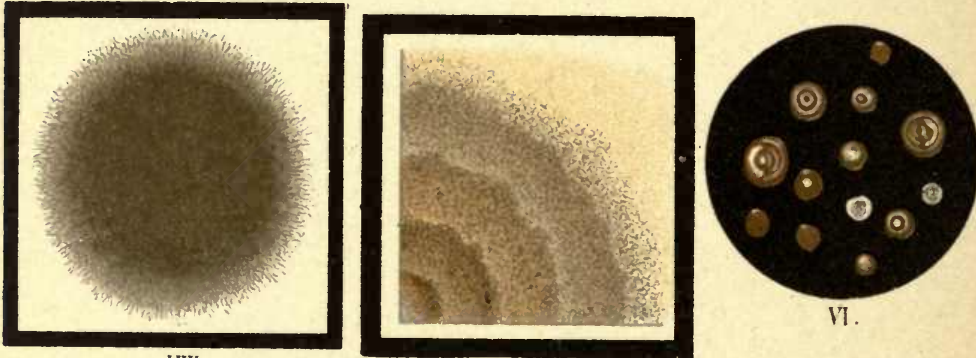

VIII

171.

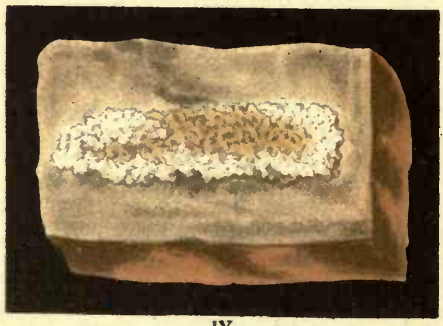

IX

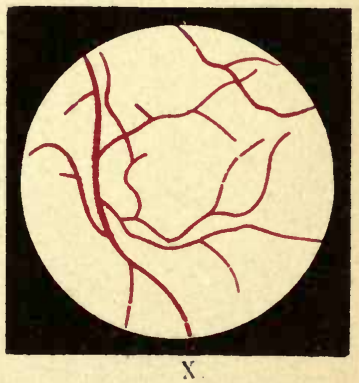




\section{PLATE 67.}

\section{Actinomyces chromogenes. Gasperini.}

I. Gelatin stab culture, six days at $22^{\circ}$.

II. Agar streak culture, six days at $22^{\circ}$.

III. Agar stab culture, six days at $22^{\circ}$. Stab canal.

IV. Agar stab culture, six days at $22^{\circ}$. Surface growth.

V. Gelatin plate, eight days at $22^{\circ}$. Natural size. Appearance upon white background.

VI. Gelatin plate, eight days at $22^{\circ}$. Natural size. Appearance upon dark background.

VII. Gelatin plate, eight days at $22^{\circ} . \times 60$. Part of a superficial colony.

VIII. Agar plate, four days at $22^{\circ} . \times 60$. Superficial and deep colony.

IX. Potato culture, three days at $22^{\circ}$. Natural size.

X. Microscopic preparation. Pure culture in bouillon, three days at $22^{\circ} . \quad X$ about 1000 . Stained with fuchsin. 


\section{PLATE 68. \\ Varia.}

I. Bacterium tussis convulsivæ L. and N. From mucus, coughed up by a child with whooping-cough. $\times$ 1000. Ordinary fuchsin stain.

II. Bact. ulceris cancrosi (Kruse) L. and N. Section of an untreated soft ulcer of twelve days' duration. Stained according to Unna. (Copied from Peterson, über Bacillenfund bei Ulcus molle, C. B. xiIr, Tafel 4.)

III. Streptococcus meningitidis cerebrospinalis (Weichselbaum). Lehm. and Neum. Smear preparation from meningeal exudate. Pus cells with flattened diplococci. (Copied after Jäger, Zeitschrift für Hygiene, Bd. 19, Tafel vi, Fig. 3.) $\times 1000$.

IV. Streptococcus meningitidis cerebrospinalis. Pure culture, grown from cerebrospinal fluid. $\times 1000$.

V. Bacterium influenzæ ( $R$. Pfeiffer) Lehm. and Neum. Smear preparation from nasal secretion. $\times 1000$. Stained with fuchsin.

\section{Bacillus gangrænæ pulpæ. Arkövy.}

VI. Gelatin stab culture, ten days at $22^{\circ}$. The little hairs along the stab canal often become much longer.

VII. Agar plate, three days at $37^{\circ}$. Natural size. Superficial colonies.

VIII. Potato culture, ten days at $22^{\circ}$. The wrinkling of the surface suggests the culture of the mesentericus.

IX. Microscopic preparation. $\times 1000$. Stained with fuchsin. Before spore-formation. 
Tab. 68 .

1.
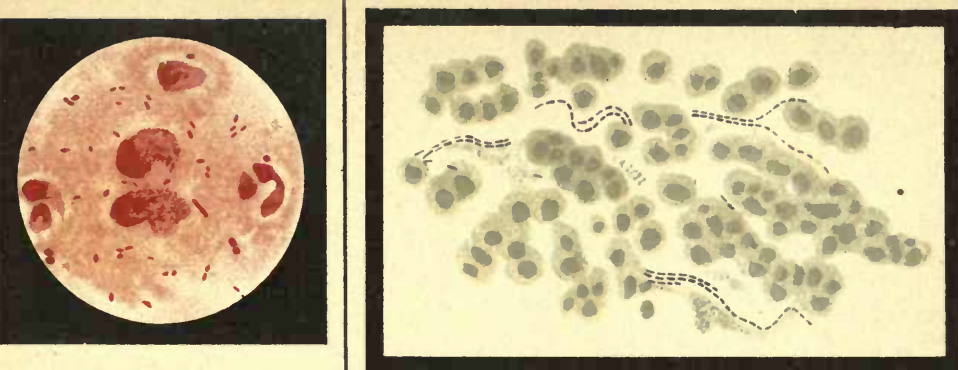

II.
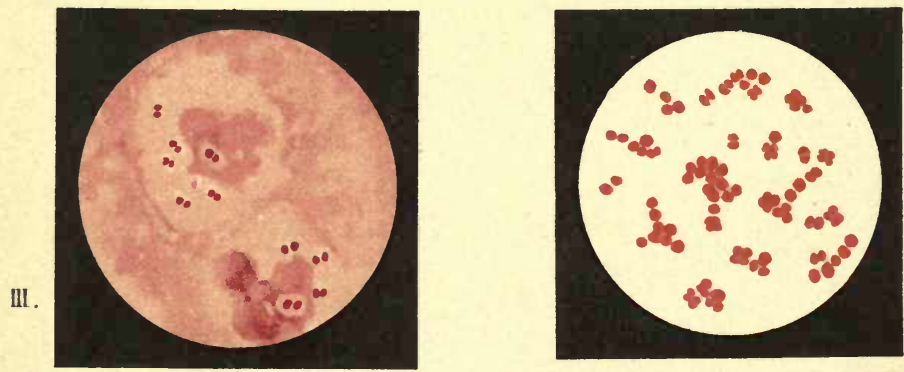

IV.

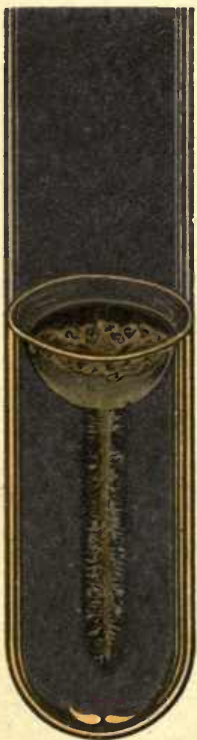

II.

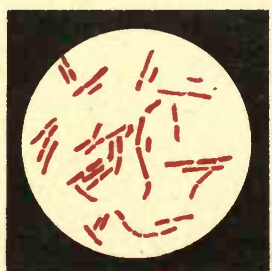

IX.

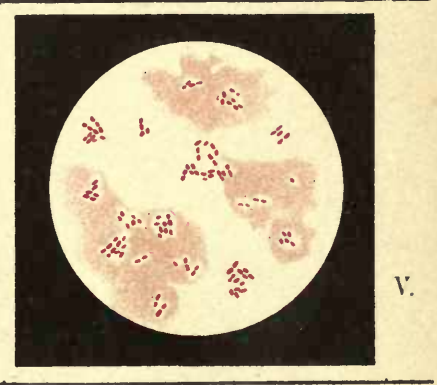

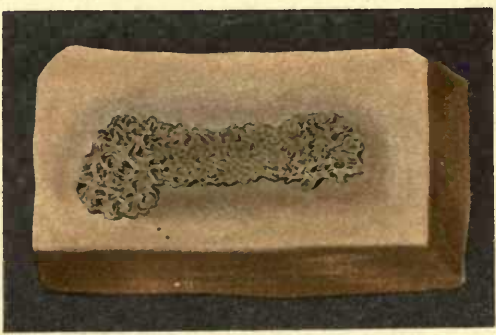

ITII .

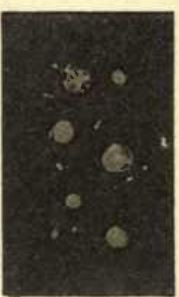

I7I. 


Tab. 69 .
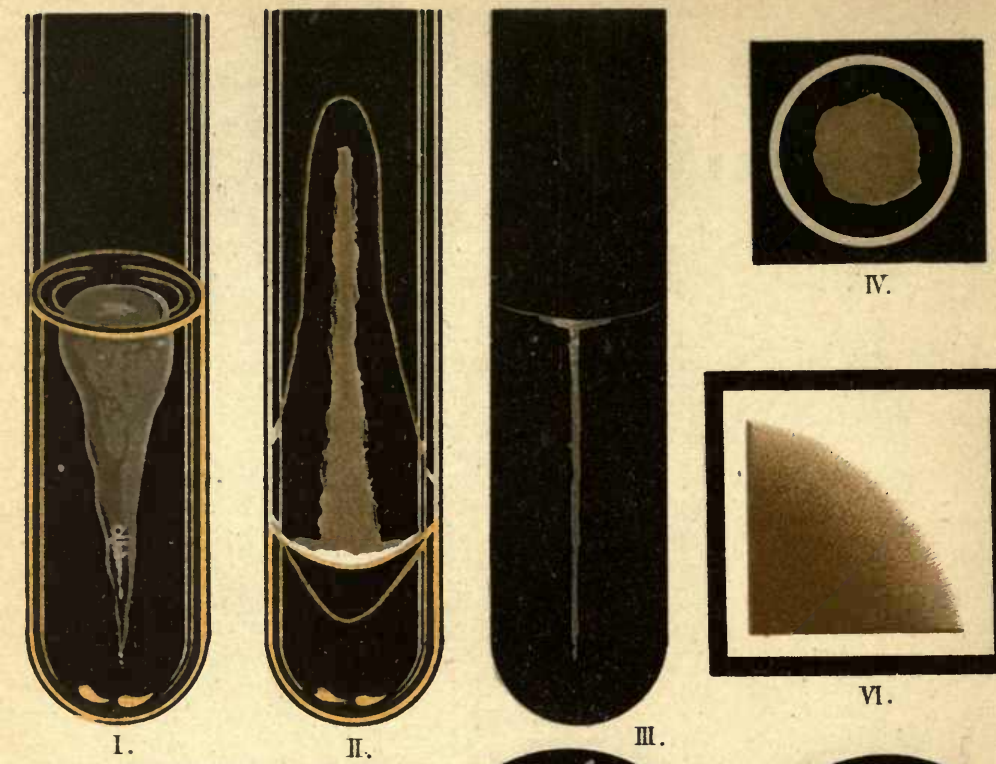

N.

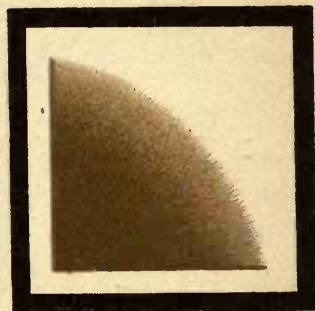

VI.
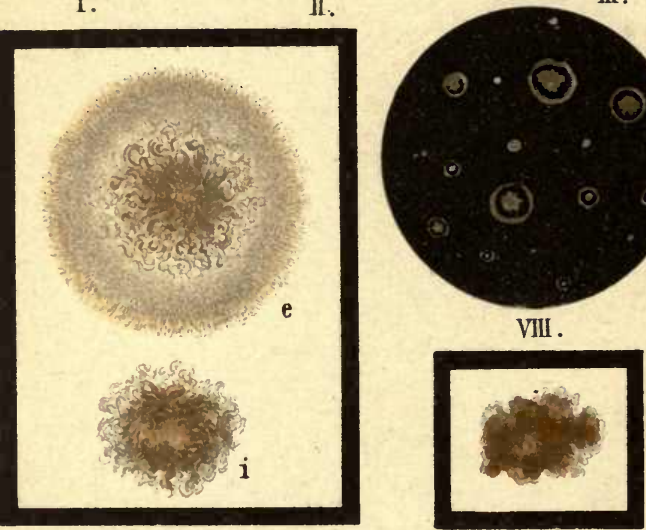

IX.

VII
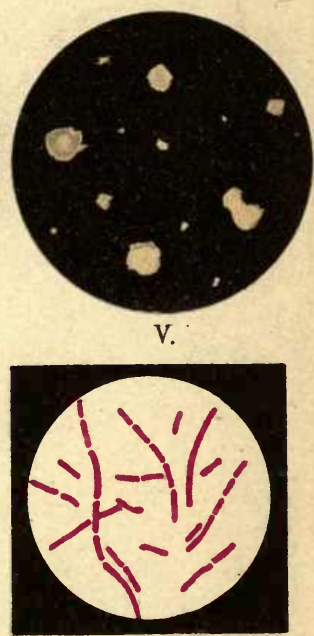

XI.
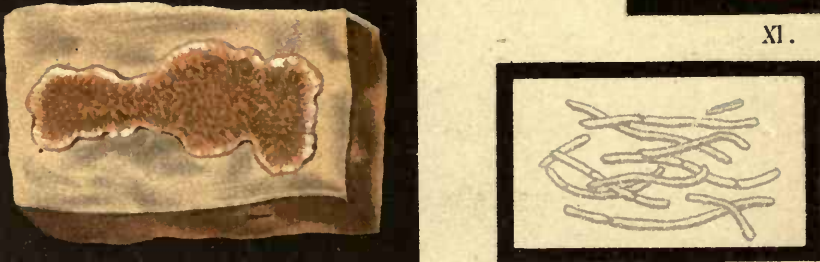

X.

XII. 


\section{PLATE 69.}

\section{Leptothrix epidermidis. Biz.}

I. Gelatin stab culture, two days at $22^{\circ}$.

II. Agar streak culture, two days at $22^{\circ}$.

III. Agar stab culture, two days at $22^{\circ}$. Stab canal.

IV. Agar stab culture, two days at $22^{\circ}$. Surface growth.

V. Agar plate, two days at $22^{\circ}$. Natural size.

VI. Agar plate, two days at $22^{\circ} . \quad \times 90$. Part of a superficial colony.

VII. Agar plate, two days at $22^{\circ} . \quad \times 90$. Deep colony.

VIII. Gelatin plate, two days at $22^{\circ}$. Natural size.

IX. Gelatin plate, one day at $22^{\circ}$ : (e) Superficial, (i) deep colony.

X. Potato culture, three days at $22^{\circ}$. Natural size.

XI. Microscopic preparation. Pure culture on agar, two days at $22^{\circ} . \times 1000$. Stained with fuchsin.

XII. Microscopic preparation. Bouillon culture in hanging drop, two days at $22^{\circ} . \quad \times$ about 1000. 





\title{
Catalogue of Medical Publications
}

\author{
a
}

W. B. SAUNDERS

PHILADELPHIA

*

925 Walnut Street $*$

* $*$

$\&$

COMPANY

* $*$

LONDON

$*$

* I6I Strand, W.C.

\section{Arranged Alphabetically and Classified under Subjects See page 18 for a List of Contents classified according to subjects}

\begin{abstract}
THE books advertised in this Catalogue as being sold by subscription are usually to be obtained from travelling solicitors, but they will be sent direct from the office of publication (charges of shipment prepaid) upon receipt of the prices given. All the other books advertised are commonly for sale by booksellers in all parts of the United States; but books will be sent to any address, carriage prepaid, on receipt of the published price.

Money may be sent at the risk of the publisher in either of the following ways: A postal money order, an express money order, a bank check, and in a registered letter. Money sent in any other way is at the risk of the sender.
\end{abstract}

SPECIAL To physicians of approved credit books will be sent, post-paid, on the following O F F E R terms : $\$ 5.00$ cash upon delivery of books, and monthly payments of $\$ 5.00$ thereafter until full amount is paid. Any one or two volumes will be sent on thirty days' time to those who do not care to make a larger purchase.

\section{AN AMERICAN TEXT=BOOK OF APPLIED THERAPEUTICS.}

Edited by James C. Wilson, M. D., Professor of Practice of Medicine and of Clinical Medicine, Jefferson Medical College, Philadelphia. Handsome imperial octavo volume of $I_{326}$ pages. Illustrated. Cloth, $\$ 7.00$ net; Sheep or Half Morocco, $\$ 8.00 \cdot$ net. Sold by Subscription.

\section{AN AMERICAN TEXT=BOOK OF THE DISEASES OF CHIL- DREN. Second Edition, Revised.}

Edited by Louis StARr, M. D., Consulting Pediatrist to the Maternity Hospital, etc. ; assisted by Thompson S. Wes'rcotT, M. D., Attending Physician to the Dispensary for Diseases of Children, Hospital of the University of Pennsylvania. Handsome imperial octavo volume of 1244 pages, profusely illustrated. Cloth, $\$ 7.00$ net; Sheep or Half Morocco, $\$ 8.00$ net. Sold by Subscription.

\section{AN AMERICAN TEXT=BOOK OF DISEASES OF THE EYE, EAR, NOSE, AND THROAT.}

Edited by G. E. DE Schweinitz, M. D., Professor of Ophthalmology, Jefferson Medical College, Philadelphia; and B. AlExander RANDALL. M. D., Clinical Professor of Diseases of the Ear, University of Pennsylvania. Imperial octavo, I25I pages; 766 illustrations, 59 of them in colors. Cloth, $\$ 7.00$ net; Sheep or Half Morocco, $\$ 8.00$ net. Sold by Subscription. 


\section{AN AMERICAN TEXT=BOOK OF GENITO=URINARY AND SKIN DISEASES.}

Edited by L. Bolton BANGS, M. D., Professor of Genito-Urinary \&urgery, University and Bellevue Hospital Medical College, New York; and W. A. HaRdaway, M. D., Professor of Diseases of the Skin, Missouri Medical College. Imperial octavo volume of 1229 pages, with 300 engravings and 20 full-page colored plates. Cloth, $\$ 7.00$ net; Sheep or Half Morocco, $\$ 8.00$ net. Sold by Subscription.

\section{AN AMERICAN TEXT=BOOK OF GYNECOLOGY, MEDICAL AND SURGICAL. Second Edition, Revised.}

Edited by J. M. BALDy, M. D., Professor of Gynecology, Philadelphia Polyclinic, etc. Handsome imperial octavo volume of 718 pages; 34 I illustrations in the text, and 38 colored and half-tone plates. Cloth, $\$ 6.00$ net; Sheep or Half Morocco, \$7.00 net. Sold by Subscription.

\section{AN AMERICAN TEXT=BOOK OF LEGAL MEDICINE AND TOXICOLOGY.}

Edited by Frederick Peterson, M. D., Chief of Clinic, Nervous Department, College of Physicians and Surgeons, New York; and WALTER S. Haines, M. D., Professor of Chemistry, Pharmacy, and Toxicology, Rush Medical College, Chicago. In Preparation.

\section{AN AMERICAN TEXT=BOOK OF OBSTETRICS.}

Edited by RICHARD C. NorRIS, M. D. ; Art Editor, RobERT L. DICKINSON, M.D. Handsome imperial octavo volume of Ior 4 pages; nearly 900 beautiful colored and half-tone illustrations. Cloth, $\$ 7.00$ net; Sheep or Half Morocco, \$8.0o net. Sold by Subscription.

\section{AN AMERICAN TEXT=BOOK OF PATHOLOGY.}

Edited by Ludwig Hektoen, M. D., Professor of Pathology in Rush Medical College, Chicago; and David Riesman, M. D., Demonstrator of Pathologic Histology in the University of Pennsylvania. Handsome imperial octavo, over Izoo pages, profusely illustrated. By Subscription.

\section{AN AMERICAN TEXT=BOOK OF PHYSIOLOGY. Second Edi= tion, Revised, in Two Volumes.}

Edited by William H. Howell, PH. D., M. D., Professor of Physiology, Johns Hopkins University, Baltimore, Md. Two royal octavo volumes of about 600 pages each. Fully illustrated. Per volume : Cloth, $\$ 3.00$ net; Sheep or Half Morocco, $\$ 3.75$ net.

\section{AN AMERICAN TEXT=BOOK OF SURGERY. Third Edition.}

Edited by William W. KeEN, M. D., LL.D., F. R. C.S. (Hon.) ; and J. William White, M. D., PH. D. Handsome octavo volume of izjo pages; 496 wood-cuts and 37 colored and half-tone plates. Thoroughly revised and enlarged, with a section devoted to "The Use of the Röntgen Rays in Surgery.:" Cloth, $\$ 7.00$ net; Sheep or Half Morocco, $\$ 8.00$ net. 


\section{THE AMERICAN ILLUSTRATED MEDICAL DICTIONARY. Second Edition, Revised.}

For Practitioners and Students. A Complete Dictionary of the Terms used in Medicine, Surgery, Dentistry, Pharmacy, Chemistry, and the kindred branches, including much collateral information of an encyclopedic character, together with new and elaborate tables of Arteries, Muscles, Nerves, Veins, etc.; of Bacilli, Bacteria, Micrococci, Streptococci; Eponymic Tables of Diseases, Operations, Signs and Symptoms, Stains, Tests, Methods of Treatment, etc., etc. By W. A. Newman Dorland, A. M., M. D., Editor of the "American Pocket Medical Dictionary." Handsome large octavo, nearly 800 pages, bound in full flexible leather. Price, $\$ 4.50$ net; with thumb index, $\$ 5.00$ net.

\section{Gives a Maximum Amount of Matter in a Minimum Space and at the Lowest Possible Cost.}

\section{This Revised Edition contains all the Latest Terms.}

"I must acknowledge my astonishment at seeing how much he has condensed within relatively small space. I find nothing to criticise, very much to commend, and was interested in finding some of the new words which are not in other recent dictionaries." Roswell Park, Professor of Principles and Practice of Surgery and Clinical Surgery, University of Buffalo.

"I congratulate you upon giving to the profession a dictionary so compact in its structure, and so replete with information required by the busy practitioner and student. It is a necessity as well as an informed companion to every doctor. It should be upon the desk of every practitioner and student of medicine."-ЈонN B. MURPhy, Professor of Surgery and Clinical Surgery, Northwestern University Medical School, Chicago.

\section{THE AMERICAN POCKET MEDICAL DICTIONARY. Third Edition, Revised.}

Edited by W. A. Newman Dorland., M. D., Assistant Obstetrician to the Hospital of the University of Pennsylvania; Fellow of the American Academy of Medicine. Containing the pronunciation and definition of the principal words used in medicine and kindred sciences, with 64 extensive tables. Handsomely bound in flexible leather, with gold edges. Price $\$ I .00$ net; with thumb index, $\$ \mathrm{I} .25$ net.

\section{THE AMERICAN YEAR=BOOK OF MEDICINE AND SURGERY.}

A Yearly Digest of Scientific Progress and Authoritative Opinion in all branches of Medicine and Surgery, drawn from journals, monographs, and text-books of the leading American and Foreign authors and investigators. Arranged with editorial comments, by eminent American specialists, under the editorial charge of GEORGE M. Gould, M.D. Year-Book of Igor in two volumes-Vol. I. including General Medicine; Vol. II., General Surgery. Per volume: Cloth, $\$ 3.00$ net; Half Morocco, $\$ 3.75$ net. Sold by Subscription.

\section{ABBOTT ON TRANSMISSIBLE DISEASES. Second Edition, Revised.}

The Hygiene of Transmissible Diseases : their Causation, Modes of Dissemination, and Methods of Prevention. By A. C. AввотT, M. D., Professor of Hygiene and Bacteriology, University of Pennsylvania. Octavo, 35I pages, with numerous illustrations, Cloth, \$2.50 net. 
ANDERS' PRACTICE OF MEDICINE. Fifth Revised Edition.

A Text-Book of the Practice of Medicine. By JAMES M. ANDERS, M. D., PH. D., LL. D., Professor of the Practice of Medicine and of Clinical Medicine, Medico-Chirurgical College, Philadelphia. Handsome octavo volume of 1292 pages, fully illustrated. Cloth, $\$ 5.50$ net; Sheep or Half Morocco, $\$ 6.50$ net.

\section{BASTIN'S BOTANY.}

Laboratory Exercises in Botany. By EDson S. BAsTiN, M. A., late Professor of Materia Medica and Botany, Philadelphia College of Pharmacy. Octavo, 536 pages, with 87 plates. Cloth, $\$ 2.00$ net.

\section{BECK ON FRACTURES.}

Fractures. By CARL BECK, M. D., Surgeon to St. Mark's Hospital and the New York German Poliklinik, etc. With an appendix on the Practical Use of the Röntgen Rays. 335 pages, r7o illustrations. Cloth, \$3.50 net.

\section{BECK'S SURGICAL ASEPSIS.}

A Manual of Surgical Asepsis. By CARL BECK, M. D., Surgeon to St. Mark's Hospital and the New York German Poliklinik, etc. 306 pages; 65 text-illustrations and I 2 full-page plates. Cloth, $\$$ I.25 net.

\section{BOISLINIĖRE'S OBSTETRIC ACCIDENTS, EMERGENCIES, AND OPERATIONS.}

Obstetric Accidents, Emergencies, and Operations. By L. CH. BoIsLINIÈRE, M. D., late Emeritus Professor of Obstetrics, St. Louis Medical College. $38 \mathrm{I}$ pages, handsomely illustrated. Cloth, $\$ 2.00$ net.

\section{BÖHM, DAVIDOFF, AND HUBER'S HISTOLOGY.}

A Text-Book of Human Histology. Including Microscopic Technic. By DR. A. A. BOHM and DR. M. VON DAVIDOFF, of Munich, and G. CARL Huber, M. D., Junior Professor of Anatomy and Director of Histological Laboratory, University of Michigan. Handsome octavo of 501 pages, with 35 I beautiful original illustrations. Cloth, $\$ 3.50$ net.

\section{BUTLER'S MATERIA MEDICA, THERAPEUTICS, AND PHARMACOLOGY. Third Edition, Revised.}

A Text-Book of Materia Medica, Therapeutics, and Pharmacology. By George F. Butler, PH. G., M. D., Professor of Materia Medica and of Clinical Medicine, College of Physicians and Surgeons, Chicago. Octavo, 874 pages, illustrated. Cloth, $\$ 4.00$ net; Sheep or Half Morocco, $\$ 5.00$ net.

\section{CERNA ON THE NEWER REMEDIES. Second Edition, Revised.}

Notes on the Newer Remedies, their Therapeutic Applications and Modes of Administration. By DAvin CERnA, M. D., PH. D., Demonstrator of Physiology, Medical Department, University of Texas. Rewritten and greatly enlarged. Post-octavo, 253 pages. Cloth, \$1.00 net. 


\section{CHAPIN ON INSANITY.}

A Compendium of Insanity. By John B. ChAPIN, M. D., LL.D., Physician-in-Chief, Pennsylvania Hospital for the Insane; Honorary Member of the Medico-Psychological Society of Great Britain, of the Society of Mental Medicine of Belgium, etc. 12mo, 234 pages, illustrated. Cloth, $\$ 1.25$ net.

\section{CHAPMAN'S MEDICAL JURISPRUDENCE AND TOXICOLOGY. Second Edition, Revised.}

Medical Jurisprudence and Toxicology. By Henry C. Chapman, M. D., Professor of Institutes of Medicine and Medical Jurisprudence, Jefferson Medical College of Philadelphia. 254 pages, with 55 illustrations and 3 full-page plates in colors. Cloth, $\$ \mathrm{r} .50$ net.

\section{CHURCH AND PETERSON'S NERVOUS AND MENTAL DIS- EASES. Third Edition, Revised and Enlarged.}

Nervous and Mental Diseases. By ARchibald Church, M. D., Professor of Nervous and Mental Diseases, and Head of the Neurological Department, Northwestern University Medical School, Chicago; and Frederick Peterson, M. D., Chief of Clinic, Nervous Department, College of Physicians and Surgeons, New York. Handsome octavo volume of 875 pages, profusely illustrated. Cloth, $\$ 5.00$ net; Sheep or Half Morocco, $\$ 6.00$ net.

\section{CLARKSON'S HISTOLOGY.}

A Text-Book of Histology, Descriptive and Practical. By ARTHUR CLARKSon, M. B., C. M. Edin., formerly Demonstrator of Physiology in the Owen's College, Manchester; late Demonstrator of Physiology in Yorkshire College, Leeds. Large octavo, 554 pages; 22 engravings and 174 beautifully colored original illustrations. Cloth, $\$ 4.00$ net.

\section{CORWIN'S PHYSICAL DIAGNOSIS. Third Edition, Revised.}

Essentials of Physical Diagnosis of the Thorax. By ARTHUR M. CoRwin, A. M., M. D., Instructor in Physical Diagnosis in Rush Medical College, Chicago. 2I9 pages, illustrated. Cloth, \$1.25 net.

\section{CROOKSHANK'S BACTERIOLOGY. Fourth Edition, Revised.}

A Text-Book of Bacteriology. By Edgar M. Crookshank, M. B., Professor of Comparative Pathology and Bacteriology, King's College, London. Octavo, 700 pages, 273 engravings and 22 original colored plates. Cloth, $\$ 6.50$ net; Half Morocco, $\$ 7.50$ net.

\section{DACOSTA'S SURGERY. Third Edition, Revised.}

Modern Surgery, General and Operative. By JoHn CHALmFrs DaCosta, M. D., Professor of Principles of Surgery and Clinical Surgery, Jefferson Medical College, Philadelphia; Surgeon to the Philadelphia Hospital, etc. Handsome octavo volume of I I I 7 pages, profusely illustrated. Cloth, $\$ 5.00$ net; Sheep or Half Morocco, $\$ 6.00$ net.

Enlarged by over 200 Pages, with more than 100 New Illustrations. 


\section{DAVIS'S OBSTETRIC NURSING.}

Obstetric and Gynecologic Nursing. By EDward P. Davis, A. M., M. D., Professor of Obstetrics in Jefferson Medical College and the Philadelphia Polyclinic; Obstetrician and Gynecologist to the Philadelphia Hospital. I 2 mo volume of 400 pages, fully illustrated. Crushed buckram, $\$$ I.75 net.

\section{DE SCHWEINITZ ON DISEASES OF THE EYE. Third Edi- tion, Revised.}

Diseases of the Eye. A Handbook of Ophthalmic Practice. By G. E. DE Schweinitz, M. D., Professor of Ophthalmology, Jefferson Medical College, Philadelphia, etc. Handsome royal octavo volume of 696 pages; 256 fine illustrations and 2 chromo-lithographic plates. Cloth, $\$ 4.00$ net; Sheep or Half Morocco, $\$ 5.00$ net.

\section{DORLAND'S DICTIONARIES.}

[See American Illustrated Medical Dictionary and American Pocket Medical Dictionary on page 3.]

\section{DORLAND'S OBSTETRICS. Second Edition, Revised and Greatly Enlarged.}

Modern Obstetrics. By W. A. Newman Dorland, M. D., Assistant Demonstrator of Obstetrics, University of Pennsylvania ; Associate in Gynecology, Philadelphia Polyclinic. Octavo volume of 797 pages, with 201 illustrations. Cloth, $\$ 4.00$ net.

\section{EICHHORST'S PRACTICE OF MEDICINE.}

A Text-Book of the Practice of Medicine. By DR. HERMAN EICHHORST, Professor of Special Pathology and Therapeutics and Director of the Medical Clinic, University of Zurich. Translated and edited by AUGUSTUS A. Eshner, M. D., Professor of Clinical Medicine, Philadelphia Polyclinic. Two royal octavo volumes, 600 pages each, 150 illustrations. Per set: Cloth, $\$ 6.00$ net; Sheep or Half Morocco, $\$ 7.50$ net.

\section{FRIEDRICH AND CURTIS ON THE NOSE, THROAT, AND EAR.}

Rhinology, Laryngology, and Otology, and their Significance in General Medicine. By DR. E. P. FrIEDRICH, of Leipzig. Edited by H. HOLBROOK CurTIS, M. D., Consulting Surgeon to the New York Nose and Throat Hospital. Octavo, 348 pages. Cloth, $\$ 2.50$ net.

\section{FROTHINGHAM'S GUIDE FOR THE BAC'TERIOLOGIST.}

Laboratory Guide for the Bacteriologist. By LANGdon FrothinghAM, M. D. V., Assistant in Bacteriology and Veterinary Science, Sheffield Scientific School, Yale University. Illustrated. Cloth, 75 cts. net.

\section{GARRIGUES' DISEASES OF WOMEN. Third Edition, Re= vised.}

Diseases of Women. By Henry J. Garrigues, A. M., M. D., Gynecologist to St. Mark's Hospital and to the German Dispensary, New York City. Octavo, $75^{6}$ pages, with 367 engravings and colored plates. Cloth, $\$ 4.50$ net; Sheep or Half Morocco, $\$ 5.50$ net. 


\section{GOULD AND PYLE'S CURIOSITIES OF MEDICINE.}

Anomalies and Curios ties of Medicine. By GEorge M. Gould, M. D., and WALTER L. PYLE, M. D. An encyclopedic collection of rare and extraordinary cases and of the most striking instances of abnormality in all branches of Medicine and Surgery, derived from an exhaustive research of medical literature from its origin to the present day, abstracted, classified, annotated, and indexed. Handsome octavo volume of 968 pages; 295 engravings and I 2 full-page plates. Popular Edition. Cloth, $\$ 3.00$ net ; Sheep or Half Morocco, $\$ 4.00$ net.

\section{GRAFSTROM'S MECHANO=THERAPY.}

A Text-Book of Mechano-Therapy (Massage and Medical Gymnastics). By Axel V. Grafstrom, B. Sc., M. D., late House Physician, City Hospital, Blackwell's Island, New York. I2mo, I39 pages, illustrated. Cloth, $\$ 1.00$ net.

\section{GRIFFITH ON THE BABY. Second Edition, Revised.}

The Care of the Baby. By J. P. Crozer Griffith, M. D., Clinical Professor of Diseases of Children, University of Pennsylvania; Physician to the Children's Hospital, Philadelphia, etc. I2mo, 404 pages, 67 illustrations and 5 plates. Cloth, \$r.50 net.

\section{GRIFFITH'S WEIGHT CHART.}

Infant's Weight Chart. Designed by J. P. Crozer Griffith, M. D., Clinical Professor of Diseases of Children, University of Pennsylvania. 25 charts in each pad. Per pad, 50 cts. net.

\section{HART'S DIET IN SICKNESS AND IN HEALTH.}

Diet in Sickness and Health. By Mrs. ERNEST HART, formerly Student of the Faculty of Medicine of Paris and of the London School of Medicine for Women; with an Introduction by SIR HENRY THOMPSON, F. R. C. S., M. D., London. 220 pages. Cloth, \$I.50 net.

\section{HAYNES' ANATOMY.}

A Manual of Anatomy. By Irving S. HAynes, M. D., Professor of Practical Anatomy in Cornell University Medical College. 680 pages ; 42 diagrams and 134 full-page half-tone illustrations from original photographs of the author's dissections. Cloth, $\$ 2.50$ net.

\section{HEISLER'S EMBRYOLOGY. Second Edition, Revised.}

A Text-Book of Embryology. By John C. Heisler, M. D., Professor of Anatomy, Medico-Chirurgical College, Philadelphia. Octavo volume of 405 pages, handsomely illustrated. Cloth, $\$ 2.50$ net.

\section{HIRST'S OBSTETRICS. Third Edition, Revised and Enlarged.}

A Text-Book of Obstetrics. By BAR'Ton Cooke HiRst, M.D., Professor of Obstetrics, University of Pennsylvania. Handsome octavo volume of 873 pages, 704 illustrations, 36 of them in colors. Cloth, $\$ 5.00$ net; Sheep or Half Morocco, $\$ 6.00$ net. 


\section{HYDE \& MONTGOMERY ON SYPHILIS AND THE VENEREAL DISEASES. 2d Edition, Revised and Greatly Enlarged.}

Syphilis and the Venereal Diseases. By James Nevins Hyde, M. D., Professor of Skin and Venereal Diseases, and Frank H. MONTGOMERY, M. D., Associate Professor of Skin, Genito-Urinary, and Venereal Diseases in Rush Medical College, Chicago, Ill. Octavo, 594 pages, profusely illustrated. Cloth, \$4.00 net.

\section{THE INTERNATIONAL TEXT=BOOK OF SURGERY. In Two Volumes.}

By American and British Authors. Edited by J. Collins WARREN, M. D., LL. D., F. R.C.S. (Hon.), Professor of Surgery, Harvard Medical School, Boston; and A. PEARCE Gould, M. S., F. R. C. S., Lecturer on Practical Surgery and Teacher of Operative Surgery, Middlesex Hospital Medical School, London, Eng. Vol. I. General Surgery.-Handsome octavo, 947 pages, with $45^{8}$ beautiful illustrations and 9 lithographic plates. Vol. II. Special or Regional Surgery.-Handsome octavo, Io72 pages, with 47 I beautiful illustrations and 8 lithographic plates. Sold by Subscription. Prices per volume: Cloth, $\$ 5.00$ net: Sheep or Half Morocco, $\$ 6.00$ net.

"It is the most valuable work on the subject that has appeared in some years. The clinician and the pathologist have joined hands in its production, and the result must be a satisfaction to the editors as it is a gratification to the conscientious reader." - Annals of Surgery.

"This is a work which comes to us on its own intrinsic merits. Of the latter it has very many. The arrangement of subjects is excellent, and their treatment by the different authors is equally so. What is especially to be recommended is the painstaking endeavor of each writer to make his subject clear and to the point. To this end particularly is the technique of operations lucidly described in all necessary detail. And withal the work is up to date in a very remarkable degree, many of the latest operations in the different regional parts of the body being given in full details. There is not a chapter in the work from which the reader may not learn something new."-Mledical Record, New York.

\section{JACKSON'S DISEASES OF THE EYE.}

A Manual of Diseases of the Eye. By Edward Jackson, A. M., M. D., Emeritus Professor of Diseases of the Eye, Philadelphia Polyclinic and College for Graduates in Medicine. I2mo, volume of 535 pages, with I78 illustrations, mostly from drawings by the author. Cloth, $\$ 2.50$ net.

\section{KEATING'S LIFE INSURANCE.}

How to Examine for Life Insurance. By John M. KEATING, M. D., Fellow of the College of Physicians of Philadelphia ; Ex-President of the Association of Life Insurance Medical Directors. Royal octavo, 2 II pages. With numerous illustrations. Cloth, $\$ 2.00$ net.

\section{KEEN ON THE SURGERY OF TYPHOID FEVER.}

The Surgical Complications and Sequels of Typhoid Fever. By WM. W. KEEN, M. D., LL.D., F, R. C.S. (Hon.), Professor of the Principles of Surgery and of Clinical Surgery, Jefferson Medical College, Philadelphia, etc. Octavo volume of 386 pages, illustrated. Cloth, $\$ 3.00$ net.

\section{KEEN'S OPERATION BLANK. Second Edition, Revised Form.}

An Operation Blank, with Lists of Instruments, etc. Required in Various Operations. Prepared by W. W. KEEN, M. D., LL.D., F. R. C.S. (Hon.), Professor of the Principles of Surgery and of Clinical Surgery, Jefferson Medical College, Philadelphia. Price per pad, of 50 blanks, 50 cts. net. 


\section{KYLE ON THE NOSE AND THROAT. Second Edition.}

Diseases of the Nose and Throat. By D. BRADEN KYLE, M. D., Clinical Professor of Laryngology and Rhinology, Jefferson Medical College, Philadelphia. Octavo, 646 pages; over 150 illustrations and 6 lithographic plates. Cloth, \$4.00 net; Sheep or Half Morocco, $\$ 5.00$ net.

\section{LAINÉ'S TEMPERATURE CHART.}

Temperature Chart. Prepared by D. T. LAINE, M. D. Size. $8 \times 13^{1 / 2}$ inches. A conveniently arranged Chart for recording Temperature, with columns for daily amounts of Urinary and Fecal Excretions, Food, Remarks, etc. On the back of each chart is given the Brand treatment of Typhoid Fever. Price, per pad of 25 charts, 50 cts. net.

\section{LEVY, KLEMPERER, AND ESHNER'S CLINICAL BACTERI= OLOGY.}

The Elements of Clinical Bacteriology. By DR. ERnST LEVY, Professor in the University of Strasburg, and DR. FELIX KLEMPERER, Privatdocent in the University of Strasburg. Translated and edited by AUGUSTUS A. Eshner, M. D., Professor of Clinical Medicine, Philadelphia Polyclinic. Octavo, 440 pages, fully illustrated. Cloth, $\$ 2.50$ net.

\section{LOCKWOOD'S PRACTICE OF MEDICINE. Second Edition, Revised and Enlarged.}

A Manual of the Practice of Medicine. By GEORGE RoE LOCKWoOD, M.D., Professor of Practice in the Women's Medical College of the New York Infirmary, etc.

\section{LONG'S SYLLABUS OF GYNECOLOGY.}

A Syllabus of Gynecology, arranged in Conformity with "An American Text-Book of Gynecology." By J. W. Long, M. D., Professor of Diseases of Women and Children, Medical College of Virginia, etc. Cloth, interleaved, \$1.00 net.

\section{MACDONALD'S SURGICAL DIAGNOSIS AND TREATMENT.}

Surgical Diagnosis and Treatment. By J. W. MACdonald, M. D. Edin., F. R. C.S. Edin., Professor of Practice of Surgery and Clinical Surgery, Hamline University. Handsome octavo, 800 pages, fully illustrated. Cloth, $\$ 5.00$ net; Sheep or Half Morocco, $\$ 6.00$ net.

\section{MALLORY AND WRIGHT'S PATHOLOGICAL TECHNIQUE. Second Edition, Revised and Enlarged.}

Pathological Technique. A Practical Manual for Laboratory Work in Pathology, Bacteriology, and Morbid Anatomy, with chapters on PostMortem Technique and the Performance of Autopsies. By Frank B. Mallory, A. M., M. D., Assistant Professor of Pathology, Harvard University Medical School, Boston; and JAMES H. WRIGHT, A. M., M.D., Instructor in Pathology, Harvard University Medical School, Boston.

\section{McFARLAND'S PATHOGENIC BACTERIA. Third Edition, increased in size by over 100 Pages.}

Text-Book upon the Pathogenic Bacteria. By JosepH MCFARLAND, M. D., Professor of Pathology and Bacteriology, Medico-Chirurgical College of Philadelphia, etc. Octavo volume of $62 \mathrm{I}$ pages, finely illustrated. Cloth, $\$ 3.25$ net. 


\section{MEIGS ON FEEDING IN INFANCY.}

Feeding in Early Infancy. By ARthur V. Meigs, M. D. Bound in limp cloth, flush edges, 25 cts. net.

\section{MOORE'S ORTHOPEDIC SURGERY.}

A Manual of Orthopedic Surgery. By JAMEs E. Moore, M. D., Professor of Orthopedics and Adjunct Professor of Clinical Surgery, University of Minnesota, College of Medicine and Jurgery. Octavo volume of 356 pages, handsomely illustrated. Cloth, $\$ 2.50$ net.

\section{MORTEN'S NURSES' DICTIONARY.}

Nurses' Dictionary of Medical Terms and Nursing Treatment. Containing Definitions of the Principal Medical and Nursing Terms and Abbreviations; of the Instruments, Drugs, Diseases, Accidents, Treatments, Operations, Foods, Appliances, etc. encountered in the ward or in the sick-room. By HONNOR MORTEN, author of "How to Become a Nurse," etc. I6mo, I40 pages. Cloth, \$I.00 net.

\section{NANCREDE'S ANATOMY AND DISSECTION. Fourth Edition.}

Essentials of Anatomy and Manual of Practical Dissection. By CHARLES B. NANCREDE, M. D., LL.D., Professor of Surgery and of Clinical Surgery, University of Michigan, Ann Arbor. Post-octavo, 500 pages, with full-page lithographic plates in colors and nearly 200 illustrations. Extra Cloth (or Oilcloth for dissection-room), \$2.00 net.

\section{NANCREDE'S PRINCIPLES OF SURGERY.}

Lectures on the Principles of Surgery. By CHARLES B. NANCREDE, M. D., LL.D, , Professor of Surgery and of Clinical Surgery, University of Michigan, Ann Arbor. Octavo, 398 pages, illustrated. Cloth, $\$ 2.50$ net.

\section{NORRIS'S SYLLABUS OF OBSTETRICS. Third Edition, Revised.}

Syllabus of Obstetrical Lectures in the Medical Department of the University of Pennsylvania. By RICHARD C. NorRIS, A. M., M. D., Instructor in Obstetrics and Lecturer on Clinical and. Operative Obstetrics, University of Pennsylvania. Crown octavo, 222 pages. Cloth, interleaved for notes, $\$ 2.00$ net.

\section{OGDEN ON THE URINE.}

Clinical Examination of the Urine and Urinary Diagnosis. A Clinical Guide for the Use of Practitioners and Students of Medicine and Surgery. By J. BERGEN OGDEN, M. D., Instructor in Chemistry, Harvard University Medical School. Handsome octavo, $4 \mathrm{I} 6$ pages, with 54 illustrations, and a number of colored plates. Cloth, $\$ 3.00$ net.

\section{PENROSE'S DISEASES OF WOMEN. Fourth Edition, Revised.}

A Text-Book of Diseases of Women. By Charles B. PEnrose, M. D., PH. D., formerly Professor of Gynecology in the University of Pennsylvania. Octavo volume of 538 pages, handsomely illustrated. Cloth, $\$ 3.75$ net. 


\section{PRYOR-PELVIC INFLAMMATIONS.}

The Treatment of Pelvic Inflammations through the Vagina. By W. R. PRYoR, M. D., Professor of Gynecology, New York Polyclinic. I2mo, 248 pages, handsomely illustrated. Cloth, \$2.00 net.

\section{PYE'S BANDAGING.}

Elementary Bandaging and Surgical Dressing. With Directions concerning the Immediate Treatment of Cases of Emergency. By WALTER PYE, F.R.C.S., late Surgeou to St. Mary's Hospital, London. Small I2mo, over 80 illustrations. Cloth, flexible covers, $75 \mathrm{cts}$. net.

\section{PYLE'S PERSONAL HYGIENE.}

A Manual of Personal Hygiene. Proper Living upon a Physiologic Basis. Edited by Walter L. PYLE, M. D., Assistant Surgeon to the Wills Eye Hospital, Philadelphia. Octavo volume of 344 pages, fully illustrated. Cloth, \$1.50 net.

\section{RAYMOND'S PHYSIOLOGY. Second Edition, Revised and Greatly Enlarged.}

A Text-Book of Physiology. By Joseph H. Raymond, A. M., M. D., Professor of Physiology and Hygiene and Lecturer on Gynecology in the Long Island College Hospital.

\section{SALINGER AND KALTEYER'S MODERN MEDICINE.}

Modern Medicine. By Julius L. Salinger, M. D., Demonstrator of Clinical Medicine, Jefferson Medical College; and F. J. KALTEYER, M. D., Assistant Demonstrator of Clinical Medicine, Jefferson Medical College. Handsome octavo, 8or pages, illustrated. Cloth, $\$ 4.00$ net.

\section{SAUNDBY'S RENAL AND URINARY DISEASES.}

Lectures on Renal and Urinary Diseases. By RobERT SAUNDBY, M. D. Edin., Fellow of the Royal College of Physicians, London, and of the Royal Medico-Chirurgical Society ; Professor of Medicine in Mason College, Birmingham, etc. Octavo, 434 pages, with numerous illustrations and 4 colored plates. Cloth, $\$ 2.50$ net.

\section{SAUNDERS' MEDICAL HAND=ATLASES. See pp. 16 and 17 .}

\section{SAUNDERS' POCKET MEDICAL FORMULARY. Sixth Edi= tion, Revised.}

By William M. Powell, M. D., author of "Essentials of Diseases of Children "; Member of Philadelphia Pathological Society. Containing I 844 formulæ from the best-known authorities. With an Appendix containing Posological Table, Formulæ and Doses for Hypodermic Medication. Poisons and their Antidotes, Diameters of the Female Pelvis and Fetal Head, Obstetrical Table, Diet List for Various Diseases, Materials and Drugs used in Antiseptic Surgery, Treatment of Asphyxia from Drowning, Surgical Remembrancer, Tables of Incompatibles, Eruptive Fevers, etc., etc. Handsomely bound in flexible morocco, with side index, wallet, and flap. $\$ 2.00$ net. 


\section{SCUDDER'S FRACTURES. Second Edition, Revised.}

The Treatment of Fractures. By Chas L. Scudder, M. D., Assistant in Clinical and Operative Surgery, Harvard University Medical School. Octavo, 433 pages, with nearly 600 original illustrations. Polished Buckram, $\$ 4.50$ net; Half Morocco, $\$ 5.50$ net.

\section{SENN'S GENITO=URINARY TUBERCULOSIS.}

Tuberculosis of the Genito-Urinary Organs, Male and Female. By NicHOLAS SENN, M. D., PH. D., LL.D., Professor of the Practice of Surgery and of Clinical Surgery, Rush Medical College, Chicago. Handsome octavo volume of 320 pages, illustrated. Cloth, $\$ 3.00$ net.

\section{SENN'S PRACTICAL SURGERY.}

Practical Surgery. By Nicholas Senn, M. D., Ph. D., LL.D., Professor of the Practice of Surgery and of Clinical Surgery, Rush Medical College, Chicago. Handsome octavo volume of I200 pages, profusely illustrated. Cloth, \$6.0o net; Sheep or Half Morocco, \$7.00 net. By Subscription.

\section{SENN'S SYLLABUS OF SURGERY.}

A Syllabus of Lectures on the Practice of Surgery, arranged in conformity with "An American Text-Book of Surgery." By Nicholas SenN, M. D., PH.D., LL.D., Professor of the Practice of Surgery and of Clinical Surgery. Rush Medical College, Chicago. Cloth, \$I.50 net.

\section{SENN'S TUMORS. Second Edition, Revised.}

Pathology and Surgical Treatment of Tumors. By Nicholas SENN, M. D., PH.D., LL.D., Professor of the Practice of Surgery and of Clinical Surgery, Rush Medical College, Chicago. Octavo volume of 7 I 8 pages, with 478 illustrations, includidg I2 full-page plates in colors. Cloth, $\$ 5.00$ net; Sheep or Half Morocco, $\$ 6.00$ net.

\section{STARR'S DIETS FOR INFANTS AND CHILDREN.}

Diets for Infants and Children in Health and in Disease. By Louis STARR, M. D., Editor of "An American Text-Book of the Diseases of Children." 230 blanks (pocket-book size), perforatec and neatly bound in flexible morocco. \$I.25 net.

\section{STENGEL'S PATHOLOGY. Third Edition, Thoroughly Revised.}

A Text-Book of Pathology. By Alfred Stengel. M. D., Professor of Clinical Medicine, University of Pennsylvania; Visiting Physician to the Pennsylvania Hospital. Handsome octavo, 873 pages, nearly 400 illustrations, many of them in colors. Cloth, $\$ 5.00$ net; Sheep or Half Morocco, $\$ 6.00$ net.

\section{STENGEL AND WHITE ON THE BLOOD.}

The Blood in its Clinical and Pathological Relations. By ALFRED STENGEL. M. D., Professor of Clinical Medicine, University of Pennsylvania ; and C. Y. White, JR., M.D., Instructor in Clinical Medicine, University of Pennsylvania. In Press. 
STEVENS' MATERIA MEDICA AND THERAPEUTICS. Third Edition, Revised and Greatly Enlarged.

A Text-Book of Modern Therapeutics. By A. A. Stevens, A. M., M. D., Lecturer on Physical Diagnosis in the University of Pennsylvania.

STEVENS' PRACTICE OF MEDICINE. Fifth Edition, Revised.

A Manual of the Practice of Medicine. By A. A. Stevens, A. M., M. D., I ecturer on Physical Diagnosis in the University of Pennsylvania. Specially intended for students preparing for graduation and hospital examinations. Post-octavo, 5I9 pages; illustrated. Flexible Leather, \$2.00 net.

\section{STEWART'S PHYSIOLOGY. Fourth Edition, Revised.}

A Manual of Physiology, with Practical Exercises. For Students and Practitioners. By G. N. Stewart, M. A., M. D., D.Sc., Professor of Physiology in the Western Reserve University, Cleveland, Ohio. Octavo volume of 894 pages ; 336 illustrations and 5 colored plates. Cloth, $\$ 3.75$ net.

\section{STONEY'S MATERIA MEDICA FOR NURSES.}

Materia Medica for Nurses. By Emily A. M. Stoney, late Superintendent of the Training-School for Nurses, Carney Hospital, South Boston, Mass. Handsome octavo volume of 306 pages. Cloth, \$1.50 net.

\section{STONEY'S NURSING. Second Edition, Revised.}

Practical Points in Nursing. For Nurses in Private Practice. By EMrly A. M. Stoney, late Superintendent of the Training-School for Nurses, Carney Hospital, South Boston, Mass. 456 pages, with 73 engravings and 8 colored and half-tone plates. Cloth, \$1.75 net.

\section{STONEY'S SURGICAL TECHNIC FOR NURSES.}

Bacteriology and Surgical Technic for Nurses. By Emily A. M. SToney, late Superintendent of the Training-School for Nurses, Carney Hospital, South Boston, Mass. I $2 \mathrm{~m} \Theta$ volume, fully illustrated. Cloth, \$1.25 net.

\section{THOMAS'S DIET LISTS. Second Edition, Revised.}

Diet Lists and Sick-Room Dietary. By Jerome B. THomas, M. D., Instructor in Materia Medica, Long Island Hospital; Assistant Bacteriologist to the Hoagland Laboratory. Cloth, \$1.25 net. Send for sample sheet.

\section{THORNTON'S DOSE=BOOK AND PRESCRIPTION=WRITING. Second Edition, Revised and Enlarged.}

Dose-Book and Manual of Prescription-Writing. By E. Q. THORnTon, M. D., Demonstrator of Therapeutics, Jefferson Medical College, Philadelphia.

\section{VAN VALZAH AND NISBET'S DISEASES OF THE STOMACH.}

Diseases of the Stomach. By William W. Van ValzaH, M. D., Professor of General Medicine and Diseases of the Digestive System and the Blood, New York Polyclinic; and J. Douglas NisbeT, M. D., Adjunct Professor of General Medicine and Diseases of the Digestive System and the Blood, New York Polyclinic. Octavo volume of 674 pages, illustrated. Cloth, $\$ 3.50$ net. 
VECKI'S SEXUAL IMPOTENCE. Second Edition, Revised.

The Pathology and Treatment of Sexual Impotence. By VICTOR G. VECKI, M.D. From the second German edition, revised and enlarged. Demioctavo, 291 pages. Cloth, $\$ 2.00$ net.

\section{VIERORDT'S MEDICAL DIAGNOSIS. Fourth Edition, Re= vised.}

Medical Diagnosis. By Dr. Oswald Vierordt, Professor of Medicine, University of Heidelberg. Translated, with additions, from the fifth enlarged German edition, with the author's permision, by Francis H. STUART, A. M., M. D. Handsome octavo volume, 603 pages; I94 woodcuts, many of them in colors. Cloth, 4.00 net; Sheep or Half-Morocco, $\$ 5.00$ net.

\section{WATSON'S HANDBOOK FOR NURSES.}

A Handbook for Nurses. By J. K. WAtson, M. D. Edin. American Edition, under supervision of A. A. STEvens, A. M., M. D., Lecturer on Physical Diagnosis, University of Pennsylvania. I2mo, 4I3 pages, 73 illustrations. Cloth, $\$ \mathrm{I} .50 \mathrm{net}$.

\section{WARREN'S SURGICAL PATHOLOGY. Second Edition.}

Surgical Pathology and Therapeutics. By JoHn Collins WARren, M. D., LL.D., F. R. C.S.(Hon.), Professor of Surgery, Harvard Medical School. Handsome octavo, 873 pages; I 36 relief and lithographic illustrations, 33 in colors. With an Appendlx on Scientific Aids to Surgical Diagnosis, and a series of articles on Regional Bacteriology. Cloth, $\$ 5.00$ net; Sheep or Half Morocco, $\$ 6.00$ net.

\section{SAUNDERS' \\ QUESTION=COMPENDS.}

ARRANGED IN QUESTION AND ANSWER FORM.

The Most Complete and Best Illustrated Series of Compends Ever Issued.

NOW THE STANDARD AUTHORITIES IN MEDICAL LITERATURE

WITH

Students and Practitioners In every City of the United States and Canada.

Since the issue of the first volume of the Saunders Question-Compends,

\section{OVER 200,000 COPIES}

of these unrivalled publications have been sold. This enormous sale is indisputable evidence of the value of these self-helps to students and physicians. 


\section{Sa und ers' \\ Question=Compend Series.}

Price, Cloth, \$1.00 net per copy, except when otherwise noted.

"Where the work of preparing students' manuals is to end we cannot say, but the Saunders Series, in our opinion, bears off the palm at present."-New York Medical Record.

1. Essentials of Physiology. By Sidney Budgetr, M. D. An entirely new work.

2. Essentials of Surgery. By Edward Martin, M. D. Seventh edition, revised, with an Appendix and a chapter on Appendicitis.

3. Essentials of Anatomy. By Charles B. Nancrede, M. D. Sixth edition, thoroughly revised and enlarged.

4. Essentials of Medical Chemistry, Organic and Inorganic. By Lawrence WOLFF, M. D. Fifth edition, revised.

5. Essentials of Obstetrics. By W. Easterly Ashton, M. D. Fourth edition, revised and enlarged.

6. Essentials of Pathology and Morbid Anatomy. By F. J. KAlteyer, M. D. In preparation.

7. Essentials of Materia Medica, Therapeutics, and Prescription-Writing. By Henry Morris, M. D. Fifth edition, revised.

8, 9. Essentials of Practice of Medicine. By Henry Morris, M. D. An Appendix on URine Examination. By Lawrence WolfF, M. D. Third edition, enlarged by some 300 Essential Formulæ, selected from eminent authorities, by WM. M. Powell, M. D. (Double number, \$1.50 net.)

10. Essentials of Gynecology. By Edwin B. Cragin, M. D. Fifth edition, revised.

11. Essentials of Diseases of the skin. By Henry W. Stelwagon, M. D. Fourth edition, revised and enlarged.

12. Essentials of Minor Surgery, Bandaging, and Venereal Diseases. By EDWARd Martin, M. D. Second edition, revised and enlarged.

13. Essentials of Legal Medicine, Toxicology, and Hygiene. This volume is at present out of print.

14. Essentials of Diseases of the Eye. By Edward Jackson, M. D. Third edition, revised and enlarged.

15. Essentials of Diseases of Children. By William M. Powell, M. D. Third

16. Essentials of Examination of Urine. By LAwrence Wolff, M. D. Colored "Vogel Scale." (75 cents net.)

17. Essentials of Diagnosis. By S. Solrs-Cohen, M. D., and A.A. Eshner, M. D. Second edition, thoroughly revised.

18. Essentials of Practice of Pharmacy. By Lucrus E. SAYre. Second edition, revised and enlarged.

19. Essentials of Diseases of the Nose and Throat. By E. B. Glesson, M. D Third edition, revised and enlarged.

20. Essentials of Bacteriology. By M. V. Ball, M. D. Fourth edition, revised.

21. Essentials of Nervous Diseases and Insanity. By Јонм C. Sнаw, M. D. Third edition, revised.

22. Essentials of Medical Physics. By Fred J. Brockway, M. D. Second edition, revised.

23. Essentials of Medical Electricity. By David D. Stewart, M. D., and EdWARD S. LAWRANCE, M. D.

24. Essentials of Diseases of the Ear. By E. B. Gleason, M. D. Second edition, revised and greatly enlarged.

25. Essentials of Histology. By Lours Leroy, M. D. With 73 original illustrations.

Pamphlet containing specimen pages, etc., sent free upon application. 


\section{Saunders' Medical Hand=Atlases.}

\section{VOLUMES NOW READY.}

\section{ATLAS AND EPITOME OF INTERNAL MEDICINE AND CLINICAL DIAGNOSIS.}

By DR. CHR. JAKOB, of Erlangen. Edited by Augustus A. Eshner, M. D., Professor of Clinical Medicine, Philadelphia Polyclinic. With 179 colored figures on 68 plates, 64 text-illustrations, 259 pages of text. Cloth, $\$ 3.00$ net.

\section{ATLAS OF LEGAL MEDICINE.}

By DR. E. R. von Hoffman, of Vienna. Edited by Frederick Peterson, M. D., Chief of Clinic, Nervous Department, College of Physicians and Surgeons, New York. With 120 colored figures on 56 plates and I93 beautiful half-tone illustrations. Cloth, $\$ 3.50$ net.

\section{ATLAS AND EPITOME OF DISEASES OF THE LARYNX.}

By Dr. L. Grunwald, of Munich. Edited by Charles P. Grayson, M. D., Physician-in-Charge, Throat and Nose Department, Hospital of the University of Pennsylvania. With ro7 colored figures on 44 plates, 25 textillustrations, and I03 pages of text. Cloth, $\$ 2.50$ net.

\section{ATLAS AND EPITOME OF OPERATIVE SURGERY.}

By DR. O. Zuckerkandl, of Vienna. Edited by J. Chalmers DaCosta, M. D., Professor of Principles of Surgery and Clinical Surgery, Jefferson Medical College, Philadelphia. With 24 colored plates, 2 I4 text-illustrations, and 395 pages of text. Cloth, $\$ 3.00$ net.

\section{ATLAS AND EPITOME OF SYPHILIS AND THE VENEREAL DISEASES.}

By Prof. Dr. Franz Mracek, of Vienna. Edited by L. Bolton Bangs, M. D., Professor of Genito-Urinary Surgery, University and Bellevue Hospital Medical College, New York. With 7 I colored plates, I6 illustrations, and 122 pages of text. Cloth, $\$ 3.50$ net.

\section{ATLAS AND EPITOME OF EXTERNAL DISEASES OF THE EYE.}

By Dr. O. HAAB, of Zurich. Edited by G. E. DE Schweinitz, M. D., Professor of Ophthalmology, Jefferson Medical College, Philadelphia. With 76 colored illustrations on 40 plates and 228 pages of text. Cloth, $\$ 3.00$ net.

\section{ATLAS AND EPITOME OF SKIN DISEASES.}

By Prof. Dr. Franz Mracek, of Vienna. Edited by HENRY W. STelWAGoN. M. D., Clinical Professor of Dermatology, Jefferson Medical College, Philadelphia. With 63 colored plates, 39 half-tone illustrations, and 200 pages of text. Cloth, $\$ 3.50$ net.

\section{ATLAS AND EPITOME OF SPECIAL PATHOLOGICAL HIS= TOLOGY.}

By DR. H. Durck, of Munich. Edited by Ludwig HekToen, M. D., Professor of Pathology, Rush Medical College, Chicago. In Two Parts. Part I. Reacy, including Circulatory, Respiratory, and Gastro-intestinal Tract, 120 colored figures on 62 plates, 158 pages of text. Part II. Ready Shortly. Price of Part I., \$3.00 net. 


\section{Saunders' Medical Hand=Atlases.}

\section{VOLUMES JUST ISSUED.}

\section{ATLAS AND EPITOME OF DISEASES CAUSED BY ACCI- DENTS.}

By DR. ED. Golebiewski, of Berlin. Translated and edited with additions by PEARCE BAlley, M. D., Attending Physician to the Department of Corrections and to the Almshouse and Incurable Hospitals, New York. With 40 colored plates, I43 text-illustrations, and 600 pages of text. Cloth, $\$ 4.00$ net.

\section{ATLAS AND EPITOME OF GYNECOLOGY.}

By DR. O. SHAEFFER, of Heidelberg. From the Second Revised German Edition. Edited by RICHARD C. NORRIS, A. M., M.D., Gynecologist to the Methodist Episcopal and the Philadelphia Hospitals; Surgeon-in-Charge of Preston Retreat, Philadelphia. With 90 colored plates, 65 text-illustrations, and 308 pages of text. Cloth, $\$ 3.50$ net.

\section{ATLAS AND EPITOME OF THE NERVOUS SYSTEM AND ITS DISEASES.}

By Professor Dr. Chr. Jakob, of Erlangen. From the Second Revised and Enlarged German Edition. Edited by EDWARD D. FISHER, M.D., Professor of Diseases of the Nervous System, University and Bellevue Hospital Medical College, New York. With 83 plates and a copious text. $\$ 3.50$ net.

\section{ATLAS AND EPITOME OF LABOR AND OPERATIVE OB- STETRICS.}

By Dr. O. SHAFFFER, of Heidelberg. From the Fifth Revised and Enlarged German Edition. Edited by J. Clifton EdgaR, M. D., Professor of Obstetrics and Clinical Midwifery, Cornell University Medical School. With I26 colored illustrations. \$2.00 net.

\section{ATLAS AND EPITOME OF OBSTETRICAL DIAGNOSIS AND TREATMENT.}

By DR. O. SHAEFFER, of Heidelberg. From the Second Revised and Enlarged German Edition. Edited by J. CLIFTON EDGAR, M. D., Professor of Obstetrics and Clinical Midwifery, Cornell University Medical School. 72 coiored plates, numerous text-illustrations, and cop:ous text. $\$ 3.00$ net.

\section{ATLAS AND EPITOME OF OPHTHALMOSCOPY AND OPH= THALMOSCOPIC DIAGNOSIS.}

By DR. O. HAAB, of Zurich. From the Third Revised and Enlarged German Edition. Edited by G. E. DE Schiwernitz, M. D., Professor of Ophthalmology, Jefferson Medical College, Philadelphia. With I52 colored figures and 82 pages of text. Cloth, $\$ 3.00$ net.

\section{ATLAS AND EPITOME OF BACTERIOLOGY.}

Including a Hand-Book of Special Bacteriologic Diagnosis. By Prof. Dr. K. B. LEhMANN and DR. R. O. Neumann, of Wurzburg. From the Second Revised German Edition. Edited by George H. WEavE.R, M. D., Assistant Professor of Pathology and Bacteriology, Rush Medical College, Chicago. Two volumes, with over 600 colored lithographic figures, numerous textillustrations, and 500 pages of text. 


\section{Nothnagel's Encyclopedia}

\section{OF

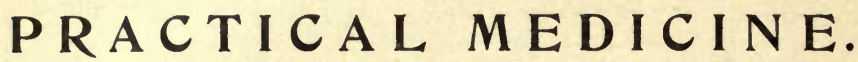

Edited by ALFRED STENGEL, M.D.,

Professor of Clinical Medicine in the University of Pennsylvania; Visiting Physician to the Pennsylvania Hospital.

T $\mathrm{T}$ is universally acknowledged that the Germans lead the world in Internal Medicine: and of all the German works on this subject, Nothnagel's "Special Pathology and Therapeutics" is conceded by scholars to be without question the best System of Medicine in existence. So necessary is this book in the study of Internal Medicine that it comes largely to this country in the original German. In view of these facts, Messrs. W. B. Saunders \& Company have arranged with the publishers to issue at once an authorized edition of this great encyclopedia of medicine in English.

For the present a set of some ten or twelve volumes, representing the most practical part of this encyclopedia, and selected with especial thought of the needs of the practical physician, will be published. These volumes will contain the real essence of the entire work, and the purchaser will therefore obtain at less than half the cost the cream of the original. Later the special and more strictly scientific volumes will be offered from time to time.

The work will be translated by men possessing thorough knowledge of both English and German, and each volume will be edited by a prominent specialist on the subject to which it is devoted. It will thus be brought thoroughly up to date, and the American edition will be more than a mere translation of the German; for, in addition to the matter contained in the original, it will represent the very latest views of the leading American specialists in the various departments of Internal Medicine. The whole System will be under the editorial supervision of Dr. Alfred Stengel, who will select the subjects for the American edition, and will choose the editors of the different volumes.

Unlike most encyclopedias, the publication of this work will not be extended over a number of years, but five or six volumes will be issued during the coming year, and the remainder of the series at the same rate. Moreover, each volume will be revised to the date of its publication by the American editor. This will obviate the objection that has heretofore existed to systems published in a number of volumes, since the subscriber will receive the completed work while the earlier volumes are still fresh.

The usual method of publishers, when issuing a work of this kind, has been to compel physicians to take the entire System. This seems to us in many cases to be undesirable. Therefore, in purchasing this encyclopedia, physicians will be given the opportunity of subscribing for the entire System at one time; but any single volume or any number of volumes may be obtained by those who do not desire the complete series. This latter method, while not so profitable to the publisher, offers to the purchaser many advantages which will be appreciated by those who do not care to subscribe for the entire work at one time.

This American edition of Nothnagel's Encyclopedia will, without question, form the greatest System of Medicine ever produced, and the publishers feel confident that it will meet with general favor in the medical profession. 


\section{NOTHNAGEL'S ENCYCLOPEDIA}

\section{VOLUMES JUST ISSUED AND IN PRESS}

\section{VOLUME I}

Editor, William Osler, M. D.,

F.R. C.P.

Professor of Medicine in Johns Hopkins

Unizersity

\section{CONTENTS}

Typhoid Fever. By Dr. H. CurschmanN, of Leipsic, Typhus Fever. By DR. H. CurschmanN, of Leipsic.

Handsome octavo volume of about 600 pages. Just Issued

\section{VOLUME II}

Editor, Sir J. W. Moore, B. A., M. D., F.R.C.P.I., of Dublin

Professor of Practice of Medicine, Royal College of Surgeons in Ireland

\section{CONTENTS}

Erysipelas and Erysipeloid. By DR. H. LENHARTz, of Hamburg. Cholera Asiatica and Cholera Nostras By Dr. K. VON LIEBERMEISTER, of Tübingen. Whooping Cough and Hay Fever. By Dr. G. Sticker, of Giessen. Varicella. By DR. TH. VON JüRGENSEN, of Tübingen. Variola (including Vaccination). By

DR. H. IMMERMANN, of Basle.

Handsome octavo volume of over 700 pages. Just Issued

\section{VOLUME III}

Editor, William P. Northrup, M. D. Professor of Pediatrics, University and Bellevue Medical College

\section{CONTENTS}

Measles. By Dr. Th. von Jürgensen, of Tübingen. Scarlet Fever. By the same author. Rotheln. By the same author.

\section{VOLUME VI}

Editor, Alfred Stengel, M. D.

Professor of Clinical Medicine, University of I'ennsylvania

\section{CONTENTS}

Anemia. By Dr. P. EHRLICH, of Frankfort-on-the-Main, and DR. A. LAzARUS, of Charlottenburg. Chlorosis. By DR. K. Von NoOrden, of Frankfort-on-the-Main. Diseases of the Spleen and Hemorrhagic Diathesis. By Dr. M. LitTen, of Berlin.

\section{VOLUME VII}

Editor, John H. Musser, M. D. Professor of Clinical Medicine, University of l'ennsylarania

\section{CONTENTS}

Diseases of the Bronchi. By Dr. F. A. HoFmAnN, of Leipsic. Diseases of the pleura. By Dr. Rosenbach, of Berlin. Pneumonia. By Dr. E. Aufrecht, of Magdeburg.

\section{VOLUME VIII}

Editor, Charles G. Stockton, M. D. Professor of Medicine, University of Bupalo CONTENTS

Diseases of the Stomach. By Dr. F. RIEGEL, of Giessen.

\section{VOLUME IX}

Editor, Frederick A. Packard, M. D.

Physician to the l'ennsylvania Hospital and to the Children's Hospital, Philadelphia

\section{CONTENTS}

Diseases of the Liver. By DRS. $H$. QuiNCKe and G. HoPPE-SEYLER, of Kiel.

\section{VOLUME $X$}

Editor, Reginald H.Fitz, A.M., M.D. Hersey Professor of the Theory and Practice of Physic, Harvard University

\section{CONTENTS}

Diseasis of the Pancreas. By DR. L. Oser, of Vienna. Diseases of the Suprarenals. By $D_{k}$. E. NEUSSEr, of Vienna.

\section{VOLUMES IV, V, and XI}

\section{Editors announced later}

Vol. IV.-Influenza and Dengue. By Dr. O. Leicht fNSTE1N, of Cologne. Malarial Diseases. By Dr. J. Mannaberg, of Vienna.

Vol.V.-Tuberculosis and Acute General Miliary Tuberculosis. Hy DR. G. CokNET, of Berlin.

Vol. XI.-Diseases of the Intestines and Peritoneum. By Dr. H. Nothnagel, of Vienna. 


\section{CLASSIFIED LIST}

\section{OF THE \\ MEDICAL PUBLICATIONS \\ OP \\ W. B. SAUNDERS \& COMPANY}

\section{ANATOMY, EMBRYOLOGY, HIS-} TOLOGY.

Bohm, Davidoff, and Huber-A TextBook of Histology,

Clarkson-A Text-Book of Histology, Haynes-A Manual of Anatomy, . . . Heisler-A Text-Book of Embryology, .

Leroy-Essentials of Histology,

Nancrede-Essentials of Anatomy,

Nancrede-Essentials of Anatomy and Manual of Practical Dissection,. . . .

\section{BACTERIOLOGY.}

Ball-Essentials of Bacteriology,. . . . I5

Frothingham-Laboratory Guide, . 6

Gorham-Laboratory Course in Bacteriology,

Lehmann and Neumann-Atlas of Bacteriology,

Levy and Klemperer's Cilinical Bacteriology,

Mallory and Wright-Pathological Technique,

McFarland-Pathogenic Bacteria,...

CHARTS, DIET-LISTS, ETC.

Griffith-Infant's Weight Chart, .

Hart-Diet in Sickness and in Health,

Keen-Operation Blank, . .

Laine-Temperature Chart,

Starr-Diets for Infants and Childen.

Thomas-Diet-Lists,

\section{CHEMISTRY AND PHYSICS.}

B rockway-Essentials of Medical Physics, .

Wolf-Essentials of Medical Chemistry

\section{CHILDREN.}

An American Text-Book of Diseases of Children.

Griffith-Care of the Baby $\cdots \cdots$

Griffith-Infant's Weight Chart, . . . .

Meigs-Feeding in Early Infancy

Powell-Essentials of Diseases of Children,

Starr-Diets for Infants and Children,

\section{DIAGNOSIS.}

Cohen and Eshner-Fssentials of Diagnosis,

Corwin-Physical Diagnosis,

Vierordt-Medical Diagnosis,

\section{DICTIONARIES.}

The American Illustrated Medical Dictionary,

The American Pocket Medical Dic tionary,

Morton-Nurses Dictionary..... 3
EYE, EAR, NOSE, AND THROAT.

An American Text-Book of Diseases of the Eye, Ear, Nose, and Throat,.. De Schweinitz-Diseases of the Eye, 6 Friedrich and Curtis-Rhinology, Laryngology, and Otology, .....6 6 Gleason-Essentials of the Ear, ... x 5 Gleason-Essentials of Nose and Throat, ${ }_{5}$ Gradle-Ear, Nose, and Throat, . . 22 Grunwald and Grayson-Atlas of Diseases of the Larynx... . . . . 6 Haab and de Schweinitz-Atlas of External Diseases of the Eye, . . . . . 6 Jackson-Manual of Diseases of the Eye, 8 Jackson-Essentials Diseases of Eye, I5 Kyle-Diseases of the Nose and Throat, 9

\section{GENITO-URINARY.}

An American Text-Book of GenitoUrinary and Skin Diseases, . . ... Hyde and Montgomery-Syphilis and the Venereal Diseases, . . . . . . Martin-Essentials of Minor Surgery, Bandaging, and Venereal Diseases, . I5 Mracek and Bangs-Atlas of Syphilis and the Venereal Diseases,..... 16 Saundby-Renal and Urinary Diseases, Ix Senn-Genito-Urinary Tuberculosis, . I 12 Vecki-Sexual Impotence, . . . . . 14

\section{GYNECOLOGY.}

American Text-Book of Gynecology, , a Cragin-Essentials of Gynecology,. : 15 Garrigues-Diseases of Women,.... 6 Long-Syllabus of Gynecology, . . . 9 Penrose-Diseases of Women,..... ro Pryor-Pelvic Inflammations, . . II Schaeffer and Norris-Atlas of Gynecology,

\section{HYGIENE.}

Abbott-Hygiene of Transmissible Diseases, ........... 3 Bergey-Principles of Hygiene, . . . 22 Pyle-Personal Hygiene, ...... II

MATERIA MEDICA, PHARMACOLOGY, and THERAPEUTICS.

An American Text-Book of Applied Therapeutics, ......... I Butler-Text-Book of Materia Medica, Therapeutics, and Pharmacology,.. 4 Morris-Ess.of M. M. and Therapeutics, 15 Saunders' Pocket Medical Formulary, . II Sayre-Essentials of Pharmacy,.... I5 Sollmann-Text-Book of Pharmacology, 22 Stevens-Modern Therapeutics, . . . $x_{3}$ Stoney-Materia Medica for Nurses, . . I3 Thornton-Prescription-Writing, ‥ 13 
MEDICAL JURISPRUDENCE AND TOXICOLOGY.

Chapman-Medical Jurisprudence and Toxicology,

Golebiewski and Bailey-Atlas of Diseases Caused by Accidents, .

Hofmann and Peterson-Atlas of Legal Medicine,

\section{NERVOUS AND MENTAL DIS-} EASES, ETC.

Brower-Manual of Insanity,

Chapin-Compendium of Insanity,

Church and Peterson-Nervous and Mental Diseases,

Jakob and Fisher-Atlas of Nervous System,

Shaw-Essentials of Nervous Diseases and Insanity, . .

\section{NURSING.}

Davis-Obstetric and Gynecologic Nursing,

Griffith-The Care of the Baby, .

Hart-Diet in Sickness and in Health.

Meigs-Feeding in Early Infancy,

Morten-Nurses' Dictionary,

Stoney-Materia Medica for Nurses,

Stoney-Practical Points in Nursing,

Stoney-Surgical Technic for Nurses,

Watson-Handbook for Nurses, .

\section{OBSTETRICS.}

An American Text-Book of Obstetrics,

Ashton-Essentials of Obstetrics, .

Boisliniere-Obstetric Accidents, . .

Dorland-Modern Obstetrics,

Hirst-Text-Book of Obstetrics,

Norris-Syllabus of Obstetrics,

Schaeffer and Edgar-Atlas of Obstetrical Diagnosis and Treatment, . . . :

\section{PATHOLOGY.}

An American Text-Book of Pathology, Durck and Hektoen-Atlas of Pathologic Histology,

Kalteyer-Essentials of Pathology,

Mallory and Wright-Pathological Technique, .

Senn-Pathology and Surgical Treatment of Tumors,

Stengel-Text-Book of Pathology, . . .

Warren-Surgical Pathology,

\section{PHYSIOLOGY.}

American Text-Book of Physiology, . Budgett-Essentials of Physiology, Raymond-Text-Book of Physiology, . Stewart-Manual of Physiology,

\section{PRACTICE OF MEDICINE.}

An American Year-Book of Medicine and Surgery, .

Anders-Practice of Medicine,

Eichhorst-Practice of Medicine,

Lockwood-Practice of Medicine, .

Morris-Ess. of Practice of Medicine,

Salinger \& Kalteyer-Mod. Medicine,

Stevens-Practice of Medicine,

\section{SKIN AND VENEREAL.}

An American Text-Book of GenitoUrinary and Skin Diseases,

Hyde and Montgomery-Syphilis and the Venereal Diseases,

Martin-Essentials of Minor Surgery, Bandaging, and Venereal Diseases,.. I5

Mracek and Stelwagon-Atlas of Diseases of the Skin,.

Stelwagon-Essentials of Diseases of the Skin,

\section{SURGERY.}

An American Text-Book of Surgery, An American Year-Book of Medicine and Surgery, . .

Beck-Fractures,

Da Costa Margical Ásepsis, . . 4

Da Costa-Manual of Surgery, . - * . 5

Keen-Operation Blank,...... 8

Keen-The Surgical Complications and Sequels of Typhoid Fever, ...... 8

Macdonald - Surgical Diagnosis and Treatment,. . . . . . . . . . .

Martin-Essentials of Minor Surgery, Bandaging, and Venereal Diseases, . . I5

Martin-Essentials of Surgery,..... I5

Moore-Orthopedic Surgery, ..... ro

Nancrede-Principles of Surgery,... . Io

Pye-Bandaging and Surgical Dressing, Ix

Scudder-Treatment of Fractures, . . I I2

Senn-Genito-Urinary Tuberculosis, . . I2

Senn-Practical Surgery, ....... 12

Senn-Syllabus of Surgery, . . . . . 12

Senn-Pathology and Surgical Treatment of Tumors, 12

Warren-Surgical Pathology and Thera peutics, . . . . . . . . . 14

Zuckerkandl and Da Costa-Atlas of Operative Surgery, . . . . . . I6

INE AND URINARY DISEASES.

Ogden-Clinical Examination of the Urine, . . . . . . . . . ro Saundby-Renal and Urinary Diseases, II Wolf-Handbook of Urine Examination, 22

Wolff-Examination of Urine,.... I5

\section{MISCELLANEOUS.}

Abbott-Hygiene of Transmissible Diseases,

Bastin-Laboratory Exercises in Botany,

Golebiewski and Bailey-Atlas of Diseases Caused by Accidents, .

Gould and Pyle-Anomalies and Curiosities of Medicine,

Grafstrom-Massage,

Keating-Examination for Life Insurance,

Pyle-A Manual of Personal Hygiene, 2 I Saunders' Medical Hand-Atlases, . 16, 17 Saunders' Pocket Medical Formulary, . I I

Saunders' Question-Compends, .. I4. I5

Stewart and Lawrence-Essentials of Medical Electricity,...... I5

Thornton-Dose-Book and Manual of Prescription-Writing,......... I3

Van Valzah and Nisbet-Diseases of the Stomach,........... I

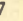




\section{THE LATEST BOOKS.}

\section{Bergey's Principles of Hygiene.}

The Principles of Hygiene: A Practical Manual for Students, Physicians, and Health Officers. By D. H. Bergey, A. M., M. D., First Assistant, Laboratory of Hygiene, University of Pennsylvania. Handsome octavo volume of about 500 pages, illustrated.

\section{Brower's Manual of Insanity.}

A Practical Manual of Insanity. By Daniel R. Brower, M.D., Professor of Nervous and Mental Diseases, Rush Medical College, Chicago. 12mo volume of 425 pages, illustrated.

\section{Gorham's Bacteriology.}

A Laboratory Course in Bacteriology: By F. P. Gorham, M. A., Assistant l'rofessor in Biology, Brown University. $12 \mathrm{mo}$ volume of about i6o pages, fully illustrated.

\section{Gradle on the Nose, Throat, and Ear.}

Diseases of the Nose, Throat, and Ear. By Henry Gradle, M. D., Professor of Ophthalmology and Otology, Northwestern University Medical School, Chicago. Handsome octavo volume of 800 pages, profusely illustrated.

\section{Sollmann's Pharmacology.}

A Text-Book of Pharmacology. By Torald Sollmann, M. D., Lecturer on Pharmacology, Western Reserve University, Cleveland, Ohio. Royal octavo volume of about 700 pages.

\section{Wolf's Examination of Urine.}

A Handbook of Physiologic Chemistry and Urine Examination. By Charles G. L. Wolf, M. D., Instructor in Physiologic Chemistry, Cornell University Medical College. I 2 mo volume of about I6o pages. 



Atlas and Epitome of Internal Medicine and Clinical Diagnosis. By DR. CHR. JAKOB, of Erlangen. Edited by AUgustus A. EsHNER, M.D., Professor of Clinical Medicine in the Philadelphia Polyclinic. With 179 colored figures on 68 plates and 259 pages of text. Cloth, $\$ 3.00$ net.

Atlas of Legal Medicine. By Dr. E. von HofmanN, of Vienna. Edited by FredERICK PETERson, M.D., Chief of Clinic, Nervous Department, College of Physicians and Surgeons, New York. . With 120 colored figures on 56 plates and 193 half-tone illustrations. Cloth, $\$ 3.50$ net.

Atlas and Epitome of Diseases of the Larynx. By DR. L. GrünwALD, of Munich. Edited by Charles P. GRAYSON, M.D., Physician-in-Charge, Throat and Nose Department, Hospital of the University of Pennsylvania. With 107 colored figures on 44 plates, 25 text-illustrations, and ro3 pages of text. Cloth, $\$ 2.50$ net.

Atlas and Epitome of Operative Surgery. By DR. O. ZUCKERKANDL, of Vienna. Edited by J. Chalmers DaCosta, M.D., Professor of the Practice of Surgery and Clinical Surgery, Jefferson Medical College, Philadelphia. With 24 colored plates, 217 illustrations in the text, and 395 pages of text. Cloth, $\$ 3.00$ net.

Atlas and Epitome of Syphilis and the Venereal Diseases. By Prof. Dr. Franz MRAČEK, of Vienna. Edited by L. BolToN BANGS, M.D., Professor of GenitoUrinary Surgery, University and Bellevue Hospital Medical College, New York. With $7 \mathrm{I}$ colored plates and 122 pages of text. Cloth, $\$ 3.50$ net.

Atlas and Epitome of External Diseases of the Eye. By DR. O. HAAB, of Zurich. Edited by G. E. DE SChWEINITZ, M.D., Professor of Ophthalmology, Jefferson Medical College, Philadelphia. With 76 colored illustrations on 40 plates and 228 pages of text. Cloth, $\$ 3.00$ net.

Atlas and Epitome of Skin Diseases. By Prof. Dr. Franz MračEK, of Vienna. Edited by HenRy W. Stelwagon, M.D., Clinical Professor of Dermatology, Jefferson Medical College, Philadelphia. With 63 colored plates, 39 half-tone illustrations, and 200 pages of text. Cloth, $\$ 3.50$ net.

Atlas and Epitome of Special Pathologic Histology. By DR. H. DüRCK, of Munich. Edited by Ludvig Hektoen, M.D., Professor of Pathology, Rush Medical College, Chicago. In two parts. Part I. just ready, including the Circulatory, Respiratory, and Gastro-intestinal Tracts, with 124 colored figures on 62 plates and $15^{8}$ pages of text. Cloth, $\$ 3.00$ net.

Atlas and Epitome of Diseases Caused by Accidents. By DR. ED. Golebiewski, of Berlin. Translated and edited, with additions, by PEARCE BAILEY, M.D., Attending Physician to the Almshouse and Incurable Hospitals, New York. With 71 colored illustrations on 40 plates, 143 text-illustrations, and 549 pages of text. Cloth, \$4.00 net.

Atlas and Epitome of Gynecology. By DR. O. SchÄFFER, of Heidelberg. From the Second Revised and Enlarged German Edition. Edited by RICHARD C. NOR-

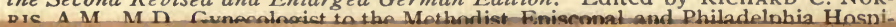


